\title{
EFFECTS OF METAL TOXICITY ON THE EARLY LIFE STAGES OF THE SEA URCHIN EVECHINUS CHLOROTICUS
}

By

Agnes Mireille Rouchon

A thesis submitted to the Victoria University of Wellington in fulfilment of the requirements for the degree of Doctor of Philosophy in Marine Biology 

To my Dad, for countless hours spent looking at snails, snakes, and other critters; this is how it all began...

À mon Papa, pour toutes ces heures passées à observer escargots, serpents et autres bestioles; c'est comme ça que tout a commencé... 


\begin{abstract}
Metals are a common source of pollution in coastal waters, and have long been recognised as a major concern for many marine species, especially their early life stages. Although effects have been examined using standard toxicity assays, the impact of metals in more complex and realistic exposure regimes is still poorly known, in particular with regards to latent effects across multiple life stages and the interaction of multiple stressors. In this thesis, the effects of metals were investigated for multiple life stages of the endemic New Zealand sea urchin Evechinus chloroticus.
\end{abstract}

Standard short-term bioassays were performed on the early life stage of E. chloroticus and also the endemic abalone Haliotis iris, for comparison. These assays evaluated the toxicity of three major pollutants (copper, lead and zinc) alone and in combination, on these species. Embryos of both species were highly vulnerable to copper (EC50s: 5.4 and $3.4 \mu \mathrm{g} / \mathrm{L}$ respectively for E. chloroticus and H. iris) and zinc (27.7 and 13.1 $\mu \mathrm{g} / \mathrm{L})$ but relatively tolerant to lead (52.2 and $775 \mu \mathrm{g} / \mathrm{L})$, and there was no evidence of synergistic effects of metal mixtures.

The latent effects of copper across two life stages in E. chloroticus, larval and juvenile, were investigated with laboratory experiments using realistic scenarios of low copper concentration, short pulses of exposure and examining exposure through dietary intake as well as waterborne exposure. Strong latent and carry-over effects were observed even at low concentration and short exposure time. For example, individuals exposed as larvae to $10.4 \mu \mathrm{g} / \mathrm{L} \mathrm{Cu}$ for two days developed normally during the larval stage but had strongly impaired subsequent growth, with average body size decreasing by $24 \%$ in the $25 \mathrm{~d}$ following settlement. Moreover, juveniles previously exposed to copper as larvae were less resistant to a subsequent exposure, with up to four times higher mortality. Latent effects were especially important when copper was present in the diet rather than dissolved in water. For example, $E$. chloroticus larvae exposed to $2.3 \mu \mathrm{g} / \mathrm{L} \mathrm{Cu}$ in water and fed with an algal diet cultured in the same concentration had a settlement success three times lower than those exposed only to waterborne copper. Furthermore, a short pulse exposure (4 days) to copper in the algal diet was generally more toxic than chronic exposure, showing that 
a short-lived bloom of contaminated phytoplankton may have a more severe impact on zooplankton than chronic pollution.

Because metal discharge in coastal water is generally associated with freshwater (e.g. storm water or river plumes), the toxicity of copper was evaluated in both normal and low salinity seawater. Low salinity (24 ppt) increased copper toxicity in $E$. chloroticus larvae under chronic exposure to high levels $(15 \mu \mathrm{g} / \mathrm{L} ; 43 \%$ and $80 \%$ lower survival and normal development rate, respectively) but not under a single pulse exposure ( 4 days) to low concentration $(5 \mu \mathrm{g} / \mathrm{L})$. This highlights the importance of using realistic exposure in laboratory assays.

Finally, the effect of copper on adult E. chloroticus and in particular on their fertilisation success was evaluated. Strong sublethal effects were observed after exposure to $50 \mu \mathrm{g} / \mathrm{L} \mathrm{Cu}$ for two weeks including spawning impairment (especially in females) and elevated copper burden in gonads (25-times higher than control animals). However, the fertilisation success of successfully spawning males was not affected.

The prevalence of local metal contamination was also measured at the mouth of local river plumes and in E. chloroticus gonads at sites expected to vary in likely exposure to pollution. Copper levels exceeding water quality criteria were found in two instances in coastal agricultural runoff (Makara stream). Other metals were within water quality cirteria in all samplings. Adult E. chloroticus had an elevated copper burden in gonads in an urban site compared to a control site $(0.77 \mu \mathrm{g} / \mathrm{g} v s .0 .27 \mu \mathrm{g} / \mathrm{g})$.

In total, this research demonstrates the need for considering toxic effects across multiple life stages and using realistic exposure regimes (e.g. timing, concentration, multiple stressors) to better understand the likely impact of metal pollution on marine populations. It also provides the first measure of metal toxicity on early life stages of an endemic species of cultural and commercial importance in New Zealand. 


\section{ACKNOWLEDGEMENTS}

First and foremost, my deepest gratitude to Nicolas Gilbert for being my anchor in the sometimes stormy sea of graduate research, for his amazing problem-solving skills that truly contributed to the quality of this thesis, and, of course, for IT support.

I am very grateful to my supervisor Nicole Phillips, for providing great feedback, encouragements when I needed them, and for being always supportive (even when life got in the way). Thanks to my secondary supervisor Simon Davy for advice and comments.

Many thanks to Sonja Miller for invaluable help in getting me started and advice and encouragements along the way.

Special thanks to Fernanda Piraud, Ursula Rojas Nazar and Alix LaFerriere for friendship and much needed support while writing and facing the challenges of combining motherhood and PhD study.

Thanks to Camille Poutrin, Katie Clemens and Jenifer Howe for great help in the lab when it was most needed. Thanks to John van der Sman for help in building experimental apparatus.

Thanks to my many helpers in the field: Paul Mensink, Jenny Oliver, Shane Geange, Cesar Cardenas Alacorn, Abi Powell, Sonja Miller, John van der Sman, Daniel McNaughtan, Simona Boschetti, Ursula Rojas Nazar, Christian Carrizo, Mauricio Cifuentes, Peter Edward; and in the lab: Fernanda Piraud, Richard Crerar, Steven Walton, Charlotte Dohrn, Laura, Nicolas Gilbert and Jean-Paul Rouchon. 
Thanks to Sonja Miller, Peter Edward and Taputu Raea for their help in keeping my broodstock well fed and happy.

Many thanks to all the VUCELers who made this journey so much fun. Thanks for all the stimulating conversations, friendships and morning teas!

I would like to acknowledge the Victoria Doctoral Scholarship, Victoria PhD Submission Scholarship and the Greater Wellington Regional Council for funding.

I am grateful to Graeme Moss and NIWA's Mahanga Bay Lab for generous use of their facilities and paua broodstock.

Thanks to Sharon van Soest from Environmental Laboratories Services in Petone for training on spectrometry techniques.

Many thanks to Gordon Heeley and Victoria University School of Chemical and Physical Sciences for letting me use their brand new GFAA.

And a huge thank you to my family in Reunion Island, France and Quebec for their love and support. Special thanks to my parents and parents-in-law for their help with babysitting, to my Mum for always been here to listen to my endless talks about my critters ("they are so cuuute!"), experiments, or other science-related subjects over the years, and, finally, to my beloved daughter who made the journey both so much more challenging and so much more worthwhile. 


\section{CONTENTS}

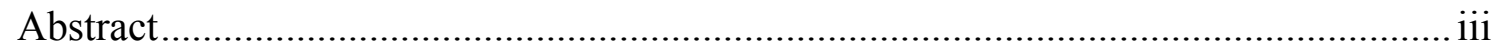

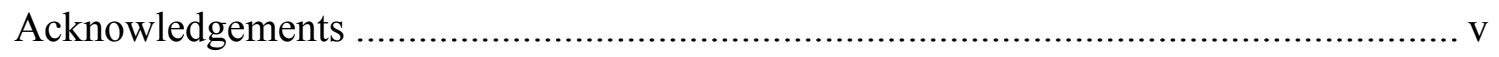

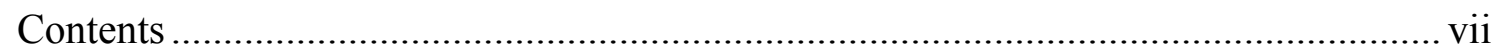

List of Tables

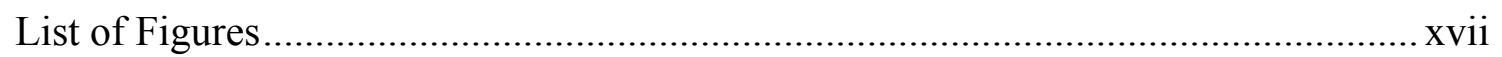

List of Abbreviations and Acronyms........................................................................

CHAPTER 1 General Introduction ........................................................................ 1

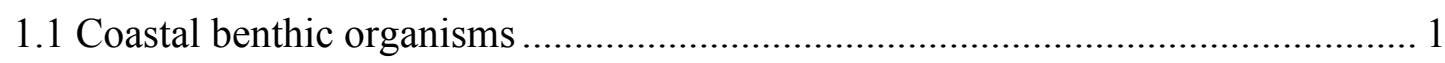

1.2 Prevalence of metal pollution worldwide ......................................................... 2

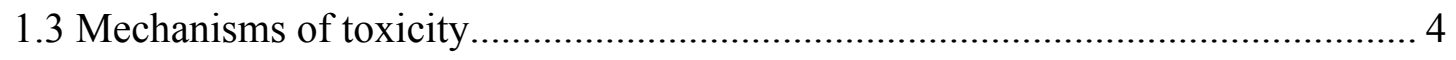

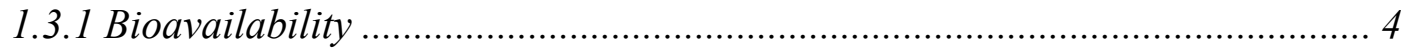

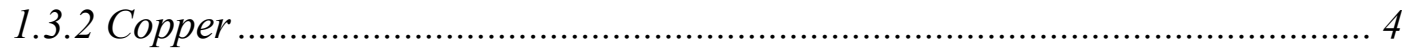

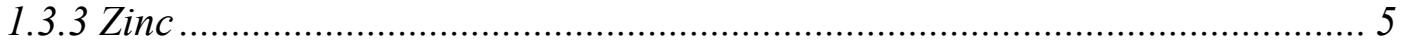

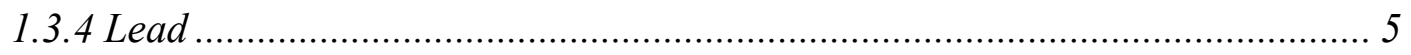

1.4 Impacts of metal pollution on marine species .................................................. 5

1.5 How to evaluate the impact of these stressors? ................................................ 7

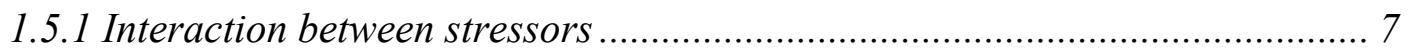

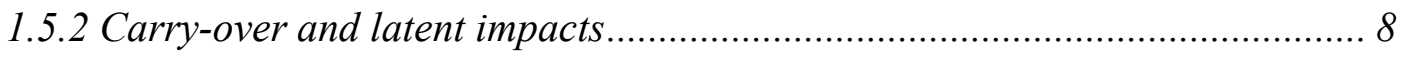

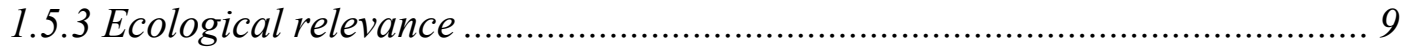

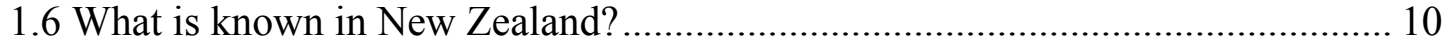

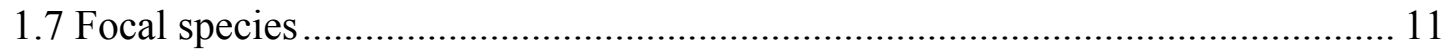

1.7.1 Evechinus chloroticus (sea urchin) .............................................................. 11

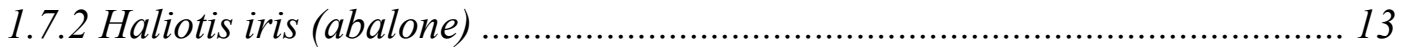

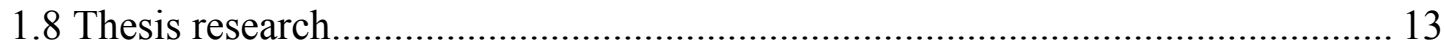

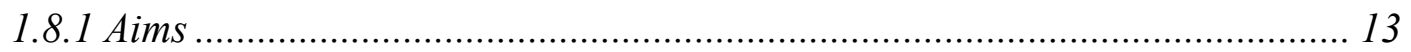

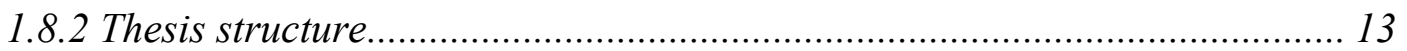


CHAPTER 2 Acute toxicity of copper, lead, zinc and their mixtures on

Evechinus chloroticus and Haliotis iris larvae ........................................................ 17

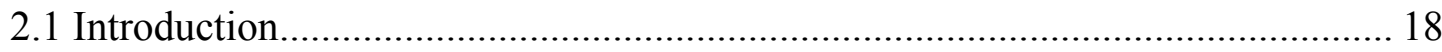

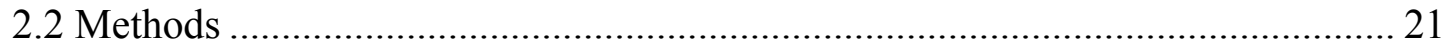

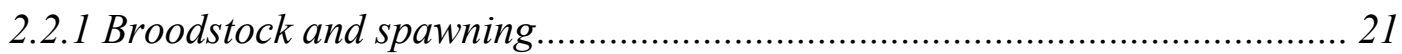

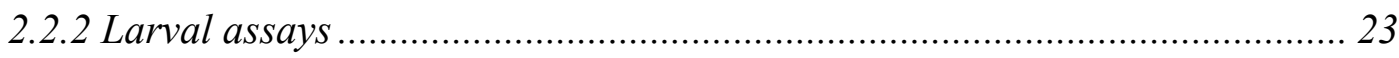

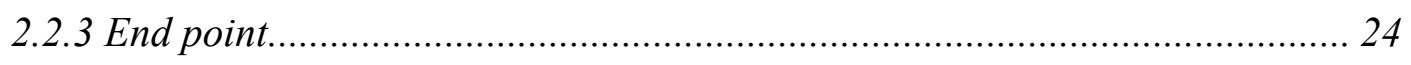

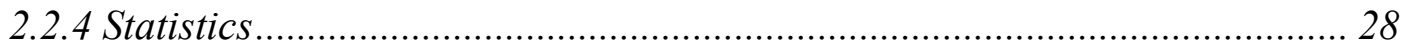

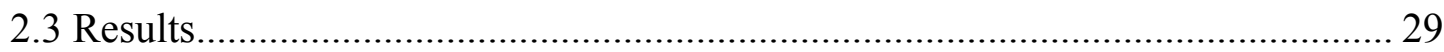

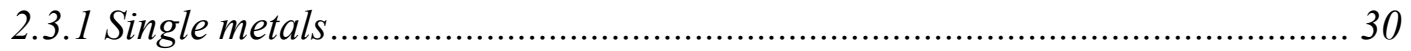

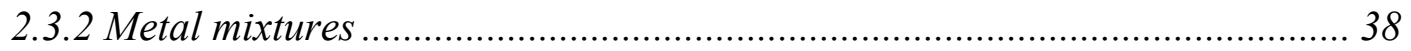

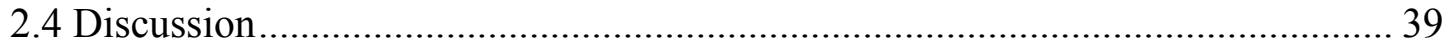

2.4.1 Comparison with current water quality criteria.......................................... 40

2.4.2 Comparison with related species............................................................... 40

2.4.3 Effect of metals on larval development........................................................ 45

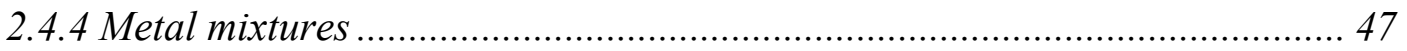

2.4.5 Consequence for field populations ......................................................... 48

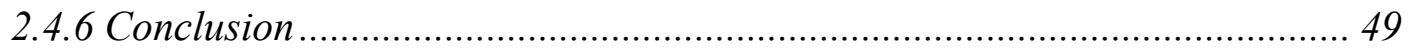

\section{CHAPTER 3 Latent effect of low level of copper contamination on Evechinus}

chloroticus early life stages.....................................................................................51

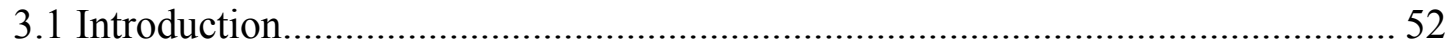

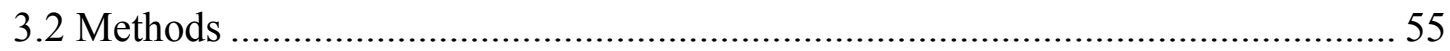

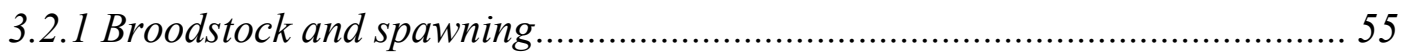

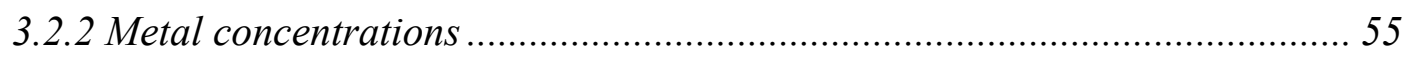

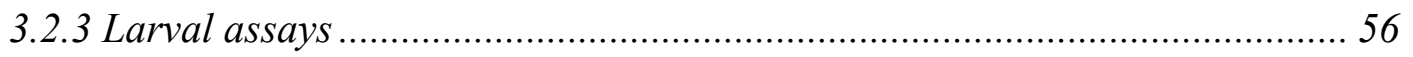

3.2.4 Settlement

3.2.5 Juvenile re-exposure experiment ............................................................... 61

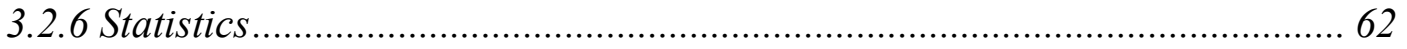

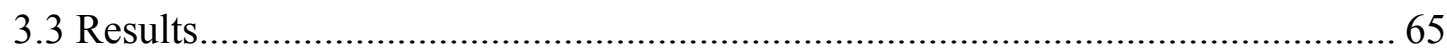

3.3.1 Larval survival, growth and development ............................................... 65

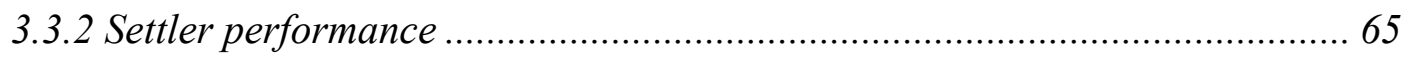




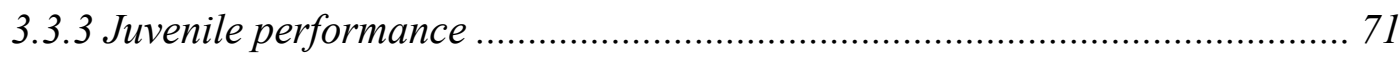

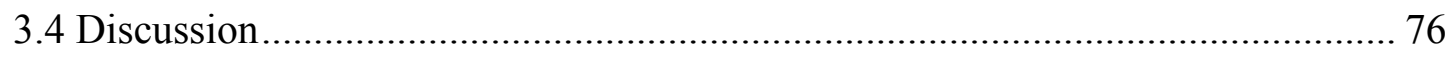

3.4.1 Latent effects of larval exposure to copper on settlers ................................. 76

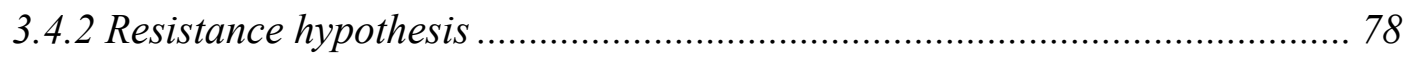

3.4.3 Timing of larval exposure to copper....................................................... 79

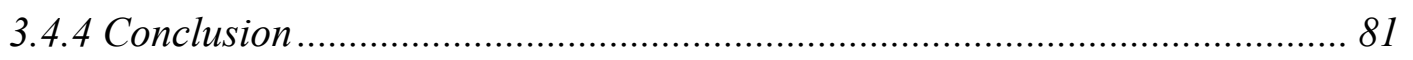

CHAPTER 4 Separate and combined impacts of waterborne and dietary copper intake on Evechinus chloroticus early life stages ......................................................83

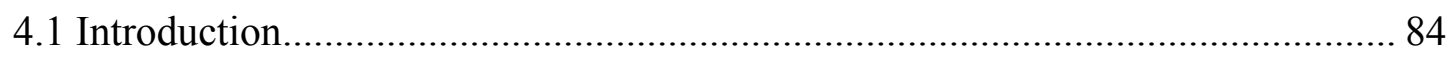

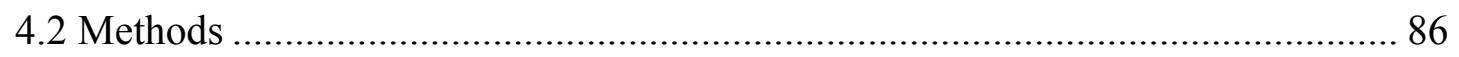

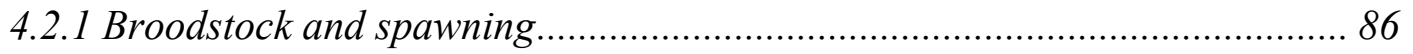

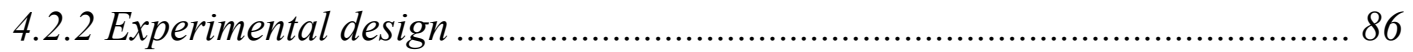

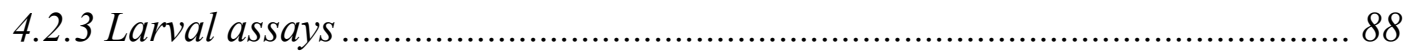

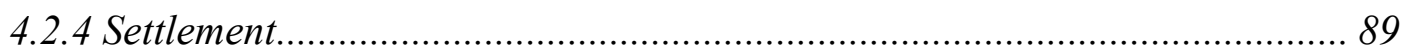

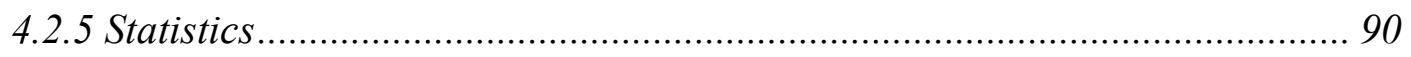

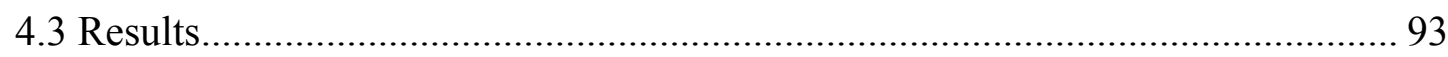

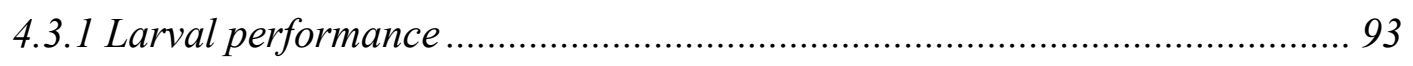

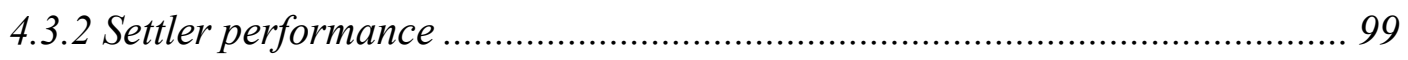

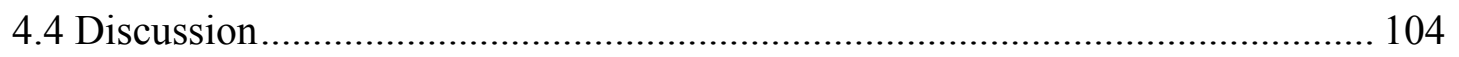

4.4.1 Dietary vs. waterborne toxicity ............................................................... 104

4.4.2 Direct and carry-over effects............................................................... 105

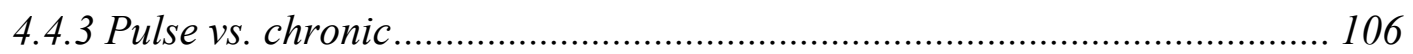

4.4.4 Implications for management ........................................................... 107

CHAPTER 5 Multiple stressors: The effect of low salinity on copper toxicity in Evechinus chloroticus early life stages .................................................................... 109

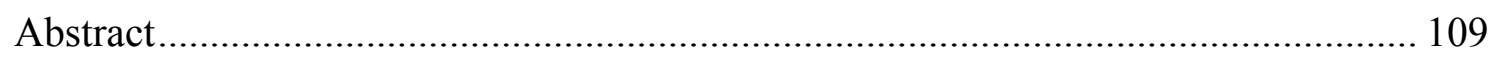

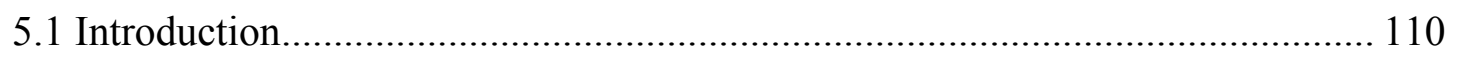

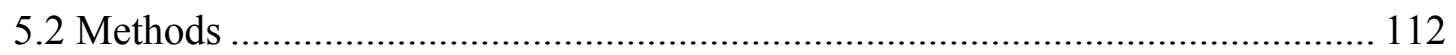

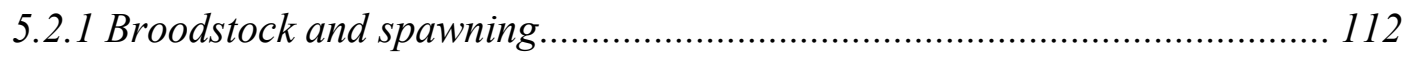

5.2.2 Embryo/early pluteus experiment ......................................................... 113 


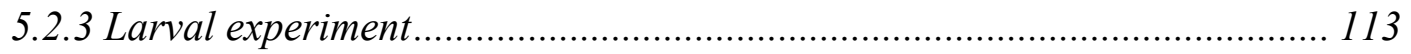

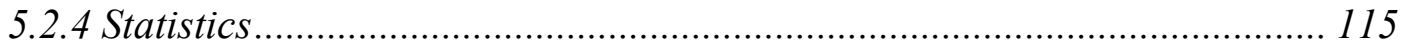

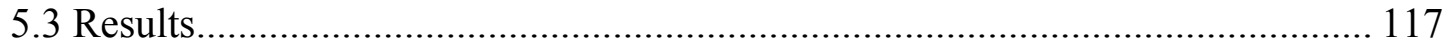

5.3.1 Embryo/early pluteus experiment …....................................................... 117

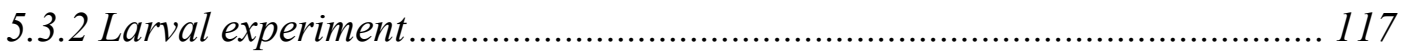

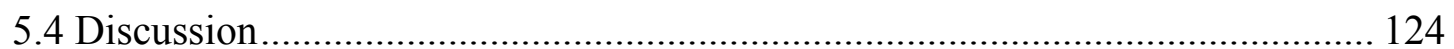

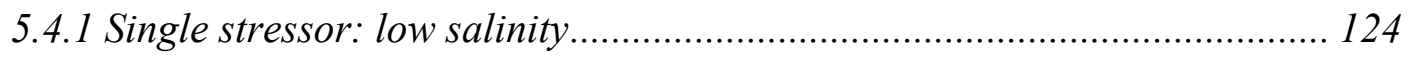

5.4.2 Single stressor: copper .................................................................. 126

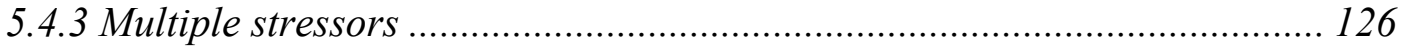

5.4.4 Consequences for field populations..................................................... 127

CHAPTER 6 Copper burden in gonads and fertilisation success in the sea urchin Evechinus chloroticus ................................................................................. 129

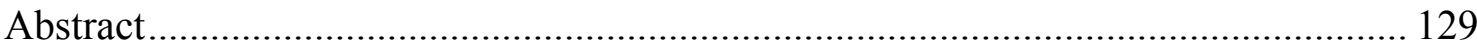

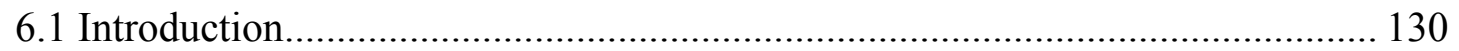

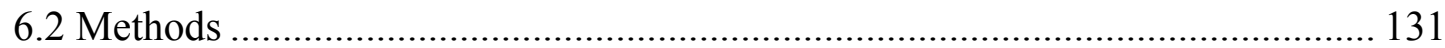

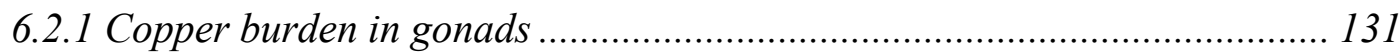

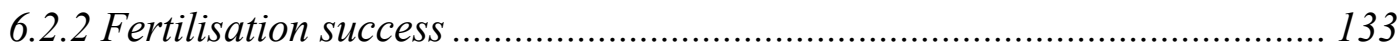

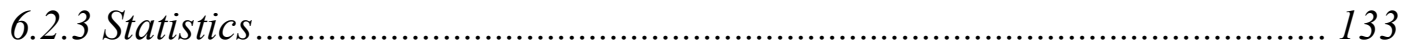

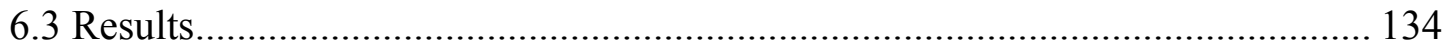

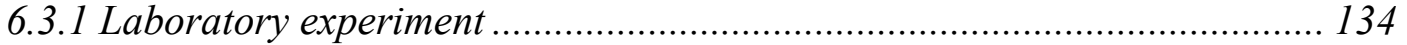

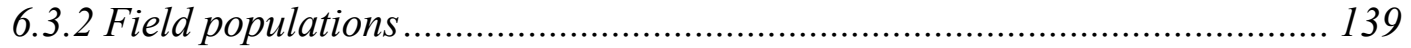

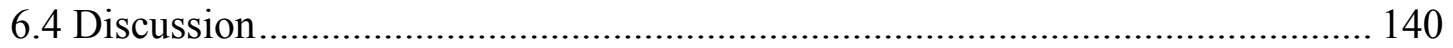

6.4.1 Copper burden in gonads ...................................................................... 140

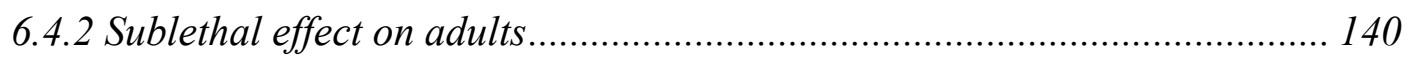

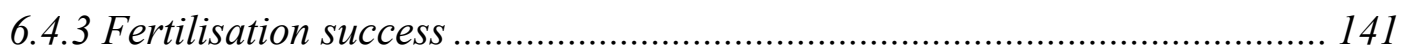

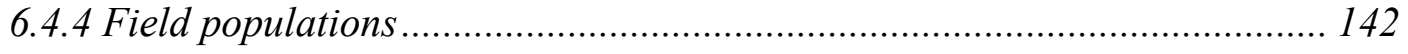

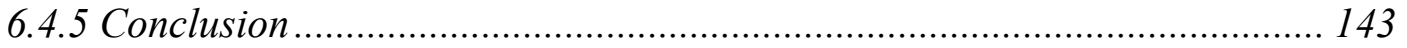

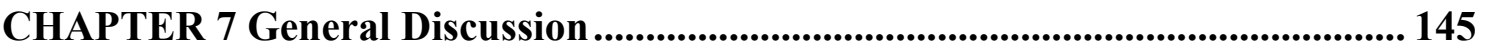

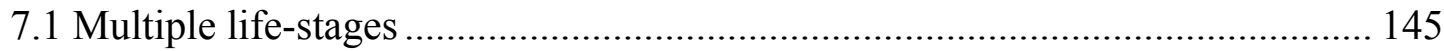

7.1.1 Vulnerability of E. chloroticus throughout its life cycle ........................... 145 


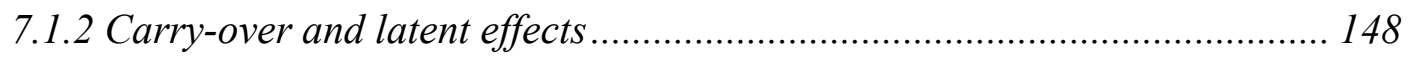

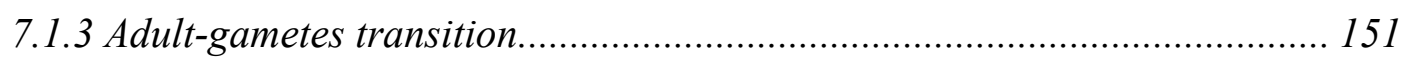

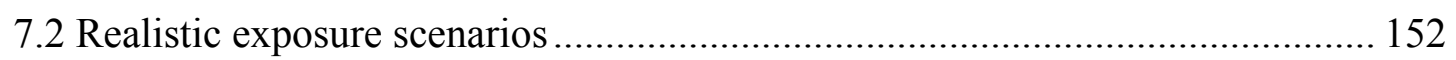

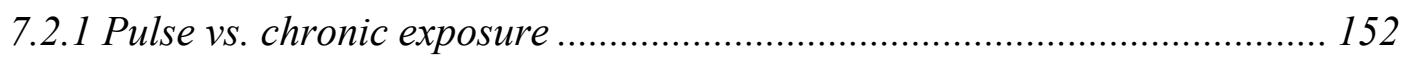

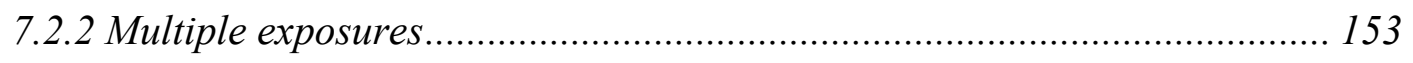

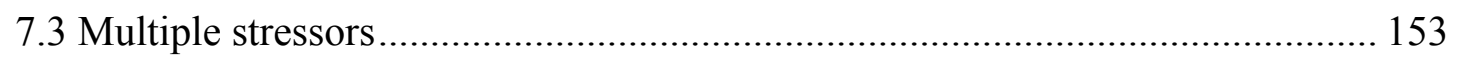

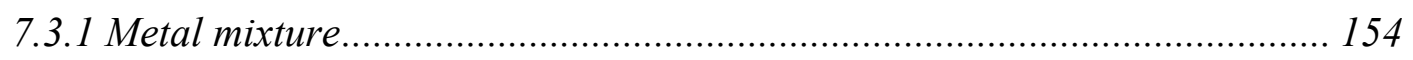

7.3.2 Metal and other abiotic stressors ............................................................ 154

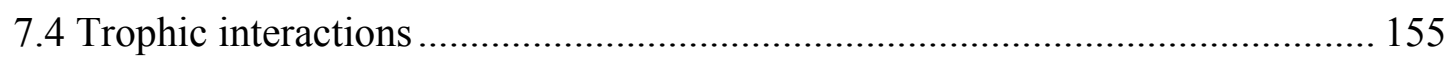

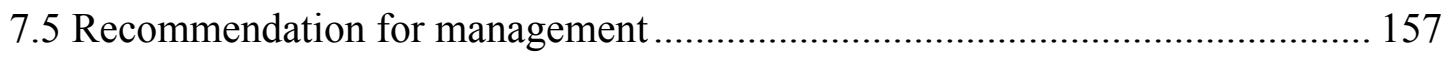

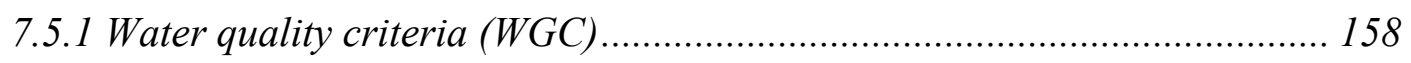

7.5.2 Preventing episodic discharge of pollutants .......................................... 159

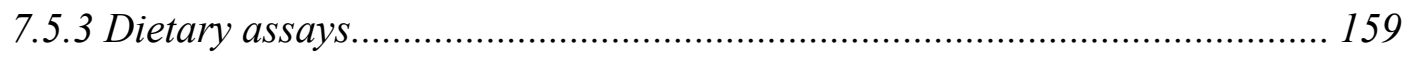

7.5.4 Monitoring programme and recommended actions .............................. 159

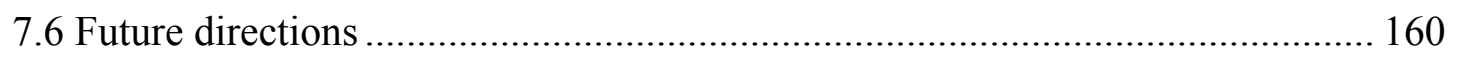

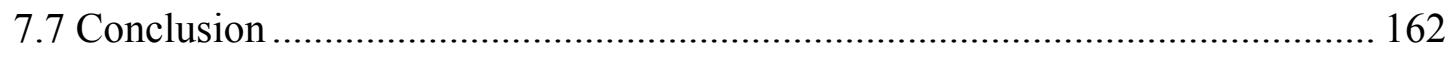

APPENDIX A Dissolved metal concentrations in Wellington coastal area ........... 163

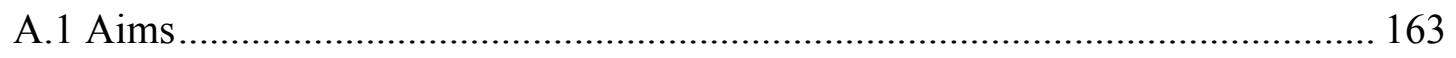

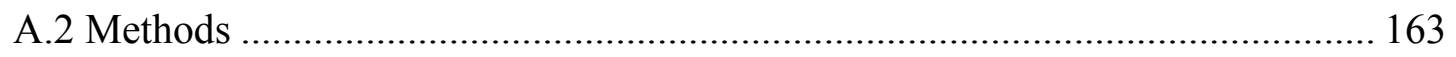

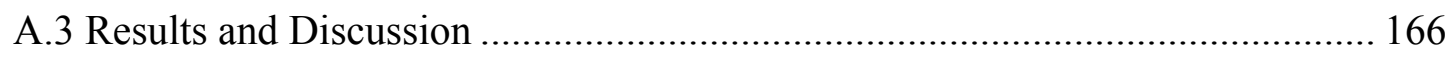

APPENDIX B Direct effects of copper exposure on Evechinus chloroticus larval stage (Additional data from Chapter 3) ............................................................... 171

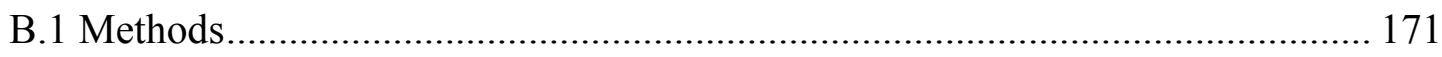

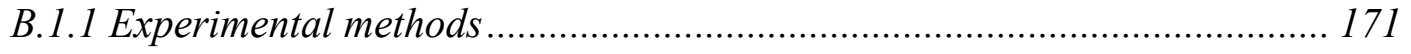

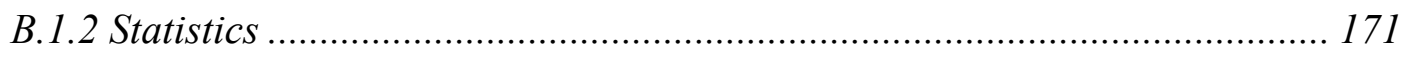

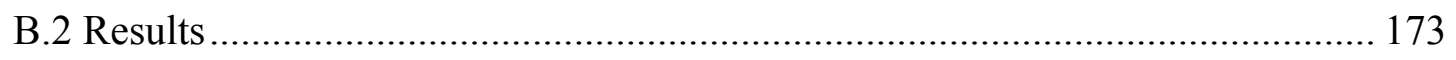

B.2.1 Larval survival and development ................................................... 173

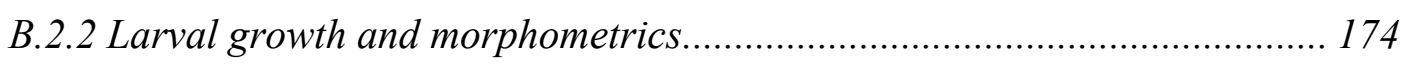


APPENDIX C Bioaccumulation of copper, lead and zinc by the planktonic alga

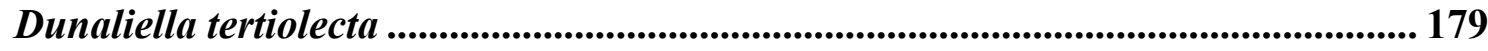

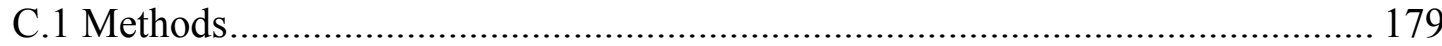

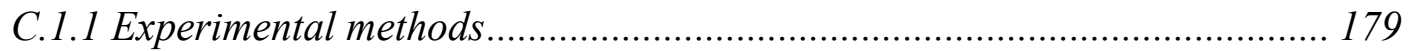

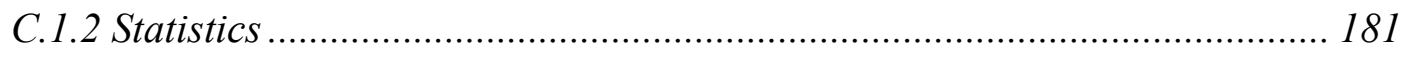

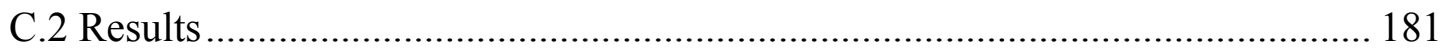

APPENDIX D Fertilisation success and copper burden in Evechinus chloroticus:

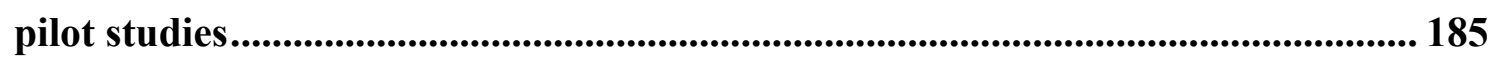

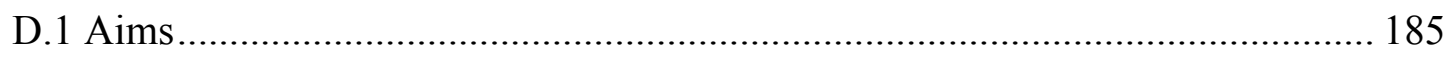

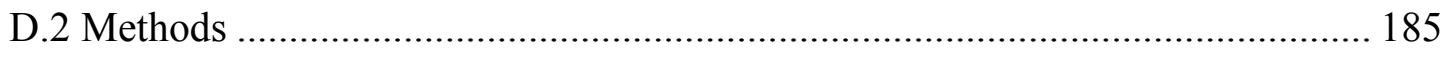

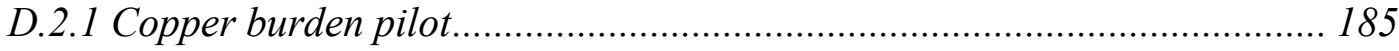

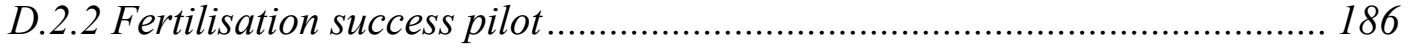

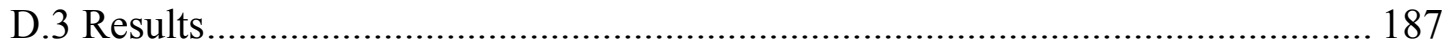

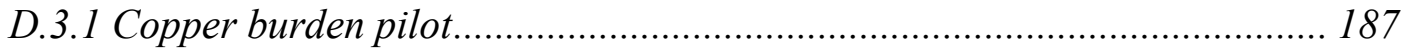

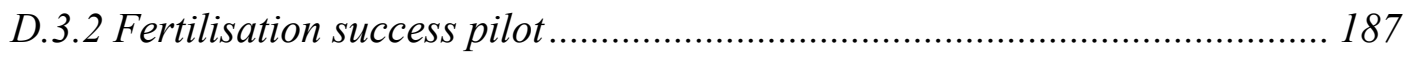

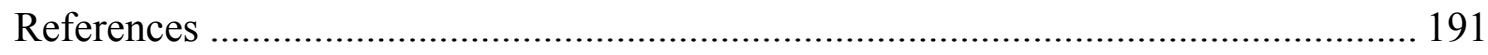




\section{LIST OF TABLES}

Table 1.1: Copper $(\mathrm{Cu})$, lead $(\mathrm{Pb})$ and zinc $(\mathrm{Zn})$ contamination $(\mu \mathrm{g} / \mathrm{L})$ in coastal water in areas of low human impact and areas of high human impact (urban/industrial, shipping activity and mining).

Table 1.2: Range of copper $(\mathrm{Cu})$, lead $(\mathrm{Pb})$ and zinc $(\mathrm{Zn})$ concentrations $(\mu \mathrm{g} / \mathrm{L})$ in rivers in Auckland and Wellington regions and water quality trigger values for $95 \%$ species protection (WQC 95\%) and 90\% species protection (WQC 90\%) in coastal water.

Table 2.1: Nominal metal concentrations ( $\mu \mathrm{g} / \mathrm{L})$ used in assays: (a) $E$. chloroticus all tests, (b) H. iris single metal test run 1, (c) H. iris single metal test run 2 and combined metal test (b).

Table 2.2: Developmental categories of Evechinus chloroticus larvae after 72 h......26

Table 2.3: Developmental categories of Haliotis iris larvae after $72 \mathrm{~h}$.

Table 2.4: Summary of $10 \%$ effective concentration (EC10) and median effective concentration (EC50) values $(\mu \mathrm{g} / \mathrm{L})$ with $95 \%$ confidence intervals $(95 \% \mathrm{CI})$, and toxicity at water quality criteria (WQC) for $95 \%$ species protection levels

Table 2.5: Toxic effect of metals in mixture based on Toxic Units (TUs).

Table 2.6: Comparative metal toxicity for the early life stages (embryo/larval)

of sea urchin species.

Table 2.7: Comparative metal toxicity for the early life stages (embryo/larval) of abalone and related species.

Table 3.1: Copper concentration chosen in larval assays.

Table 3.2: Developmental categories of Evechinus chloroticus larvae.

Table 3.3: Developmental categories of Evechinus chloroticus juveniles.

Table 3.4: Effect of larval experiences on Evechinus chloroticus settler size at 8 $\mathrm{d}$ post-settlement. Both variables, (A) radial length and (B) spine/body ratio, were analysed using an ANCOVA on linear mixed effect models.

Table 3.5: Effect of larval experience on Evechinus chloroticus settlers (A) survival and $(\mathrm{B}, \mathrm{C})$ growth at $25 \mathrm{~d}$ post-settlement.

Table 3.6: Effect of larval experience on Evechinus chloroticus juveniles (A) mortality and $(\mathrm{B}, \mathrm{C})$ growth two weeks after re-exposure to copper.

Table 4.1: Experimental design. 
Table 4.2: Copper concentration in water and in diet used in larval assays.

Table 4.3: Addition of 2 new developmental categories of Evechinus chloroticus larvae: pluteus with small rudiment and competent pluteus....

Table 4.4: Repeated measures ANOVA of Evechinus chloroticus larval daily per capita mortality rate (A) and percent normal development (B)

Table 4.5: Two-way ANOVA of Evechinus chloroticus proportion of larvae with a rudiment (A) and proportion of larvae with a large rudiment with protruding spines $(\mathrm{B})$

Table 4.6: Effect of copper exposure (Level) and source of copper (Source) on Evechinus chloroticus growth between 15 and 24 days post-fertilisation.

Table 4.7: Effect of larval experiences on Evechinus chloroticus size at settlement: (A) radial length and (B) spine/body ratio (SBR).

Table 4.8: Effect of larval experience of Evechinus chloroticus on settlers' normal development at 38 days post-settlement.

Table 5.1: Repeated measures ANOVA of Evechinus chloroticus larval survival to test effects of copper exposure $(0 \mu \mathrm{g} / \mathrm{L}, 15 \mu \mathrm{g} / \mathrm{L})$ and salinity (24 ppt, $36 \mathrm{ppt}$ ) at 16, 21 and $25 \mathrm{~d}$ post-fertilisation

Table 5.2: Repeated measures ANOVA of Evechinus chloroticus larval normal development to test effects of copper exposure and salinity at 16, 21 and $25 \mathrm{~d}$ post-fertilisation (Age) during the larval stage. Exposure to both stressors was either chronic (A), from 4 to 25 days post-fertilisation, or pulse (B), a single 4-day pulse at 7 days post-fertilisation.

Table 5.3: Follow-up two-way ANOVA of the proportion of normal Evechinus chloroticus larvae, to test effects of copper exposure (none, $15 \mu \mathrm{g} / \mathrm{L}$ ), salinity (24 ppt, $36 \mathrm{ppt}$ ) and their interaction on separate age classes.

Table 5.4: One-way ANOVA of Evechinus chloroticus growth, to test effects of chronic copper at normal salinity $(15 \mu \mathrm{g} / \mathrm{L} \mathrm{Cu}, 36 \mathrm{ppt})$ and chronic low salinity with no added copper (24 ppt) between 16 and $25 \mathrm{~d}$ postfertilisation.

Table 6.1: Effect of Evechinus chloroticus copper treatment (A) or source populations (B) and individual characteristics on copper burden in gonads .....135

Table 6.2: Feeding of Evechinus chloroticus during the last nine days of exposure (total exposure time was 15 days) to $50 \mu \mathrm{g} / \mathrm{L}$ of copper.

Table 7.1: Comparative toxicity of copper in Evechinus chloroticus life stages......146

Table 7.2: Latent effects of pollutants in aquatic invertebrates. 
Table 7.3: The relative toxicity of waterborne and dietary metals on

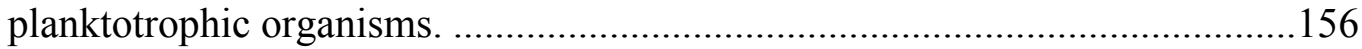

Table A.1: Details of the freshwater input during sampling..................................165

Table A.2: Dissolved metal $(\mu \mathrm{g} / \mathrm{L})$ and salinity from $3 \mathrm{~m}$ to $1 \mathrm{~km}$ offshore (A) in the Hutt river plume for three days following a rain event (B)

Table B.1: Repeated measures ANOVA of Evechinus chloroticus larval survival rate (A) and larval normal development rate (B)

Table B.2: Effect of copper exposure (Level) and timing of exposure (Timing) on Evechinus chloroticus growth rate during the last 14 days of larval stage

Table B.3: Effect of copper exposure (copper level) on Evechinus chloroticus morphometric measurements in late larval stage

Table C.1: Concentrations of copper (A), lead (B) and zinc (C) used in algal culture (nominal concentration) and corresponding cellular concentration in Dunaliella tertiolecta.

Table C.2: Effect of metal exposure on cellular metal concentration of Dunaliella tertiolecta.

Table D.1: Copper burden in Evechinus chloroticus from seven sites across Wellington Harbour. 



\section{LIST OF FIGURES}

Figure 1.1: Evechinus chloroticus life cycle

Figure 2.1: Proportion of normal larvae of the sea urchin Evechinus chloroticus after a $72 \mathrm{~h}$ exposure to increasing levels of (a) copper, (b) lead and (c) zinc.

Figure 2.2: Postoral arm / total body length ratio (PO/BL) of Evechinus chloroticus larvae after $72 \mathrm{~h}$ exposure to increasing levels of copper $(\mathrm{Cu})$, lead $(\mathrm{Pb})$, and zinc $(\mathrm{Zn})$.

Figure 2.3: Relative frequency of each abnormal development categories in single metal assays on Evechinus chloroticus after $72 \mathrm{~h}$ exposure to increasing levels of copper $(\mathrm{Cu})$, lead $(\mathrm{Pb})$ and zinc $(\mathrm{Zn})$.

Figure 2.4: Proportion of normal larvae of the abalone Haliotis iris after a $72 \mathrm{~h}$ exposure to increasing levels of (a) copper, (b) lead and (c) zinc.

Figure 2.5: Shell length $(\mu \mathrm{m})$ of Haliotis iris larvae after $72 \mathrm{~h}$ exposure to increasing levels of copper $(\mathrm{Cu})$, lead $(\mathrm{Pb})$ and zinc $(\mathrm{Zn})$.

Figure 2.6: Relative frequency of each abnormal development categories in single metal assays on Haliotis iris after $72 \mathrm{~h}$ exposure to increasing levels of copper $(\mathrm{Cu})$, lead $(\mathrm{Pb})$ and zinc $(\mathrm{Zn})$......

Figure 3.1: Effect of timing of copper exposure during larval stage and rudiment size before settlement on Evechinus chloroticus settlement success

Figure 3.2: Evechinus chloroticus settlers size at $8 \mathrm{~d}$ post-settlement.

Figure 3.3: Effect of level and timing of copper exposure during larval development on Evechinus chloroticus (a) radial growth and (b) spine growth rate at $25 \mathrm{~d}$ post-settlement.

Figure 3.4: Effect of copper exposure during larval development on juvenile Evechinus chloroticus mortality after subsequent exposure to $10 \mu \mathrm{g} / \mathrm{L} \mathrm{Cu}$ at $25 \mathrm{~d}$ post-settlement.

Figure 3.5: Effect of copper exposure during larval development on juvenile Evechinus chloroticus growth, both of (a) radial growth and (b) spine growth, after subsequent exposure to $10 \mu \mathrm{g} / \mathrm{L} \mathrm{Cu}$ at $25 \mathrm{~d}$ post-settlement.

Figure 3.6: Evechinus chloroticus radial length from 8 to $40 \mathrm{~d}$ post-settlement, showing the latent effects of copper exposure (a) early and (b) late during the larval stage on settler size. 
Figure 4.1: Evechinus chloroticus daily per capita mortality rate in early (4$15 \mathrm{~d}$ post-fertilisation) and late $(15-24 \mathrm{~d}$ post-fertilisation) larval development under different levels of copper exposure.

Figure 4.2: Evechinus chloroticus normal development in mid (15 - 16 d postfertilisation) and late (23 - $24 \mathrm{~d}$ post-fertilisation) larval development under different levels and sources of copper.

Figure 4.3: Proportion of Evechinus chloroticus larvae with a small rudiment and/or with a protruding rudiment (i.e. competent larvae) at $23-24$ days post-fertilisation under different regimes of copper exposure.

Figure 4.4: Evechinus chloroticus daily posterodorsal arm (PD) and preoral arm (EO) growth between 15 - 16 and 23 - 24 d post-fertilisation under different regimes of copper exposure.

Figure 4.5: Settlement success of Evechinus chloroticus, 8 days postsettlement, under three different levels of copper exposure: control (Ctrl), ANZECC Chronic (A.), High Pulse (H.p.) and High Chronic (H.c.).

Figure 4.6: Evechinus chloroticus radial length (a) and spine/body ratio (b) at 8 and 38 days post-settlement under different copper regimes

Figure 5.1: Evechinus chloroticus survival from 4 to $25 \mathrm{~d}$ post-fertilisation under different levels of copper exposure and salinity.

Figure 5.2: Proportion of normal Evechinus chloroticus larvae from $4 \mathrm{~d}$ to $25 \mathrm{~d}$ post-fertilisation under different levels of copper exposure and salinity. Larvae were exposed to low salinity (Low, $24 \mathrm{ppt}$ ) or natural seawater salinity (Normal, $36 \mathrm{ppt}$ ). Exposure to both stressors was either chronic (A) or a single 4-day pulse exposure (B).

Figure 5.3: Proportion of 8-armed Evechinus chloroticus larvae with or without rudiment at 25 days post-fertilisation when exposed to stressors chronically (A), from day 4 to 25 , and a single 4-day pulse (B).

Figure 5.4: Anterolateral arm (AL) and posterodorsal arm (PD) growth in Evechinus chloroticus larvae between 16 and 25 days post-fertilisation under different regimes of copper exposure and salinity.

Figure 6.1: Copper accumulation in gonads ( $\mu \mathrm{g} / \mathrm{g}$ wet weight) of the sea urchin Evechinus chloroticus.

Figure 6.2: Copper burden in Evechinus chloroticus gonads vs. total gonad weight (wet weight), after two weeks of exposure to $50 \mu \mathrm{g} / \mathrm{L}$ (LAB group)....137

Figure 6.3: Fertilisation success of Evechinus chloroticus pairs after $1 \mathrm{~h}$. 139

Figure A.1: Location of the water sampling sites in the region of Wellington. 164 
Figure A.2: Dissolved copper (A), lead (B) and zinc (C) in costal water near a stream or river discharge.

Figure B.1: Delayed development of Evechinus chloroticus larvae exposed to copper

Figure B.2: Proportion of growth of Evechinus chloroticus larvae body length (BL), postoral arms (PO) and anterolateral arms (AL) during the last 2 weeks of larval stage.

Figure C.1: Bioaccumulation of copper $(\mathrm{Cu})$, lead $(\mathrm{Pb})$ and zinc $(\mathrm{Zn})$ by Dunaliella tertiolecta after 1 week of culture in metal-spiked medium............182

Figure D.1: Map of Wellington Harbour showing sampling sites...... 186

Figure D.2: Fertilisation success of Evechinus chloroticus with gamete exposure to increasing copper concentrations. ..............................................188 



\section{LIST OF ABBREVIATIONS AND ACRONYMS}

AL: $\quad$ Anterolateral arm length. Used for Evechinus chloroticus pluteus larvae

ANZECC: Australian and New Zealand Environment and Conservation Council. It this thesis this acronym is used to describe a metal concentration similar to the water quality criteria defined by ANZECC (2000). See WQC

BL: $\quad$ Body Length. Used for E. chloroticus pluteus larvae

d: day

DOC: $\quad$ Dissolved organic carbon

EC10: $\quad$ Effective Concentration 10\%; i.e. concentration at which $10 \%$ of the test population is affected.

EC50: Effective Concentration 50\%; i.e. concentration at which $50 \%$ of the test population is affected.

EO: $\quad$ Preoral arm length. Used for E. chloroticus pluteus larvae

FSW: $\quad$ Filtered seawater $(0.2 \mu \mathrm{m})$

LC50: Lethal Concentration 50\%; i.e. concentration at which $50 \%$ of the test population has died.

LOEC: $\quad$ Lowest Observable Effect Concentration; i.e. lowest concentration tested for which deleterious effects were observed.

NOEC: $\quad$ No Observable Effect Concentration; i.e. highest concentration tested for which no effects were observed.

PD: $\quad$ Posterodorsal arm length. Used for E. chloroticus pluteus larvae

PO: $\quad$ Postoral arm length. Used for E. chloroticus pluteus larvae

RL: $\quad$ Radial length. Used for E. chloroticus pluteus juveniles

SBR: $\quad$ Spine/body ratio = spine length / radial length. Used for E. chloroticus pluteus juveniles

WQC: Water quality criteria. Unless otherwise stated, these refer to the acceptable metal concentrations in coastal water defined by ANZECC (2000) for $95 \%$ species protection $(1.3 \mu \mathrm{g} / \mathrm{L} \mathrm{Cu}, 4.4 \mu \mathrm{g} / \mathrm{L} \mathrm{Pb}$ and 15 $\mu \mathrm{g} / \mathrm{L} \mathrm{Zn})$ 



\section{CHAPTER 1 \\ General Introduction}

Effects of land-based impacts, such as effluent, on coastal communities are a growing concern (Bryan 1971, Thrush et al. 2004, Green et al. 2007). As a result of increased urbanisation, agriculture and industrial discharge, effluent composition has changed in impacted streams and rivers worldwide. These changes have strong effects on river health and also on coastal communities (Bryan 1971, Johnston \& Keough 2002, Thrush et al. 2004, Shahidul Islam \& Tanaka 2004). Coastal organisms subjected to river plumes are simultaneously exposed to a vast array of stressors, including pollutants, suspended sediments and low salinity. In New Zealand, rainstorms are predicted to increase in frequency and intensity due to climate change, leading to an increased volume of effluents discharged in coastal waters (Morrison et al. 2009). It is crucial to understand the impact of effluent on coastal systems to develop appropriate regulations on water quality.

\subsection{COASTAL BENTHIC ORGANISMS}

Coastal systems are often dominated by benthic organisms, both algae and invertebrates. Some of these organisms shape the substrate and are habitat forming (eg. kelp, coral but also to a lesser extent bivalves, sponges, anemones, etc.) and therefore determine local assemblages (Mann 2000). Benthic organisms also constitute the lower levels of the food chain as they are usually primary producers, grazers or suspension-feeders. Indeed, coastal systems are highly productive, providing numerous services and supporting most exploited fisheries (Mann 2000, Morrison et al. 2009). 
Studies evaluating anthropogenic impacts on coastal organisms tend to focus on adult populations (Johnston \& Keough 2002, Lindegarth \& Underwood 2002, Fukunaga et al. 2010). However, most invertebrate species have a planktonic larval stage and these larvae may be exposed to different stressors or react differently to the same stressors than do later life stages (Pechenik 1987, Pechenik et al. 1998). For example, a rocky reef subtidal benthic population may not be exposed to significant level of pollution. Yet planktonic larvae may encounter a highly polluted river plume far away from the source population and be affected by even a short exposure time. Therefore pollution may induce a decrease in the adult population via impacts on early life stages.

Early life stages are usually more vulnerable to disturbance than are later stages (Pechenik 1987, Diederich et al. 2011). In addition, stress experienced in early life may have cascading effects on performance in later life (Pechenik et al. 1998, 2001, Gimenez et al. 2004, Allen \& Marshall 2010, Marshall \& Morgan 2011). Finally, survival and quality of larvae and new recruits is a critical factor limiting adult population size and persistence (Caley et al. 1996, Pechenik et al. 1998, Crean et al. 2011). Therefore it is crucial to take into account early life stages and multiple life stages when evaluating the potential impact of anthropogenic disturbances on coastal organisms.

\subsection{PREVAlENCE OF METAL POLLUTION WORLDWIDE}

Pollution is one of the major threats to coastal systems. With an increased awareness of the risks pollution causes to marine organisms and human health, many countries have developed a routine monitoring program to keep track of pollutants present in coastal water (Milne 2006, Osman 2010, Roose et al. 2011, Engle 2012). Metals are amongst the contaminants most commonly found in concentrations toxic to marine life (US EPA 2014). Metal concentration in coastal water is highly variable in areas strongly affected by human activities and range from near natural to two orders of magnitude higher than natural concentrations (Table 1.1). Cadmium, copper and lead are commonly found in high concentrations in many coastal areas especially in areas 
affected by urban and industrial discharges or mining activities (Fatoki \& Mathabatha 2001, Kobayashi \& Okamura 2004, SFEI 2015). Zinc is generally not considered a priority pollutant (US EPA 2014) but its prevalence is increasing as a result of urbanisation in many countries including New Zealand (Eisler 2007, Milne \& Watts 2008, Neale 2009, SFEI 2015).

Table 1.1: Copper $(\mathrm{Cu})$, lead $(\mathrm{Pb})$ and zinc $(\mathrm{Zn})$ contamination $(\mu \mathrm{g} / \mathrm{L})$ in coastal water in areas of low human impact and areas of high human impact (urban/industrial, shipping activity and mining). All concentrations reported are the dissolved fraction $(<0.45 \mu \mathrm{m})$. The highest concentrations are highlighted in bold.

\begin{tabular}{|c|c|c|c|c|c|}
\hline Site & Country & $\mathbf{C u}$ & $\mathbf{P b}$ & Zn & Reference \\
\hline \multicolumn{6}{|l|}{ Low impact } \\
\hline Waitemata Harbour & New Zealand & $<1-1.3$ & - & $<4$ & $\begin{array}{l}\text { (Gadd \& Cameron } \\
\text { 2012) }\end{array}$ \\
\hline Seto & Japan & 0.79 & 0.1 & 4.9 & $\begin{array}{l}\text { (Kobayashi \& } \\
\text { Okamura 2004) }\end{array}$ \\
\hline Various locations & Antarctica & $0.18-1.17$ & $0.22-0.49$ & $0.41-1.26$ & (Honda et al. 1987) \\
\hline \multicolumn{6}{|c|}{ High impact, urban/industrial } \\
\hline Port Phillip Bay & Australia & $0.4-0.6$ & $0.02-0.13$ & $0.3-1.1$ & $\begin{array}{l}\text { (Gorski \& } \\
\text { Nugegoda 2006) }\end{array}$ \\
\hline East London Harbour & South Africa & $0.6-42.6$ & $0.6-16.3$ & $0.5-27.6$ & $\begin{array}{l}\text { (Fatoki \& } \\
\text { Mathabatha 2001) }\end{array}$ \\
\hline $\begin{array}{l}\text { Port Elizabeth } \\
\text { Harbour }\end{array}$ & South Africa & $0.5-11.3$ & $0.6-4.2$ & $0.7-16.2$ & $\begin{array}{l}\text { (Fatoki \& } \\
\text { Mathabatha 2001) }\end{array}$ \\
\hline Southwest Coast & India & $3.9-13.1$ & $0.05-5.3$ & $3.9-35.6$ & $\begin{array}{l}\text { (Udayakumar et al. } \\
\text { 2011) }\end{array}$ \\
\hline Pondicherry Coast & India & $0.7-61.5$ & - & $16.7-135.7$ & $\begin{array}{l}\text { (Govindasamy et al. } \\
\text { 1998) }\end{array}$ \\
\hline San Francisco Bay & USA & $0.4-10.8$ & $0.003-2.97$ & $0.04-14.3$ & $\left(\right.$ SFEI 2015) ${ }^{\mathrm{a}}$ \\
\hline San Jorge Bay & Chile & $0.62-1.96$ & $0.02-0.09$ & $1.41-8.99$ & (Valdés et al. 2011) \\
\hline \multicolumn{6}{|c|}{ High impact, shipping activity } \\
\hline Auckland's Marinas & New Zealand & $<1-20.0$ & - & $<4-22$ & $\begin{array}{l}\text { (Gadd \& Cameron } \\
\text { 2012) }\end{array}$ \\
\hline $\begin{array}{l}\text { San Diego Bay's } \\
\text { Marinas }\end{array}$ & USA & $1.1-21.0$ & - & - & (Schiff et al. 2007) \\
\hline \multicolumn{6}{|l|}{ High impact, mining } \\
\hline Kanayama Cove & Japan & 0.1 & 16 & 35 & $\begin{array}{l}\text { (Kobayashi \& } \\
\text { Okamura 2004) }\end{array}$ \\
\hline Chanaral Bay & Chile & $<1-32$ & - & $<1-6.7$ & $\begin{array}{l}\text { (Stauber et al. } \\
2005 \text { ) }\end{array}$ \\
\hline
\end{tabular}




\subsection{MECHANISMS OF TOXICITY}

\subsubsection{BIOAVAILABILITY}

Metals in water tend to form organic and inorganic complexes or bind with sediments (Di Toro et al. 2001). Only the free ions are available for uptake by aquatic organisms. The bioavailable portion is largely dependent on water chemistry such as $\mathrm{pH}$, dissolved organic carbon and ions composition (Santore et al. 2001, McGeer et al. 2002, Paquin et al. 2002). For freshwater organisms, a biotic ligand model (BLM) has been developed to predict metal accumulation in organisms under specific water chemistry conditions (US EPA 2007). In seawater, until a similar model is developed, the best method to measure bioavailable metals is by analysing the fraction $<0.45 \mu \mathrm{m}$ (dissolved fraction; US EPA 2007).

\subsubsection{COPPER}

Most studies on the mechanisms underlying copper toxicity focus on freshwater fish or crustaceans (Hinton et al. 2005, Grosell et al. 2007). In freshwater organisms, copper causes toxicity mainly by impairing sodium uptake at the gills and thus disrupting osmoregulation (Grosell et al. 2002, Eisler 2007). Most marine invertebrates and especially their early life stages are both osmo- and ionoconformers - their ionic composition and osmotic pressure are similar to the marine environment. Mechanisms of copper toxicity for such organisms are likely to be very different from those of fish (Grosell et al. 2007). In marine invertebrates copper toxicity has been associated with respiratory impairment, in particular by disrupting haemocyanin functions (Bielmyer et al. 2005, Lee et al. 2010, Jakimska et al. 2011) as well as disruption of protein and enzyme activity (Flemming \& Trevors 1989, Durkina \& Evtushenko 1991). In addition, copper has been shown to causes DNA damage both in vitro and in vivo (Haldsrud \& Krokje 2009, Al-Shami et al. 2011). 


\subsubsection{ZINC}

Zinc has an important role in regulating protein and cellular activites (Oteiza \& Mackenzie 2005) but it induces oxidative stress in high concentration (Formigari et al. 2007). In fish, zinc impairs osmoregulation and damages the gills (Eisler 2007). However, zinc is commonly found in high concentration in invertebrates tissues with no apparent adverse effects, possibly due to their ability to sequester zinc in hard tissues or granules (Eisler 2007). Adult mollusks in particular have been found to bioaccumulate high levels of zinc (Chong \& Wang 2001). When zinc toxicity occurs in marine invertebrates, it involves respiratory impairment and metabolic dysfunction (Devi 1995) as well as oxidative damage (Franco et al. 2006, Trevisan et al. 2014).

\subsubsection{LEAD}

The mechanisms of lead toxicity are different from copper and zinc as lead acts mainly on the nervous system by replacing calcium ions (Eisler 2007, Zizza et al. 2013). Accordingly, in vertebrates, lead also accumulates in hard tissues (e.g. bones) creating an internal source of exposure potentially leading to chronic poisoning (Eisler 2007, Mager 2012). Lead toxicity pathways in marine invertebrates, especially their early life stages, is poorly known but would presumably be similar to those in vertebrates. For example, in invertebrate larvae with a calcium carbonate structure such as echinoderm larvae, the replacement of calcium ions by lead might account for the 'skeletal' abnormality observed in presence of lead (Ghorani et al. 2013). A recent study showing a lower whole body calcium accumulation in sea urchin larvae in presence of lead seems to confirm this hypothesis (Tellis et al. 2014).

\subsection{IMPACTS OF METAL POLLUTION ON MARINE SPECIES}

As the larval stage is usually the most sensitive stage to pollutants, many studies have used early life stages to determine the sensitivity of species to pollutants (Hunt \& Anderson 1993, Conroy et al. 1996, US EPA 2002a). These sorts of ecotoxicology studies, however, are typically very short (no more than 96 hours) and use high 
concentrations of pollutants that are not necessarily representative of realistic levels in coastal environments. Standard ecotoxicity tests are useful in determining priority pollutants and providing fast and cost-effective methods for routine monitoring and defining water quality criteria (WQC). However, they have limited use in predicting the likely effects of pollutants on marine populations. Further studies using environmentally relevant concentrations and longer-term end points are needed to evaluate the likely impacts of pollutants on early life stages in the field.

Moreover, many pollutants tend to accumulate in tissues of marine organisms. Nonessential metals (i.e. metals that cannot be used by the organism) and metals with a low rate of excretion (e.g. lead and mercury) are of special concern (Bryan 1971, Shahidul Islam \& Tanaka 2004). In addition, biomagnification may occur; that is, metal and organic pollutants pass up the food chain with little loss (reviewed in Meyer et al. 2005). Therefore, organisms are not only exposed to waterborne concentrations but also to pollutants in their diet. For some species and pollutants, dietary intake may be the major route by which heavy metals are accumulated. For example, cadmium accumulation was almost 10-fold higher in sea urchins exposed to metal-spiked algae than it was when the urchins were exposed to a similar seawater concentration of metals (Bremer et al. 1990).

A decrease in salinity occurs when effluents enter the coastal system, especially after a strong rain event. While it is a natural phenomenon, a decrease in salinity can be an important stressor for coastal organisms especially during the larval stage (Pechenik et al. 2001, Gimenez et al. 2004, Allen \& Pechenik 2010, Diederich et al. 2011). A study showed that low salinity was actually the main factor responsible for a change in the adult community composition near an effluent (Roberts et al. 2008). Therefore, salinity may be a confounding factor and need to be taken into account when attempting to evaluate effluent impact on populations. In addition, salinity stress may affect the resilience of coastal organisms to other stressors occurring simultaneously, such as sediment or pollutants (Lee et al. 2010). 


\subsection{HOW TO EVALUATE THE IMPACT OF THESE STRESSORS?}

\subsubsection{INTERACTION BETWEEN STRESSORS}

Existing studies typically evaluate the impact of different stressors associated with effluent independently, although there is some evidence that the presence of more than one pollutant produces a different outcome than each taken separately (King et al. 2006, Mann et al. 2009, Manzo et al. 2010, Xu et al. 2011). For example, copper had no impact in isolation but increased the impact of polycyclic aromatic hydrocarbons (PAH) on sponge early life stages (Cebrian \& Uriz 2007). Some studies have investigated the effects of metal mixtures but these vary strongly both between species and between pollutant mixtures (reviewed in Norwood et al. 2003). Given the large number of pollutants present in coastal water, more work needs to be done to characterise the effect of pollutant mixtures on the major groups of marine organisms.

Furthermore, salinity affects the toxicity of pollutants (Ozoh 1992, Du Laing et al. 2009, Barbieri \& Doi 2011). Chloride in seawater tends to form complexes with metals, thus reducing a metal's free ion activity and bioavailability (Du Laing et al. 2009). Therefore the same level of pollutant may be more toxic in low salinity waters (Ozoh 1992). However, the toxicity of metals under realistic scenarios of low salinity has rarely been evaluated in marine larvae (but see MacInnes \& Calabrese 1979, Nadella et al. 2013). Larvae of many species, including echinoderms, are able to avoid freshwater and position themselves at or below the halocline (Mann et al. 1991, Vazquez \& Young 1996, Metaxas \& Young 1998). In New Zealand, the presence of such an avoidance behaviour in a local echinoid, Evechinus chloroticus, is supported by an absence of larvae in the low salinity layer in fjords (Lamare 1998, Antonie 2003). This behaviour may strongly mitigate the risk of exposure to pollutants in hyposaline conditions. However, pollutants discharge increases during major rain events and strong rain events tend to be associated to high wind. Therefore larvae may be unable to maintain their position in the water column under such condition of high turbulence. 


\subsubsection{CARRY-OVER AND LATENT IMPACTS}

The study of pollution impacts on early life stages derives from toxicology and uses similar standard toxicity protocols of typically short duration over a single life stage. However, there is increasing evidence that larval-stage experience influences performance in later life (Pechenik et al. 1998, Gimenez et al. 2004, Pechenik 2006, Crean et al. 2011), i.e. carry-over effects, where the stressor visibly affects larvae but the effect does not stop with settlement and continues to affect the juveniles. For example, starvation decreases larval growth but juveniles continue to have a low growth rate even when raised with normal food levels after settlement. The reason for this carry-over effect is that starved larvae metamorphose into smaller juveniles with feeding structures that are less developed, thus reducing feeding ability and growth rate (Phillips 2002, 2004, Pechenik 2006, Allen \& Marshall 2010). Latent effects occur at later juvenile or adult stages even though larvae have not been notably affected. These type of effects are well known in humans where a stressor such as maternal intake of alcohol during fetal development may impact learning ability, detectable only years after birth citation (O'Callaghan et al. 2007). In aquatic organisms, carry-over and latent effects have been shown for nutritional stress (Phillips 2002, 2004, Allen \& Marshall 2010), low salinity stress (Pechenik et al. 2001, Diederich et al. 2011) and delayed metamorphosis (Pechenik 1990, 2006, Marshall et al. 2003). Very few studies have investigated the potential carry-over or latent effects of pollutants (Hoare et al. 1995, Pechenik et al. 2001, Ng \& Keough 2003). Effects may occur a long time after exposure, such as the latent impact seen in bryozoans 11 weeks after settlement (Ng \& Keough 2003). Similarly, arthropods exposed to copper suffered no observable effect throughout their life cycle but failed to produce viable offsprings (Manyin \& Rowe 2010).

On the other hand, stressors may have a negative impact on larvae but surviving individuals may be more resistant when exposed later in life to the same stressor. A change in stressor tolerance has been reported with multiple exposures during the same life stage in freshwater fish (Dixon \& Sprague 1981, Brinkman \& Woodling 2014). In aquatic organisms, one study recently investigated the effect of further exposure to a pollutant in later life stages (Kimberly \& Salice 2014). This study showed an increase in sensitivity to cadmium in juvenile freshwater snails, Physa 
pomilia, previously exposed to the same stressor during embryonic development. In marine organisms, the resistance/weakening hypothesis has been investigated for hyposaline stress but not for metal pollution (Diederich et al. 2011, Russell 2013).

\subsubsection{ECOLOGICAL RELEVANCE}

By their nature, ecotoxicology studies tend to demonstrate impacts at the individual level, e.g. mortality, growth rate. However, to develop management strategies it is important to understand the ecological relevance of impacts, e.g. whether increased larval mortality is likely to affect the population. Evaluating a stressor's effect on field populations or communities is a very complex task as many factors, such as the effect of the stressor on interacting species (e.g. prey, competitors or predators), will influence the response (Johnston et al. 2003, Mayer-Pinto et al. 2010). Several studies have used soft sediment or hard substrate assemblages to test the impact of different stressors (pollutant, sedimentation, nutrients) in the field (Johnston \& Keough 2002, Lindegarth \& Underwood 2002, Fukunaga et al. 2010). However, this approach can be done only with low mobility organisms such as juvenile and adult stages of sessile organisms, and is not suited to the study of larval stages.

Where the study of whole communities is not possible, a common strategy is to use test species. Test species are usually selected for their importance in the community (ecosystem engineers), sensitivity (indicator species) and/or cultural and economic importance (valuable stock). To investigate the effects of a stressor using key species while aiming for ecological relevance, it is important to use realistic concentrations and exposure times. For example, it is unlikely that larvae are going to be exposed to high levels of suspended sediment throughout the full duration of their larval stage. It is more relevant to use 'pulse exposure' in which organisms are exposed only for a short time to mimic exposure to a sediment plume after a rain event. In addition, long-term experiments should be used to investigate potential carry-over or latent effects. Test organisms should at least be kept for several weeks after settlement or for their full life cycle for short-lived species. Finally, effort should be made to correlate lab findings to populations in the field. 


\subsection{WHAT IS KNOWN IN NEW ZEALAND?}

Local authorities have a statutory obligation under the Resource Management Act (1991) concerning contaminant discharge into receiving water. Most coastal cities monitor sediment levels, especially in harbours and estuaries, and pollutant concentration is monitored in sewage water, and sometimes in rivers and in coastal sediments (Milne \& Watts 2008, Neale 2009, Table 1.2). Pollutants of concern are usually copper, zinc, lead, PAH and ammonia. The regulation concerning the acceptable levels of pollutants and sediment is based on the Australian and New Zealand Environment and Conservation Council (ANZECC) WQC (ANZECC 2000). These criteria, however, have been developed mainly using studies on Australian species; few studies on local species are available. New Zealand is a highly isolated system with a high endemism rate especially amongst invertebrates and coastal fish with a short range dispersal (MacDiarmid 2007). Land-use impacts including pollution and sedimentation have been identified as a major threat to coastal invertebrates in NZ (Morrison et al. 2009, Freeman et al. 2010). New Zealand has an extensive coastline of more than $15000 \mathrm{~km}$ (ratio coast/land of 53) with coastal fisheries including some of the most valued species such as snapper, lobster and paua (Morrison et al. 2009). It is therefore particularly important to verify whether the WQC are appropriate for local species.

Table 1.2: Range of copper $(\mathrm{Cu})$, lead $(\mathrm{Pb})$ and zinc $(\mathrm{Zn})$ concentrations $(\mu \mathrm{g} / \mathrm{L})$ in rivers in Auckland and Wellington regions and water quality trigger values for $95 \%$ species protection (WQC 95\%) and $90 \%$ species protection (WQC $90 \%$ ) in coastal water. Dissolved $=$ fraction $<0.45 \mu \mathrm{m}$.

\begin{tabular}{|c|c|c|c|c|c|c|}
\hline & \multicolumn{2}{|c|}{$\mathrm{Cu}$} & \multicolumn{2}{|c|}{$\mathbf{P b}$} & \multicolumn{2}{|c|}{ Zn } \\
\hline & Total & Dissolved & Total & Dissolved & Total & Dissolved \\
\hline WGC $95 \%$ a & - & 1.3 & - & 4.4 & - & 15 \\
\hline WGC $90 \%$ a & - & 3.0 & - & 6.6 & - & 23 \\
\hline Auckland b & $0.6-17$ & $0.25-6.4$ & $0.7-4.6$ & $0.03-0.7$ & $2.3-180$ & $0.3-120$ \\
\hline Wellington ${ }^{c}$ & $1.1-64.5$ & $0.8-9.3$ & $0.4-168$ & $<0.1-0.8$ & $3-1170$ & $2-135$ \\
\hline
\end{tabular}

Very few studies have evaluated the impacts of pollution on the NZ environment. Fukunaga (2010) found an adverse effect of copper and zinc in sediments on infaunal 
abundance and species richness in Auckland (Fukunaga et al. 2010). To my knowledge, no study has investigated the impacts of waterborne pollutants on sensitive organisms in New Zealand.

Rocky reefs are a major component of coastal ecosystems throughout New Zealand. They are highly productive systems supporting a suite of invertebrate species of significance to commercial, recreational, and customary fishing e.g. abalone, urchins and rock lobster (Morrison et al. 2009). However, the impacts of pollutants on rocky reefs have been largely ignored as it is thought that pollutants are rapidly flushed out of the system by wave action. As discussed above, however, pollutants may affect rocky reef populations in the water column via planktonic larval stages.

\subsection{FOCAL SPECIES}

\subsubsection{EVECHINUS CHLOROTICUS (SEA URCHIN)}

Sea urchins are an ideal test species due to their high sensitivity to pollutants, ecological importance and ease of maintenance in the laboratory. As such, they have been widely used in ecotoxicity studies (US EPA 2002a, ASTM 2012). In New Zealand, the endemic sea urchin E. chloroticus is not only important ecologically but also supports an important customary and commercial fishery (Miller \& Abraham 2011). E. chloroticus has a major effect on the community structure of subtidal rocky reef by changing the nature and abundance of macroalgal cover (Andrew 1988). This shift in algal composition/cover has important indirect effects on mollusks and many fish species. However the vulnerability of E. chloroticus to metal pollution has not yet been studied.

E. chloroticus is a shallow subtidal species primarily found on hard substrates and is distributed around New Zealand mainland and Snares and Chatham Islands (Dix 1969, 1970a). The spawning season occurs between October to April with variation between populations (Dix 1970b, Lamare et al. 2002). E. chloroticus is a broadcast spawner with indirect development and planktotrophic larvae. Embryos hatch within two days post-fertilisation and pelagic larval development is highly variable 
depending on environmental conditions such as temperature, occurring in 17 to 30 days in the laboratory and upwards of $6-8$ weeks in the field (Dix 1969, Lamare \& Barker 1999). The larval development is typical for a sea urchin species (Dix 1969, Strathmann 1987). The first hatching stage is the gastrula, followed by the feeding pluteus stage (Figure 1.1). At the 8-armed stage, a juvenile rudiment develops within larvae (Dix 1970b, Lamare \& Barker 2001). The rudiment grows into a juvenile urchin and the larval body is gradually resorbed. Eventually, metamorphosis occurs and the larval body is completely shed. The mouth of young juveniles opens after approximately 8 days post-settlement and feeding can begin. E. chloroticus reaches sexual maturity at around 4 years of age (Dix 1970b).

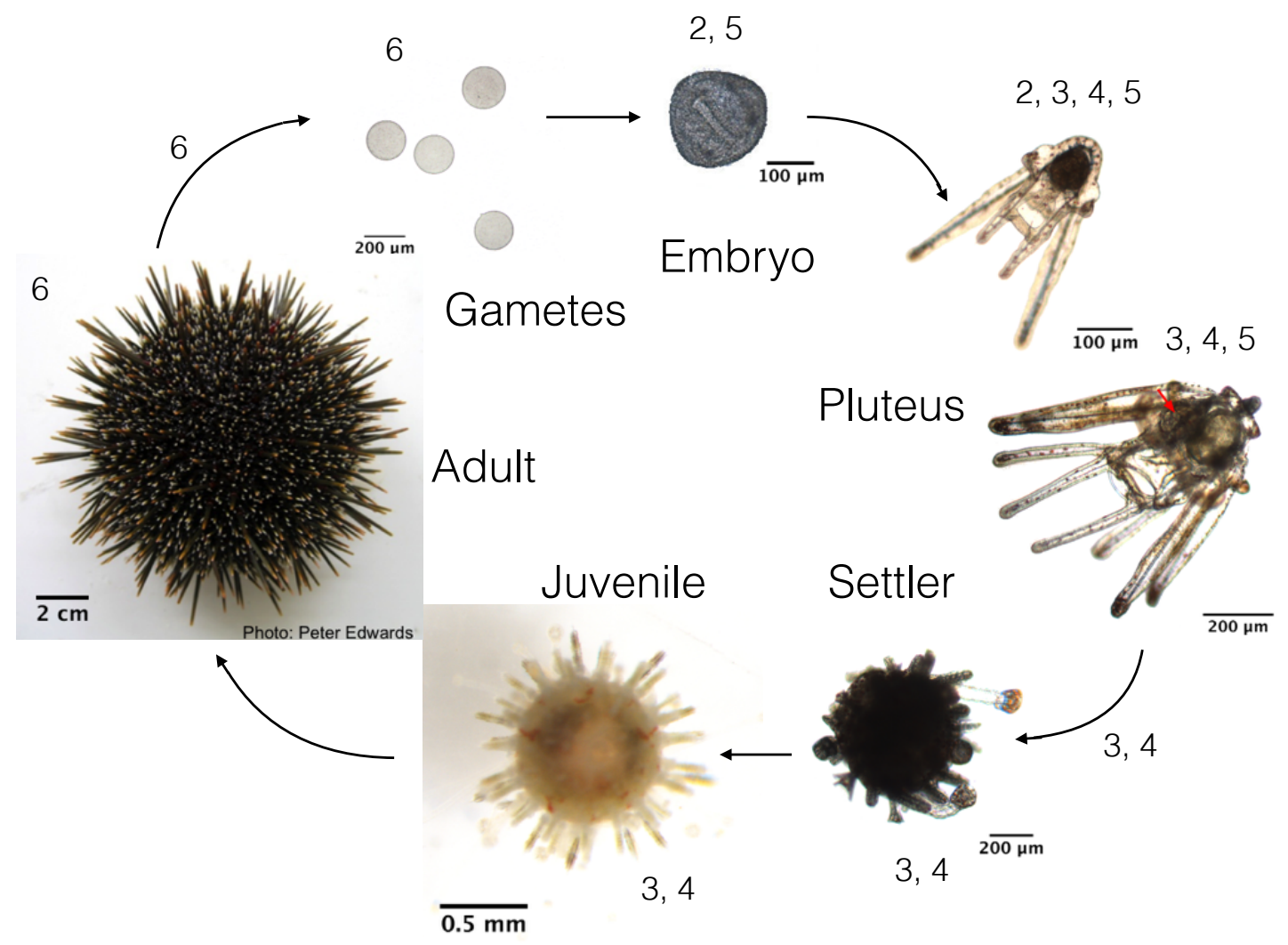

Figure 1.1: Evechinus chloroticus life cycle. The numbers next to the life stages show the chapter in which the corresponding life stage was used. The numbers on arrows represent chapters in which the carry-over effects between the two linked life stages were investigated. The red arrow on the fully developed pluteus larvae shows the juvenile rudiment. 


\subsubsection{HALIOTIS IRIS (ABALONE)}

For comparison, because the response to pollutants is highly species specific and very little data on metal tolerance is available for New Zealand species (ANZECC 2000), another species was used in toxicity assays in Chapter 2. The abalone Haliotis iris is an important fishery species in New Zealand and has also high cultural and ecological importance (Naylor et al. 2006, Morrison et al. 2009). H. iris has a shorter larval development than E. chloroticus (Moss \& Tong 1992, Tong et al. 1992). Larvae hatch as trochophores 1 day after fertilisation, reach the veliger stage in 2 to 3 days postfertilisation and settle approximately 9 days post-fertilisation depending mainly on the seawater temperature. Only the embryo/early veliger life stages (i.e. the first 3 days of development) were used in this research.

\subsection{THESIS RESEARCH}

\subsubsection{AIMS}

The effects of metals were investigated for E. chloroticus across multiple life stages using laboratory experiments with realistic exposure scenarios. A special emphasis was given to early life stages and carry-over and/or latent effects across the larval and juvenile development (Figure 1.1). In addition, the effect of multiple pollutants, multiple stressors (metal and salinity) and trophic interactions were evaluated.

\subsubsection{THESIS STRUCTURE}

In Chapter 2, standard short-term bioassays (72 h) were performed on the embryo/early larval stages of E. chloroticus and also the endemic abalone Haliotis iris, for comparison. These assays evaluated the toxicity of three major pollutants (copper, lead and zinc) alone and in combination, on these species. This provided a first measure of metal toxicity on theses species.

In Chapter 3, the latent effects of copper across two life stages in E. chloroticus larval and juvenile, were investigated using realistic scenarios of low copper 
concentration and short pulses of exposure. Organisms were followed for six weeks post-settlement. Stage-dependent toxicity was evaluated by exposing larvae either early (4 - $6 \mathrm{~d}$ post-fertilisation) or late $(11-13 \mathrm{~d}$ post-fertilisation) during development, and as young juveniles $(25-27 \mathrm{~d}$ post-settlement). I then tested resistance of the surviving juveniles to a further exposure to the same stressor.

In Chapter 4, I investigated separate and combined impact of dietary and waterborne copper by exposing E. chloroticus larvae to dissolved copper and to algal food (Dunaliella terticola) cultured in environmentally relevant copper concentrations. Direct effect on larvae as well as carry-over and latent effects on juveniles five weeks post-settlement were evaluated. I also compared the effect of pulse (four days) versus chronic exposure both for the dietary and waterborne route.

In Chapter 5, the toxicity of copper was evaluated in both normal and low salinity seawater, as metal discharge in coastal water is generally associated with freshwater (e.g. storm water or river plumes). Here I used embryos and larvae of E. chloroticus to characterise the effect of low salinity on copper toxicity with variable timing of exposure. In embryo/early pluteus assays, embryos were exposed for $72 \mathrm{~h}$ shortly after fertilisation. In larval assays, larvae were either exposed chronically to treatments or in a single pulse to better mimic realistic field conditions.

In Chapter 6, I evaluate whether acute exposure to high copper concentration lead to an increase in copper burden in gonads within a short time frame (two weeks) and I examined the fertilisation success of exposed animal. Gametes were also subjected to direct exposure to moderately elevated level of copper during fertilisation to investigate parental effect on gametes tolerance to copper. Finally I compared copper burden in gonads between natural populations and animals exposed in the laboratory to evaluate whether populations from a moderately polluted urban site might be at risk of reproductive impairment.

In addition, the prevalence of local metal contamination was measured in coastal water near four rivers or streams in the Wellington region. These field measurements 
provided the basis for the metals concentrations used in Chapters 3,4 and 5 (Appendix A). 



\section{CHAPTER 2}

\section{Acute toxicity of copper, lead, zinc and their mixtures on Evechinus chloroticus and Haliotis iris larvae}

\section{ABSTRACT}

Short-term bioassays on marine invertebrate early life stages are a widely used method to evaluate toxicity of a single compound or mixed compounds. This study provides the first evaluation of toxicity of three major pollutants (copper, lead and zinc) on Evechinus chloroticus and Haliotis iris; two large benthic invertebrates species endemic to New Zealand. Larval development assays were conducted for $72 \mathrm{~h}$ with individual metals and their binary mixtures. All three metals significantly affected larval development of both species. Median effective concentrations (EC50) based on nominal concentrations were $5.4 \mu \mathrm{g} / \mathrm{L} \mathrm{Cu}, 52.2 \mu \mathrm{g} / \mathrm{L} \mathrm{Pb}, 27.7 \mu \mathrm{g} / \mathrm{L} \mathrm{Zn}$ for $E$. chloroticus and $3.4 \mu \mathrm{g} / \mathrm{L} \mathrm{Cu}, 775 \mu \mathrm{g} / \mathrm{L} \mathrm{Pb}, 13.1 \mu \mathrm{g} / \mathrm{L} \mathrm{Zn}$ for H. iris. 'No observable effect concentrations' (NOEC) based on larval size were lower than those based on larval development for lead but not for copper and zinc in E. chloroticus. None of the metals tested affected $H$. iris larval size. Effects of metal mixtures were analysed using a toxic unit (TU) method. $\mathrm{Cu}+\mathrm{Zn}$ had an antagonistic effect on E. chloroticus development. All other pairs were found to have a slightly less-than-additive or strictly additive effect. None of the interactions were strong, with sums of TU ranging from 1.00 to 1.85 . Both species were extremely sensitive to copper and zinc with EC50 values near or above current NZ water quality criteria (WQC) and highlight the 
importance of obtaining toxicity data for species of special importance instead of relying exclusively on indicator species or international studies.

\subsection{INTRODUCTION}

For many aquatic species, early life stages are the most vulnerable to environmental stressors, and therefore embryos and larvae are commonly used to determine the sensitivity of organisms to pollutants (Kobayashi 1980, Anderson et al. 1994, Fitzpatrick et al. 2008). Despite being short term (hours to days), these tests are presumed to be ecologically relevant because sublethal impacts on these critical life stages can persist after exposure, causing mortality or imparing reproduction later in life (Conroy et al. 1996, Raimondo \& McKenney 2005, Tellis et al. 2014).

Decades of toxicity studies have revealed that sensitivity to particular pollutants is strongly species-specific (US EPA 2007, Grosell et al. 2007). Toxicity values can span several orders of magnitude and vary with the life stage tested, size of organisms and physiology, with closely related species tending to have a similar response (Grosell et al. 2007). Therefore a toxicity threshold found for a test species cannot necessarily be applied to other, especially phylogenetically distant, species. Given this restriction, acceptable pollutant levels for water bodies as determined by environmental agencies are usually defined by compiling results from a wide range of local organisms (ANZECC 2000, US EPA 2014).

More recently, it has become evident that the presence of more than one pollutant often produces a different outcome than each does separately (King et al. 2006, Mann et al. 2009, Manzo et al. 2010, Xu et al. 2011). Effects are complex and variable, even for the same metal pair on different organisms (Norwood et al. 2003), and as a result methods have been developed to analyse toxicant interaction (reviewed in Norwood et al. 2003 and Newman 2012). Concentration addition (CA) methods assume that each component of the mixture acts in a similar way and can be substituted for another component at the appropriate dilution, with no change to the observed toxic 
effect. These methods are effective at predicting mixture toxicity of similarly acting toxicants (Faust 2001).

Environmental regulation bodies emphasise the need to acquire data on local species to define locally acceptable pollution levels (ANZECC 2000, US EPA 2007). This is especially important for geographically isolated areas where many species are endemic or have isolated populations that might have evolved a different response to pollutants. In New Zealand, the regulations concerning the acceptable levels of pollutants and sediment on coastal organisms is based on the Australian and New Zealand Environment and Conservation Council (ANZECC) water quality criteria (WQC) (ANZECC 2000). Theses criteria have been developed mainly using data from Australian species, as few studies on local NZ species are available. However, given NZ geographic isolation and high endemism rate, it is especially important to verify whether the WQC are appropriate for local species.

Sea urchins, echinoderms in the Class Echinoidea, are commonly used in ecotoxicity assays around the world due to the ease of handling and spawning in the laboratory, and their high sensitivity to pollutants, which makes them good indicator species (US EPA 2002a, ASTM 2012). Pluteus (the urchin larval type) formation has been shown to be more sensitive than fertilisation or gastrula development in many species, thus the early pluteus stage is a common endpoint in toxicity assays (Kobayashi 1980, King \& Riddle 2001). Abalone, molluscs in the Class Gastropoda, are less extensively studied but have been shown to be extremely sensitive to pollutants and environmental stressors in general during the larval stage (Hunt \& Anderson 1989, Conroy et al. 1996). Declines in abalone populations have been linked to urban and industrial discharges in North America and Australia (Martin et al. 1977, Anderson et al. 1990, Bielmyer et al. 2005, Gorski \& Nugegoda 2006). Importantly, urchins and abalone are common and ecologically important members of subtidal reef communities that are likely to be impacted by coastal runoff (Andrew 1988, Morrison et al. 2009).

This study investigated the toxicity of three major pollutants, copper, lead, zinc and a combination of these, on Haliotis iris (abalone) and Evechinus chloroticus (sea 
urchin), two endemic species of high ecological, cultural and commercial importance (MacDiarmid 2007, Morrison et al. 2009). Responses of H. iris and E. chloroticus to pollutants have never been investigated. Both species are endemic but also distantly related to other abalone and sea urchin species (Degnan et al. 2006, Gillard et al. 2014). Therefore their sensitivity to pollutants may be different from their Australian counterparts and they might not be protected by the current WQC.

Copper, lead and zinc are major pollutants in many industrial countries and are considered as priority pollutants by environmental authorities due to their high toxicity to aquatic life (ANZECC 2000, US EPA 2014). A study on complex urban effluents identified copper, lead and zinc as being responsible for most of the toxicity observed (McCready et al. 2006). In New Zealand, these three metals are commonly found in concentrations exceeding WQC in urban effluents (Milne \& Watts 2008, Neale 2009), but very few studies have investigated their effects on local coastal organisms (Fukunaga et al. 2010, 2011). An adverse effect of copper and zinc on soft sediment infaunal species has been shown (Fukunaga et al. 2010, 2011) but no study has investigated the effect of metals on hard substrate macro-invertebrates.

Despite a lack of understanding of metal physiology on marine invertebrates, copper lead and zinc all appear to act in a similar way in marine organisms (Section 1.3) especially in their disruption of ion transport and calcium absorption, supporting the use of CA models to predict how they will act in combination. In this study, copper, lead and zinc binary mixtures were evaluated using a commonly used CA model: the Toxic Unit method first described by Sprague (1970). The effect of metal mixtures is not well studied but appears to be highly variable depending on the metal pairs and test organisms. In a review of more than 60 studies on aquatic organisms, more than half of the studies reported a less-than-additive effect of metal mixtures while the other half reported a more-than-additive effect (Norwood 2003). Few studies have addressed metal mixtures on larval development of sea urchins (but see Fernández \& Beiras 2001, Phillips et al. 2003, Kobayashi \& Okamura 2005, Xu et al. 2011) and to the best of my knowledge none on abalone. Furthermore, ANZECC have established a criterion based on the CA approach to predict whether a simple metal mixture $(<6$ toxicants) exceeds WQC: 


$$
T T M=\sum\left(\frac{C_{i}}{W Q C_{i}}\right)
$$

where TTM is the predicted total toxicity of the mixture, $\mathrm{C}_{\mathrm{i}}$ is the concentration of the compound and $\mathrm{WQC}_{\mathrm{i}}$ is the guideline for that compound. The mixture is considered as exceeding the WQC if TTM is greater than 1 (ANZECC 2000). This criterion assumes simple additivity of the toxic effect of the mixture and does not account for potential synergism.

The aims of this study were to provide 1) a first measure of metal toxicity in two important coastal NZ species, 2) a comparison of metal toxicity with the current WQC to assess its validity using local species, and 3) an evaluation of toxicity behaviour (e.g. synergistic, antagonistic) in simple metal mixtures. These aims were addressed with standard biotoxicity assays on H. iris and E. chloroticus embryo and larval stages.

\subsection{METHODS}

\subsubsection{BROODSTOCK AND SPAWNING}

\subsubsection{Sea urchin}

Adult E. chloroticus (8 - $20 \mathrm{~cm}$ test diameter) were collected from Kau Bay in October 2011 and October 2013. A total of 25 adults were kept at Victoria University Coastal Ecology Laboratory (VUCEL) in a $200 \mathrm{~L}$ tank with flow-through raw seawater. VUCEL's seawater is pumped $\sim 5 \mathrm{~m}$ from shore in the Taputeranga Marine Reserve. Raw seawater receives no treatment while filtered seawater (FSW) is prefiltered $(15 \mu \mathrm{m})$ and then filtered through a $0.2 \mu \mathrm{m}$ paper cartridge. Adults were fed twice a week with native kelp (Macrocystis pyrifera) or commercial feed (ABMAX, E.N. Hutchinson Ltd Auckland NZ). Single metal tests were run in February 2012 and January 2014; combined metal tests were done in January 2012. For each spawning, 3-4 males and females were haphazardly selected. Spawning was induced by injecting $3 \mathrm{ml}$ of $0.5 \mathrm{M}$ potassium chloride into the abdominal cavity through the perioral membrane (ASTM 2012). Eggs were collected by inverting females over a 
beaker of FSW, and sperm were collected 'dry' and placed on ice until fertilisation. After spawning, the eggs were filtered through a $125 \mu \mathrm{m}$ sieve and placed in fresh FSW. Gametes of each spawning adult were pooled in approximately similar quantity to produce a composite sperm and egg stock. Fertilisation occurred less than $1 \mathrm{~h}$ after spawning in the presence of a high concentration of sperm (estimated sperm concentration $10^{6}-10^{8}$ cells $/ \mathrm{ml}$ ). Eggs were left in contact with sperm for $15 \mathrm{~min}$ and rinsed thoroughly to avoid polyspermy.

\subsubsection{Abalone}

Due to difficulties in spawning wild $H$. iris, I used cultured animals kept at the National Institute for Water and Atmospheric research (NIWA) aquaculture facilities in Wellington. All individuals had been in culture for more than two years and were kept in flow-through tanks with a system of tipping buckets to recreate wave motion and sufficient oxygenation. They were fed a blend of commercial feed (ABMAX, E.N. Hutchinson Ltd Auckland NZ) and locally abundant brown seaweed including Macrocystis pyrifera, Lessonia variegata and Durvillaea antartica. Single metal runs were conducted in June and November 2012; metal mixture experiments were conducted in November 2012 only. For each spawning, 16 mature females and 12 mature males were selected from a pool of more than 50 individuals. Maturity was determined by the size of the gonad. Spawning was induced at NIWA's facilities following the protocol by Tong et al. (1992). Males and females were placed in separate $8 \mathrm{~L}$ buckets, with two animals per bucket. Spawning was induced by the addition of hydrogen peroxide and sodium hydroxide to the seawater. After spawning, all eggs were pooled in a single bucket, poured through a $400 \mu \mathrm{m}$ sieve, collected in an $80 \mu \mathrm{m}$ sieve and rinsed thoroughly in FSW for $15 \mathrm{~min}$. Sperm were then added to the eggs and the mixture was constantly stirred. After $15 \mathrm{~min}$, the eggs were rinsed to wash off excess sperm and avoid polyspermy and deterioration of the egg membrane. Fertilised eggs were then transferred to a clean $5 \mathrm{~L}$ glass bottle maintained at room temperature $\left(13-14^{\circ} \mathrm{C}\right)$ in ambient light during transportation $(30 \mathrm{~min})$ and brought back to VUCEL where the larval assays were conducted. 


\subsubsection{LARVAL ASSAYS}

H. iris and E. chloroticus larvae were raised for $72 \mathrm{~h}$ in $300 \mathrm{ml} \mathrm{FSW}$ in glass jars placed in a flowing seawater bath to maintain a near constant temperature. Water temperature was $16^{\circ} \mathrm{C} \pm 1$ in all E. chloroticus assays and $14^{\circ} \mathrm{C} \pm 1$ in all $H$. iris assays. Embryos were placed in culture jars before $1^{\text {st }}$ cell division, no more than $1 \mathrm{~h}$ after fertilisation. Embryo density was 30/ml for E. chloroticus (ASTM 2012) and 1/ml for H. iris (Anderson et al. 1994), and was confirmed to be suitable for these species in previous pilot experiments. All glassware was washed with hot water, soaked in $10 \%$ hydrochloric acid for a minimum of $4 \mathrm{~h}$, rinsed and soaked in distilled water for $12 \mathrm{~h}$, and rinsed in FSW before use. Two experiments were conducted: one with single metals $(\mathrm{Cu}, \mathrm{Zn}$ and $\mathrm{Pb})$ and one with combined metals $(\mathrm{Cu}+\mathrm{Zn}, \mathrm{Cu}+\mathrm{Pn}$ and $\mathrm{Zn}+$ $\mathrm{Pb}$ ). The single metal experiment had two runs for both species and the combined metal experiment a single run. Metal concentrations are shown in Table 2.1. They were based on a range-finding pilot trial, and the current experiments were designed to have one concentration producing no toxic effect, one producing close to $100 \%$ abnormal larvae, and two concentrations producing intermediate effects as required for accurate estimation of EC50s (US EPA 2002a). The concentration range was adjusted between the two runs of single metal tests on $H$. iris to add more intermediate effects and reduce EC50s confidence intervals. Each metal level and control had three replicates, plus an additional replicate jar in control conditions (FSW) and one in the highest metal level for each metal, in which to monitor $\mathrm{pH}$ and temperature. 
Table 2.1: Nominal metal concentrations ( $\mu \mathrm{g} / \mathrm{L})$ used in assays: (a) E. chloroticus all tests, (b) H. iris single metal test run 1, (c) H. iris single metal test run 2 and combined metal test (b).

\begin{tabular}{llllll}
\hline Species & Metal & Level 1 & Level 2 & Level 3 & Level 4 \\
\hline \multirow{2}{*}{$\begin{array}{l}\text { (a) } \text { chloroticus } \\
\text { Copper }\end{array}$} & 1 & 5 & 10 & 20 \\
& Lead & 10 & 20 & 50 & 100 \\
& Zinc & 5 & 10 & 20 & 40 \\
H. iris & Copper & 1 & 4 & 16 & 32 \\
(b) & Lead & 400 & 800 & 1600 & 3200 \\
& Zinc & 8 & 16 & 32 & 64 \\
\hline $\begin{array}{l}\text { H. } \text { iris } \\
\text { (c) }\end{array}$ & Copper & 1 & 2 & 4 & 8 \\
& Lead & 400 & 600 & 800 & 1600 \\
\hline
\end{tabular}

Metal stock solutions were made from reagent grade metal salts, namely copper sulphate $\left(\mathrm{CuSO}_{4} .5 \mathrm{H}_{2} \mathrm{O}\right)$, zinc sulphate $\left(\mathrm{ZnSO}_{4} .7 \mathrm{H}_{2} \mathrm{O}\right)$ and lead nitrate $\left(\mathrm{Pb}\left(\mathrm{NO}_{3}\right)_{2}\right)$ mixed with deionised water (ASTM 2012). Stock solutions were analysed by Environmental Laboratory Services, Lower Hutt and were always within 96\% recovery for copper, $105 \%$ for lead and $110 \%$ for zinc. Therefore, all concentrations reported in this study are nominal concentrations.

\subsubsection{END POINT}

After 72 h, E. chloroticus larvae had reached the pluteus stage while H. iris larvae had reached the veliger stage. Larvae in all jars, except the temperature and $\mathrm{pH}$ control jars, were collected and preserved in $40 \%$ ethanol. Larvae were then checked for developmental abnormalities or delayed development and measured within two weeks.

Larvae were placed on a microscope slide with a raised cover slip. The first 100 larvae encountered were rated into seven and eight developmental categories, respectively (Table 2.2 and Table 2.3). The first ten normal larvae encountered were measured using an ocular micrometer (body length, BL, and postoral arm length, PO, for E. chloroticus, Table 2.2; shell length for H. iris, Table 2.3). In one E. chloroticus assay, larval size was determined by taking a photo of each larva using a different microscope than in the previous assays, and measuring BL and PO using the image 
software Image J. In order to remove any bias due to the difference in methodology, only the $\mathrm{PO} / \mathrm{BL}$ ratio was used in subsequent analyses. 
Table 2.2: Developmental categories of Evechinus chloroticus larvae after $72 \mathrm{~h}$. Categories in bold are considered as normal, while other categories are considered as severely delayed or abnormal. BL: total body length, PO: postoral arms, AL: anterolateral arms.

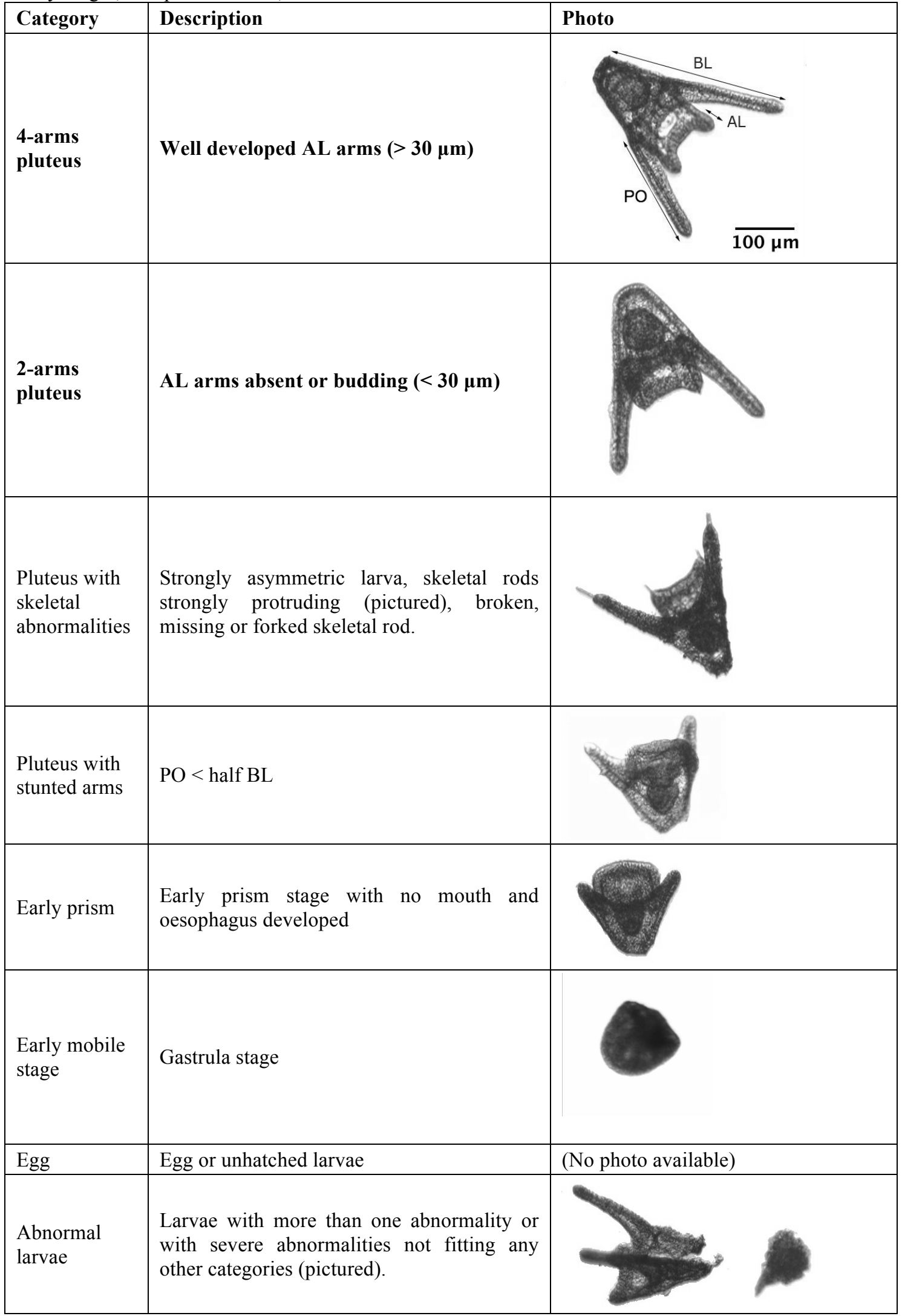


Table 2.3: Developmental categories of Haliotis iris larvae after $72 \mathrm{~h}$. Categories in bold are considered as normal, while other categories are considered as severely delayed or abnormal. SL: shell length.

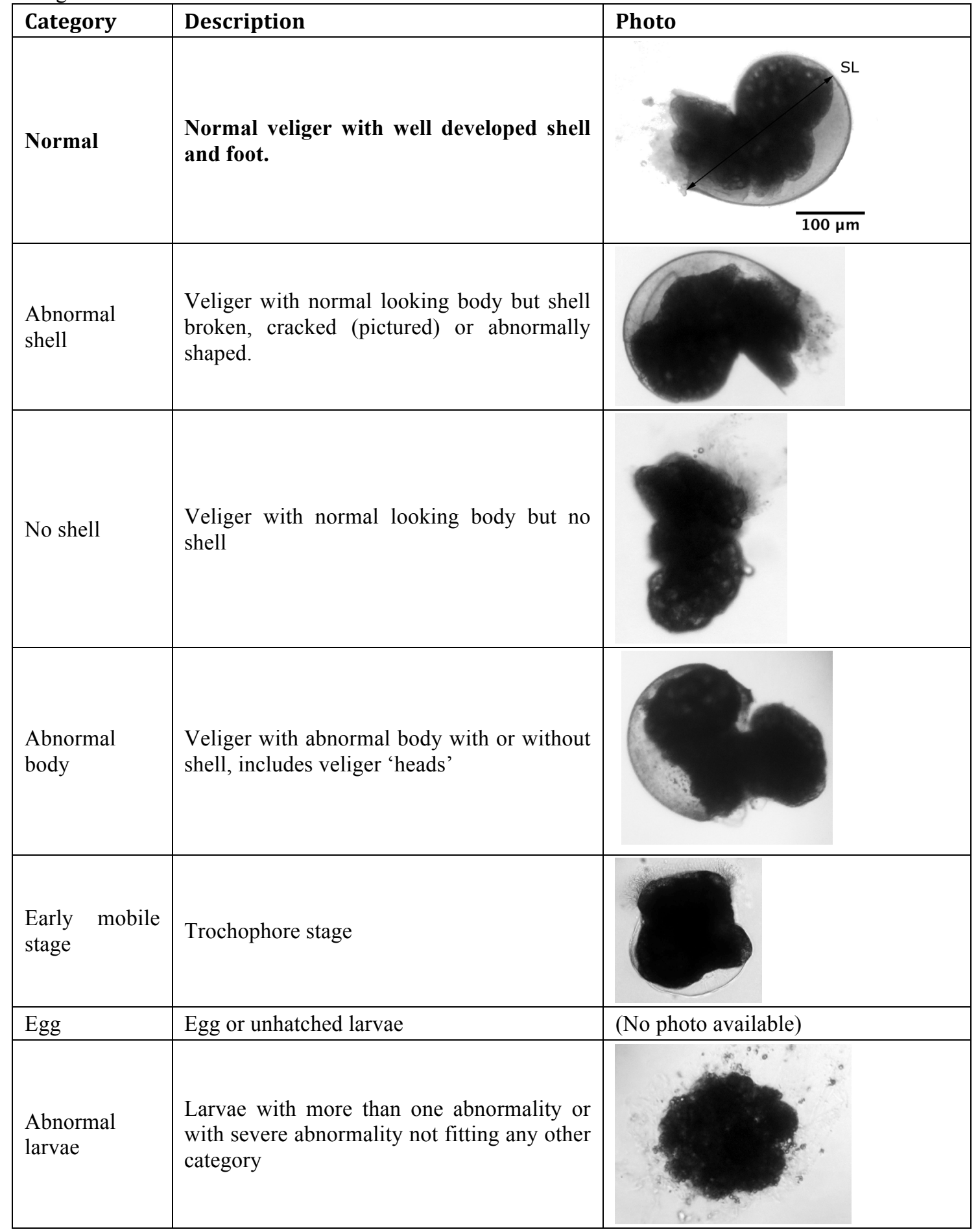




\subsubsection{STATISTICS}

\subsubsection{Single metals}

All data analyses were based on U.S. EPA methods (US EPA 2002a). Data from the separate runs for single metal assays were pooled. All abnormal categories were pooled to determine toxic effect. Both point estimation techniques and hypothesis testing were used.

For point estimation techniques, a probit regression in SPSS (v.22) was used to estimate EC50s (median effective concentration), EC10s (effective concentration affecting more than $10 \%$ of the population) and their respective $95 \%$ confidence intervals. These probit regressions were also used to estimate the proportion of abnormal larvae at metal concentrations of special interest, such as WQC level.

Hypothesis testing, where each metal concentration was compared to the control, was performed in $\mathrm{R}$ version 3.1, package multcomp (Hothorn et al. 2008). NOEC (No Observable Effect Concentration) and LOEC (Lowest Observable Effect Concentration) on the proportion of normal development data (arcsine transformed) and size data (PO/BL ratio or shell length) were determined using one-way ANOVA followed by Dunnett's pairwise comparison when sample sizes were equal (all $E$. chloroticus experiments and H. iris combined metal experiment) or Games-Howell pairwise comparison for unequal sample size ( $H$. iris single metal experiment). Jars with less than 5 normal larvae measured were removed from the size analyses. Minimum significant differences (MSD) were calculated following U.S. EPA (2002) methods and expressed as the percentage of the controls mean to give a measure of Dunnett's test sensitivity.

\subsubsection{Metal mixtures}

Metal interactions were evaluated using the Toxic Unit approach described in Sprague (1970). Each compound is given a Toxic Unit (TU) determined from its concentration in the mixture and its toxic effect as a single toxicant. The chosen toxic effect was EC50 based on a probit regression as described for single metals. 
The sum of TUs was calculated using the following equation:

$$
\Sigma T U_{i}=\sum_{i=1}^{n} \frac{c_{i}}{T E_{i}}
$$

Where $n$ is the number of components in the mixture, $c_{i}$ is the individual concentration of the $i^{\text {th }}$ substance in the mixture at toxic effect level, and $T E_{i}$ is the individual toxic effect of the $i^{\text {th }}$ substance.

A mixture was classified as strictly additive if the sum of TUs $=1$, and less-thanadditive and more-than additive, respectively, if the sum of TUs $>1$ and $<1$ (Norwood 2003, Faust 2001). It is worth noting that terminology in the literature varies between authors. A synergetic effect is used to describe more-than-additive mixtures while 'less-than-additive' is often termed an antagonistic effect. However, the term 'antagonistic' suggests that a mixture is less toxic than any of its components taken individually. For instance a mixture can be as toxic as its most toxic component with no added effect of other chemicals, in which case it will be less-than-additive but the term antagonistic would be misleading (Newman 2012, Norwood 2003). In this study, 'less-than-additive' was used if the sum of TUs $>1$ but $\mathrm{TE}_{\text {mix }}<\mathrm{TE}_{\mathrm{i}}$, while 'antagonistic' was used if the sum of TUs $>1$ and $\mathrm{TE}_{\mathrm{mix}}>\mathrm{TE}_{\mathrm{i}}$ (i.e. the mixture was less toxic than the most toxic metal individually). To give a measure of experimental variation, a range for the sum of TUs was determined using both extreme values of the EC50s 95\% confidence interval, obtained from probit regression as described above.

\subsection{RESULTS}

In all tests, the proportion of normal larvae in controls for E. chloroticus and H. iris was a minimum of $92 \%$ and $80 \%$ respectively, which is deemed acceptable by the U.S. EPA method (US EPA 2002a). Salinity was 34 ppt and pH was $7.99 \pm 0.2$ in all tests, with no differences between treatments and controls. 


\subsubsection{SINGLE METALS}

\subsubsection{Sea urchin}

All of the metals tested significantly affected E. chloroticus larval development with the proportion of normal larvae decreasing with increasing doses (One-way ANOVA; $\left.\mathrm{Cu}: \mathrm{F}_{(4,25)}=159, \mathrm{p}<0.001, \mathrm{~Pb}: \mathrm{F}_{(4,24)}=63.4, \mathrm{p}<0.001, \mathrm{Zn}: \mathrm{F}_{(4,23)}=61.5, \mathrm{p}<0.001\right)$. The resulting $72 \mathrm{~h}-\mathrm{EC} 50 \mathrm{~s}$ were $5.4 \mu \mathrm{g} / \mathrm{L} \mathrm{Cu}, 52.2 \mu \mathrm{g} / \mathrm{L} \mathrm{Pb}$ and $27.7 \mu \mathrm{g} / \mathrm{L} \mathrm{Zn} \mathrm{(Figure}$ 2.1). There was a significant disruption of pluteus development (LOEC) at concentrations from $5 \mu \mathrm{g} / \mathrm{L} \mathrm{Cu}, 100 \mu \mathrm{g} / \mathrm{L} \mathrm{Pb}$ and $30 \mu \mathrm{g} / \mathrm{L} \mathrm{Zn}$ (Dunnett's comparisons; $\mathrm{Cu}: \mathrm{t}=-15.22, \mathrm{p}<0.001, \mathrm{~Pb}: \mathrm{t}=-13.30, \mathrm{p}<0.001, \mathrm{Zn}: \mathrm{t}=-3.80, \mathrm{p}=0.003)$. Corresponding NOEC were $1 \mu \mathrm{g} / \mathrm{L} \mathrm{Cu}, 50 \mu \mathrm{g} / \mathrm{L} \mathrm{Pb}$ and $10 \mu \mathrm{g} / \mathrm{L} \mathrm{Zn}$. Dunnett's comparisons could detect a significant difference in normal development (MSD) of more than $3.9 \%(\mathrm{Cu})$ and $5.2 \%(\mathrm{~Pb}$ and $\mathrm{Zn})$ of the control means. Point estimates (EC10) were 2 to 5 times more sensitive than hypothesis testing (LOEC), with concentrations of $2.1 \mu \mathrm{g} / \mathrm{L} \mathrm{Cu}, 19.1 \mu \mathrm{g} / \mathrm{L} \mathrm{Pb}$ and $9.7 \mu \mathrm{g} / \mathrm{L} \mathrm{Zn}$ or greater resulting in more than $10 \%$ abnormal development (Table 2.4). Metal effects were severe, with very little normal development (<10\%) at $10 \mu \mathrm{g} / \mathrm{L} \mathrm{Cu}(9.3 \%), 100 \mu \mathrm{g} / \mathrm{L} \mathrm{Pb}(3.8 \%)$ and $60 \mu \mathrm{g} / \mathrm{L} \mathrm{Zn} \mathrm{(1.8 \% )} \mathrm{or} \mathrm{greater} \mathrm{(Figure} \mathrm{2.1).}$ 


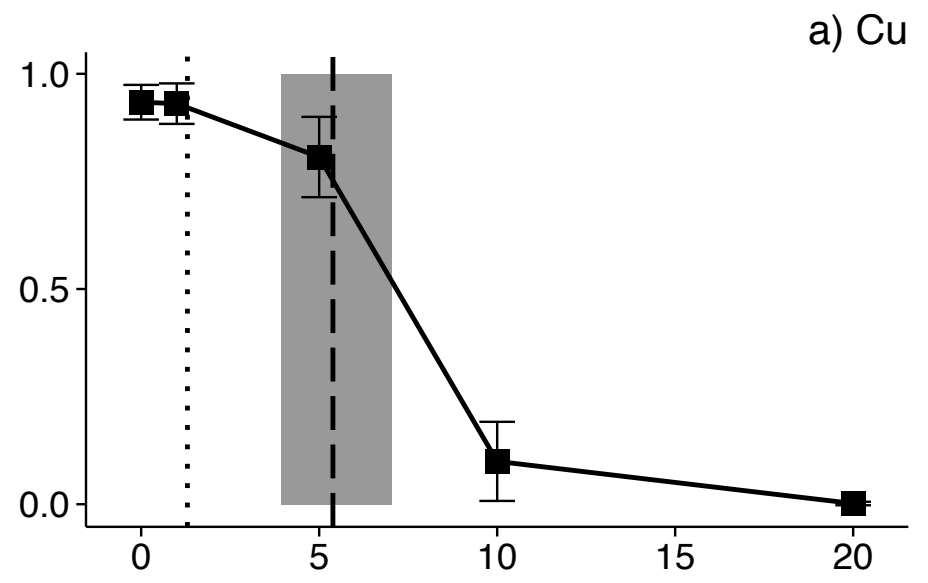

Figure 2.1: Proportion of normal larvae of the sea urchin Evechinus chloroticus after a $72 \mathrm{~h}$ exposure to increasing levels of (a) copper, (b) lead and (c) zinc. Error bars represent the standard deviation $(\mathrm{N}=3)$. Dashed lines represent the median effective concentration (EC50, probit regression analysis). Shaded grey areas represent the EC50s $\quad 95 \%$ confidence interval. Dotted lines

b) $\mathrm{Pb}$ represent current $\mathrm{NZ}$ water

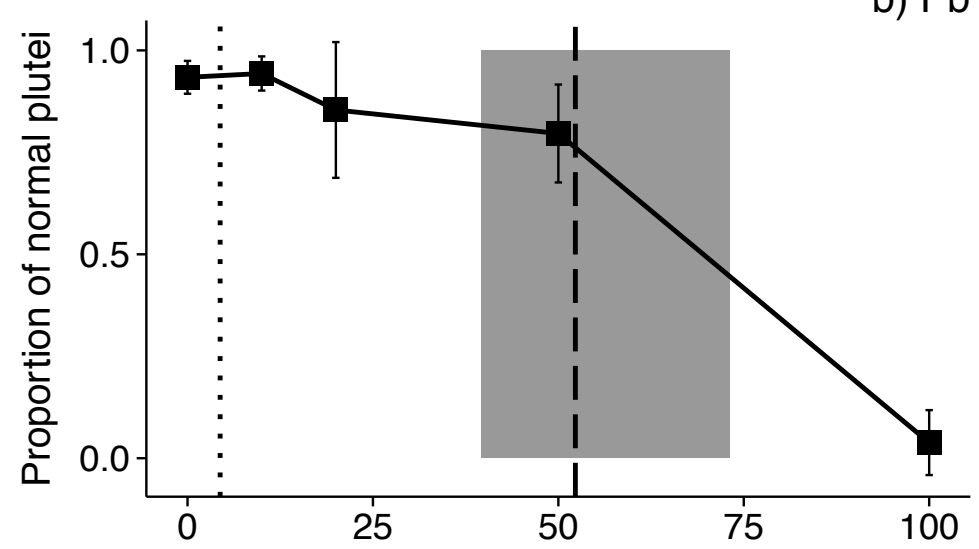
quality trigger values for $95 \%$ species protection (ANZECC 2000).

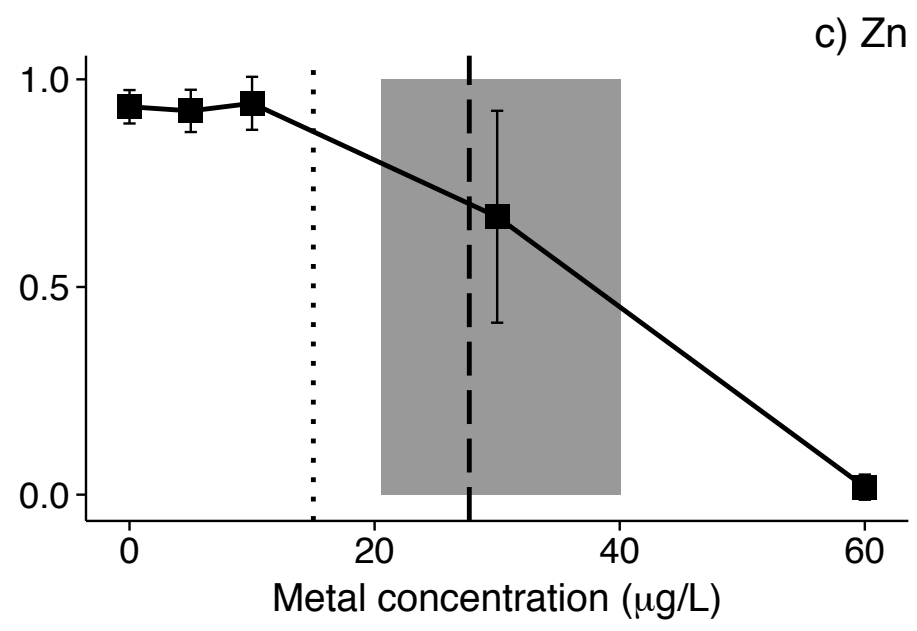


EC50s were well above WQC for all three metals, while EC10s were below WQC for zinc, near WQC for copper and well above WQC for lead. Based on the probit regression, metal concentrations at WQC levels induced a low frequency of abnormal larvae for copper and lead $(<3 \%)$, and a moderate frequency for zinc $(25 \%$, Table 2.4).

Table 2.4: Summary of $10 \%$ effective concentration (EC10) and median effective concentration (EC50) values $(\mu \mathrm{g} / \mathrm{L})$ with $95 \%$ confidence intervals $(95 \% \mathrm{CI})$, and toxicity at water quality criteria (WQC) for 95\% species protection levels (ANZECC 2000) derived from probit regression for each heavy metal tested in a $72 \mathrm{~h}$ bioassay on Evechinus chloroticus and Haliotis iris larvae.

\begin{tabular}{llllll}
\hline Species & Metal & EC10 (95\% CI) & EC50 (95\% CI) & $\begin{array}{l}\text { Toxicity } \\
\text { at WQC level } \\
\text { (\%abnormal } \\
\text { larvae })\end{array}$ & WQC \\
\hline $\begin{array}{l}\text { E. chloro- } \\
\text { ticus }\end{array}$ & Copper & $2.1(1.0-3.0)$ & $5.4(3.9-7.0)$ & 3 & 1.3 \\
& Lead & $19.1(10.3-26.7)$ & $52.2(39.6-73.0)$ & $<1$ & 4.4 \\
& Zinc & $9.7(5.4-13.7)$ & $27.7(20.5-40.1)$ & 25 & 15 \\
\hline \multirow{2}{*}{ H. iris } & Copper & $0.7(0.03-1.5)$ & $3.4(1.7-9.0)$ & 20 & 1.3 \\
& Lead & $417(292-510)$ & $775(658-934)$ & $<1$ & 4.4 \\
& Zinc & $3.3(0.3-6.0)$ & $13.1(7.9-25.0)$ & 55 & 15 \\
\hline
\end{tabular}

All three metals significantly affected pluteus size (PO/BL ratio; one-way ANOVA, $\left.\mathrm{Cu}: \mathrm{F}_{(2,15)}=6.01, \mathrm{p}=0.012, \mathrm{~Pb}: \mathrm{F}_{(3,19)}=4.19, \mathrm{p}=0.02, \mathrm{Zn:} \mathrm{F}_{(3,19)}=4.70, \mathrm{p}=0.013\right)$. However, LOEC and NOEC could not be calculated for zinc, as none of the treatments were significantly different from the control (Dunnett's comparison, $\mathrm{t}=$ $2.20, \mathrm{p}=0.10)$, despite being within detectable range (MSD $=1.5 \%$ of control mean). LOECs for copper and lead were $5 \mu \mathrm{g} / \mathrm{L} \mathrm{Cu}$ and $50 \mu \mathrm{g} / \mathrm{L} \mathrm{Pb}$ (Dunnett's comparison; $\mathrm{Cu}: \mathrm{t}=-2.62, \mathrm{p}=0.035, \mathrm{~Pb}: \mathrm{t}=-2.99, \mathrm{p}=0.02$; Figure 2.2) with a MSD of 1.2 and $1.3 \%$ of the control mean, respectively. Corresponding NOECs were lower for lead $(20 \mu \mathrm{g} / \mathrm{L})$ than NOEC based on normal development $(50 \mu \mathrm{g} / \mathrm{L})$, but identical for copper $(1 \mu \mathrm{g} / \mathrm{L})$. Overall, copper and lead induced a slightly shorter PO arm relative to the total body length, but the effect was small. E. chloroticus larvae exposed to 5 $\mu \mathrm{g} / \mathrm{L} \mathrm{Cu}$ had only a marginally lower PO/BL ratio than did the control larvae (mean $\mathrm{PO} / \mathrm{BL}$ ratio \pm standard deviation: $0.57 \pm 0.015$ vs. $0.60 \pm 0.017$ in controls). A very similar effect was observed in plutei exposed to $50 \mu \mathrm{g} / \mathrm{L} \mathrm{Pb}(\mathrm{PO} / \mathrm{BL}$ ratio: $0.57 \pm$ 0.018 vs. $0.60 \pm 0.017$ in controls). 


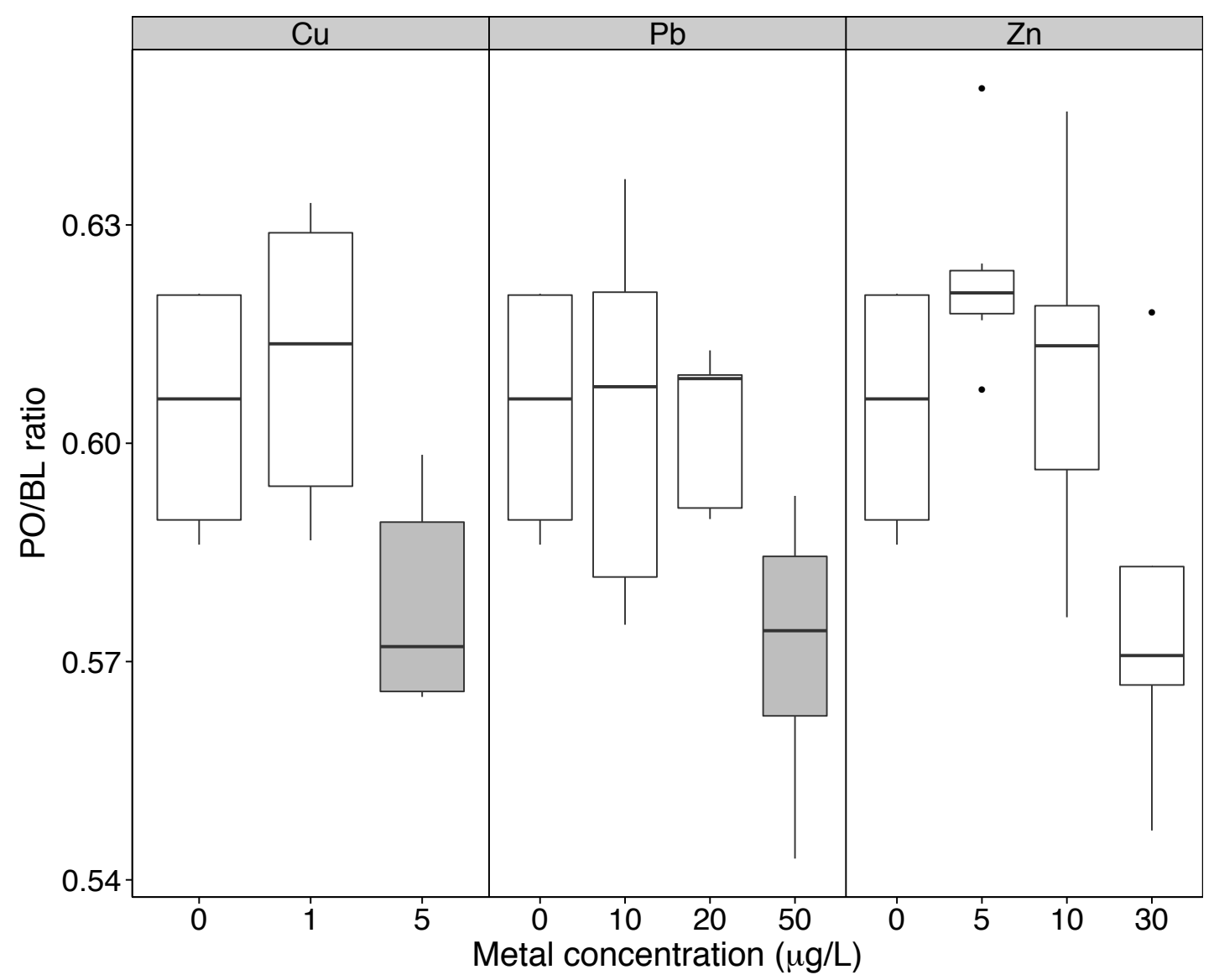

Figure 2.2: Postoral arm / total body length ratio (PO/BL) of Evechinus chloroticus larvae after $72 \mathrm{~h}$ exposure to increasing levels of copper $(\mathrm{Cu})$, lead $(\mathrm{Pb})$, and zinc $(\mathrm{Zn})$. Grey shading represents treatment significantly different from control (Dunnett's pairwise comparison, $\mathrm{p}<0.05$ ).

Abnormal development categories were widely variable within treatments. Nonetheless, a trend of increasing severity of abnormality with increasing metal concentration was observable (Figure 2.3). Observations with a total of less than ten abnormal individuals were removed from the dataset. The dominant abnormal category at a low concentration of copper was minor arm abnormality (skeletal), with stunted E. chloroticus becoming progressively dominant at intermediate concentrations, and the majority of larvae arrested in the gastrula stage at the highest concentration. A similar pattern was visible for zinc, but starting at intermediate-high concentrations with an increased frequency of stunted larvae, and a majority of severely abnormal larvae at the highest concentration. For lead, skeletal abnormalities were dominant at low and intermediate concentrations, with stunted arms and arrested development at the prism stage being the main abnormalities visible at the highest 
concentration. Furthermore, all three metals appeared to delay development of normal larvae, with the proportion of 4-armed pluteus amongst normal larvae decreasing with metal concentration.

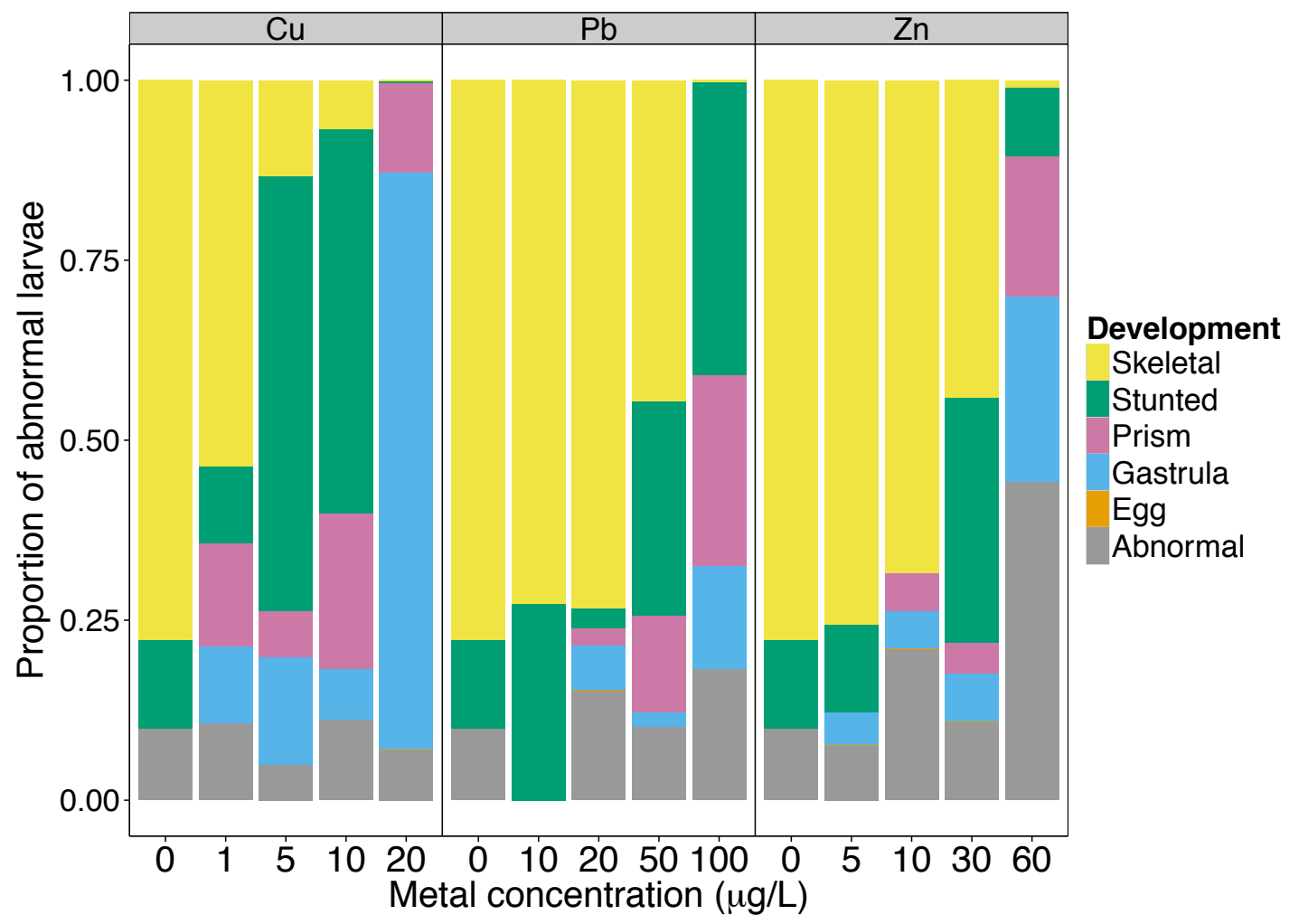

Figure 2.3: Relative frequency of each abnormal development categories in single metal assays on Evechinus chloroticus after $72 \mathrm{~h}$ exposure to increasing levels of copper $(\mathrm{Cu})$, lead $(\mathrm{Pb})$ and zinc $(\mathrm{Zn})$.

\subsubsection{Abalone}

All three metals significantly affected $H$. iris larval development (One-way ANOVA; $\mathrm{Cu}: \mathrm{F}_{(5,22)}=7.13, \mathrm{p}<0.001, \mathrm{~Pb}: \mathrm{F}_{(5,26)}=24.1, \mathrm{p}<0.001, \mathrm{Zn}: \mathrm{F}_{(6,25)}=11.5, \mathrm{p}<$ 0.001). The resulting EC50s were $3.4 \mu \mathrm{g} / \mathrm{L} \mathrm{Cu}, 775 \mu \mathrm{g} / \mathrm{L} \mathrm{Pb}$ and $13.1 \mu \mathrm{g} / \mathrm{L} \mathrm{Zn}$ (Figure 2.4). A significant decrease in the proportion of normal veliger (LOEC) occurred from $8 \mu \mathrm{g} / \mathrm{L} \mathrm{Cu}, 1600 \mu \mathrm{g} / \mathrm{L} \mathrm{Pb}$ and $24 \mu \mathrm{g} / \mathrm{L} \mathrm{Zn}$ (Games-Howell's comparison; $\mathrm{Cu}: \mathrm{t}=15.9, \mathrm{p}=0.002, \mathrm{~Pb}: \mathrm{t}=16.5, \mathrm{p}<0.001, \mathrm{Zn}: \mathrm{t}=11.9, \mathrm{p}=0.011$ ). Corresponding NOECs were $4 \mu \mathrm{g} / \mathrm{L} \mathrm{Cu}, 800 \mu \mathrm{g} / \mathrm{L} \mathrm{Pb}$ and $16 \mu \mathrm{g} / \mathrm{L} \mathrm{Zn}$. No MSD could be calculated with Games-Howell's tests due to unequal sample sizes. However, hypothesis testing on this dataset had a poor detection power due to unequal sample size and large variability within treatments. For instance, at NOEC level for lead, an 
average of only $36 \%$ ( $\pm 31 \%$ standard deviation) of veligers were normal compared to $80 \%( \pm 6 \%)$ in controls.
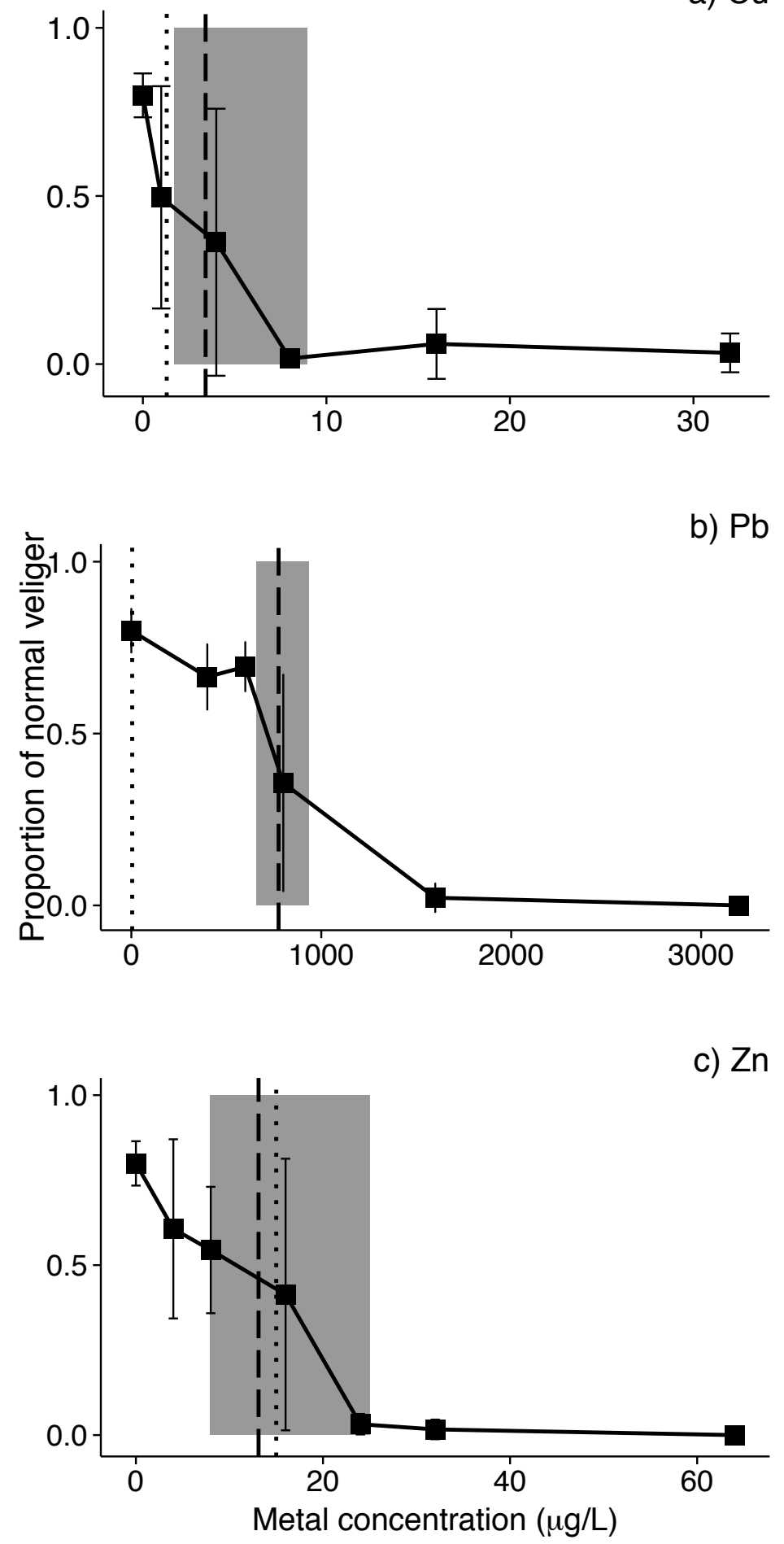

Figure 2.4: Proportion of normal larvae of the abalone Haliotis iris after a $72 \mathrm{~h}$ exposure to increasing levels of (a) copper, (b) lead and (c) zinc. Error bars represent the standard deviation $(\mathrm{N}=3)$. Dashed lines represent the median effective concentration (EC50, probit regression analysis). Shaded grey areas represent the EC50s $95 \%$ confidence interval. Dotted lines represent current NZ water quality trigger values for $95 \%$ species protection (ANZECC 2000). 
Point estimates (EC10s) were 4 to 11 times more sensitive than hypothesis testing (LOEC), with concentrations of $0.7 \mu \mathrm{g} / \mathrm{L} \mathrm{Cu}, 417 \mu \mathrm{g} / \mathrm{L} \mathrm{Pb}$ and $3.3 \mu \mathrm{g} / \mathrm{L} \mathrm{Zn}$ or greater resulting in more than $10 \%$ abnormal development (Table 2.4). Very low rates of normal development were observed at $8 \mu \mathrm{g} / \mathrm{L} \mathrm{Cu}(1.6 \%$ normal veliger $), 1600 \mu \mathrm{g} / \mathrm{L}$ $\mathrm{Pb}(3.8 \%)$ and $24 \mu \mathrm{g} / \mathrm{L} \mathrm{Zn} \mathrm{(3.2 \% )} \mathrm{or} \mathrm{greater} \mathrm{(Figure} 2.4)$.

H. iris appeared to be more sensitive than E. chloroticus to copper and zinc, with an EC50 that was 1.6 and 2.1 times lower respectively, but more tolerant to lead with an EC50 that was more than 3 times higher. EC50s were below WQC for zinc, with an estimate of $55 \%$ abnormal larvae at this level, close to WQC for copper with $20 \%$ abnormal larvae, and well above for lead with less than $1 \%$ abnormal larvae (Table 2.4).

Shell length of normal veligers was not influenced by any of the three metals tested (One-way ANOVA; $\mathrm{Cu}: \mathrm{F}_{(3,12)}=1.7, \mathrm{p}=0.22, \mathrm{~Pb}: \mathrm{F}_{(3,15)}=1.7, \mathrm{p}=0.21, \mathrm{Zn}: \mathrm{F}_{(3,14)}=$ $1.1, \mathrm{p}=0.38 ;$ Figure 2.5). 


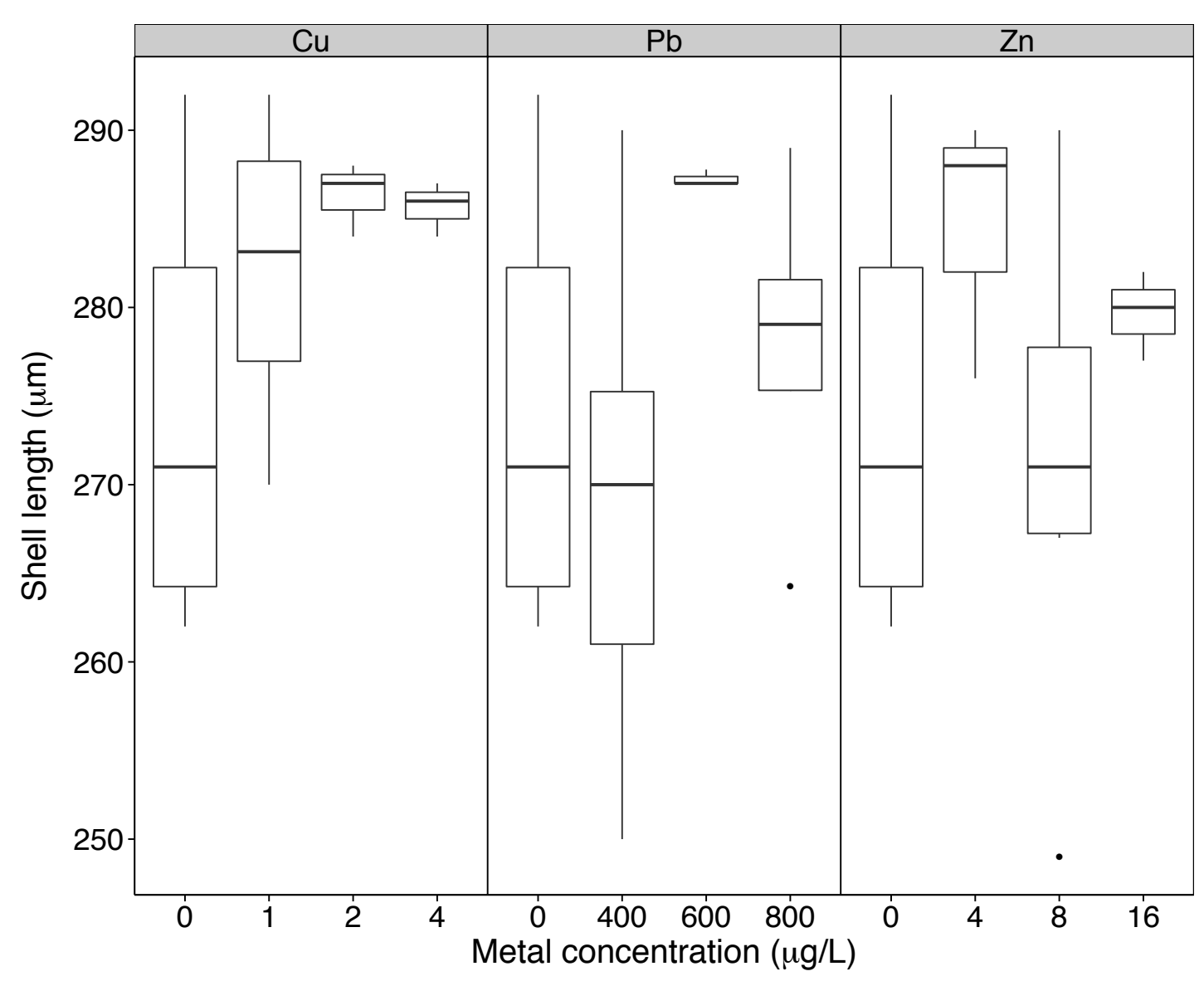

Figure 2.5: Shell length $(\mu \mathrm{m})$ of Haliotis iris larvae after $72 \mathrm{~h}$ exposure to increasing levels of copper $(\mathrm{Cu})$, lead $(\mathrm{Pb})$ and zinc $(\mathrm{Zn})$. Grey shading represents treatment significantly different from control (Dunnett's pairwise comparison, $\mathrm{p}<0.05$ ).

Abnormality categories varied greatly within treatment but general patterns and trends could be observed. The most common developmental abnormalities at low concentrations were those relating to the shell, such as a flattened or cracked shell, but these were not concentration dependent and occurred in equally high proportions in controls. In copper and zinc, a general trend of increasing frequency of undeveloped eggs and severely abnormal veligers at intermediate and high concentrations was visible. No trend was apparent with lead (Figure 2.6). 


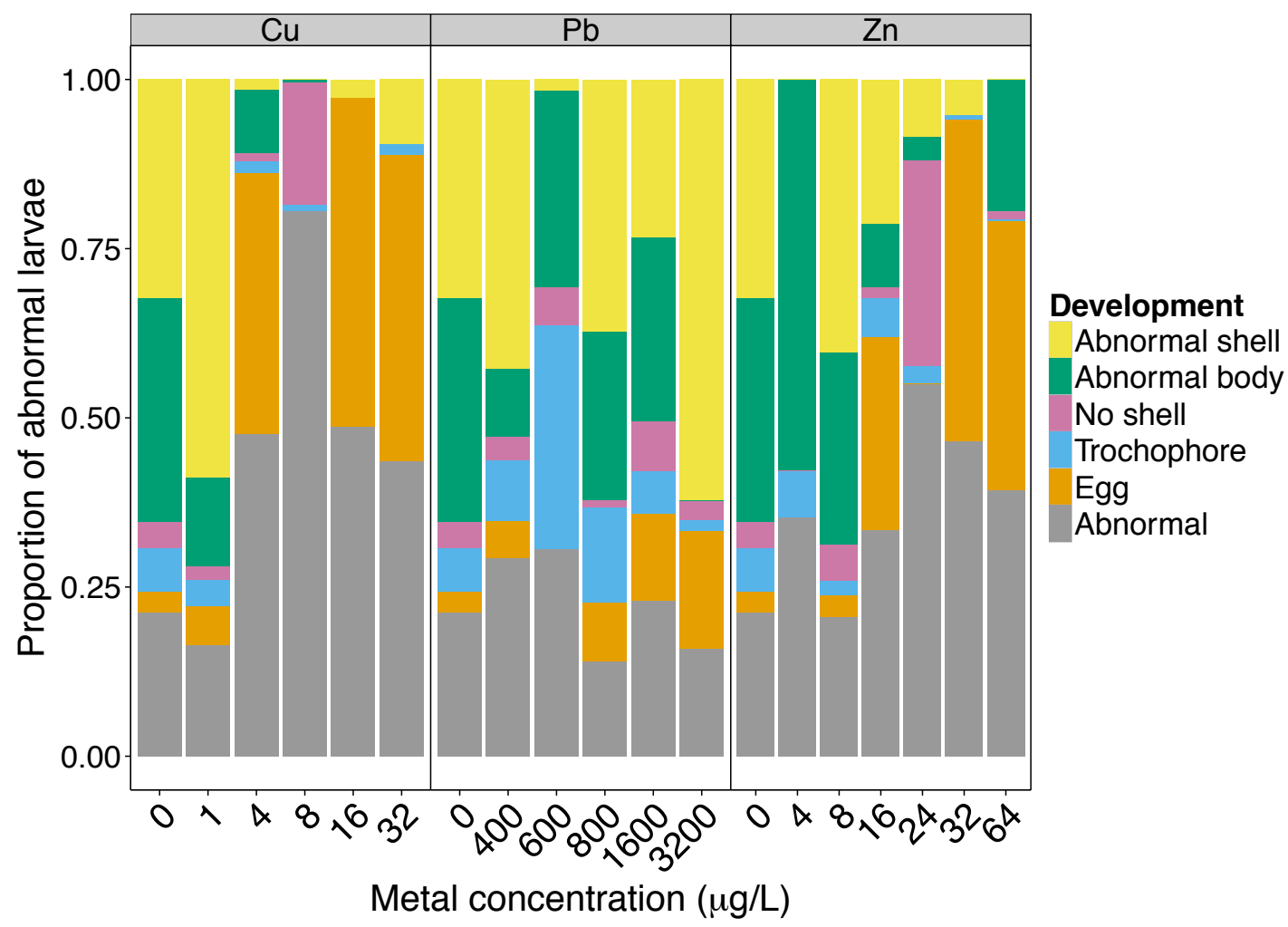

Figure 2.6: Relative frequency of each abnormal development categories in single metal assays on Haliotis iris after $72 \mathrm{~h}$ exposure to increasing levels of copper $(\mathrm{Cu})$, lead $(\mathrm{Pb})$ and zinc $(\mathrm{Zn})$.

\subsubsection{METAL MIXTURES}

Normal development rates in mixture controls were $92 \pm 4 \%$ for E. chloroticus and $89 \pm 3 \%$ for $H$. iris. Sum of TUs with their range for each metal combination are shown in Table 2.5. For E. chloroticus, all three mixtures produced different interactions. $\mathrm{Cu}+\mathrm{Zn}$ had the strongest interaction with a sum of TUs of 1.85 (range 1.7 - 1.99). These two metals were antagonists and produced a higher EC50 in combination $(6.9 \mu \mathrm{g} / \mathrm{L} \mathrm{Cu}, 95 \% \mathrm{CI}: 3.8-4.5 \mu \mathrm{g} / \mathrm{L})$ than when the most toxic metal (i.e. copper) was present singly $(5.4 \mu \mathrm{g} / \mathrm{L} \mathrm{Cu}, 95 \% \mathrm{CI}: 3.9-7.0 \mu \mathrm{g} / \mathrm{L}) . \mathrm{Cu}+\mathrm{Pb}$ had a less-than-additive effect and $\mathrm{Zn}+\mathrm{Pb}$ mixtures were strictly additive. For H. iris, all three mixtures produced a less-than-additive effect, with a sum of TUs ranging from $1.44(1.37-1.5)$ to $1.64(1.56-1.71)$. None of these interactions were very strong and the EC50s of the mixtures were always similar to the EC50 of the most toxic metal of the pair $(<30 \%$ of difference). 
Table 2.5: Toxic effect of metals in mixture based on Toxic Units (TUs). EC $50_{\text {mix }}$ is the value (72 hEC50) for the mixture; EC50 is the value for individual metals. Sum of TUs is determined from each metal concentration in the mixture and its toxic effect as a single toxicant. Sum of TUs range is based on EC50s $95 \%$ confidence intervals.

\begin{tabular}{|c|c|c|c|c|c|c|}
\hline Species & Pair & Metal & EC50 $_{\text {mix }}$ & $\mathrm{EC50}_{\mathrm{i}}$ & $\begin{array}{l}\text { Sum of TUs } \\
\text { (range) }\end{array}$ & Interaction \\
\hline \multirow{6}{*}{$\begin{array}{l}\text { E. } \\
\text { chloroticus }\end{array}$} & \multirow[t]{2}{*}{$\mathrm{Cu}+\mathrm{Pb}$} & $\mathrm{Cu}$ & 4.16 & 5.39 & 1.21 & \multirow[t]{2}{*}{$\begin{array}{l}\text { less-than- } \\
\text { additive }\end{array}$} \\
\hline & & $\mathrm{Pb}$ & 22.60 & 52.20 & $(1.11-1.30)$ & \\
\hline & \multirow[t]{2}{*}{$\mathrm{Cu}+\mathrm{Zn}$} & $\mathrm{Cu}$ & 6.95 & 5.39 & 1.85 & \multirow[t]{2}{*}{ antagonistic } \\
\hline & & $\mathrm{Zn}$ & 15.48 & 27.73 & $(1.70-1.99)$ & \\
\hline & \multirow[t]{2}{*}{$\mathrm{Zn}+\mathrm{Pb}$} & $\mathrm{Zn}$ & 12.79 & 27.73 & 1.00 & \multirow[t]{2}{*}{$\begin{array}{l}\text { strictly } \\
\text { additive }\end{array}$} \\
\hline & & $\mathrm{Pb}$ & 28.20 & 52.20 & $(0.94-1.06)$ & \\
\hline \multirow{6}{*}{ H. iris } & \multirow[t]{2}{*}{$\mathrm{Cu}+\mathrm{Pb}$} & $\mathrm{Cu}$ & 2.49 & 3.42 & 1.57 & \multirow[t]{2}{*}{$\begin{array}{l}\text { less-than- } \\
\text { additive }\end{array}$} \\
\hline & & $\mathrm{Pb}$ & 653 & 775 & $(1.52-1.63)$ & \\
\hline & \multirow[t]{2}{*}{$\mathrm{Cu}+\mathrm{Zn}$} & $\mathrm{Cu}$ & 2.40 & 3.42 & 1.44 & \multirow[t]{2}{*}{$\begin{array}{l}\text { less-than- } \\
\text { additive }\end{array}$} \\
\hline & & Zn & 9.60 & 13.11 & $(1.37-1.5)$ & \\
\hline & \multirow[t]{2}{*}{$\mathrm{Zn}+\mathrm{Pb}$} & $\mathrm{Zn}$ & 10.09 & 13.11 & 1.64 & \multirow[t]{2}{*}{$\begin{array}{l}\text { less-than- } \\
\text { additive }\end{array}$} \\
\hline & & $\mathrm{Pb}$ & 671 & 775 & $(1.56-1.71)$ & \\
\hline
\end{tabular}

\subsection{DISCUSSION}

The results of this study provide the first examination of copper, lead and zinc toxicity on E. chloroticus and H. iris larvae. All developmental anomalies recorded were severe and likely to result in larval death before settlement, for example the absence of shell in H. iris. In the case of delayed or arrested development, development might resume when larvae return to uncontaminated water. A recent study showed that sea urchin larvae (Strongylocentrotus nudus from Korea) displaying arrested development after exposure to triclosan could recover only if exposure was for less than $30 \mathrm{~h}$ (Hwang et al. 2014). Further, prolonging time in the plankton due to increased development time can have a range of adverse effects, such as increased predation risk, dispersal away from suitable habitat, and lower settlement success and juvenile growth rate, especially for non-feeding larvae such as $H$. iris that are dependent on maternal reserves (Pechenik 1999). Therefore, although toxic effects observed are sublethal in the sense that they are categorized as developmental abnormalities, they are likely to result in mortality, in many cases quite rapidly. 
Both point estimation (probit-derived) and hypothesis testing (pairwise comparison) toxicity values were given in this study. Hypothesis testing was reported as NOEC and LOEC values are often used in defining WQC. However, discussion will focus on EC50s and EC10s, as probit-derived values are considered more robust because they are more representative of the whole dataset and more sensitive than pairwise comparison (Moore \& Caux 1997). This is especially the case when intermediate proportions have a high variance, as observed in the present study with $H$. iris. EC10 may be considered as being equivalent to LOEC but without the shortcoming of being directly affected by concentrations chosen in tests, which is arbitrary.

\subsubsection{COMPARISON WITH CURRENT WATER QUALITY CRITERIA}

The $72 \mathrm{~h}$-EC50s showed a decreasing order of toxicity for each metal as follows for both species: $\mathrm{Cu}>\mathrm{Zn}>\mathrm{Pb}$. H. iris and E. chloroticus appeared to be highly sensitive to copper with EC50s being near, but above, WQC. Cu EC10 for H. iris was below WQC, suggesting that $H$. iris larvae could be notably affected if such a concentration ever occurs frequently in coastal waters ( $20 \%$ abnormal larvae at WQC level). This is of concern as, in New Zealand, copper has been found to be above WQC in urban effluents (Milne \& Watts 2008, Neale 2009), marinas (Gadd \& Cameron 2012) and, to a lesser extent, coastal water near agricultural effluent (Appendix A). While zinc was less toxic than copper, WQC are higher for this metal and concentrations at this level are likely to severely affect $H$. iris (55\% abnormal larvae at WQC level) and moderately affect E. chloroticus (25\% abnormal larvae at WQC level). The EC50 value for $H$. iris was lower than WQC, indicating a potential failure of WQC to protect this species in NZ. Lead was not a concern for either species, with both EC50s and EC10s well above WQC.

\subsubsection{COMPARISON WITH RELATED SPECIES}

Metal toxicity for E. chloroticus were toward the low end of the range of toxicities reported for sea urchin embryos for all 3 metals. Toxicity range is $1.4-100 \mu \mathrm{g} / \mathrm{L}$ for copper, $34->2000 \mu \mathrm{g} / \mathrm{L}$ for lead and 7.2 - $327 \mu \mathrm{g} / \mathrm{L}$ for zinc (Table 2.6). E. chloroticus is the only species of its genus and belongs to the Echinometridae family with Australian species of the genus Heliocidaris thought to be its closest related 
species based on morphological evidence (McRae 1959). However, a recent study showed E. chloroticus as being phylogenetically distinct from other members of its family (Gillard et al. 2014). Toxicity values reported for Heliocidaris were very similar to the present study and mostly toward the low end of the toxicity range although the different toxicity endpoints (EC50, NOEC, LOEC) make direct comparison between studies difficult.

Table 2.6: Comparative metal toxicity for the early life stages (embryo/larval) of sea urchin species. Present study is shaded in grey. Other members of Evechinus chloroticus family (Echinometridae) are highlighted in bold.

\begin{tabular}{|c|c|c|c|c|c|}
\hline Metal & Species & $\begin{array}{l}\text { Test } \\
\text { endpoint }\end{array}$ & $\begin{array}{l}\text { Test } \\
\text { duration }\end{array}$ & $\begin{array}{l}\text { Toxicity } \\
(\mu \mathrm{g} / \mathrm{L})\end{array}$ & Reference \\
\hline \multirow{28}{*}{ Copper } & Sterechinus neumayeri & EC50 & $20 \mathrm{~d}$ & 1.4 & (King \& Riddle 2001) \\
\hline & Evechinus chloroticus & EC10 & $72 \mathrm{~h}$ & 2.1 & present study \\
\hline & Heliocidaris crassispina & NOEC & $30 \mathrm{~h}$ & 3.8 & (Kobayashi \& Okamura 2005) \\
\hline & Heliocidaris erythrogramma & LOEC & $15 \mathrm{~h}$ & 5 & (Kobayashi 1980) \\
\hline & Evechinus chloroticus & EC50 & $72 \mathrm{~h}$ & 5.4 & present study \\
\hline & Strongylocentrotus purpuratus & EC50 & $48-96 \mathrm{~h}$ & 6.3 & (in King \& Riddle 2001) \\
\hline & Heliocidaris tuberculata & EC50 & $72 \mathrm{~h}$ & 8 & (Doyle et al. 2003) \\
\hline & Heliocidaris tuberculata & EC50 & $96 \mathrm{~h}$ & 9.4 & (in King \& Riddle) \\
\hline & Hemicentrotus pulcherrimus & EC50 & $48 \mathrm{~h}$ & $10-20$ & (in King \& Riddle 2001) \\
\hline & Diadema antillarum & EC50 & $40 \mathrm{~h}$ & 11 & (Bielmyer et al. 2005) \\
\hline & Centrostephanus rodgersii & EC50 & $96 \mathrm{~h}$ & 11.8 & (in King \& Riddle 2001) \\
\hline & Arbacia punctulata & EC50 & $2-4 d$ & 14 & (in King \& Riddle 2001) \\
\hline & Strongylocentrotus purpuratus & EC50 & $96 \mathrm{~h}$ & 15.3 & (Phillips et al. 2003) \\
\hline & Paracentrotus lividus & LOEC & $48 \mathrm{~h}$ & 16 & (Fernández \& Beiras 2001) \\
\hline & Diadema savignyi & EC50 & $48 \mathrm{~h}$ & 19 & (Rosen et al. 2015) \\
\hline & Peronella japonica & LOEC & $24 \mathrm{~h}$ & 20 & (Kobayashi 1980) \\
\hline & Strongylocentrotus droebachiensis & EC50 & $48-96 \mathrm{~h}$ & 21 & (in King \& Riddle 2001) \\
\hline & Echinodermata lucunte & EC50 & $24 \mathrm{~h}$ & 21.9 & (Rumbold \& Snedaker 1997) \\
\hline & Paracentrotus lividus & EC50 & $48 \mathrm{~h}$ & $<32$ & (in King \& Riddle 2001) \\
\hline & Paracentrotus lividus & EC50 & $48 \mathrm{~h}$ & 32.9 & (Lorenzo et al. 2002) \\
\hline & Lytechinus variegatus & EC50 & $24 \mathrm{~h}$ & 33.8 & (Rumbold \& Snedaker 1997) \\
\hline & Diadema setosum & EC50 & $48 \mathrm{~h}$ & 43 & (Ramachandran et al. 1997) \\
\hline & Paracentrotus lividus & EC50 & $48 \mathrm{~h}$ & 46 & (Manzo et al. 2008) \\
\hline & Hemicentrotus puleherrimus & LOEC & $24 \mathrm{~h}$ & 50 & (Kobayashi 1980) \\
\hline & Heliocidaris crassispina & EC50 & $24 \mathrm{~h}$ & $50-100$ & (in King \& Riddle 2001) \\
\hline & Paracentrotus lividus & EC50 & $72 \mathrm{~h}$ & 62 & (Novelli et al. 2003) \\
\hline & Paracentrotus lividus & EC50 & $48 \mathrm{~h}$ & 66.8 & (Fernández \& Beiras 2001) \\
\hline & Paracentrotus lividus & EC50 & $48 \mathrm{~h}$ & 85 & (Manzo 2004) \\
\hline
\end{tabular}

Table 2.6 continued on next page 


\begin{tabular}{|c|c|c|c|c|c|}
\hline Metal & Species & $\begin{array}{l}\text { Test } \\
\text { endpoint }\end{array}$ & $\begin{array}{l}\text { Test } \\
\text { duration }\end{array}$ & $\begin{array}{l}\text { Toxicity } \\
(\mu \mathrm{g} / \mathrm{L})\end{array}$ & Reference \\
\hline \multirow{13}{*}{ Lead } & Evechinus chloroticus & EC10 & $72 \mathrm{~h}$ & 19.1 & present study \\
\hline & Heliocidaris crassispina & NOEC & $30 \mathbf{h}$ & 34 & (Kobayashi \& Okamura 2005) \\
\hline & Heliocidaris tuberculata & EC50 & $72 \mathrm{~h}$ & 47 & (Doyle et al. 2003) \\
\hline & Evechinus chloroticus & EC50 & $72 \mathrm{~h}$ & 52.2 & present study \\
\hline & Paracentrotus lividus & EC50 & $72 \mathrm{~h}$ & 68 & (Novelli et al. 2003) \\
\hline & Strongylocentrotus purpuratus & EC50 & $72 \mathrm{~h}$ & 74 & (Nadella et al. 2013) \\
\hline & Paracentrotus lividus & EC50 & $96 \mathrm{~h}$ & $210-620$ & (in King \& Riddle 2001) \\
\hline & Paracentrotus lividus & LOEC & $48 \mathrm{~h}$ & 250 & (Fernández \& Beiras 2001) \\
\hline & Paracentrotus lividus & EC50 & $48 \mathrm{~h}$ & 509 & (Fernández \& Beiras 2001) \\
\hline & Echinometra mathaei & EC50 & $30 \mathrm{~h}$ & 2179 & (Ghorani et al. 2013) \\
\hline & Strongylocentrotus purpuratus & EC50 & $48-96 \mathrm{~h}$ & $<9700$ & (in King \& Riddle 2001) \\
\hline & Strongylocentrotus droebachiensis & EC50 & $48-96 \mathrm{~h}$ & $<9700$ & (in King \& Riddle 2001) \\
\hline & Arbacia punctulata & EC50 & $2-4 d$ & $<32500$ & (in King \& Riddle 2001) \\
\hline \multirow{21}{*}{ Zinc } & Heliocidaris crassispina & NOEC & $30 \mathrm{~h}$ & 7.2 & (Kobayashi \& Okamura 2005) \\
\hline & Evechinus chloroticus & EC10 & $72 \mathrm{~h}$ & 9.7 & present study \\
\hline & Hemicentrotus pulcherrimus & EC50 & $48 \mathrm{~h}$ & $10-20$ & (in King \& Riddle 2001) \\
\hline & Diadema setosum & EC50 & $48 \mathrm{~h}$ & $10-20$ & (in King \& Riddle 2001) \\
\hline & Arbacia lixula & EC50 & $96 \mathrm{~h}$ & $10-100$ & (in King \& Riddle 2001) \\
\hline & Strongylocentrotus purpuratus & EC50 & $48-96 \mathrm{~h}$ & 23 & (in King \& Riddle 2001) \\
\hline & Strongylocentrotus droebachiensis & EC50 & $48-96 \mathrm{~h}$ & 27 & (in King \& Riddle 2001) \\
\hline & Evechinus chloroticus & EC50 & $72 \mathrm{~h}$ & 27.7 & present study \\
\hline & Paracentrotus lividus & EC50 & $48 \mathrm{~h}$ & $<33$ & (in King \& Riddle 2001) \\
\hline & Paracentrotus lividus & EC50 & $72 \mathrm{~h}$ & 49 & (Novelli et al. 2003) \\
\hline & Peronella japonica & LOEC & $24 \mathrm{~h}$ & 50 & (Kobayashi 1980) \\
\hline & Hemicentrotus puleherrimus & LOEC & $24 \mathrm{~h}$ & 50 & (Kobayashi 1980) \\
\hline & Heliocidaris crassispina & EC50 & $24 \mathrm{~h}$ & $50-100$ & (in King \& Riddle 2001) \\
\hline & Strongylocentrotus purpuratus & EC50 & $96 \mathrm{~h}$ & 96.9 & (Phillips et al. 2003) \\
\hline & Strongylocentrotus purpuratus & EC50 & $96 \mathrm{~h}$ & 97.2 & (Phillips et al. 1998) \\
\hline & Strongylocentrotus purpuratus & EC50 & $72 \mathrm{~h}$ & 151 & (Nadella et al. 2013) \\
\hline & Heliocidaris tuberculata & EC50 & $72 \mathrm{~h}$ & 160 & (Doyle et al. 2003) \\
\hline & Arbacia punctulata & EC50 & $2-4 d$ & 205 & (in King \& Riddle 2001) \\
\hline & Heliocidaris tuberculata & EC50 & $96 \mathrm{~h}$ & 280 & (in King \& Riddle 2001) \\
\hline & Centrostephanus rodgersii & EC50 & $96 \mathrm{~h}$ & 289 & (in King \& Riddle 2001) \\
\hline & Sterechinus neumayeri & EC50 & $20 \mathrm{~d}$ & 327 & (King \& Riddle 2001) \\
\hline
\end{tabular}


Very few studies have reported metal toxicity values for abalone, with only two species from the Southern Hemisphere having been tested (Table 2.7). Toxicity range was $5.6-114 \mu \mathrm{g} / \mathrm{L}$ for copper and $35-102 \mu \mathrm{g} / \mathrm{L}$ for zinc, and only one study reported a toxicity value of $5111 \mu \mathrm{g} / \mathrm{L}$ of lead (Gorski \& Nugegoda 2006). H. iris appears to be considerably more sensitive to metals than are other abalone species, especially for zinc. All abalone species belong to the same genus, however, a phylogeny study showed H. iris as basal to other southern Haliotidae, suggesting that it is not closely related to Southern Hemisphere abalone species except for $\mathrm{New}$ Zealand's H. virginia, for which no toxicity data are available (Degnan et al. 2006). This evolutionary distance could contribute to the difference in metal sensitivity. 
Table 2.7: Comparative metal toxicity for the early life stages (embryo/larval) of abalone and related species. Southern hemispheres abalone species are highlighted in bold and results from the present study are shaded in grey.

\begin{tabular}{|c|c|c|c|c|c|c|}
\hline Metal & Animal & Species & $\begin{array}{l}\text { Toxicity } \\
\text { endpoint }\end{array}$ & $\begin{array}{l}\text { Test } \\
\text { duration }\end{array}$ & $\begin{array}{l}\text { Toxicity } \\
\text { value }(\mu g / L)\end{array}$ & Reference \\
\hline \multirow{9}{*}{ Copper } & Abalone & Haliotis iris & EC10 & $72 \mathrm{~h}$ & 0.7 & present study \\
\hline & Abalone & Haliotis iris & EC50 & $72 \mathrm{~h}$ & 3.4 & present study \\
\hline & Abalone & Haliotis midae & LC50 & $48 \mathrm{~h}$ & 5.6 & (Stofberg et al. 2011) \\
\hline & Oyster & Crassostrea gigas & EC50 & $48 \mathrm{~h}$ & 6.1 & (Chapman 1990) \\
\hline & Abalone & Haliotis rubra & EC50 & $48 \mathrm{~h}$ & 7 & (Gorski \& Nugegoda 2006) \\
\hline & Oyster & Pteria colymbus & EC50 & $24 \mathrm{~h}$ & 7 & (Rumbold \& Snedaker 1997) \\
\hline & Abalone & Haliotis rufescens & EC50 & $48 \mathrm{~h}$ & 9 & (Hunt \& Anderson 1993) \\
\hline & Mollusk & Strombus gigas & EC50 & $24 \mathrm{~h}$ & 21.3 & (Rumbold \& Snedaker 1997) \\
\hline & Abalone & Haliotis rufescens & $\mathrm{LC} 50$ & $48 \mathrm{~h}$ & 114 & (Martin et al. 1977) \\
\hline \multirow{6}{*}{ Lead } & Mussel & Mytilus trossolus & EC50 & $48 \mathrm{~h}$ & 45 & (Nadella et al. 2013) \\
\hline & Mussel & Mytilus galloprovincialis & EC50 & $48 \mathrm{~h}$ & 63 & (Nadella et al. 2013) \\
\hline & Abalone & Haliotis iris & EC10 & $72 \mathrm{~h}$ & 417.3 & present study \\
\hline & Oyster & Crassostrea gigas & EC50 & $48 \mathrm{~h}$ & 680 & (Chapman 1990) \\
\hline & Abalone & Haliotis iris & EC50 & $72 \mathrm{~h}$ & 775.3 & present study \\
\hline & Abalone & Haliotis rubra & EC50 & $48 \mathrm{~h}$ & 5111 & (Gorski \& Nugegoda 2006) \\
\hline \multirow{12}{*}{ Zinc } & Abalone & Haliotis iris & EC10 & $72 \mathrm{~h}$ & 3.3 & present study \\
\hline & Abalone & Haliotis iris & EC50 & $72 \mathrm{~h}$ & 13.1 & present study \\
\hline & Abalone & Haliotis rubra & EC50 & $48 \mathrm{~h}$ & 35 & (Gorski \& Nugegoda 2006) \\
\hline & Abalone & Haliotis rufescens & EC50 & $48 \mathrm{~h}$ & 37 & (Conroy et al. 1996) \\
\hline & Abalone & Haliotis rufescens & EC50 & $48 \mathrm{~h}$ & 68 & (Hunt \& Anderson 1989) \\
\hline & Abalone & Haliotis midae & EC50 & $48 \mathrm{~h}$ & 102.25 & (Stofberg et al. 2011) \\
\hline & Mussel & Mytilus trossolus & EC50 & $48 \mathrm{~h}$ & 135 & (Nadella et al. 2013) \\
\hline & Mussel & Mytilus galloprovincialis & EC50 & $48 \mathrm{~h}$ & 172 & (Nadella et al. 2013) \\
\hline & Mussel & Mytilus edulis & EC50 & $48 \mathrm{~h}$ & 175 & (Martin et al. 1981) \\
\hline & Oyster & Crassostrea gigas & EC50 & $48 \mathrm{~h}$ & 199 & (Martin et al. 1981) \\
\hline & Oyster & Crassostrea gigas & EC50 & $48 \mathrm{~h}$ & 206.5 & (Chapman 1990) \\
\hline & Oyster & Crassostrea virginica & EC50 & $48 \mathrm{~h}$ & 209 & (MacInnes \& Calabrese 1979) \\
\hline
\end{tabular}

Echinoderm embryos are commonly used for toxicity assays because of their extreme sensitivity to pollutants in general, and metals in particular (Kobayashi 1980, Phillips et al. 2003, Bielmyer et al. 2005, Grosell et al. 2007). However, our results show that H. iris is even more sensitive to copper and zinc than is E. chloroticus, and highlights the importance of obtaining metal toxicity data for species of special importance or concern instead of relying exclusively on indicator species.

Many factors affect the toxicity of metal in aquatic organisms in addition to variation between species; for example, exposure time, abiotic factors such as salinity, $\mathrm{pH}$, 
temperature, and organic matter (Eisler 2007, Green et al. 2007, Rozman et al. 2010). Ecotoxicity studies use test duration ranging from $24 \mathrm{~h}$ to several days. This is because assays typically end when test animals reach the pluteus stage for echinoderms (ASTM 2012) or the veliger stage for molluscs (Hunt \& Anderson 1993), and development time is regulated by temperature (Strathmann 1987). Tropical species typically reach these stages after 24 h (Kobayashi 1980, Rumbold \& Snedaker 1997, Bielmyer et al. 2005), warm temperate species in 48 h (Manzo 2004, Gorski \& Nugegoda 2006), and colder temperate species in 72 to $96 \mathrm{~h}$ (King \& Riddle 2001, Phillips et al. 2003). A study even used a 20-day test for an extremely slow developing Antarctic sea urchin (King \& Riddle 2001). Longer assays may allow more time for metal absorption and result in generally lower EC50 values than shorter assays. Indeed, tropical species are often less sensitive than their temperate counterparts (Table 2.6 and Table 2.7); similarly, the only toxicity value reported for an Antarctic sea urchin was the lowest reported so far (King \& Riddle 2001). Therefore, the relatively low toxicity values reported in this study may in part be due to longer test duration because of slower development time than most but not all other species.

\subsubsection{EFFECT OF METALS ON LARVAL DEVELOPMENT}

All three metals adversely affect calcification in addition to various enzymatic processes, as illustrated by the predominance of shell deformity in $H$. iris and abnormal arm development in E. chloroticus. These abnormalities are typical of metal effects on abalone (Conroy et al. 1996, Gorski \& Nugegoda 2006, Stofberg et al. 2011) and sea urchins (Bielmyer et al. 2005, Ghorani et al. 2013). Such abnormal development in the very early stages of larval development is a severe consequence of metal exposure, that usually results in failure to metamorphose and thus is a strong indicator of eventual mortality. A study on abalone showed that abnormal veligers did not recover even when maintained in clean seawater for an extended period following toxicant exposure (Conroy et al. 1996).

Copper and lead induced shorter arms compared to total body length in normal $E$. chloroticus larvae. With lead this effect was visible before developmental 
abnormality. This suggests that pluteus size is a better indicator of lead toxicity than development in E. chloroticus but not in H. iris. Previous studies showed a similar effect of lead on pluteus size from $250 \mu \mathrm{g} / \mathrm{L}$ (Parocentrotus lividus and Echinometra mathaei), although total body length was measured instead of arm/body ratio (Fernández \& Beiras 2001, Ghorani et al. 2013). Lead competes with calcium for absorption in many organisms (Eisler 2007) and has recently been shown to lower whole body calcium accumulation in sea urchin larvae (Tellis et al. 2014). Leadinduced calcium deficiency may impair skeletal rod and thus arm formation in pluteus larvae (Warnau \& Pagano 1994, Ghorani et al. 2013).

The severity of reduced arm or body length is less straightforward than abnormal development. Smaller pluteus larvae might be at greater risk of predation (Morgan 1995, Marshall \& Keough 2008). Furthermore, plutei use their arms to feed and an increase in arm length leads to an increase in feeding rate (Strathmann 1971). Indeed food limitation studies on echinoderms showed that plutei respond to food limitation by elongating their arms to attempt to increase feeding rate (Strathmann et al. 1992, Fenaux et al. 1994, Sewell et al. 2004). Early stunting is therefore likely to have a cascading effect, leading to lower growth rate throughout the larval stage and beyond. Studies on mussels found a cascading effect of low food on larval and juvenile growth, with smaller larvae metamorphosing into slower growing juveniles, thus further increasing the size difference and mortality rate in the juvenile stage (Phillips 2002, 2004).

Metal pollution may impact larvae physiologically in ways that do not result in gross developmental or size abnormalities, which would be unnoticed in this study. More sensitive measurements such as levels of metallothionein proteins have been proposed (Damiens et al. 2006, Geffard et al. 2007). Despite being a sign of metal-induced stress, elevated metallothionein might have no negative impact on short- or long-term growth and survival, and may not necessarily be present as invertebrate physiological responses to metals vary between species (Eisler 2007). Therefore, more research is needed to determine the relevance of such measurements at individual- and population-levels. 


\subsubsection{METAL MIXTURES}

Most metal mixtures tested had a strictly additive or slightly less-than-additive effect, except the pair $\mathrm{Cu}+\mathrm{Zn}$, which had an antagonistic effect on E. chloroticus but not on H. iris. However, none of these interactions were very strong and the EC50s of the mixtures were always similar to the EC50 of the most toxic metal of the pair. CA models suffer from the lack of a standardized way to account for experimental variability and to define a significant difference from 1 (Norwood et al. 2003, Manzo et al. 2010). Hayes' criterion proposes that additive indices differing from 1 by no more than a factor of 2 could not be distinguished from simple additivity (Rozman et al. 2010). In this study, the sum of TUs was always within the range 0.5-2; so all mixtures could be considered as strictly additive.

There is considerable variation in the combined effect of these three metals in the literature depending of the test organisms, method used for data analysis and interpretation. Norwood et al. (2003), in their review of 210 tests from 68 studies, showed that re-analysis with coherent statistical methods still yielded a wide range of interaction effects for the same metal pairs. They identified the wide range of organisms, life stages, metal ratio in the mixtures, and endpoints as likely being responsible for the differences observed.

Few studies have tested the effects of copper, lead and zinc binary mixtures on sea urchins (but see Fernández \& Beiras 2001, Phillips et al. 2003, Kobayashi \& Okamura 2005, Xu et al. 2011) and, to the best of my knowledge, none on abalone. Overall, metal mixtures seem to be mostly additive or have only a slight interactive effect (synergistic or less-than additive) on sea urchin larvae. Fernández \& Beiras (2001) reported a slight synergistic effect of $\mathrm{Cu}+\mathrm{Pb}$ on Parocentrotus lividus from Spain's Atlantic coast but warned that it should not be considered as significantly different from additivity based on Hayes' criterion. Phillips et al. (2003), working in California, found a less-than-additive effect of $\mathrm{Cu}+\mathrm{Zn}$ on Strongylocentrotus purpuratus, but with a sum of TUs less than 2. Another study on Strongylocentrotus intermedius from the East China Sea concluded that there was a synergistic effect of $\mathrm{Cu}+\mathrm{Zn}$ and $\mathrm{Zn}+\mathrm{Pb}$, and an antagonistic effect of $\mathrm{Cu}+\mathrm{Pb}$. However, the authors did not take into account experimental variability and TU standard error for every 
mixture tested overlapped 1 , so the mixtures were likely all strictly additive (Xu et al. 2011). Finally Kobayashi and Okamura (2005) suggested that copper and lead enhanced zinc toxicity for Anthocidaris crassispina from Japan, however, no formal additive indices were provided.

In other aquatic organisms, copper and zinc mixtures had a less-than-additive effect in approximately half of the 21 tests and a more-than additive effect in the other half, in Norwood et al.'s (2003) review. The exact mechanisms of metal interaction in marine organisms are not known, but it has been hypothesized that copper may enhance zinc absorption (Flemming \& Trevors 1989, Stauber \& Florence 1990). However, the opposite has been observed as well; the presence of zinc in water decreased copper accumulation in tissues of juvenile catfish and barnacles, and vice versa (Eisler 2007). Effects of the pair $\mathrm{Pb}+\mathrm{Zn}$ were evenly distributed between the three interactions (less-than-additive, strictly additive and more-than-additive) but this metal pair was rarely studied with only 5 assays reviewed by Norwood et al. (2003). Copper and lead mixtures were more rarely studied, but these were strictly additive for larval development of the sea urchin Strongylocentrotus intermedius (Xu et al. 2011), and synergistic for chironomid larvae (Eisler 2007) and Parocentrotus lividus when in tertiary mixture with cadmium (Manzo et al. 2010).

\subsubsection{CONSEQUENCE FOR FIELD POPULATIONS}

For many marine invertebrates, survival and quality of larvae and new recruits is a critical factor limiting adult population size (Caley et al. 1996, Pechenik et al. 1998, Crean et al. 2011). H. iris in particular already suffers from a low recruitment rate, which is thought to be a main limiting factor in population growth (McShane et al. 1994, McShane 1995). Furthermore, this species may be especially vulnerable to metal contamination, as the larval stage is very short and larvae stay close to shore where they are more likely to encounter metal pollution. They also have a limited dispersal due to the short larval stage, so populations in contaminated areas are less likely to receive recruits from an unpolluted area. In addition, $H$. iris tends to spawn during storms, increasing the risk of exposure to large river plumes with maximal metal contamination. Abalone vulnerability to pollutants is recognised in the US and 
Australia, where populations have become locally extinct or unhealthy in coastal areas that receive industrial and urban discharges (Martin et al. 1977, Anderson et al. 1990, Bielmyer et al. 2005, Gorski \& Nugegoda 2006).

Ecotoxicity assays are a cost-efficient way of evaluating a species' sensitivity to pollutants. Their main advantage is to be standardized, allowing for easy comparison between pollutants, species and life stages. They are thus very useful for identifying priority pollutants and species. However, interpreting the ecological relevance of bioassays is always a difficult challenge (Clements \& Kiffney 1994, Calow et al. 1997). Some studies attempted to use population-modeling tools with input from acute toxicity data and natural survival data, to model toxicant impacts on populations (Munns et al. 1997, Gleason et al. 2000). These models could be used with short lived species for which metal effects can be evaluated over their full life cycle (Raimondo \& McKenney 2005). With long-lived species, however, such models suffer from lack of data for one or more life stage, and potential carry-over effects are totally disregarded, i.e. survival in one life stage is independent of pollutant exposure in the previous life stage (Gleason et al. 2000). More research is needed to predict pollutant effects on populations based on individual bioassays, especially for organisms for which full life cycle assays are not possible.

\subsubsection{CONCLUSION}

Both E. chloroticus and H. iris embryos are extremely sensitive to copper and zinc, but relatively robust to exposure to lead. NZ WQC should be reviewed and adjusted for zinc to provide better protection for vulnerable $H$. iris populations near major urban and industrial effluents. Effort should be made to reduce copper discharge in agricultural effluents and prevent metal contamination from becoming chronic. More research is needed to translate ecotoxicity results into ecologically relevant information, including investigating the importance of carry-over and latent effects. Concerning metal mixtures, my results are similar to previous studies on sea urchins and show that mixture toxicity for copper, lead and zinc may be accurately predicted with CA models. Therefore, the current additive criterion (ANZECC 2000) to adjust WQC when a mixture of contaminants is present seems appropriate, at least for 
copper, lead and zinc. However, from a management point of view, the toxicity of an effluent containing multiple metals is still slightly higher than the toxicity of an effluent with only the most toxic metal present. Therefore, toxicity assays with single metals should be taken as a best-case scenario. 


\section{CHAPTER 3}

\section{Latent effect of low level of copper contamination on Evechinus chloroticus early life stages}

\section{ABSTRACT}

Exposure to environmental stressors, such as pollutants, early in life may have latent effects visible only in later life stages. This study follows sea urchin larvae (Evechinus chloroticus) exposed briefly (two days) to four treatments of low level of copper $(2.3-10.4 \mu \mathrm{g} / \mathrm{L})$. Stage-dependent sensitivity to copper was evaluated by exposing larvae early or late during larval development, and then examining settlers for $40 \mathrm{~d}$ after settlement. Some of the juveniles were exposed to a further short pulse of copper $(10.4 \mu \mathrm{g} / \mathrm{L})$ to investigate a potential resistance to pollution. No major direct effect was observed on larvae or settlement success. However, complex latent effects started to appear from eight days post-settlement. Individuals exposed to the highest level of copper late in larval stage metamorphosed into 14\% larger settlers with $45 \%$ longer spines. However, they had strongly impaired subsequent growth, with an average radial length and spine to body ratio decreasing by $24 \%$ for both variables, and were $23 \%$ smaller than controls with $15 \%$ shorter spines by $25 \mathrm{~d}$ postsettlement. Juveniles previously exposed to copper as larvae were less resistant to a subsequent pulse, with up to four times higher mortality in groups previously exposed to copper during the larval stage. On the other hand, survivors exposed as larvae to the highest copper level had a $35 \%$ higher growth rate than naïve juveniles (i.e. no previous exposure). Overall copper impact was stronger in larvae exposed early rather 
than late in development. Surprisingly, juveniles were more sensitive than pluteus larvae, with direct growth impairment in the highest copper treatment $(-8 \%$ growth in naïve juveniles $v s+15 \%$ in controls). These results highlight the importance of considering latent effects when evaluating the impacts of pollution. The effect of exposure to contaminants in larval stages may be far-reaching and much more complex than can be observed in shorter-term experiments.

\subsection{INTRODUCTION}

In organisms with complex life stages, early life history plays a major role in adult population dynamics. Both larval quantity and quality drive adult abundance and performance (Gaines et al. 1985, Johnson 2008). In the last 20 years it has become more and more evident that larval quality can vary strongly between cohorts due to environmental stresses encountered in early life (Pechenik et al. 1998, Shima \& Swearer 2009). Understanding the impact of environmental disturbances on early life stages and their cascading effects on later life stages is crucial for managing vulnerable populations.

Pollution is one of the most important anthropogenic disturbances. Among the myriad of pollutants entering coastal waters, copper is one of the most toxic to aquatic life (Bryan 1971, Flemming \& Trevors 1989, US EPA 2007, Watson et al. 2008). While extensive ecotoxicity studies have been carried out on copper and other metals (Fernández \& Beiras 2001, Doyle et al. 2003, Bielmyer et al. 2005), the ecologically relevant effects of metal pollution are still poorly understood (Mayer-Pinto et al. 2010). Indeed, most toxicity studies are very short term (days) and use unrealistic concentrations and/or prolonged exposure. In the field, larvae are exposed to relatively low levels of copper in most countries (Table 1.1) and are unlikely to be exposed chronically to toxicants, except perhaps in enclosed bays or harbours with low water renewal. Thus, one of the most common sources of pollution affecting plankton is river plumes or terrestrial run off during rain events. Exposure to pollutants is probably on the order of a few days at the most. Sampling of coastal 
water following a heavy rain event in Wellington showed a fast decrease in copper concentration, dropping to undetectable levels in two days (Table A.2).

Nevertheless, early life stages are highly vulnerable to environmental disturbances and even short exposure to a stressor may have strong, lasting effects (Pechenik et al. 1998, 2001, Gimenez et al. 2004). For example, abalone larvae had a dramatically increased mortality rate lasting throughout the larval stage following a three-day exposure to elevated sediment (Phillips \& Shima 2006). In addition to direct effects such as larval mortality or larval growth, some effects may cross the metamorphic boundary and continue affecting performance in later life, i.e. carry-over effects, while other effects originating in the larval stage may become visible only in later life stages, i.e. latent effects. Latent and carry-over effects are difficult to investigate on long-lived species and most studies have focused on the effect of food availability and delayed metamorphosis (reviewed in Pechenik 2006). However, latent effects of metal exposure have been observed in bryozoans ( $\mathrm{Ng} \&$ Keough 2003) and arthropods (Manyin \& Rowe 2010).

Early exposure to an environmental stressor may also impact resistance to a subsequent exposure later in life. In the field, juveniles will likely encounter similar environmental disturbances as those encountered during the larval stage, especially in species with low dispersal. However, to the best of my knowledge, no studies have looked into the effects of subsequent exposure to pollutants later in life. On one hand, surviving juveniles may be less resistant to further stress. For example, two recent studies have shown that environmental stress in early life reduces resistance to further stress in the limpet Siphonaria australis (Fischer \& Phillips 2014) and in the barnacle Amphibalanus improvises (Nasrolahi et al. 2012). On the other hand, surviving juveniles may be more resistant to subsequent stress, which can be caused by acquired resistance or selective mortality in favour of the more resistant individuals. Acquired resistance, or acclimation, to a pollutant has been observed repeatedly in fish and generally involves physiological processes that are quickly lost after exposure to the contaminant has stopped (Dixon \& Sprague 1981, Brinkman \& Woodling 2014). However, literature on whether acquired resistance may persist across the metamorphic boundary is lacking. Another aspect of resistance to 
pollutants is inherited resistance and local adaptation at population level (reviewed by Wirgin \& Waldman 2004); this has been observed for copper in short-lived marine invertebrates (McKenzie et al. 2011, Sun et al. 2014). While highly relevant for population persistence in the long term, inherited resistance is beyond the scope of this study.

While early life stages are usually the most sensitive to pollutants and environmental disturbances, a specific developmental stage may be particularly sensitive sometimes called the 'critical life stage' (Kobayashi 1980, Hunt \& Anderson 1993, Conroy et al. 1996, Jezierska et al. 2009). As a general rule (although not always the case), younger organisms tend to be more vulnerable than older ones (King \& Riddle 2001, Jezierska et al. 2009, Aronzon et al. 2011). In echinoids, the early pluteus stage (occurring between fertilisation and the two-armed pluteus stage, which takes one to few days post-fertilisation depending on the species) has been shown to be the most sensitive in many species (Kobayashi 1980, King \& Riddle 2001, Bielmyer et al. 2005). As a result, most studies on pollutants have focused their observations during this critical life stage and little is known about the sensitivity of later pluteus stages (but see Kobayashi 1980, Phillips \& Shima 2006) and young juveniles. Understanding the effect of pollutants outside of the critical life stage period is important for evaluating the impact of pollutants in the field and for natural populations.

The aim of this study was to investigate the ecologically relevant impact (i.e. shortterm, low concentrations) of copper pollution on marine invertebrate larvae and young juveniles, with a focus on latent and carry-over effects, using the sea urchin Evechinus chloroticus as the focal species. Stage-dependent toxicity was evaluated by exposing larvae either early $(4-6 \mathrm{~d}$ post-fertilisation) or late $(11-13 \mathrm{~d}$ postfertilisation) during development, and as young juveniles ( $25-27 \mathrm{~d}$ post-settlement). I then tested resistance of the surviving juveniles to a further exposure to the same stressor. All copper concentrations used were derived from field measures in low to moderately polluted areas of New Zealand, and were expected to produce no major direct effects on larval survival or development when administered in a very short 
pulse and outside of the critical life stage of early pluteus development. Young larvae were expected to be more vulnerable than older larvae and juveniles.

\subsection{METHODS}

\subsubsection{BROODSTOCK AND SPAWNING}

Adult E. chloroticus (8 - $20 \mathrm{~cm}$ test diameter) were collected from Kau Bay, Wellington $\left(41.2882^{\circ} \mathrm{S}, 174.8326^{\circ} \mathrm{E}\right)$ in November 2012 . A total of 45 urchins were kept at Victoria University Coastal Ecology Laboratory (VUCEL) in a 200 L tank with flow-through raw seawater. VUCEL's seawater is pumped $\sim 5 \mathrm{~m}$ from shore in the Taputeranga Marine Reserve. Raw seawater receives no treatment, while filtered seawater (FSW) is pre-filtered $(15 \mu \mathrm{m})$ and then filtered through a $0.2 \mu \mathrm{m}$ paper cartridge. Adult E. chloroticus were fed twice a week with native kelp (Macrocystis pyrifera) and/or commercial abalone feed (ABMAX, E.N. Hutchinson Ltd Auckland NZ). The experiment was run from November 2012 to January 2013. E. chloroticus larvae were the product of multiple parents (five males, two females). Spawning was induced by injecting $3 \mathrm{ml}$ of $0.5 \mathrm{M}$ potassium chloride into the abdominal cavity through the perioral membrane (ASTM 2012). Eggs were collected by inverting females over a beaker of FSW and sperm were collected 'dry' and placed on ice until fertilisation. After spawning, the eggs were filtered through a $125 \mu \mathrm{m}$ sieve and placed in fresh FSW. Gametes of each spawning adult were pooled in approximately similar quantity to produce a composite sperm and egg stock. Fertilisation occurred less than $1 \mathrm{~h}$ after spawning at high sperm concentration (estimated sperm concentration $10^{7}-10^{9}$ cells $/ \mathrm{ml}$ ). Eggs were left in contact with sperm for $15 \mathrm{~min}$ and rinsed thoroughly to avoid polyspermy.

\subsubsection{METAL CONCENTRATIONS}

Larvae were exposed to one of four concentrations of copper, plus a control, either early or late in their development. Copper exposure lasted for a maximum of $48 \mathrm{~h}$ in all treatments. The 'Early' group received a copper spike at $4 \mathrm{~d}$ and the 'Late' group 
at $11 \mathrm{~d}$ post-fertilisation. Each metal level and control had three replicate jars for each of the two timing of exposure.

Copper concentrations for the four treatments are shown in Table 3.1. The ANZECC level was based on the current recommended water quality trigger value for $95 \%$ species protection (ANZECC 2000). The 'Field' concentration was based on the maximum dissolved copper concentration measured from 29 seawater samples collected across four sites in the Wellington region between September 2011 and January 2012 (Appendix A). The 'High' level was chosen as a realistic level occurring in moderately polluted water such as near large cities (Table 1.1). Metal stock solutions were made from reagent grade copper sulphate $\left(\mathrm{CuSO}_{4} .5 \mathrm{H}_{2} \mathrm{O}\right)$. Actual copper concentrations were determined by recreating experimental conditions without urchin larvae in January 2013 using the same protocol, culture medium, glassware and stock solution as during the actual experiment. Water samples were analysed by Environmental Laboratory Services, Lower Hutt.

Table 3.1: Copper concentration chosen in larval assays. Measured dissolved concentrations were filtered through a $0.45 \mu \mathrm{m}$ mesh and send to ELS.

\begin{tabular}{lll} 
Copper level & $\begin{array}{l}\text { Nominal concentration } \\
(\mu \mathrm{g} / \mathrm{L})\end{array}$ & $\begin{array}{l}\text { Measured dissolved } \\
\text { concentration }(\mu \mathrm{g} / \mathrm{L})\end{array}$ \\
\hline Control & 0 & $<0.5-1.2$ \\
ANZECC & 1.3 & 2.3 \\
Field & 2.9 & 3.8 \\
Field x2 & 5.8 & 6.1 \\
High & 10 & 10.4 \\
\hline
\end{tabular}

\subsubsection{LARVAL ASSAYS}

E. chloroticus larvae were raised for $28 \mathrm{~d}$ in a standing-renewal system composed of $2 \mathrm{~L}$ glass jars placed in a flowing seawater bath to maintain a near constant temperature. Water temperature was $16^{\circ} \mathrm{C} \pm 1$ throughout the whole experiment and $\mathrm{pH}$ was measured in each jar at one and three week post-fertilisation. Jars were gently stirred by a system of motorised paddles as described in Strathmann (1987), to provide adequate oxygenation. Embryos were placed in their culture jar within $1 \mathrm{~h}$ post-fertilisation at a density of 1 embryo/ml. All glassware was washed with hot 
water, soaked in $10 \%$ hydrochloric acid for a minimum of $4 \mathrm{~h}$, rinsed and soaked in distilled water for $12 \mathrm{~h}$ and rinsed in FSW before use. FSW in jars was renewed three times per week by inverse siphoning. From $4 \mathrm{~d}$ post-fertilisation, larvae were fed following each water change with Dunaliella tertiolecta at a concentration of 8000 cells/ml of culture. Dunaliella stocks were rinsed thoroughly by three successive centrifugations (1201 $\mathrm{g}$ for $5 \mathrm{~min}$ ) and resuspensions in clean FSW before being fed to the larvae, to remove traces of algal culture medium that was rich in essential metals.

All jars were sampled at $4 \mathrm{~d}$ and $11 \mathrm{~d}$ post-fertilisation; jars in the Early timing group were sampled at $25 \mathrm{~d}$, and jars in the Late timing group at $13 \mathrm{~d}$ and $27 \mathrm{~d}$ postfertilisation. During sampling, the water level in each jar was lowered to $750 \mathrm{ml}$ to increase larval density and 3 x $15 \mathrm{ml}$ aliquots were taken per jar. Jars were randomly numbered and all measurements were done blind with regard to the treatment classification. Number of live larvae was measured in each aliquot using a dissecting microscope (40x magnification). Each live larva was assigned to one of eight developmental categories (Table 3.2). The first ten normal larvae encountered were preserved in $40 \%$ ethanol to be photographed under a compound microscope (50x magnification). When two developmental stages were considered normal (e.g. at $25 \mathrm{~d}$ post-fertilisation both 6 -armed plutei and 8 -armed plutei were rated as normal), only larvae belonging to the most advanced developmental stage (e.g. 8-armed plutei at 25 d) were taken for morphometric measurements. Measurements of larval body and arm lengths (average of $\mathrm{R}$ and $\mathrm{L}$ arms where possible; Table 3.2) as well as presence and size of the rudiment in the late larval stage were done using the software ImageJ. 
Table 3.2: Developmental categories of Evechinus chloroticus larvae. Arrows on 8-armed pluteus show morphometric measurments. BL: total body length, PO: postoral arms, AL: anterolateral arms, PD: posterodorsal arms, EO: preoral arms, S: stomach, R: rudiment.

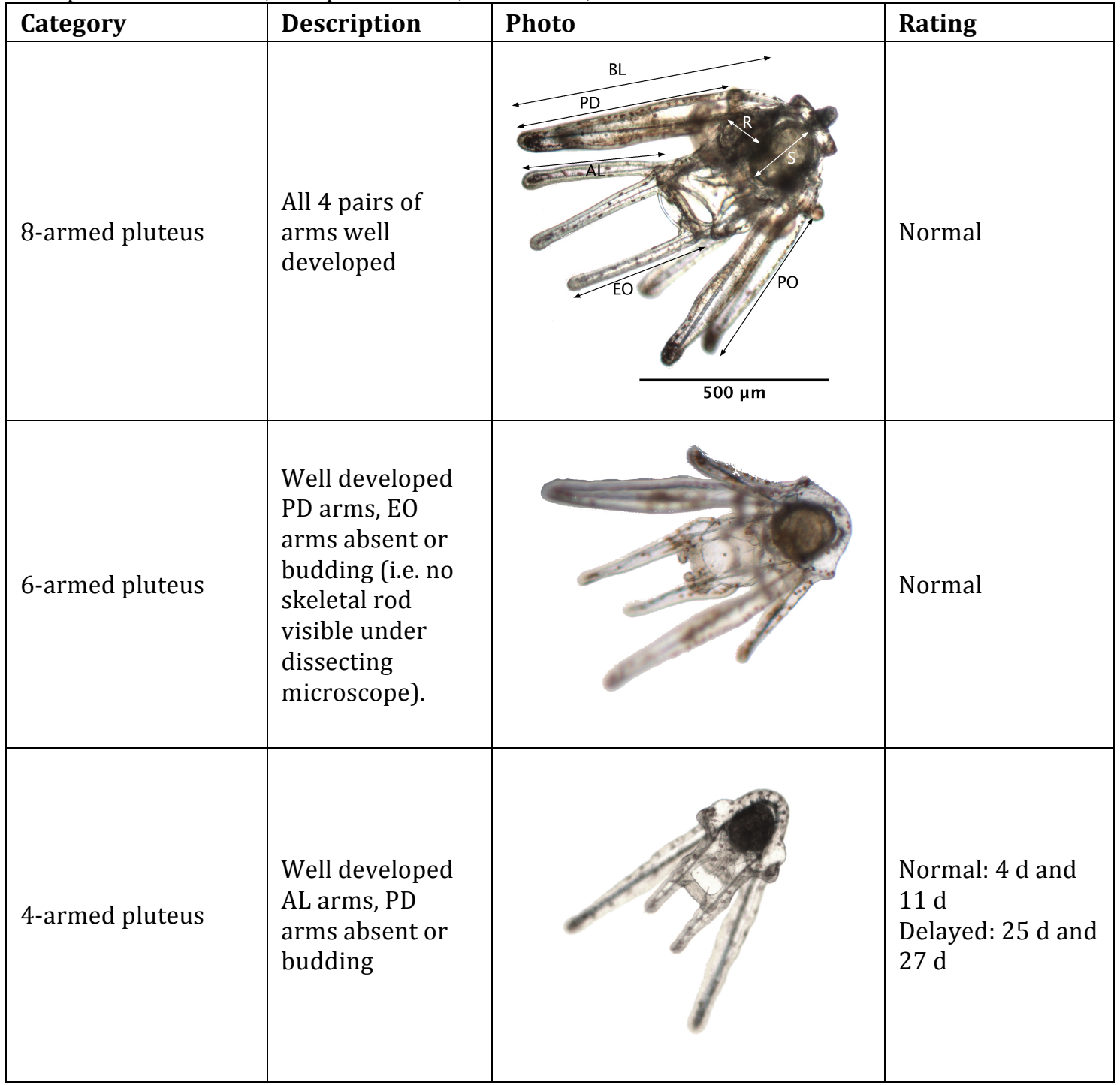

Table 3.2 continued on next page 


\begin{tabular}{|c|c|c|c|}
\hline Category & Description & Photo & Rating \\
\hline 2-armed pluteus & $\begin{array}{l}\text { Well developed } \\
\text { PO arms, AL } \\
\text { arms absent or } \\
\text { budding }\end{array}$ & & $\begin{array}{l}\text { Normal: } 4 \mathrm{~d} \\
\text { Delayed: } 11 \mathrm{~d}, 25 \\
\mathrm{~d} \text { and } 27 \mathrm{~d}\end{array}$ \\
\hline Missing arm & $\begin{array}{l}\text { One or more arm } \\
\text { missing. Only if } \\
\text { the other arm of } \\
\text { the pair is well } \\
\text { developed. }\end{array}$ & & Abnormal \\
\hline Broken & $\begin{array}{l}\text { Broken arm or } \\
\text { skeletal rod in } \\
\text { body }\end{array}$ & & Abnormal \\
\hline Stunted & $\begin{array}{l}\text { PO arms }<\text { half } \\
\text { BL }\end{array}$ & & Abnormal \\
\hline Abnormal & $\begin{array}{l}\text { Larvae with } \\
\text { more than one } \\
\text { abnormality or } \\
\text { with severe } \\
\text { abnormality not } \\
\text { fitting any other } \\
\text { categories. }\end{array}$ & & Abnormal \\
\hline
\end{tabular}




\subsubsection{SETTLEMENT}

Settlement containers consisted of $2 \mathrm{~L}$ white plastic containers with mesh sides (80 $\mu \mathrm{m})$ to allow for water circulation. Larvae in replicate jars were pooled to remove variation between jars and then divided into three replicate containers per copper level and timing of exposure, and 12 control replicates. Initial larval density was measured in pooled jars. Containers were placed into large plastic trays (ten randomly assigned containers per tray) filled with FSW and oxygenated with two airlines per tray. Trays were placed in a flowing seawater bath to maintain a near constant temperature similar to the temperature during larval development. Each settlement container was inoculated with benthic diatoms (mixed species) eight days prior to settlement to provide a settlement cue and food for young settlers (Xing et al. 2007). Complete water renewals were done three times per week. Temperature was measured daily while $\mathrm{pH}$ and dissolved oxygen were measured weekly in trays. All measures were constant across trays. All treatments except those from the High copper level were placed in settlement containers after $28 \mathrm{~d}$ of larval development. Larvae in High copper treatments, both Early and Late exposure groups, appeared to be delayed and were therefore given five additional days (33 $\mathrm{d}$ post-fertilisation) to achieve similar development as the other treatments (i.e. $>75 \%$ of normal larvae being at the 8 -armed stage) before being transferred to the settlement containers. Time post-settlement was counted from the first day that larvae were placed in settlement containers. Larvae were given eight days to settle after which any remaining larvae were removed from the containers.

Settler density was measured by counting the total number of settlers per container under a dissecting microscope at 8 and $25 \mathrm{~d}$ post-settlement. The first 20 settlers encountered were photographed under a dissecting microscope (25x magnification). Body diameter (radial length) and the length of three spines were measured using the software ImageJ. Benthic diatom cover was recorded qualitatively as low, medium or dense at $25 \mathrm{~d}$ and $40 \mathrm{~d}$ post-settlement to ensure food was not a limiting factor. 


\subsubsection{JUVENILE RE-EXPOSURE EXPERIMENT}

Out of the 12 control replicates from the larval exposure experiment, six were exposed to copper for the first time at the juvenile stage, i.e. naïve group, and the remaining six were kept in clean FSW, i.e. control group. At $25 \mathrm{~d}$ post-settlement, juveniles in all groups, except for controls, were exposed to a High level $(10.4 \mu \mathrm{g} / \mathrm{L})$ of copper for two days. Juveniles were then placed into clean FSW until 40 d postsettlement when mortality, growth and normal development were assessed. Experimental set-up and maintenance routine were the same as described for settlers. Mortality and growth were measured as described for settlers. All juveniles in each container were rated for normal development and were deemed as 'abnormal' when body shape was strongly irregular, or lacked spines or pigmentation (Table 3.3) when observed under a dissecting microscope (40x magnification). 
Table 3.3: Developmental categories of Evechinus chloroticus juveniles. All juveniles pictured are 25 day-old.

\begin{tabular}{|l|l|l|}
\hline Categories & Description & Photo \\
\hline Normal & $\begin{array}{l}\text { Spherical body with pigmentation and well } \\
\text { developed spines }\end{array}$ & \\
\hline Irregular & $\begin{array}{l}\text { Strongly irregular body, typically with a large } \\
\text { protrusion on top of the test (pictured) }\end{array}$ & \\
\hline Spineless & Juvenile completely lacking spines & \\
\hline Ghost & $\begin{array}{l}\text { Juveniles lacking pigmentation in the body but } \\
\text { with moving tubular feet or spines }\end{array}$ & \\
\hline
\end{tabular}

\subsubsection{STATISTICS}

All data analyses were conducted using the software R (version 3.1) with package multcomp (Hothorn et al. 2008) for pairwise comparisons and package nlme (Pinheiro et al. 2015) for mixed effects models.

\subsubsection{Larval performance}

Direct effects of copper treatments on larvae were evaluated by (1) larval survival rate, (2) larval normal development, (3) delayed development, (4) larval growth and (5) larval morphometrics. More details concerning data analysis of all larval variables are given in Appendix B because they were not the main focus of this study. 


\subsubsection{Settler performance}

Settler performance was evaluated by (1) settlement success, (2) size at settlement, (3) mortality and (4) growth after $17 \mathrm{~d}$. Settlement success was expressed as the number of settlers observed $8 \mathrm{~d}$ post-settlement divided by the initial number of larvae in containers. Size at settlement was evaluated by two variables: radial length (RL) and spine/body ratio (SBR). Settler mortality was the proportion of dead settlers (no moving tube feet or spines) at $25 \mathrm{~d}$ post-settlement. Settler growth was measured by two variables: body growth (radial length at $25 \mathrm{~d} /$ radial length at $8 \mathrm{~d}$ postsettlement, averaged by container) and spine growth (average spine length at $25 \mathrm{~d} /$ average spine length at $8 \mathrm{~d}$, averaged by containers).

The effect of larval experiences on settler performance was evaluated by fitting an initial model including all of the following factors and covariates. Level of copper exposure and timing of copper exposure (main factors), and larval traits at the end of the larval stage (covariates): larval survival, proportion of normal larvae, larval size, proportion of larvae with a rudiment and rudiment size. All larval traits were averaged per treatment, as replicate jars were pooled before settlement. In addition to larval experience, two non-larval related covariates were used: initial larval density in settlement containers (initial density) for settlement success and size at settlement analyses; and settler density at $8 \mathrm{~d}$ post-settlement (settler density) for settler survival and growth analyses.

The best model was selected from the initial model (full model) described above, using a stepwise regression based on AIC criterion for each settler performance variable. Best models were then analysed using ANCOVAs or mixed effect models with the selected factors and covariates, which are presented in the result section (section 3.3.2). Interactions were included only when selected in the best model. Settlement success and settler survival were fitted with an ANCOVA and were square-root arcsin transformed to meet model assumptions. RL and SBR were fitted with a mixed effect linear model with 'container' as the random effect and 'individual settler' as the residual. Body growth and spine growth were fitted with an ANCOVA. 
For all settler performance analyses, when copper level was significant, a priori coefficient contrasts were used to compare all treatments against their control. If timing of exposure was also significant, Dunnett's post hoc test was conducted on both exposure-timing groups separately. R-squared values reported for mixed effects models were conditional $\mathrm{R}^{2}$ as described by Nakagawa \& Schielzeth (2013) and Johnson (2014), calculated using rsquared.glmer v0.2-4 function (Lefcheck \& Casallas 2014). Partial $\mathrm{R}^{2}$ values for each component of the model were estimated by hierarchical partitioning (Chevan \& Sutherland 1991, Mac Nally 1996) using the hier.part package (Walsh \& Mac Nally 2013). Containers 10 and 13 (both treatment controls) were not measured at $8 \mathrm{~d}$ post-settlement and were removed from the analysis.

\subsubsection{Juvenile performance after re-exposure}

Juvenile performance was evaluated by (1) mortality, (2) growth: radial growth and spine growth, (3) normal development two weeks after re-exposure to copper (40 d post-settlement). Mortality was the inverse proportion of individuals alive before reexposure ( $25 \mathrm{~d}$ post-settlement) that were still alive at $40 \mathrm{~d}$ post-settlement. Mortality was square-root arcsin transformed to meet ANCOVA assumptions. Juvenile growth in each container was defined as: (average size at $40 \mathrm{~d}$ - average size at $25 \mathrm{~d}$ ) / average size at $25 \mathrm{~d}$. Normal development was measured as the proportion of live juveniles having a normal body at $40 \mathrm{~d}$ post-settlement.

For all variables, two independent hypotheses were tested separately: comparison between naïve juveniles (i.e. juveniles exposed for the first time at $25 \mathrm{~d}$ postsettlement) and controls (i.e. juveniles never exposed to copper); and the effect of larval experience on juveniles exposed to copper at $25 \mathrm{~d}$ post-settlement, either for the first time (Naïve group) or for the second time (ANZEEC, Field, Field x 2 and High groups). Best models for the later analyses were selected as described for settler performance and then analysed using ANCOVAs on linear model, with copper level and timing of exposure as the main factors and larval traits as the covariates. In addition, final radial length (at $40 \mathrm{~d}$ post-settlement) was analysed using a mixed effect linear model, with container as the random effect and individual settler as the 
residual. Model fit, partitioning of variance and contrasts were calculated as described for settler performance. Type II SS are reported for all ANOVAs or ANCOVAs.

\subsection{RESULTS}

\subsubsection{LARVAL SURVIVAL, GROWTH AND DEVELOPMENT}

Overall there were no major direct effects of copper exposure during larval development on any of the variables measured (see details in Appendix B).

\subsubsection{SE LE PE FO MANCE}

Benthic diatom cover remained abundant throughout the experiment. At $25 \mathrm{~d}$ postsettlement, all containers had a medium benthic cover. At $40 \mathrm{~d}$ post-settlement, six containers had a denser diatom cover (1 control, 2 naïve, 1 ANZECC, 1 Field and 1 Field $\mathrm{x} 2$ treatment) and two had a lower diatom cover (1 control and 1 ANZECC treatment). Variation in benthic cover did no appear to be linked with treatment and even in containers with lower than average benthic cover, food supply seemed to remain in excess with scarce grazing tracks.

\subsubsection{Settlement success}

Settlement success was low in most containers and widely variable across containers, ranging from $3.5 \%$ to $68 \%$. It was significantly driven by timing of copper exposure and rudiment size at the end of the larval stage (Timing: $F_{(1,31)}=47.60, p<0.001$; Rudiment size: $\left.\mathrm{F}_{(1,31)}=39.79, \mathrm{p}<0.001\right)$. Overall the model explained $61 \%$ of the observed variation (multiple $\mathrm{R}^{2}$ ) of which $58 \%$ was explained by timing of exposure and $42 \%$ by rudiment size. Settlers exposed as young larvae had a higher rate of settlement than settlers exposed later during the larval stage (Early exposure: $28 \% \pm$ 15; Late exposure: $18 \% \pm 15$ ). In both 'timing of exposure' groups, settlement success increased with rudiment size at the end of the larval stage (Figure 3.1). 


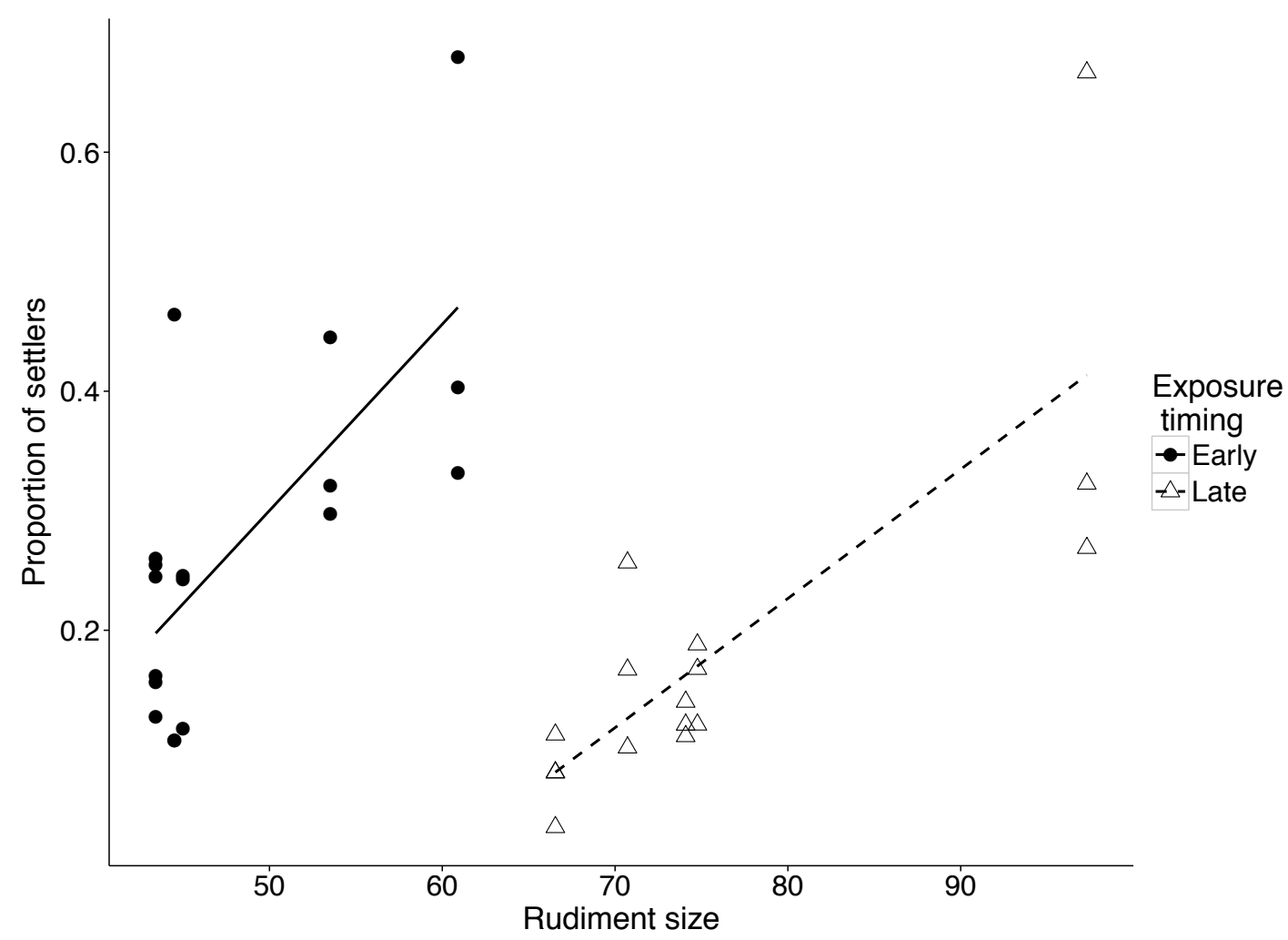

Figure 3.1: Effect of timing of copper exposure during larval stage and rudiment size before settlement on Evechinus chloroticus settlement success expressed as proportion of settlers observed at $8 \mathrm{~d}$ postsettlement. Settlers in the Early treatment group were exposed to various levels of copper as larvae at 4 $\mathrm{d}$ post-fertilisation. Settlers in the Late treatment group were exposed later during larval development (11 d post-fertilisation).

\subsubsection{Settler size at settlement}

Size at settlement was significantly affected by copper exposure for both radial length and SBR (Table 3.4).

Radial length was best explained by both timing and level of copper, rudiment size and initial density (Table 3.4a). The model was weak, with only 13\% of the variation explained (conditional $\mathrm{R}^{2}$ ) by the following factors (in decreasing order of contribution): copper level, rudiment size, heterogeneity across containers (random term), initial density and timing of exposure. Settler radial length was significantly higher for controls only in the Late High copper treatment $(812 \mu \mathrm{m} \pm 103$ vs $714 \mu \mathrm{m}$ \pm 70 in Late control; Dunnett's contrasts: $\mathrm{z}=5.92, \mathrm{p}<0.001)$. Individuals from jars in which average rudiment size was large at the end of the larval stage tended to metamorphose into larger settlers (Figure 3.2a). Settlers that had been exposed early 
in the larval stage were significantly smaller than settlers that had been exposed later, but only by $2.2 \%$ on average (Table $3.4 \mathrm{a}$ ).

Table 3.4: Effect of larval experiences on Evechinus chloroticus settler size at $8 \mathrm{~d}$ post-settlement. Both variables, (A) radial length and (B) spine/body ratio, were analysed using an ANCOVA on linear mixed effect models. Spine/body ratio was square-root arcsin transformed to meet ANCOVA assumptions. Significant effects $(p<0.05)$ are highlighted in bold; $p$ values are based on chi-squared statistic.

\begin{tabular}{lccc}
\hline Source & num df, den df & $\mathbf{C h i}^{2}$ & $\mathbf{p}$ \\
\hline (A) Radial length & 1,26 & 6.72 & $\mathbf{0 . 0 1}$ \\
Timing & 4,26 & 9.84 & $\mathbf{0 . 0 4}$ \\
Copper level & 1,26 & 2.63 & 0.10 \\
Initial density & 1,26 & 10.94 & $\mathbf{0 . 0 0 1}$ \\
Rudiment size & & & \\
\hline (B) Spine/Body ratio & 4,28 & 31.5 & $<\mathbf{0 . 0 0 1}$ \\
Copper level & 1,28 & 18.9 & $<\mathbf{0 . 0 0 1}$ \\
Larval body size & & &
\end{tabular}

SBR was significantly affected by the level of copper exposure and larval size but not by timing of exposure (Table 3.4b). Level of copper exposure accounted for most of the variation explained by the model after heterogeneity across containers (random term), with a conditional $\mathrm{R}^{2}$ of $25 \%$ for the full model. However, only settlers from the High copper level were significantly different from controls, with spines an average of $49 \% \pm 10$ of body size against $40 \% \pm 12$ of body size in controls (Coefficients contrasts: $\mathrm{t}=5.10, \mathrm{p}<0.001$ ). Larvae from jars in which average body size was large at the end of the larval stage tended to produce settlers with larger spines relative to their body size (Figure $3.2 b$ ). 


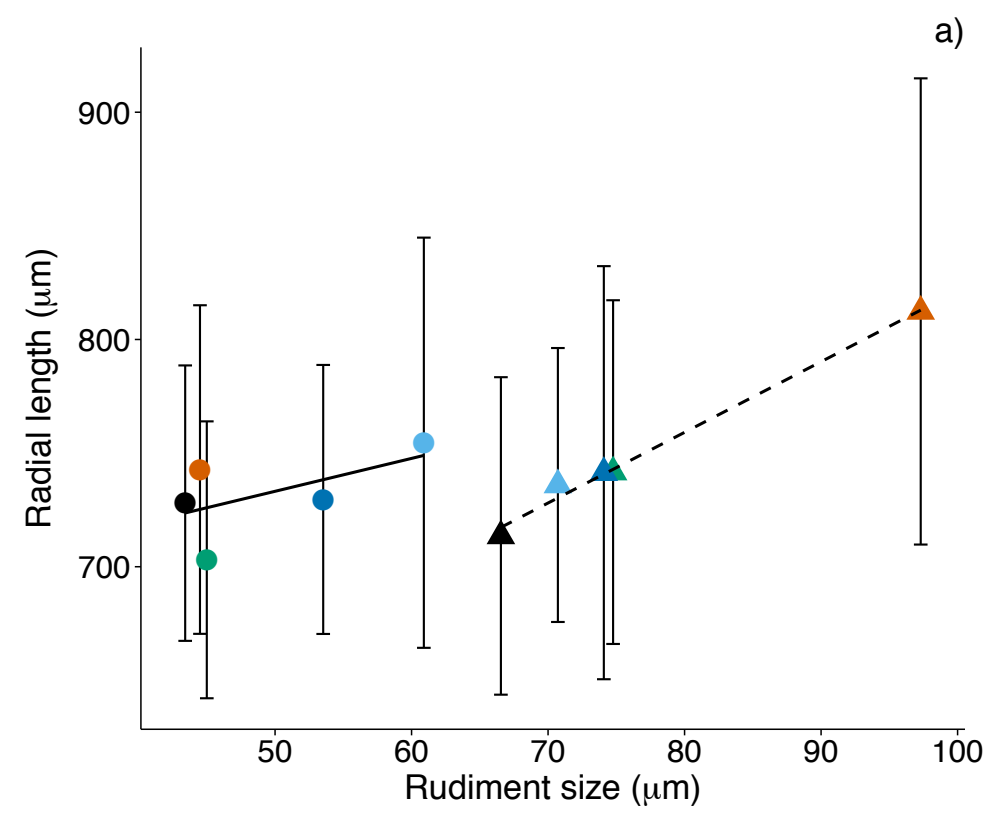

b)

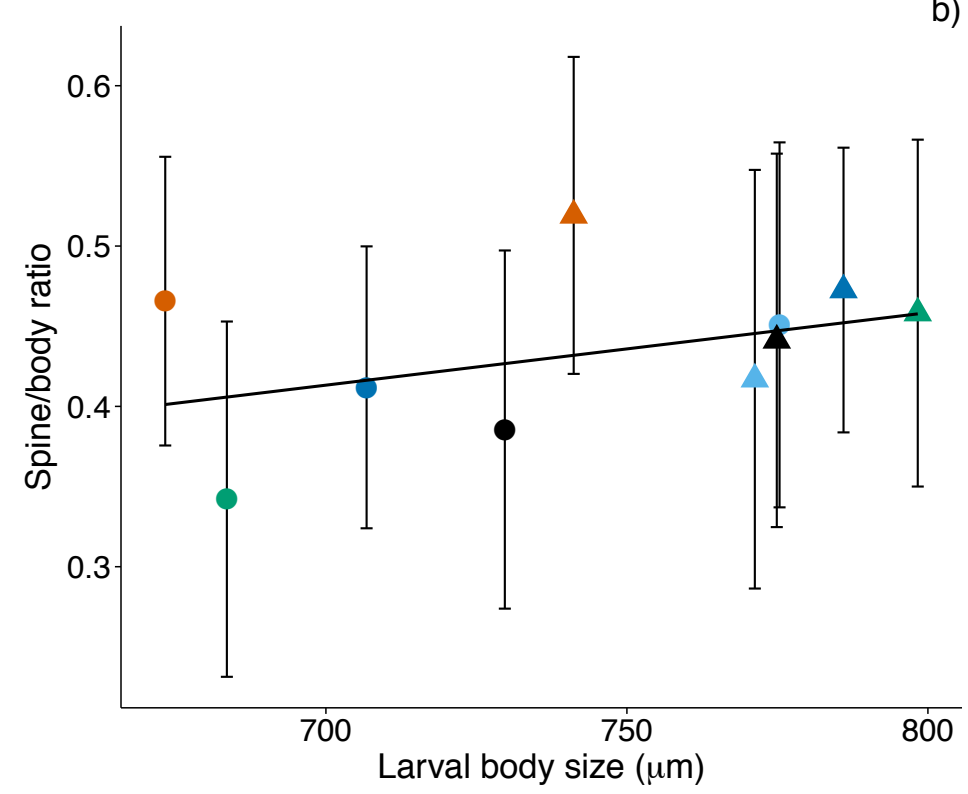

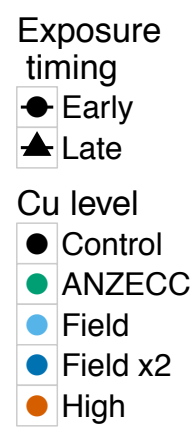

Exposure timing

- Early

Cu level

- Control

Field

- Field $\mathrm{x}$

- High

Figure 3.2: Evechinus chloroticus settlers size at $8 \mathrm{~d}$ post-settlement showing the effects of level and timing of copper exposure during larval development and rudiment size before settlement on (a) settler radial length, and effect of level of copper exposure during larval development and larval size before settlement on (b) settler spine/body ratio. Error bars represent the standard deviation $(\mathrm{N}=3)$.

\subsubsection{Settler survival}

Survival after $25 \mathrm{~d}$ post-settlement was very high in all containers, ranging from $78 \%$ to $100 \%$. The best model for survival explained $43 \%$ of the variation and included timing of copper exposure (but not level of copper), settler density and rudiment size (Table 3.5a). Survival was slightly higher in settlers having been exposed to copper early during the larval stage (96\% \pm 6 in Early group, $92 \% \pm 8$ in Late group). Timing 
of exposure contributed to $43 \%$ of the multiple $\mathrm{R}^{2}$. Settler survival declined with density and increased with rudiment size. Both factors accounted for $22 \%$ and $23 \%$ of the variation, respectively.

Table 3.5: Effect of larval experience on Evechinus chloroticus settlers (A) survival and (B, C) growth at $25 \mathrm{~d}$ post-settlement. All variables were analysed using ANCOVAs on linear models. Settler survival was square-root arcsin transformed to meet ANCOVA assumptions. Significant effects $(\mathrm{p}<0.05)$ are highlighted in bold. $F$-ratios are calculated from Type II SS.

\begin{tabular}{|c|c|c|c|c|}
\hline Source & df & SS & $\boldsymbol{F}$ & $\mathbf{p}$ \\
\hline \multicolumn{5}{|l|}{ (A) Settler survival } \\
\hline Timing & 1 & 0.33 & 14.07 & 0.001 \\
\hline Settler density & 1 & 0.13 & 5.46 & 0.03 \\
\hline Rudiment size & 1 & 0.25 & 10.82 & 0.003 \\
\hline Larval size & 1 & 0.04 & 1.78 & 0.19 \\
\hline Larval development & 1 & 0.04 & 1.77 & 0.19 \\
\hline Residuals & 28 & 0.66 & & \\
\hline \multicolumn{5}{|l|}{ (B) Radial growth } \\
\hline Timing & 1 & 0.01 & 3.71 & 0.07 \\
\hline Copper level & 4 & 0.28 & 44.25 & $<0.001$ \\
\hline Rudiment size & 1 & 0.01 & 5.16 & 0.03 \\
\hline Larval size & 1 & 0.01 & 4.71 & 0.04 \\
\hline Residuals & 26 & 0.04 & & \\
\hline \multicolumn{5}{|l|}{ (C) Spine growth } \\
\hline Copper level & 4 & 1.39 & 7.47 & $<0.001$ \\
\hline Proportion of rudiment & 1 & 0.27 & 6.00 & 0.02 \\
\hline Larval development & 1 & 0.15 & 3.27 & 0.08 \\
\hline Residuals & 27 & 1.26 & & \\
\hline
\end{tabular}

\subsubsection{Settler growth}

Settler radial growth was significantly affected by level of copper exposure, rudiment size and larval size (Table 3.5b). Model fit was excellent, with $93 \%$ of the variation in growth explained. Copper level accounted for most of the explained variation (71\%), with settler growth from larvae exposed to the High copper level being strongly suppressed (Coefficients contrasts: $t=-9.82, p<0.001$ ). Indeed settlers that had been exposed as larvae to the High copper treatment were $24 \%$ smaller at $25 \mathrm{~d}$ than at $8 \mathrm{~d}$ post-settlement $(778 \mu \mathrm{m} \pm 95$ at $8 \mathrm{~d} v s 594 \mu \mathrm{m} \pm 93$ at $25 \mathrm{~d})$. In contrast, control groups had an average growth of $6 \% \pm 5$ (Figure 3.3a). Consequently, settlers from the High treatment were significantly smaller than controls by $25 \mathrm{~d}(594 \mu \mathrm{m} \pm 93$ in High level, $768 \mu \mathrm{m} \pm 95$ in controls; Coefficient contrasts: $\mathrm{t}=-9.88, \mathrm{df}=30, \mathrm{p}<$ 0.001). Settler radial growth was positively related to larval size and rudiment size, with both factors accounting for $11 \%$ and $9 \%$ of the explained variance, respectively. 


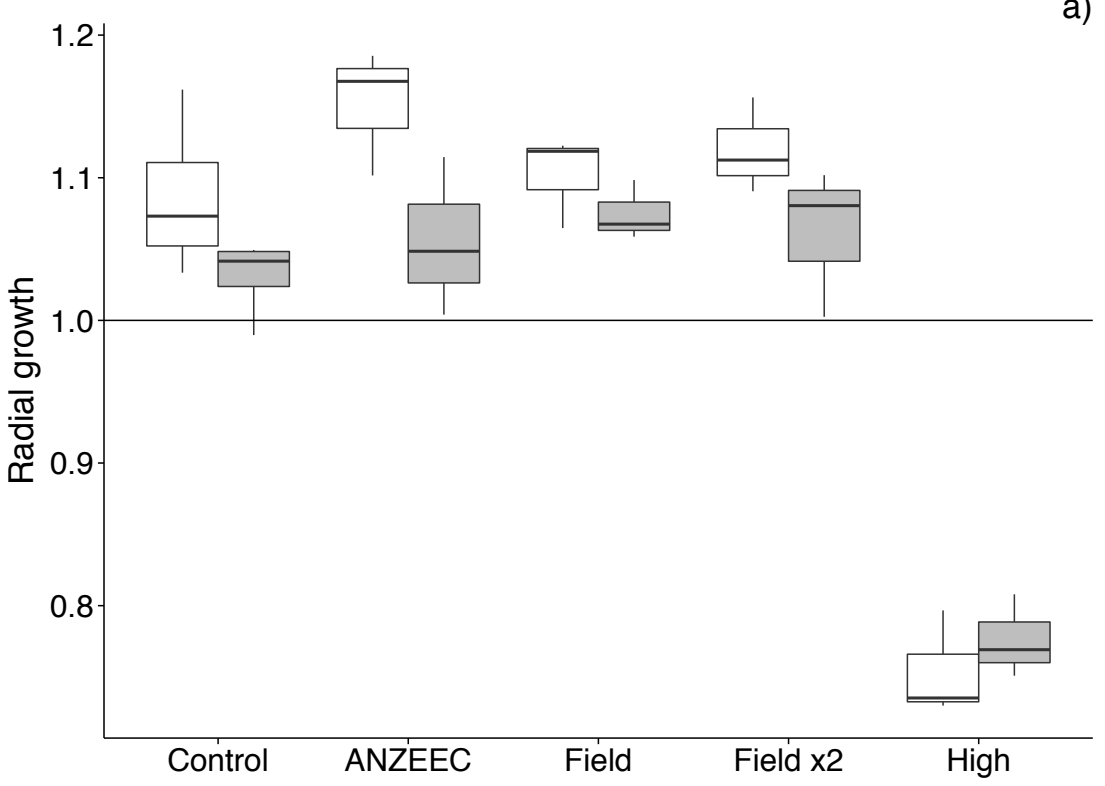

a)

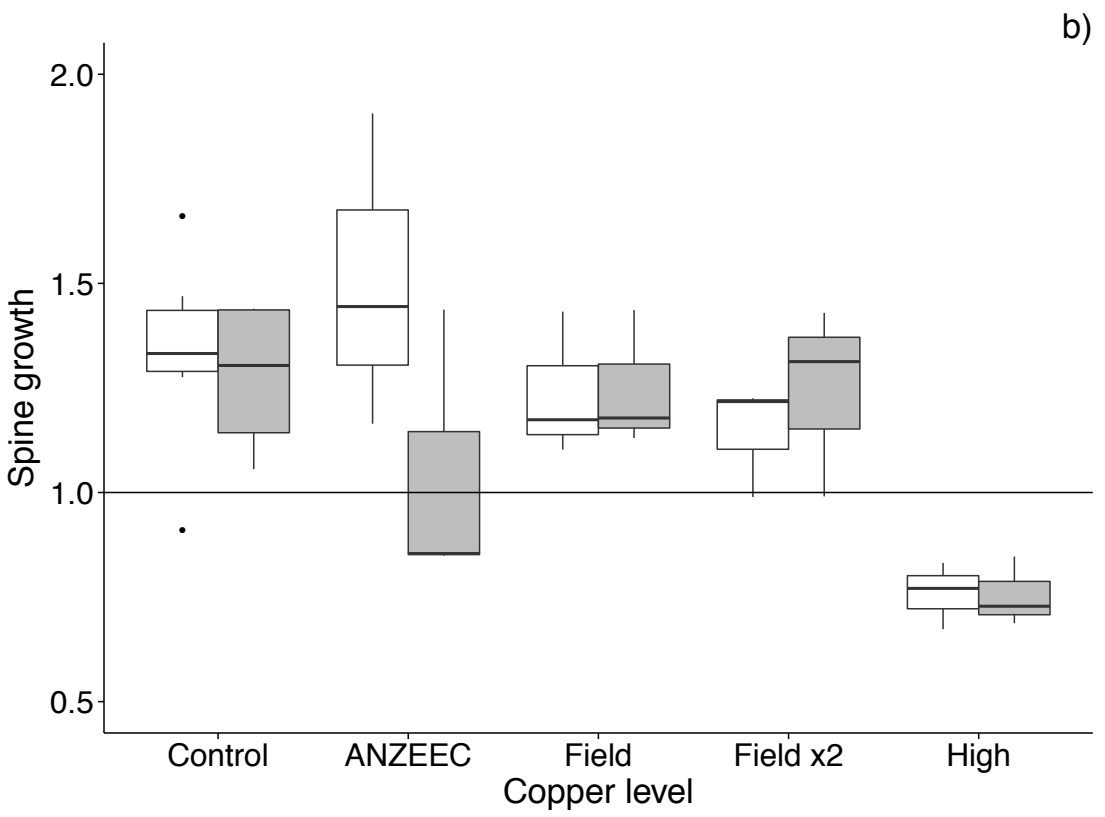

Figure 3.3: Effect of level and timing of copper exposure during larval development on Evechinus chloroticus (a) radial growth and (b) spine growth rate at $25 \mathrm{~d}$ post-settlement. Growth rate was expressed as the ratio of size at $25 \mathrm{~d}$ post-settlement to size at $8 \mathrm{~d}$ post-settlement. Boxplots represent medians and quartiles. Horizontal black line marks the null growth ratio; values above the line represent positive growth, values below represent negative growth. Note the difference in scale on the y-axes.

Settler spine growth followed a similar pattern to that of radial growth, however, model fit was lower with a multiple $\mathrm{R}^{2}$ of $56 \%$. Level of copper exposure was the most important factor, accounting for $83 \%$ of the explained variance (Table $3.5 \mathrm{c}$ ). Settlers exposed to High level of copper during the larval stage had a significantly lower spine growth compared to controls, with an average negative growth of $-24 \% \pm$ 7 versus a positive growth of $31 \% \pm 22$ in controls (Figure 3.3b). Settlers from the 
High treatments had, on average, a shorter spine length at $25 \mathrm{~d}$ post-settlement than at 8 d post-settlement ( $8 \mathrm{~d}: 380 \mu \mathrm{m} \pm 94,25 \mathrm{~d}: 285 \mu \mathrm{m} \pm 52$; Coefficients contrasts: $\mathrm{t}=$ 4.92, p $<0.001)$. At $25 \mathrm{~d}$, settlers from High level also had shorter spines than controls (285 $\mu \mathrm{m} \pm 52$ in High level, $334 \mu \mathrm{m} \pm 66$; Coefficient contrast: $\mathrm{t}=-2.85$, df $=30, \mathrm{p}=0.01)$. The proportion of larvae with a rudiment and larval normal development at the end of larval development were included as covariates and accounted for less than $9 \%$ of the total $\mathrm{R}^{2}$.

\subsubsection{JUVENILE PERFORMANCE}

\subsubsection{Naive juveniles}

Juvenile mortality two weeks after re-exposure to copper was less than $8 \%$ in controls and was not different between juveniles exposed for the first time to copper (Naive group) and juveniles never exposed to copper (controls) (ANOVA: $\mathrm{F}_{(1,7)}<0.001, \mathrm{p}=$ 0.99; Figure 3.4). Radial growth was lower in Naive juveniles than controls (ANOVA: $\left.F_{(1,7)}=9.26, p=0.02\right)$. Naïve juveniles had a near null growth of $-8 \% \pm 14$ compared with a positive growth of $15 \% \pm 7$ in controls (Figure 3.5a). Spine growth in control and Naive groups was not significantly different $\left(\right.$ ANOVA: $F_{(1,7)}=1.08, p$ $=0.33$ ). Similarly, there was no significant difference in normal development between Naive and control groups (Wilcoxon test: $\mathrm{W}=20, \mathrm{p}=0.22$ ). 


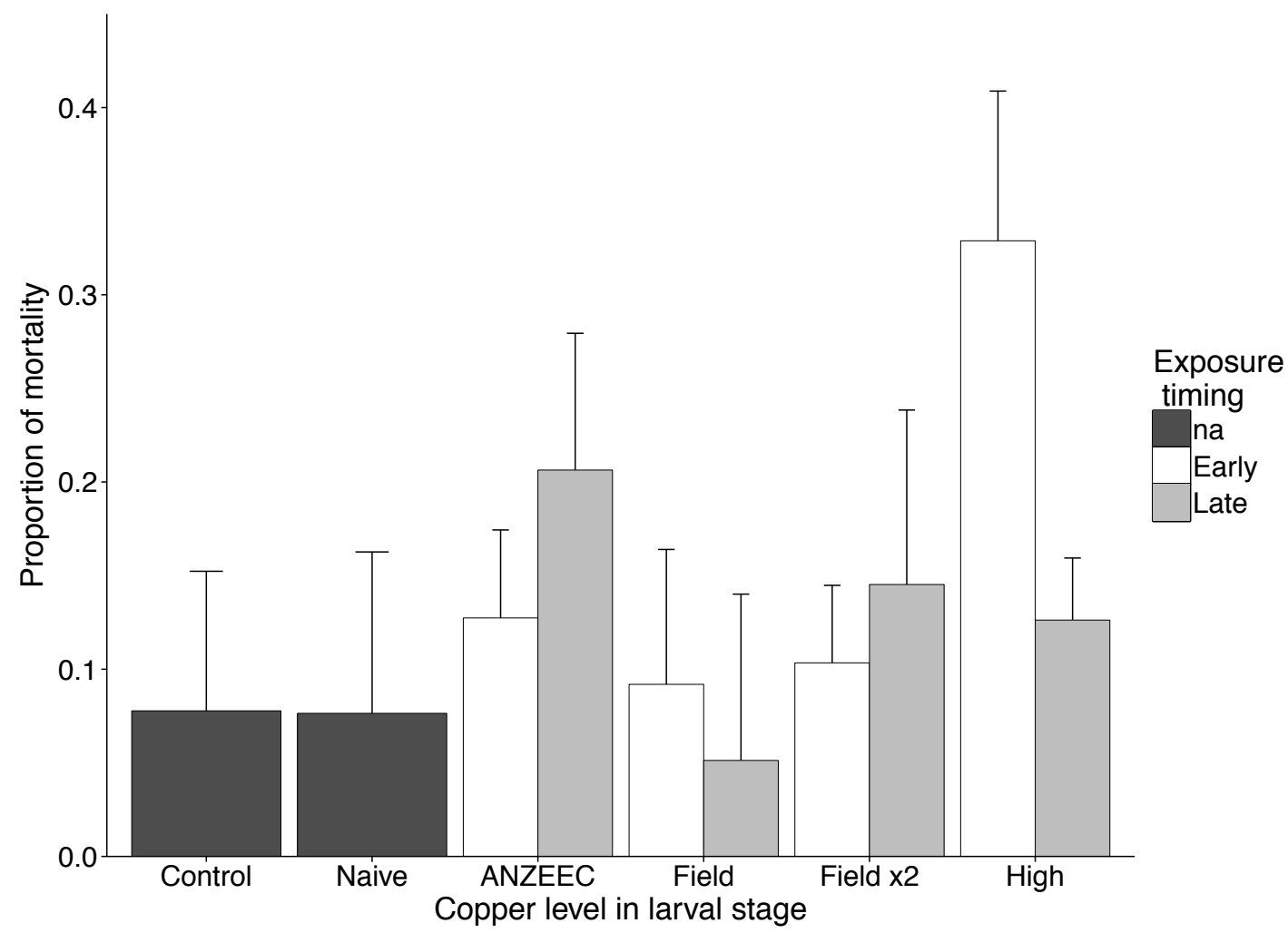

Figure 3.4: Effect of copper exposure during larval development on juvenile Evechinus chloroticus mortality after subsequent exposure to $10 \mu \mathrm{g} / \mathrm{L} \mathrm{Cu}$ at $25 \mathrm{~d}$ post-settlement. Juveniles in control group were never exposed to copper. Juveniles in Naive group were exposed to copper for the first time as juveniles. White bars represent individuals exposed early during larval development (4 d postfertilisation); grey bars represent individuals exposed late during larval development (11 d postfertilisation). Error bars represent the standard deviation $(\mathrm{N}=3)$. 


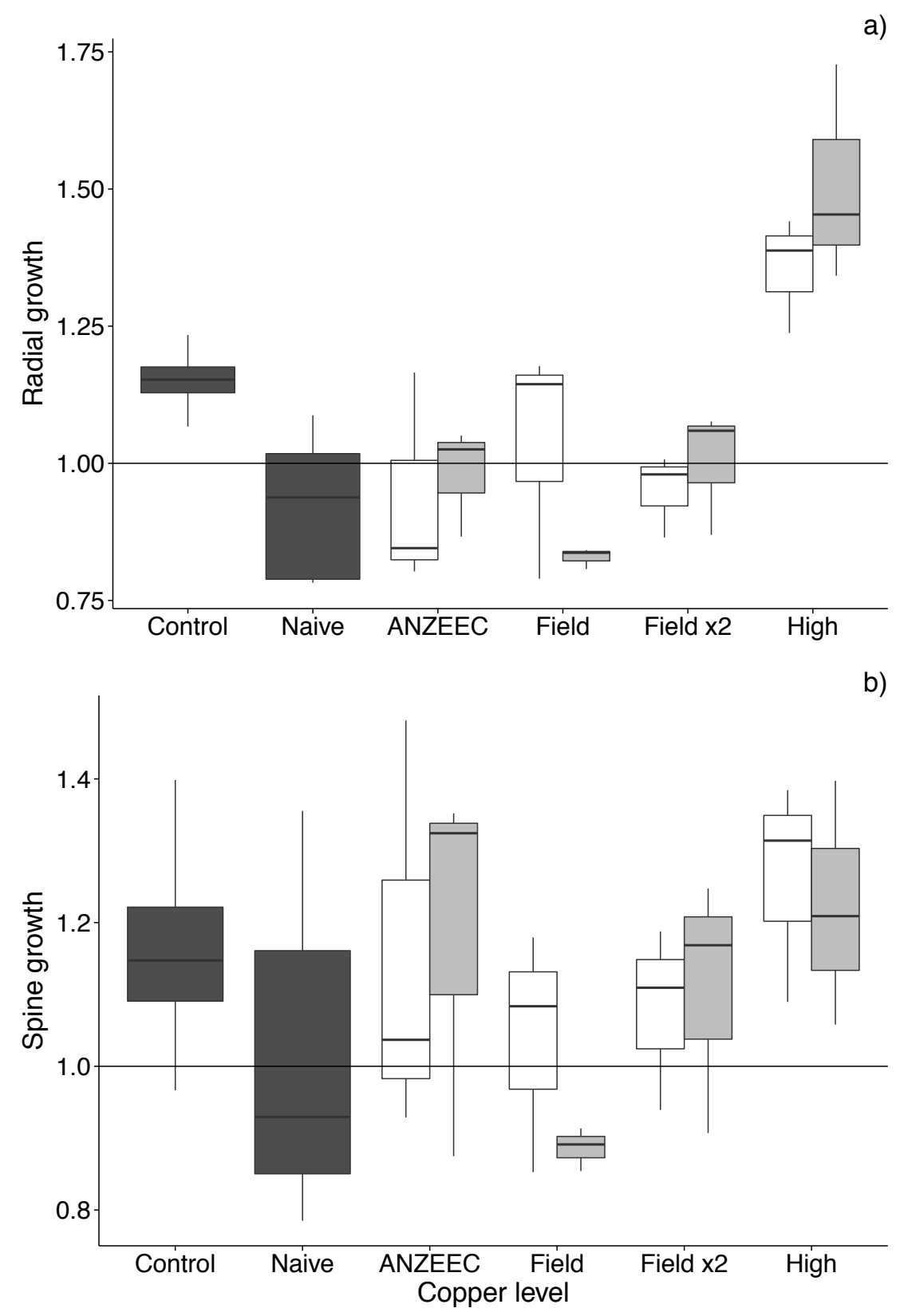

a)

Figure 3.5: Effect of copper exposure during larval development on juvenile Evechinus chloroticus growth, both of (a) radial growth and (b) spine growth, after subsequent exposure to $10 \mu \mathrm{g} / \mathrm{L} \mathrm{Cu}$ at 25 d post-settlement. Juveniles in the control group were never exposed to copper. Juveniles in the 'Naive' group were exposed to copper for the first time as juveniles. Horizontal black line marks the null growth ratio; values above the line represent positive growth, values below represent negative growth. Note the difference in scale on the y-axes.

\subsubsection{Juveniles previously exposed to copper as larvae}

For juveniles that had been previously exposed to copper during the larval stage, mortality was influenced mainly by level of copper exposure ( $76 \%$ of the explained variance, multiple $\mathrm{R}^{2}=45 \%$; Table 3.6a). Mortality was higher in juveniles that had 
been exposed to ANZEEC and High levels of copper, but not for those exposed to Field and Field $\mathrm{x} 2$ levels (ANZEEC level: $\mathrm{t}=2.16, \mathrm{p}=0.04$, High level: $\mathrm{t}=2.18, \mathrm{p}=$ 0.04; Figure 3.4). Mortality was more than four times higher for juveniles that had been exposed to High level of copper early during larval development $(33 \% \pm 8$ in Early High vs. $8 \% \pm 9$ in Naïve). Mortality decreased with rudiment size and larval size, each explained 10 and $14 \%$ of the explained variability, respectively.

Table 3.6: Effect of larval experience on Evechinus chloroticus juveniles (A) mortality and (B, C) growth two weeks after re-exposure to copper. All variables were analysed using ANCOVAs on linear models. Settler survival was square-root arcsin transformed to meet ANCOVA assumptions. Significant effects $(\mathrm{p}<0.05)$ are highlighted in bold. $F$-ratios are calculated from Type II SS.

\begin{tabular}{lllll}
\hline Source & df & SS & $\boldsymbol{F}$ & $\mathbf{p}$ \\
\hline (A) Juvenile mortality & & & 4.01 & $\mathbf{0 . 0 0 6}$ \\
Copper level & 4 & 0.39 & 5.83 & $\mathbf{0 . 0 2}$ \\
Rudiment size & 1 & 0.12 & 4.87 & $\mathbf{0 . 0 4}$ \\
Larval size & 1 & 0.10 & & \\
Residuals & 22 & 0.45 & 14.7 & $\mathbf{0 . 0 0 1}$ \\
\hline (B) Radial growth & & & 2.41 & 0.14 \\
Copper level & 4 & 1.12 & 2.48 & 0.13 \\
Settler density & 1 & 0.05 & & \\
Larval size & 1 & 0.05 & & 0.11 \\
Residuals & 22 & 0.42 & 2.12 & \\
\hline (C) Spine growth & & & & \\
Copper level & 4 & 0.30 & 0.84 & \\
Residuals & 24 & & & \\
\hline
\end{tabular}

Radial growth of juveniles was significantly affected by the level of copper exposure during larval development, with a high model fit of 74\% (Table 3.6b). Juveniles exposed to High level of copper during the larval stage had a four-fold higher growth rate two weeks after subsequent copper exposure $(43 \% \pm 16$ growth in High level $v s$. $9 \% \pm 13$ in Naive juveniles; Contrasts: $t=6.24, p<0.001$; Figure 3.5a). Radial length at $40 \mathrm{~d}$ post-settlement was not significantly different between copper levels (twoway ANOVA on mixed effect model; $\mathrm{Chi}^{2}=9.53, \mathrm{df}=5, \mathrm{p}=0.09$ ), timing of exposure $\left(\mathrm{Chi}^{2}=0.32, \mathrm{df}=1, \mathrm{p}=0.57\right)$, or their interaction $\left(\mathrm{Chi}^{2}=10.64, \mathrm{df}=5, \mathrm{p}=\right.$ 0.06; Figure 3.6a and b). Spine growth, on the other hand, was unaffected by copper exposure or larval history (Figure 3.5b). The best model included copper level but differences between groups were non-significant (Table 3.6c). 

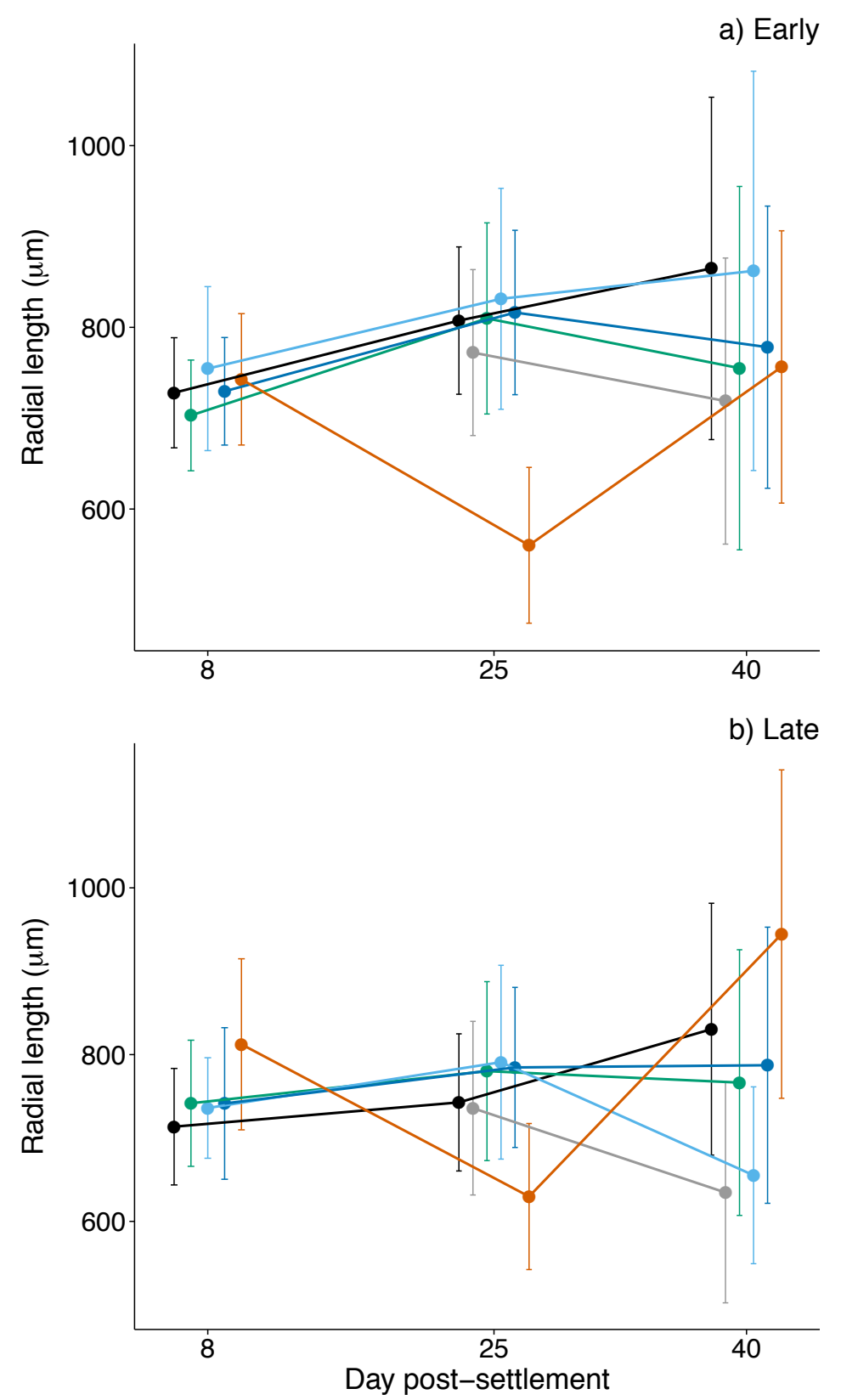

Cu level

- Control

- Naive

- ANZECC

$\rightarrow$ Field

$\rightarrow$ Field x2

$\rightarrow-$ High

Figure 3.6: Evechinus chloroticus radial length from 8 to $40 \mathrm{~d}$ post-settlement, showing the latent effects of copper exposure (a) early and (b) late during the larval stage on settler size. All settlers (except controls) were exposed to copper at $25 \mathrm{~d}$ post-settlement. Error bars represent the standard deviation $(\mathrm{N}=3)$.

Normal juvenile development was high in all containers, with most juveniles having a regular body shape (91\% to $100 \%$ ), and was unaffected either by juvenile re-exposure to copper or by larval traits and life history (best model was the null model, KruskalWallis test on copper level: $\mathrm{Chi}^{2}=0.37, \mathrm{df}=4, \mathrm{p}=0.98$ ). 


\subsection{DISCUSSION}

My study shows that short exposure to low concentrations of copper has complex latent impacts on E. chloroticus juvenile performance, visible only from $8 \mathrm{~d}$ postsettlement, and that it especially affects juvenile resistance to further copper exposure.

\subsubsection{LATENT EFFECTS OF LARVAL EXPOSURE TO COPPER ON SETTLERS}

Successful settlers were larger and had longer spines relative to body size when they had been exposed to the highest concentration of copper as larvae. However, this positive effect at settlement was cancelled by negative subsequent growth. Settlers that had been exposed to the highest copper concentration both early and late during larval development dramatically decreased in both body size and spine length between $8 \mathrm{~d}$ and $25 \mathrm{~d}$ post-settlement. As a result, at $25 \mathrm{~d}$ post-settlement, settlers that had been in the High copper level groups, were substantially smaller than controls.

Juveniles were not individually followed during this experiment and thus a decrease in average size may be due to selective mortality of larger individuals. However, the reduction in average size was large (24\%), with very little mortality (less than $5 \%$, corresponding to an average of three individuals per container) suggesting that settlers had actually shrunk. Shrinkage in test diameter of adult sea urchins as the result of food limitation has been reported for some species, including E. chloroticus (Dix 1972, Levitan 1988, Constable 1993). In the current study, food abundance in settlement containers was not directly measured, however a broad estimation of benthic diatom cover was recorded and no difference was noted between treatments. In addition, benthic coverage appeared more than sufficient for grazing pressure (i.e. well developed brown film with sparse grazing tracks) and almost all settlers had visibly full guts at $25 \mathrm{~d}$ post-settlement. Furthermore, growth was not related to settler density, as would be expected if food limitation was a factor. This study provides the first evidence that test shrinkage in urchins might occur as a result of environmental stressors other than food limitation. Furthermore, for these very young juveniles it is a latent effect of larval experience, not their current experience as is the case for food 
limitation. However, further experimental work following individual settlers would be needed to confirm this pattern.

While there was no difference in settler survival for those from different larval copper concentrations in my experimental setting, growth impairment is likely to result in higher subsequent mortality due to predation in the field. Indeed, young juveniles in many benthic species are thought to be the most at risk of predation (Hunt \& Scheibling 1997). Predators of juvenile urchins typically include crabs, demersal fish and sea stars (Hunt \& Scheibling 1997, Clemente et al. 2013). Although little is known about predation patterns on small juveniles due to inherent difficulties in studying highly cryptic early life stages, Clemente et al. (2013) showed that the smallest Strongylocentrotus purpuratus juveniles tested (5 - $14 \mathrm{~mm})$ were more than three times more likely to be eaten by crabs than larger juveniles, regardless of predator size. It has been suggested that juvenile urchins may reach an threshold size at which the predation rate dramatically decreases (Menge \& Sutherland 1976) or at which they may start feeding on macroalgae thus substantially increasing their growth rate (Rowley 1990). Any delay in reaching this escape size would therefore have a strong impact on a juvenile's chance of survival or growth, thus affecting population dynamics and adult abundance (Ebert 1983, Underwood \& Fairweather 1989). Furthermore, if the observed negative growth was due to shrinkage, then juveniles may also be in poorer body condition as was observed for shrinking Heliocidaris erythrogramma (Constable 1993), and thus be less likely to survive in the field.

Very few studies have followed the impact of copper on long-lived benthic invertebrates for as long after settlement as in this study (6 weeks post-settlement). Indeed most studies on pollutants are typically either short-term assays (days) or end shortly after settlement. However, Ng \& Keough (2003) reported a dramatic decrease in survival and growth following larval copper exposure in bryozoans visible only weeks to months post-settlement. In contrast, no carry-over effects were observed in growth or survival of juvenile sponges up to six months after larval copper exposure (Cebrian \& Uriz 2007). 
In sea urchins, the early days post-settlement are arguably the lesser known, due to difficulties in finding highly cryptic, small individuals in the field and the time necessary to raise them from larvae in the laboratory. However, latent growth impairment following exposure to stressors during embryonic or larval development has been documented in various invertebrate species for low food availability (Miller \& Emlet 1999, Phillips 2002, 2004, Pechenik 2006), ocean acidification (Gobler \& Talmage 2013, Lane et al. 2013), and other environmental stressors (Pechenik et al. 2001, Fischer \& Phillips 2014). The mechanisms underlying latent and carry-over effects in marine invertebrates are not well understood, but Pechenik et al. (1998) suggested an impairment in gene transcription while Hoare et al. (1995) suggested that copper exposure could reduce larval lipid reserves, thus impairing growth postsettlement. In my study, the duration of exposure was only two days and it is unclear whether the above mechanisms could have been triggered by such a short exposure. All latent effects reported occurred only at the highest copper concentration. However, this concentration is environmentally realistic (Table 1.1).

\subsubsection{RESISTANCE HYPOTHESIS}

Having been exposed to copper as larvae, juveniles were less resistant to a subsequent re-exposure. Mortality increased dramatically, in particular for those juveniles that had been exposed to a high copper concentration during early larval development, but also to a lesser extent in those exposed to the ANZEEC level. This is one of the first studies that demonstrate the effect of further exposure to a pollutant in later life stages. A recent study showed in increase in sensitivity to cadmium in juvenile freshwater snails, Physa pomilia, previously exposed to the same stressor during embryonic development (Kimberly \& Salice 2014). In sea urchin, similar results have been observed for ocean acidification in Strongylocentrotus droebachiensis, where juveniles in elevated $\mathrm{pCO} 2$ had a higher mortality rate only when they had also been raised in elevated pCO2 as larvae (Dupont et al. 2013).

On the other hand, surviving juveniles that had been previously exposed to the highest concentration of copper as larvae, had on average a higher radial growth rate when re-exposed than did naïve juveniles that had never been exposed to copper 
before, and juveniles from all other groups. Faster growth arising from larval exposure to the highest concentration of copper may be explained by selective settler mortality in favour of fast growing juveniles, or increased mortality after re-exposure may have decreased conspecific competition. Patterns of lower survival but faster growth following copper stress in a previous life stage have been observed before for mussels (Hoare et al. 1995). Authors attributed this pattern to intra-specific competition, however as mentioned previously, there was no evidence of conspecific competition in my settlement containers. The selective mortality hypothesis is supported by a decrease in size heterogeneity in treatments with exposure early during larval development, where juvenile mortality was the highest, but not treatments with exposure later during larval development. It is important to note that, while growth was faster at the highest copper concentration after re-exposure, juvenile final size was no different from controls due to the strong growth impairment that occurred in this group shortly after settlement.

\subsubsection{TIMING OF LARVAL EXPOSURE TO COPPER}

My previous experiment showed 50\% severe abnormality (EC50) at $5.4 \mu \mathrm{g} / \mathrm{L} \mathrm{Cu}$ for E. chloroticus when exposed during the critical life stage period of 1 - 3 d postfertilisation (Table 2.4). In the current study, both early (4 - $6 \mathrm{~d}$ post-fertilisation) and late (11 - $13 \mathrm{~d}$ post-fertilisation) timing of exposure produced no direct effect on either mortality, growth or abnormal development, even at the highest copper concentration of $10.4 \mu \mathrm{g} / \mathrm{L}$. The duration of exposure in the two experiments was different: two days in the current study against three days in the previous chapter, and probably contributed, at least in part, to the higher sensitivity observed in the previous experiment. However, it is likely that larvae are also less sensitive to copper outside of the early pluteus formation timeframe. This is consistent with the commonly accepted critical life stage of early pluteus formation for sea urchins (US EPA 2002b, ASTM 2012).

The difference between early and late timing of exposure was important for many, but not all variables. Juveniles exposed early during larval development were more vulnerable to a subsequent copper exposure than those exposed later. On the other 
hand, individuals exposed early during the larval stage seemed to fare slightly better, or similar, after settlement than those exposed late during larval stage in the absence of a further exposure. Vulnerability of younger larvae was expected, as similar results were found for sediment stress on E. chloroticus (Phillips \& Shima 2006).

Surprisingly however, young juveniles were more vulnerable than larvae to a first copper exposure. Indeed, a short pulse of the highest concentration copper to naive juveniles impaired radial growth, while no direct effect of copper on larval size or survival was observed. Copper toxicity has never been assessed for young juvenile urchins. Comparison of sensitivity to stressors between life stages of the sea urchin usually includes all the stages of larval development until, or shortly after, metamorphosis, but not young settlers and juveniles (Kobayashi 1980, King \& Riddle 2001).

These findings confirm that E. chloroticus is sensitive to copper during the whole larval stage as well as shortly after settlement, although severity of impact decreases with larval age. Therefore, punctuated pollution events such as runoff are likely to affect, to some extent, all larval and young juvenile cohorts that occur in locations where they are common, such as near river mouths or in harbours.

Besides exposure to copper, various larval traits significantly impacted subsequent performance in settlers and juveniles. Rudiment size at the end of the larval stage seems to be the best predictor of settler performance, significantly influencing settlement success, body size at settlement, settler survival and growth. This suggests that stress affecting rudiment formation may have long lasting impacts on settler performance. Larval body size at the end of the larval stage also influenced spine size at settlement and settler growth. This provides further evidence that 'metamorphosis is not a new beginning' (Pechenik et al. 1998) and that larval traits have a continued influence on performance in later life stages. 


\subsubsection{CONCLUSION}

My results show that even a short pulse of copper during larval development may have long lasting effects, especially on settler growth and resistance to further stress. When larvae are vulnerable to a stressor throughout their whole larval development, as was the case here, adult populations close to the source of larval stress not only produce few recruits but also have a low chance of acquiring recruits dispersed from populations further from the stressor source (Shima et al. 2010). Therefore, transient larval exposure, as in a river plume, may have a strong impact on recruitment and local population persistence. Decreased resistance to further stress is of special importance as larvae exposed to pollution are likely to settle in a polluted area; this is especially the case for species with low dispersal. On the other hand, selective mortality after subsequent copper exposure might mitigate the impact at the population level, as only the fitter, faster growing juveniles would survive. Only the highest level of copper $(10.4 \mu \mathrm{g} / \mathrm{L})$ produced latent effects after a single exposure, but even very low level approaching ANZEEC water quality criterion $(2.3 \mu \mathrm{g} / \mathrm{L})$ produced a decreased resistance to further copper exposure. This study highlights the importance of evaluating long-term effect of toxicants, as no strong impact was seen until 8 d post-settlement. 



\title{
CHAPTER 4
}

\section{Separate and combined impacts of waterborne and dietary copper intake on Evechinus chloroticus early life stages}

\begin{abstract}
Most marine toxicity studies focus on waterborne pollutants, while organisms living in a polluted area are likely to be exposed to contaminated food as well. This study investigated the toxic effect of environmentally realistic levels of copper from the diet versus waterborne exposure, on larvae of the sea urchin Evechinus chloroticus. Larvae were exposed to two levels of copper: $1.3 \mu \mathrm{g} / \mathrm{L}$ or $10 \mu \mathrm{g} / \mathrm{L}$ via one of three copper sources: dissolved copper, algal diet (Dunaliella tertiolecta) cultured at these copper levels, or in a combined treatment. In addition, the effect of pulse (4 days exposure) vs. chronic exposure was evaluated. In chronic exposure, the experimental design was fully crossed between copper source and copper level. In pulse exposure, only the highest copper level was used for all copper sources. Sea urchins were monitored for $38 \mathrm{~d}$ post-settlement to investigate carry-over effects. Detrimental effects observed during larval development included a decrease in normal development at the highest copper level, and a delay in development (30\% larvae with a rudiment across all copper levels vs. $65 \%$ in controls) with waterborne exposure. Settlement success was strongly impaired in most treatments $(25-55 \%$ of controls) and was $30 \%$ lower in dietary than in waterborne treatments. Surviving settlers exposed to dietary copper as larvae were on average $30 \%$ smaller than
\end{abstract}


controls, while those exposed to dissolved copper were $60 \%$ larger. Overall toxic effects on larvae were stronger with waterborne exposure, but dietary exposure elicited stronger carry-over effects. Pulse exposure was more toxic than chronic exposure when copper was present in the diet but not when present in water only, suggesting that acclimation may occur; however this is dependent on the route of copper intake. Toxic effects occurred at a level of copper commonly found in the field, indicating the importance of considering pollutant intake from the diet by larvae.

\subsection{INTRODUCTION}

In polluted coastal areas, marine organisms are exposed not only to contaminated water but also, in most cases, to contaminated food. However, most toxicity studies focus primarily on the impact of dissolved waterborne pollutants (Hunt \& Anderson 1993, US EPA 2002a). Traditionally, the dietary route of uptake has been disregarded as of little importance compared to the dissolved route, except for a very few pollutants, such as mercury, for which biomagnification occurrs (i.e. metal burden increases with trophic level). Most of these early studies were conducted on fish, particularly salmonids (reviewed by Meyer et al. 2005).

During recent years, the importance of the dietary route for the uptake of metal contaminants has become well established (Meyer et al. 2005, Ahn et al. 2009, Bielmyer et al. 2012). Dietary intake can be a dominant pathway for a variety of metals, especially in invertebrates (Reinfelder \& Fisher 1991, Wang \& Fisher 1998, Griscom et al. 2002). Furthermore, different intake routes also affect the distribution of metals in tissues (Fisher et al. 1996, Hook \& Fisher 2001b, Campbell et al. 2005). For example, in mussels waterborne metals tend to accumulate in the shell, while metals taken up from food are deposited in the soft tissue (Fisher et al. 1996). Given the difference in accumulation patterns within an organism, the toxic effect of dietary intake of metals is likely to be different and may not be predicted from dissolved metal toxic effects. However, most studies have focused on the mechanisms of metal intake and few have investigated the actual toxicity of metals from contaminated diet in marine invertebrates, and those that have are generally on adults (Hook \& Fisher 
2001a, De Schamphelaere et al. 2004, Bielmyer et al. 2006). These studies have generally found a stronger response to metals taken up from food than to waterborne metals, with effective concentrations (EC) up to two orders of magnitude lower in dietary assays. This highlights the risk of underestimating the toxic effect of a pollutant when only waterborne effects are evaluated.

Invertebrate larvae are commonly used in toxicity tests due to their high vulnerability to environmental stressors, including metals (Anderson et al. 1994, Fitzpatrick et al. 2008). Furthermore, stressors encountered early in life may have long lasting effects on an individual's performance later in life, known as carry-over effects (Pechenik et al. 1998, 2001, Gimenez et al. 2004). However, only one study of dietary toxicity has been conducted on planktotrophic (i.e. feeding) larvae (Gambardella et al. 2014) and none have investigated potential carry-over effects in later life-stages. Gambardella et al. (2014) found a decrease in survival (as low as 30\% of controls) after dietary exposure to metal nanoparticles in the larvae of the sea urchin Paracentrotus lividus. However, no direct comparison with waterborne toxicity was provided.

Sea urchin larvae are known to be strongly affected by copper exposure, with effective concentrations based on waterborne exposure often approaching water quality criteria (WQC; Tables 2.4 and 2.6). If sea urchin larvae are more severely affected by dietary copper than by waterborne exposure, current WQC may fail to protect these species. Evechinus chloroticus, a sea urchin endemic to New Zealand, is extremely sensitive to copper during its larval stage, with an EC10 of $2.1 \mu \mathrm{g} / \mathrm{L}$ (Table 2.4) while current WQC in New Zealand (WQC) for copper are set at $1.3 \mu \mathrm{g} / \mathrm{L}$ for 95\% species protection and $3.0 \mu \mathrm{g} / \mathrm{L}$ for $90 \%$ species protection (ANZECC 2000).

Here I investigated the separate and combined impacts of dietary and waterborne copper, by exposing E. chloroticus larvae to dissolved copper and to algal food (Dunaliella terticola) cultured at environmentally relevant copper concentrations. My aims were to: (1) evaluate the direct and carry-over effects of dietary copper; (2) compare the effects of waterborne and dietary uptake; and (3) to establish whether WQC are appropriate for E. chloroticus protection when the dietary route is taken 
into consideration. I also compared the effect of pulse (4 days) vs. chronic exposure, both for the dietary and waterborne routes.

\subsection{METHODS}

\subsubsection{BROODSTOCK AND SPAWNING}

Adult E. chloroticus $(8-20 \mathrm{~cm}$ test diameter) were collected from Kau Bay, Wellington $\left(41.2882^{\circ} \mathrm{S}, 174.8326^{\circ} \mathrm{E}\right)$ in November 2012 . A total of 50 urchins were kept at Victoria University Coastal Ecology Laboratory (VUCEL) in two 50 L tanks with flow-through raw seawater. VUCEL's seawater is pumped $\sim 5 \mathrm{~m}$ from shore in the Taputeranga Marine Reserve. Raw seawater receives no treatment, while filtered seawater (FSW) is pre-filtered $(15 \mu \mathrm{m})$ and then filtered through a $0.2 \mu \mathrm{m}$ paper cartridge. Adult E. chloroticus were fed twice a week with native kelp (Macrocystis pyrifera) and/or commercial feed (ABMAX, E.N. Hutchinson Ltd, Auckland, NZ). The experiment was run from February to April 2013. E. chloroticus larvae were the product of multiple parents (two males, four females). The spawning and fertilisation protocol is described in section 3.2.1.

\subsubsection{EXPERIMENTAL DESIGN}

Larvae were exposed to copper in one of three ways (copper source): via dissolved copper in water ('Water' treatment), via algal food cultured in copper-enriched medium for approximately two weeks ('Diet' treatment), or both via food and water ('Diet + Water' treatment). Two concentrations of copper were used (copper level): ANZECC $(1.3 \mu \mathrm{g} / \mathrm{L}$, nominal concentration) and High $(10 \mu \mathrm{g} / \mathrm{L})$, plus a control. In addition, two types of exposure to copper were used: a chronic exposure lasting throughout the larval development, and a 4-day pulse exposure. In the dietary treatments, a pulse exposure means that larvae were fed copper-enriched algae during $4 \mathrm{~d}$. The algal cultures themselves were always cultured chronically in copper (Appendix C). The experimental design was fully crossed between copper source and copper level with chronic exposure, but with pulse exposure only the High copper level was used for all copper sources (Table 4.1). 
Table 4.1: Experimental design. Chronic exposure started at $4 \mathrm{~d}$ post-fertilisation and lasted through the larval development. Pulse exposure lasted for 4 days midway through larval development ( 8 to 12 d post-fertilisation).

\begin{tabular}{lll}
\hline Source of copper & \multicolumn{2}{c}{ Copper concentration } \\
& ANZECC $(1.3 \mu \mathbf{g} / \mathbf{L})$ & High $(\mathbf{1 0} \mu \mathbf{g} / \mathbf{L})$ \\
\hline Diet & Chronic & Chronic and Pulse \\
Diet + Water & Chronic & Chronic and Pulse \\
Water & Chronic & Chronic and Pulse \\
\hline
\end{tabular}

The actual copper concentration present in the algae and approximate copper ration delivered per feed is shown in Table 4.2. Detailed methods for algal culture and metal bioaccumulation in D. tertiolecta are shown in Appendix C. In the chronic exposure, larvae received a copper spike or were fed contaminated algae every 2 - 3 days from three days post-fertilisation to settlement; while in pulse exposure, a single 4-day pulse was administered midway through larval development $(8-12 \mathrm{~d}$ postfertilisation). Each of the treatments, including the controls, were done in triplicate.

Table 4.2: Copper concentration in water and in diet used in larval assays. Dissolved concentrations are measured concentrations in water (filtered through a $0.45 \mu \mathrm{m}$ mesh). Dissolved copper in control seawater was measured four times between 2010 and 2014, and the range of concentrations is reported. Other dissolved concentrations were measured once in 2013. Metal in algae is the total metal accumulated in Dunaliella tertiolecta from two week-old cultures $(\mathrm{N}=3)$. Ration per feed is the total metal present in a feed (ng / 8000 algal cells).

\begin{tabular}{lllll}
\hline Level & $\begin{array}{l}\text { Nominal } \\
\text { concentration } \\
(\mu \mathrm{g} / \mathrm{L})\end{array}$ & $\begin{array}{l}\text { Dissolved } \\
\text { concentration } \\
(\mu \mathrm{g} / \mathrm{L})\end{array}$ & $\begin{array}{l}\text { Metal in } \\
\text { algae }(\mu \mathrm{g} / \mathrm{g} \\
\text { dry weight) }\end{array}$ & $\begin{array}{l}\text { Approx. ration } \\
\text { per feed } \\
(\mathrm{ng}) \pm \mathrm{sd}\end{array}$ \\
\hline Control & 0 & $<0.5-1.2$ & 17.5 & $0.011 \pm 0.010$ \\
ANZECC & 1.3 & 2.3 & 66.3 & $0.042 \pm 0.006$ \\
High & 10 & 10.4 & 351.3 & $0.225 \pm 0.006$ \\
\hline
\end{tabular}

Metal stock solutions were made from reagent grade copper sulphate $\left(\mathrm{CuSO}_{4} .5 \mathrm{H}_{2} \mathrm{O}\right)$. Concentrations given are nominal concentrations, but actual dissolved copper concentrations in treatments were measured in January 2013 using the same experimental conditions without urchin larvae as described in section 3.2.2 (Table 4.2). The ANZECC level was based on the current recommended water quality trigger value for 95\% species protection (ANZECC 2000). The High level was chosen as a realistic level occurring in moderately polluted water, such as near large cities (Table 1.1). 


\subsubsection{LARVAL ASSAYS}

Fertilised eggs were first cultured in a 4-L glass jar at a density of 30 embryos $/ \mathrm{ml}$ for three days, before being transferred to 2-L glass jars at a density of 1 larva/ml. Details of the experimental set-up are provided in section 3.2.3. The temperature was $16.5^{\circ}$ $\mathrm{C} \pm 1$ throughout the whole experiment. Larvae were fed after each water change with D. tertiolecta from a clean culture or a copper enriched culture, depending on treatment, at a concentration of 8000 cells $/ \mathrm{ml}$. Algal stocks were rinsed thoroughly by three successive centrifugations (1201 g for $5 \mathrm{~min}$ ) and re-suspensions in clean FSW, before being fed to the larvae to remove traces of metal unabsorbed by algae.

Jars in the Diet and Diet + Water treatments, including both chronic and pulse exposure, were sampled at 15 and $24 \mathrm{~d}$ post-fertilisation, and jars in the Water treatment were sampled 16, 23 and $29 \mathrm{~d}$ post-fertilisation. Controls were sampled at 15 and $23 \mathrm{~d}$ post-fertilisation. During sampling, the water level in each jar was lowered to $750 \mathrm{ml}$ to increase larval density and $3 \times 15 \mathrm{ml}$ aliquots were taken per jar. Jars were randomly numbered and all measurements were conducted blind with regard to the treatment classification. The number of live larvae was counted in each aliquot using a dissecting microscope (40x magnification). Each live larva was assigned to one of nine developmental categories. The categories were the same as in Table 3.2, except that the 8 -armed pluteus category was further divided in three categories: 8-armed pluteus with no visible rudiment, pluteus with small rudiment and competent pluteus (Table 4.3). Plutei with a rudiment and 8-armed plutei were always considered as normal. While 6-armed plutei were considered as normal until day 16 (inclusive). The first ten normal larvae encountered were preserved in $40 \%$ ethanol to be photographed under a compound microscope (50x magnification). Measurements of larval body and arm lengths (average of $\mathrm{R}$ and $\mathrm{L}$ arms where possible; Table 4.3), as well as size of the juvenile rudiment in the late larval stage, were performed using the software ImageJ. 
Table 4.3: Addition of 2 new developmental categories of Evechinus chloroticus larvae: pluteus with small rudiment and competent pluteus. Arrows on pluteus with small rudiment show morphometric measurements. BL: total body length, PO: postoral arms, AL: anterolateral arms, PD: posterodorsal arms, EO: preoral arms, S: stomach, R: rudiment.

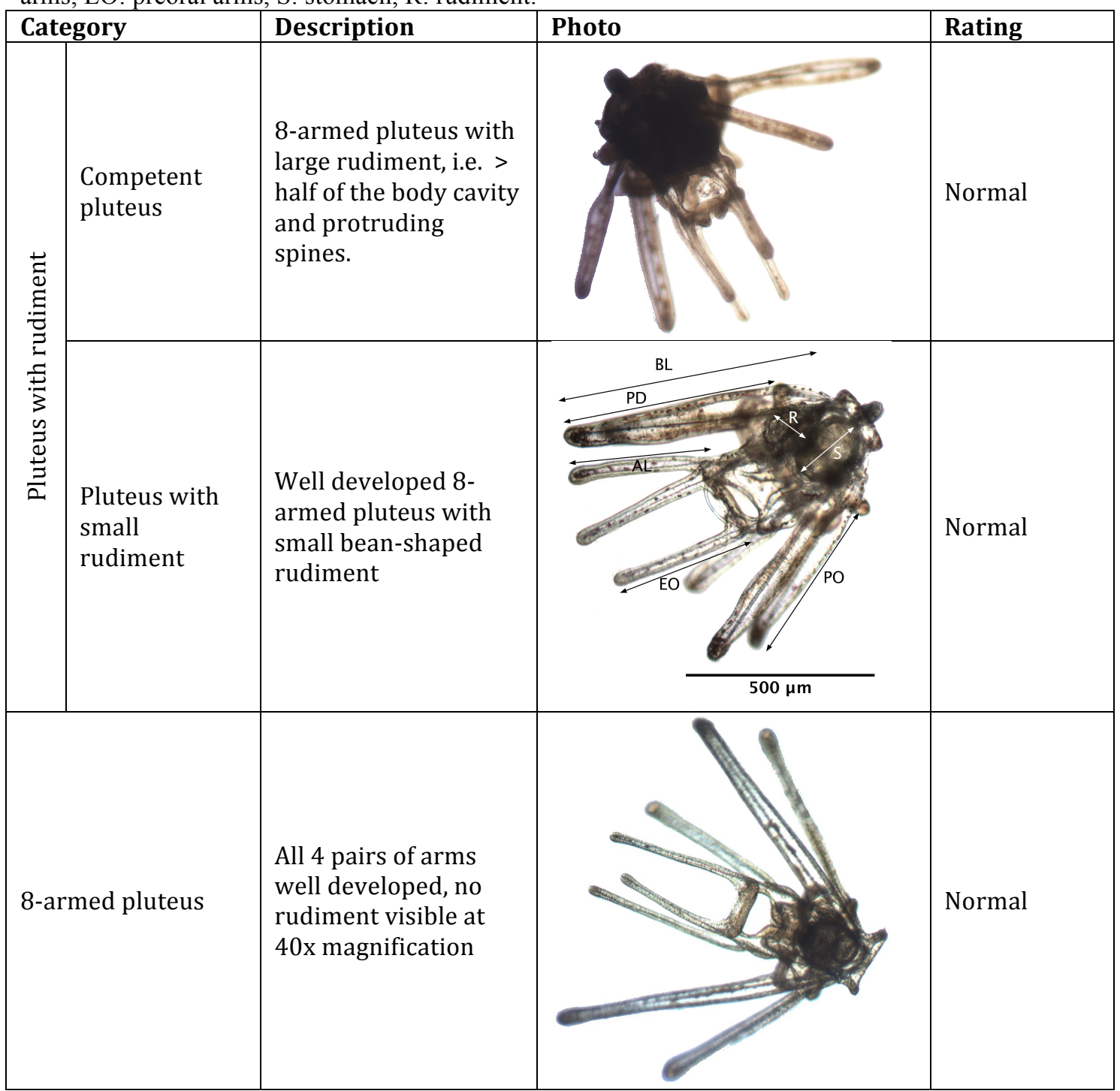

\subsubsection{SETTLEMENT}

Diet and Diet + Water treatments and controls were placed in settlement containers after 26 days of larval development. Larvae in the Water treatment appeared to be delayed and were therefore given three additional days ( $29 \mathrm{~d}$ post-fertilisation) to achieve similar development as in the other treatments (i.e. $>50 \%$ of 8 -armed plutei having a rudiment) before being transferred to the settlement containers. Details of the settlement procedure are described in section 3.2.4. Larvae were given eight days to settle, after which any remaining larvae were removed from the containers. Time 
post-settlement was counted from the first day larvae were placed in settlement containers, as many larvae settled within a day.

The total number of settlers per container was counted under a dissecting microscope (40x magnification) at 8 and $38 \mathrm{~d}$ post-settlement. All juveniles in each container were rated for normal development and were deemed as 'abnormal' when body shape was strongly irregular, or lacked spines or pigmentation (Table 3.3) when observed under a dissecting microscope (40x magnification). The first 20 settlers encountered were photographed under a dissecting microscope (25x magnification). Body diameter (radial length) and three spines were measured using the software ImageJ.

\subsubsection{STATISTICS}

All data analyses were conducted using the software R (version 3.1) with package multcomp (Hothorn et al. 2008) for pairwise comparisons and package nlme (Pinheiro et al. 2015) for mixed effects models.

\subsubsection{Larval performance}

Direct effects of copper treatments on larvae were evaluated by: (1) larval mortality rate; (2) larval normal development; (3) delayed development; (4) larval growth; and (5) larval size at the latest sampling.

Larval mortality rate was the difference in larval density divided by the initial number of larvae and time interval, to obtain the daily probability of mortality per capita early (from 4 to 15 or $16 \mathrm{~d}$ post-fertilisation) and late (from 15 or 16 to 23 or $24 \mathrm{~d}$ postfertilisation) in development. Normal larval development was the proportion of 6- and 8-armed pluteus larvae midway through development (i.e. 15 or $16 \mathrm{~d}$ postfertilisation) and the proportion of 8-armed pluteus larvae late in development (i.e. 23 or $24 \mathrm{~d}$ post-fertilisation). Mortality and normal development were analysed using repeated measures ANOVA with copper level and source of copper (Diet, Water or Diet + Water) as 'between' factors and larval stage (early, mid or late) as the 'within' factor. Both variables were square-root arcsin transformed. 
Delayed development was composed of three variables measured at 23 or $24 \mathrm{~d}$ postfertilisation: the proportion of normal larvae having reached the 8-armed pluteus stage; the proportion of 8 -armed larvae having a rudiment; and the proportion of larvae with a rudiment that were competent (Table 4.3). The effects of source of copper, copper level, and their interaction were analysed using two-way ANOVA. All three variables were square-root arcsin transformed.

Larval growth was expressed as the difference in average size per jar divided by initial size and time interval to obtain a daily growth rate. Variables were body length (BL), postoral arms (PO), anterolateral arms (AL), posterodorsal arms (PD), and preoral arms lengths (EO; Table 4.3). Average size per jar was calculated only if more than five larvae could be measured per jar for each sampling. The ANZECC copper level was removed from all arm growth analyses, as only one jar in the Diet and Diet + Water treatments was preserved well enough to take arm measurements. All growth measurements were analysed separately using two-way ANOVA and were log-transformed to meet assumptions. A Bonferroni correction was applied to control type I error rate on multiple testing (alpha $=0.01)$.

Larval size late in development was the individual larval size at 23 or $24 \mathrm{~d}$ postfertilisation. Variables were BL, PO, AL, PD, EO and rudiment size. Mixed effect linear models to account for non-independence of individual larvae within a jar were used with copper level as a fixed effect, jars as a random effect and individual larvae as residuals. Separate ANOVAs were performed on the three copper sources, as larval measurements were not taken on the same day. Assumptions were graphically checked and all variables were log-transformed.

\subsubsection{Settler performance}

Settler performance was evaluated by: (1) settlement success; (2) size at settlement; (3) survival; (4) normal development; and (5) final size at $38 \mathrm{~d}$ post-settlement.

Settlement success was expressed as the number of settlers observed $8 \mathrm{~d}$ postsettlement divided by the initial number of larvae in the containers. Settler survival was the proportion of live settlers (moving tube feet and/or spines) at $38 \mathrm{~d}$ post- 
settlement. Settler size $8 \mathrm{~d}$ post-settlement and final size were evaluated by two variables: radial length (RL) and spine/body ratio (SBR).

The effect of larval experiences on settler performance was evaluated by fitting an initial model including all of the following factors and covariates; level of copper exposure and source of copper exposure were the main factors, and larval traits at the end of the larval stage ( $24 \mathrm{~d}$ post-fertilisation for the Diet and Diet + Water treatments, $29 \mathrm{~d}$ post-fertilisation for the Water treatment) were the covariates. Larval traits were the proportion of normal larvae, larval body size, proportion of larvae with a rudiment and rudiment size. All larval traits were averaged across triplicates, as replicate jars were pooled before settlement. In addition to larval experience, two non-larval related covariates were used: initial larval density in settlement containers (initial density) for settlement success and size-at-settlement analyses; and settler density at $8 \mathrm{~d}$ postsettlement (settler density) for settler survival, normal development, and final size analyses.

The best model was selected from the initial model (full model) described above, using a stepwise regression based on AIC criterion for each settler performance variable. Best models were then analysed using ANCOVAs or mixed effect models with the selected factors and covariates, which are presented in the result section (section 4.3.2). Interactions were included only when selected in the best model. Containers 10 and 13 (both controls) were not measured at $8 \mathrm{~d}$ post-settlement and were removed from the analysis.

Settlement success and settler survival were fitted with an ANCOVA and were square-root arcsin transformed to meet model assumptions. For settler size, both variables were fitted with a mixed effect linear model with container as the random effect and individual settler as the residual. Sources of copper (i.e. Diet, Water and Diet + Water) were analysed separately for final size analyses, as not all copper levels were present for all copper source: less than five settlers could be measured at the High pulse level in the Diet and Diet + Water treatments. 
For all larval and settler ANOVAs or ANCOVAs, when copper level was significant $(p<0.05)$, a priori coefficient contrasts were used to compare copper levels against controls. If source of copper was also significant, coefficient contrasts from one-way ANOVAs were conducted on each treatment separately. For two-way ANOVAs, Fratios were calculated from Type II SS. Partial $\mathrm{R}^{2}$ for each component of the model were estimated by hierarchical partitioning (Chevan \& Sutherland 1991, Mac Nally 1996) using the hier.part package (Walsh \& Mac Nally 2013). R-squared values reported for mixed effects models were conditional $\mathrm{R}^{2}$, as described by Nakagawa \& Schielzeth (2013) and Johnson (2014), calculated using rsquared.glmer v0.2-4 function (Lefcheck \& Casallas 2014).

\subsection{RESUlts}

\subsubsection{LARVAL PERFORMANCE}

\subsubsection{Daily per capita mortality rate}

Mortality rate varied with copper level and source of copper exposure (Table 4.4a, Figure 4.1). Overall, daily mortality rate was higher for early larval stages and dropped for later stages. This pattern was reversed in both the Diet and Water High Pulse treatments where mortality rate increased as larval development progressed, and to a lesser extend for the Water ANZECC Chronic treatment. However, the mortality rate was not significantly different between copper levels and control at the early and late larval stage (Dunnett contrasts: $p>0.05$ ). 
Table 4.4: Repeated measures ANOVA of Evechinus chloroticus larval daily per capita mortality rate (A) and percent normal development (B), to test effects of copper exposure (copper level) and source of copper (source) early and late (Age) during larval development. Significant effects $(p<0.05)$ are highlighted in bold.

\begin{tabular}{lllll}
\hline Source of variation & df & SS & $\boldsymbol{F}$ & p \\
\hline (A) Daily per capita mortality rate & & & \\
Source & 2 & 0.08 & 4.39 & $\mathbf{0 . 0 2}$ \\
Copper level & 3 & 0.01 & 0.48 & 0.70 \\
Age & 1 & 0.42 & 11.02 & $\mathbf{0 . 0 0 3}$ \\
Source x Copper level & 6 & 0.08 & 1.46 & 0.23 \\
Source x Age & 2 & 0.27 & 3.56 & $\mathbf{0 . 0 4}$ \\
Copper level x Age & 3 & 0.39 & 3.35 & $\mathbf{0 . 0 4}$ \\
\hline (B) Larval normal development & & & \\
Source & 2 & 18.46 & 5.61 & $\mathbf{0 . 0 1}$ \\
Copper level & 3 & 4.15 & 0.84 & 0.48 \\
Age & 1 & 4.78 & 5.05 & $\mathbf{0 . 0 3}$ \\
Source x Copper level & 6 & 24.79 & 2.51 & $<\mathbf{0 . 0 5}$ \\
Source x Age & 2 & 3.71 & 1.96 & 0.16 \\
Copper level x Age & 3 & 31.54 & 11.11 & $<\mathbf{0 . 0 0 1}$ \\
\hline
\end{tabular}

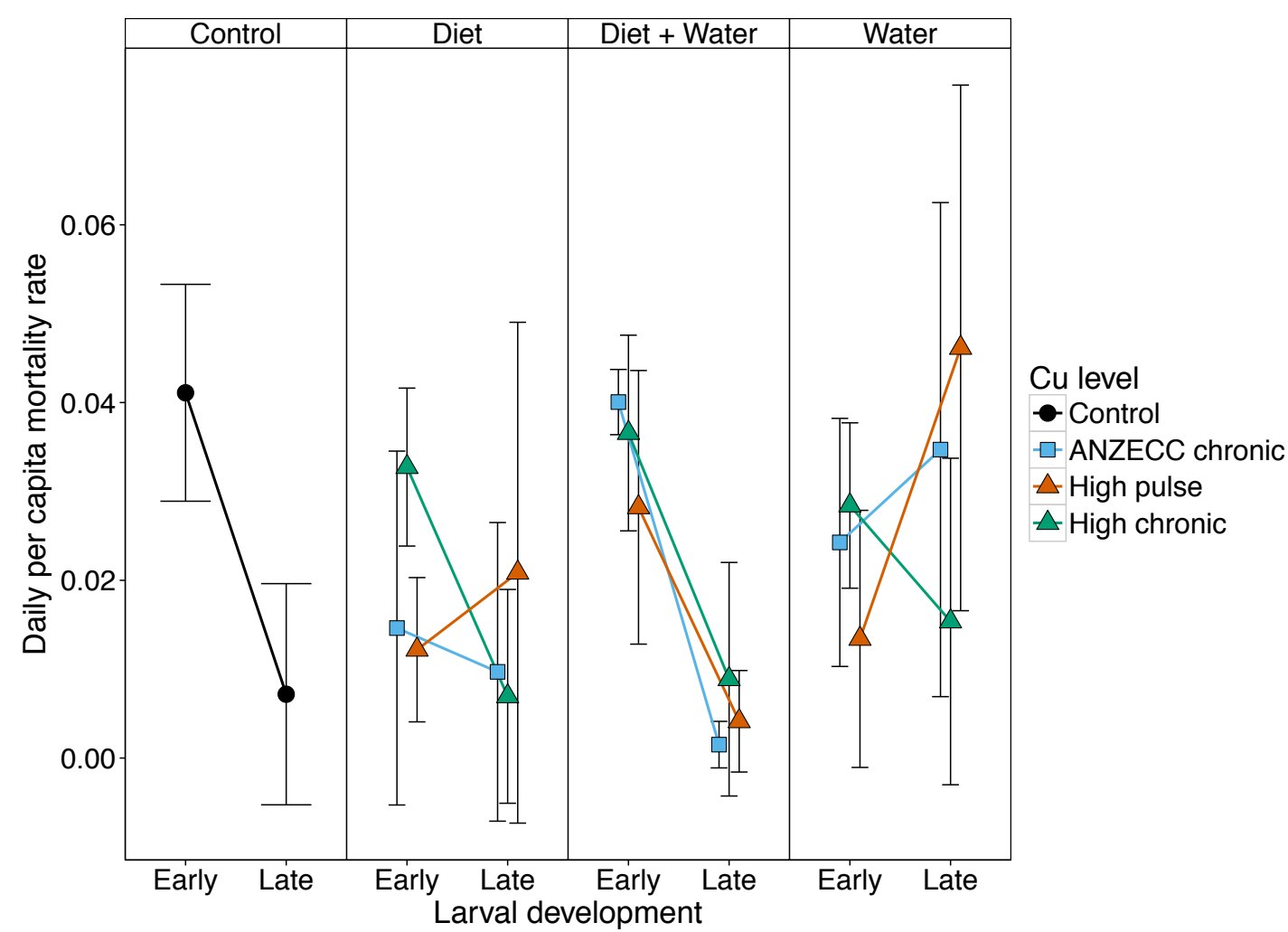

Figure 4.1: Evechinus chloroticus daily per capita mortality rate in early (4 - $15 \mathrm{~d}$ post-fertilisation) and late (15 - $24 \mathrm{~d}$ post-fertilisation) larval development under different levels of copper exposure. Larvae were exposed to copper via contaminated food (Diet), dissolved metal (Water) or both (Diet + Water). Error bars represent the standard deviation $(\mathrm{N}=3)$. 


\subsubsection{Larval development}

Larval development differed with copper level and route of copper intake, however the latter was barely significant (Table 4.4b). In controls, the percentage of normal larvae midway through development increased from $61 \%$ to $83 \%$. In the Diet and Diet + Water treatments, the proportion of normal larvae changed less markedly than in the controls, but the final normal proportion was similar to in the controls, ranging from $66 \%$ to $81 \%$ (Figure 4.2 ). In the Water treatment, however, the proportion of normal larvae decreased sharply in both the High Pulse and High Chronic copper levels, to $44 \%$ and $50 \%$ respectively (Coefficient contrasts; $p<0.02$ ).

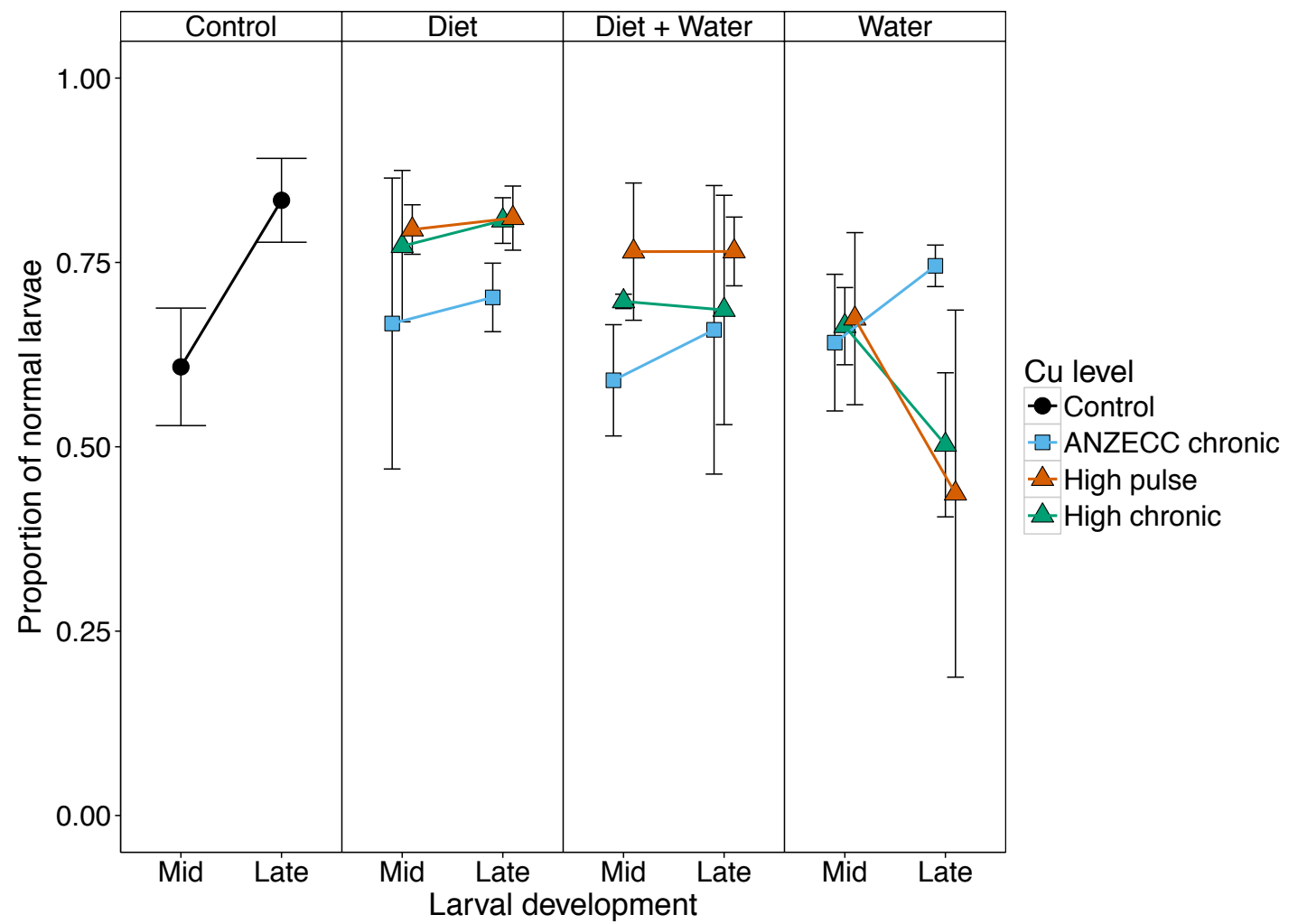

Figure 4.2: Evechinus chloroticus normal development in mid (15 - $16 \mathrm{~d}$ post-fertilisation) and late (23 - 24 d post-fertilisation) larval development under different levels and sources of copper. Larvae were exposed to copper via contaminated food (Diet), dissolved metal (Water) or both (Diet + Water). Error bars represent the standard deviation $(\mathrm{N}=3)$.

\subsubsection{Delayed development}

There was evidence of delayed development, with the proportion of plutei with a rudiment and competent plutei (protruding rudiment) decreasing with increasing copper level, especially in the Water treatment (Table 4.5a and b, Figure 4.3). In the 
Water treatment, only $4 \%$ of larvae were competent in the ANZECC Chronic treatment and none in the High Chronic treatment, compared with 39\% in the controls (Coefficient contrasts; in all cases $\mathrm{p}<0.01$ ). There was no difference across all treatments with respect to the proportion of 8-armed plutei in late larval development (Two-way ANOVA; Source: $\mathrm{F}_{(2,24)}=2.7, \mathrm{p}=0.09$, Copper level: $\mathrm{F}_{(3,24)}=0.12, \mathrm{p}=$ 0.95 , Interaction: $\left.\mathrm{F}_{(6,24)}=1.4, \mathrm{p}=0.27\right)$.

Table 4.5: Two-way ANOVA of Evechinus chloroticus proportion of larvae with a rudiment (A) and proportion of larvae with a large rudiment with protruding spines (B), to test for effects of copper exposure (copper level) and source of copper (source) late in larval development. Significant effects (p $<0.05)$ are highlighted in bold.

\begin{tabular}{lclll}
\hline Source of variation & df & SS & $\boldsymbol{F}$ & p \\
\hline (A) Larvae with rudiment & 2 & & & \\
Source & 3 & 0.13 & 1.50 & 0.24 \\
Copper level & 0.56 & 4.28 & $\mathbf{0 . 0 2}$ \\
Source x Copper level & 6 & 0.31 & 1.17 & 0.35 \\
\hline (B) Competent larvae & & & & \\
Source & 2 & 1.01 & 13.54 & $<\mathbf{0 . 0 0 1}$ \\
Copper level & 3 & 0.35 & 3.09 & $<\mathbf{0 . 0 5}$ \\
Source x Copper level & 6 & 0.48 & 2.16 & 0.08 \\
\hline
\end{tabular}




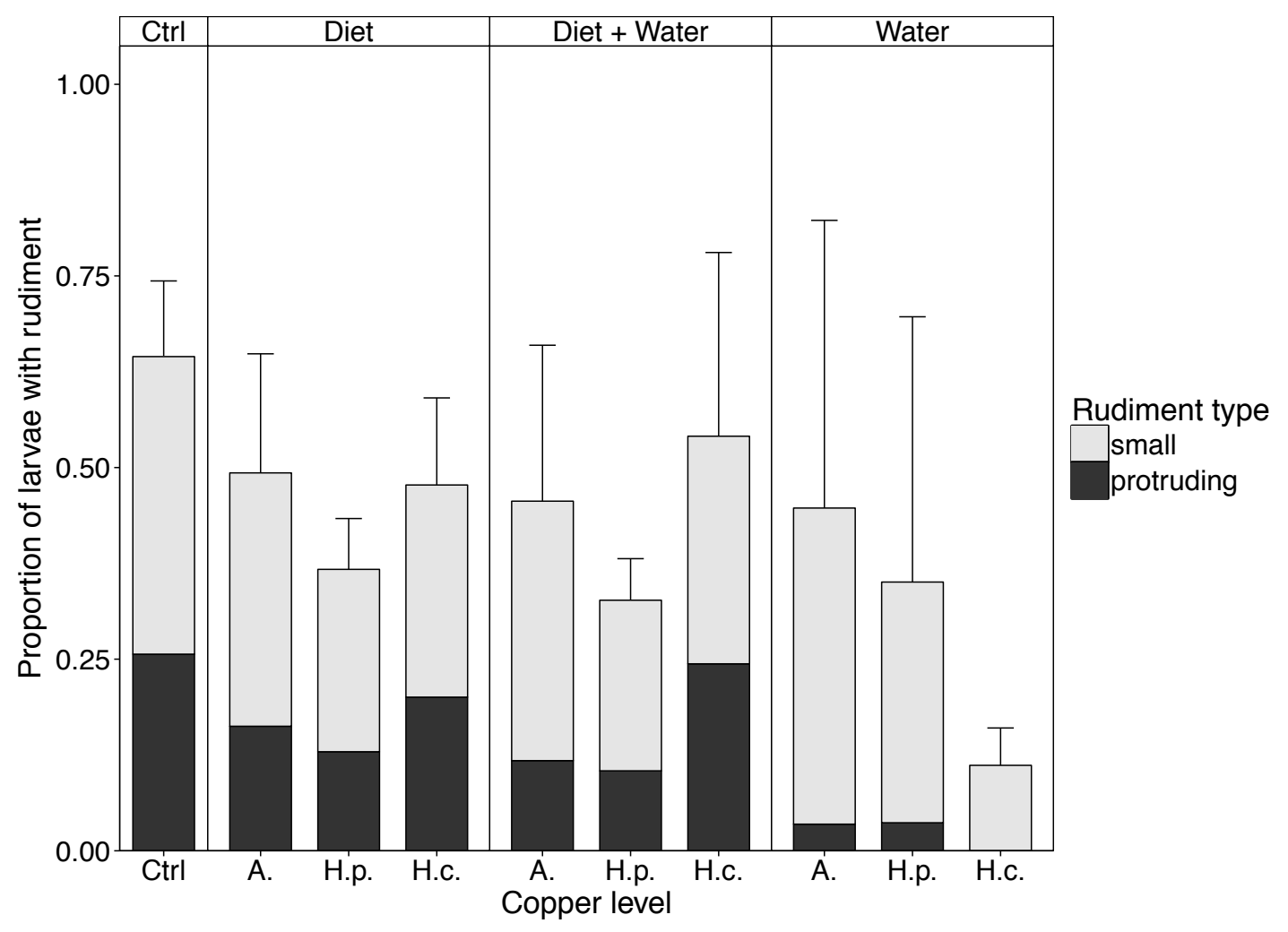

Figure 4.3: Proportion of Evechinus chloroticus larvae with a small rudiment and/or with a protruding rudiment (i.e. competent larvae) at $23-24$ days post-fertilisation under different regimes of copper exposure. Copper levels were: control (Ctrl), ANZECC Chronic (A.), High Pulse (H.p.) and High Chronic (H.c.). Larvae were exposed to copper-contaminated food (Diet), dissolved metal (Water) or both (Diet + Water). Error bars represent the standard deviation of the total proportion of larvae with a rudiment $(\mathrm{N}=3)$. 


\subsubsection{Larval size}

A delay in development was also evident with respect to the growth of the last two pairs of arms to develop (PD and EO). In controls, these arms reached near-maximum length by $15 \mathrm{~d}$ post-fertilisation, with little subsequent growth (Figure 4.4). However, in all copper treatments, PD and EO were not fully developed by $15 \mathrm{~d}$ and daily growth rate was significantly higher than controls, especially in the High Chronic treatment, with no difference between sources of copper (Table 4.6). The final size late in development was not significantly different between copper levels and controls.

Table 4.6: Effect of copper exposure (Level) and source of copper (Source) on Evechinus chloroticus growth between 15 and 24 days post-fertilisation. Analysed using two-way ANOVA on linear model with Bonferroni correction. Significant effects $(\mathrm{p}<0.01)$ are highlighted in bold.

\begin{tabular}{lccc}
\hline Variable & Source $\boldsymbol{F}(\mathbf{p})$ & Level $\boldsymbol{F}(\mathbf{p})$ & Source $\mathbf{x}$ Level $\boldsymbol{F}(\mathbf{p})$ \\
\hline $\begin{array}{l}\text { Posterodorsal arm length } \\
\text { (PD) }\end{array}$ & $0.37(0.70)$ & $\mathbf{2 3 . 8 1}(<\mathbf{0 . 0 0 1 )}$ & $0.15(0.96)$ \\
Preoral arm length (E0) & $4.44(0.04)$ & $\mathbf{2 2 . 8 1 ( < 0 . 0 0 1 )}$ & $2.83(0.07)$ \\
\hline
\end{tabular}
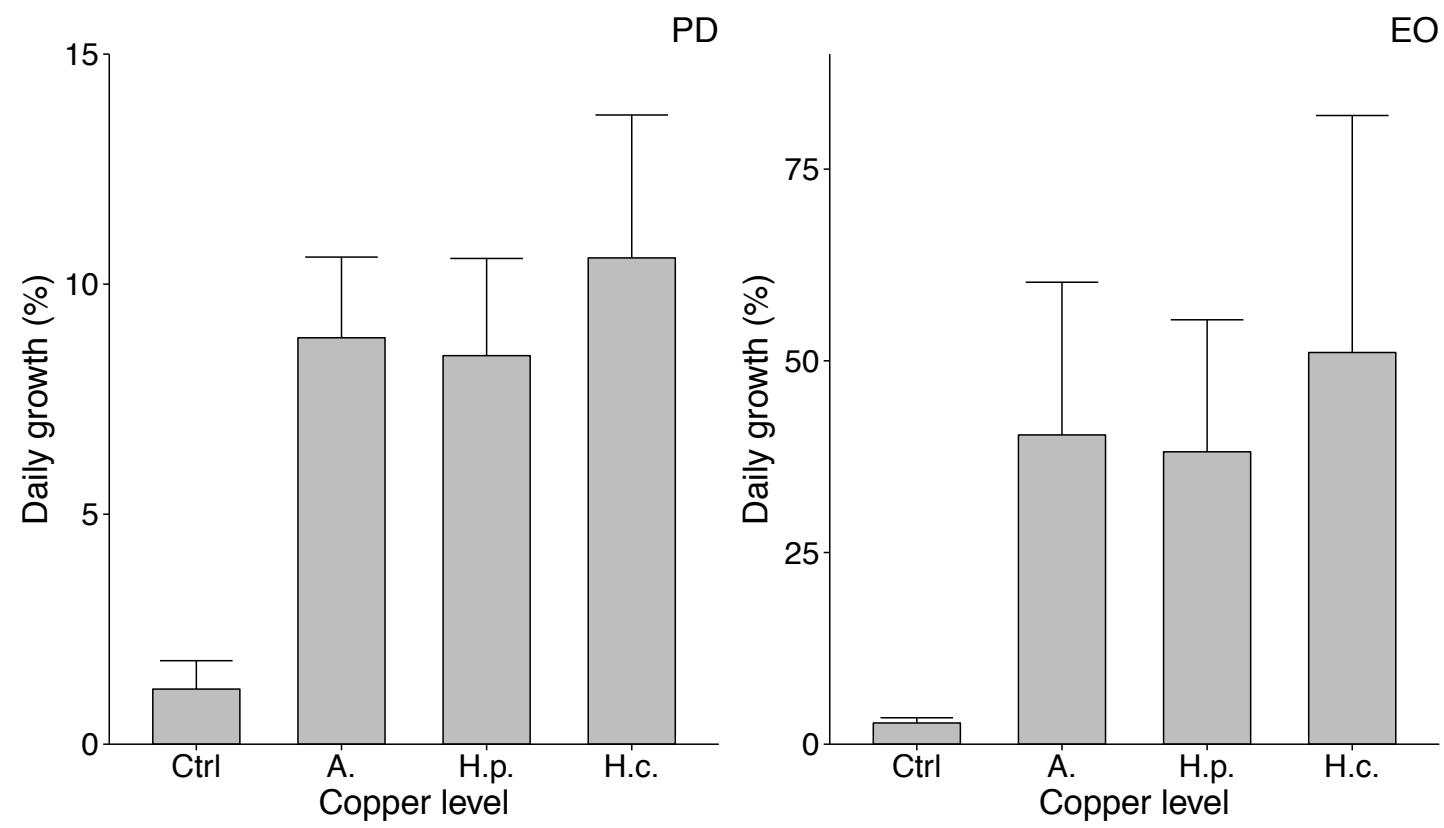

Figure 4.4: Evechinus chloroticus daily posterodorsal arm (PD) and preoral arm (EO) growth between 15 - 16 and 23 - 24 d post-fertilisation under different regimes of copper exposure. Copper levels were: control (Ctrl), ANZECC Chronic (A.), High Pulse (H.p.) and High Chronic (H.c.). Larvae were exposed to copper via contaminated food (Diet), dissolved metal (Water) or both (Diet + Water). Under normal conditions, larval arms have reached near maximum length by 15 days, and thus little growth occurred in controls between 15 to $23 \mathrm{~d}$ post-fertilisation. Error bars represent the standard deviation $(\mathrm{N}=3)$. 


\subsubsection{SETTLER PERFORMANCE}

\subsubsection{Settlement success}

Settlement success was strongly affected by concentration of copper and patterns of variation were significantly different with the source of copper (two-way ANOVA; Source: $\mathrm{F}_{(2,24)}=11.4, \mathrm{p}<0.001$; Copper level: $\mathrm{F}_{(2,24)}=53.7, \mathrm{p}<0.001$; Interaction term: $F_{(6,24)}=16.2, p<0.001$; Figure 4.5). Eight days after having been placed in settlement containers, significantly less urchins had settled successfully in the ANZECC and High Pulse levels in the Diet treatment, and across all copper levels in the Diet + Water treatments (Tukey HSD, $p<0.05$; Figure 4.5). The High Pulse level had a stronger impact than the High Chronic level in the Diet and the Diet + Water treatments, with almost no settlement at the High Pulse level. In the Water treatment, only the High Chronic level was significantly different from controls, with $3.6 \%$ settlement success. The best model included no covariates and model fit was excellent, with a $92 \%$ multiple $\mathrm{R}^{2}$. 


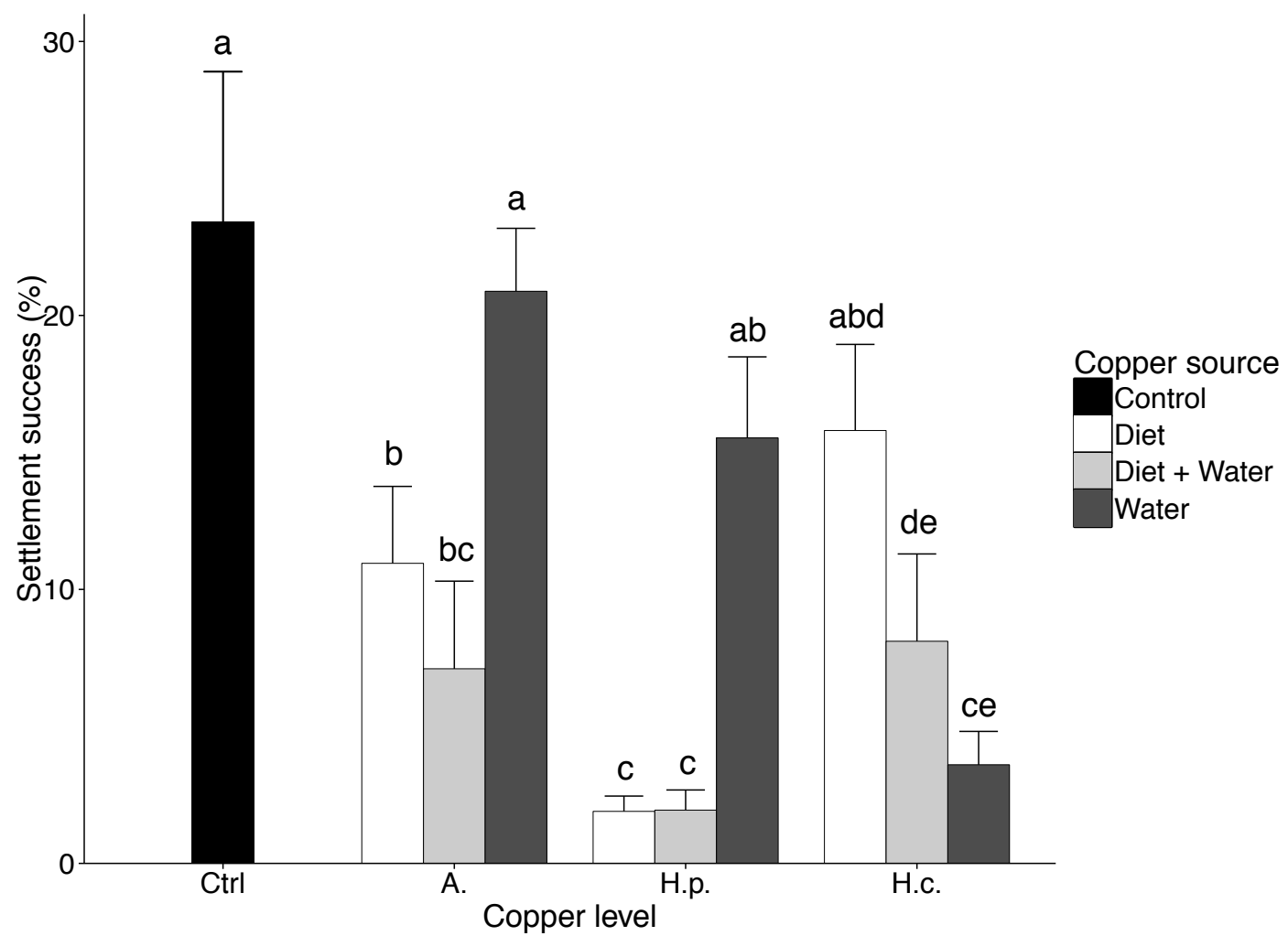

Figure 4.5: Settlement success of Evechinus chloroticus, 8 days post-settlement, under three different levels of copper exposure: control (Ctrl), ANZECC Chronic (A.), High Pulse (H.p.) and High Chronic (H.c.). Larvae were exposed to copper via contaminated food (Diet), dissolved metal (Water) or both (Diet + Water). Error bars represent the standard deviation $(\mathrm{N}=3)$. Lower case letters show groupings based on pairwise comparisons (Tukey test, $\mathrm{p}<0.05$ ).

\subsubsection{Settler size}

Radial length at settlement was significantly affected by copper level, initial density, rudiment size, and proportion of normal larvae (Table $4.7 \mathrm{a}$ ). Conditional $\mathrm{R}^{2}$ was $40 \%$, with most of the variation explained by heterogeneity across containers (random term) followed by (in decreasing order of contribution): rudiment size, copper level, proportion of normal larvae and initial density. Settler radial length was significantly higher than controls only at the High Pulse level (Coefficient contrasts: $p=0.02$; Figure 4.6a). However, the difference was very small, with an average of $559 \mu \mathrm{m}$ at the High Pulse level compared with $549 \mu \mathrm{m}$ in the controls. 
Table 4.7: Effect of larval experiences on Evechinus chloroticus size at settlement: (A) radial length and (B) spine/body ratio (SBR), analysed using ANCOVA on mixed effect models. SBR was logtransformed to meet ANCOVA assumptions. Significant effects $(p<0.05)$ are highlighted in bold; $p$ values are based on the chi-square statistic.

\begin{tabular}{llll}
\hline Source of variation & $\mathbf{d f}$ & $\mathbf{C h i}^{\mathbf{2}}$ & $\mathbf{p}$ \\
\hline (A) Radial length & & & $\mathbf{0 . 0 0 6}$ \\
Copper level & 3 & 12.60 & $\mathbf{0 . 0 4}$ \\
Density & 1 & 4.10 & $<\mathbf{0 . 0 0 1}$ \\
Rudiment size & 1 & 13.45 & $\mathbf{0 . 0 3}$ \\
Larval development & 1 & 4.61 & \\
\hline (B) Spine/body ratio & & & $<\mathbf{0 0 1}$ \\
Copper level & 3 & 26.41 & 0.05 \\
Larval size & 1 & 14.15 & \\
\hline
\end{tabular}

Final radial length at $38 \mathrm{~d}$ post-settlement was significantly higher at all copper levels in the Water treatment (One-way ANOVA: $\mathrm{F}_{(3,7)}=14.41, \mathrm{p}=0.002$; Coefficients contrasts: in all cases $p<0.03)$. Juveniles were nearly two times larger at ANZECC levels than in controls, more than 1.5 times larger at the High Pulse level and 1.3 times larger at High Chronic levels (Figure 4.6a). In contrast, in the Diet + Water treatment, juveniles were smaller with increasing copper exposure (One-way ANOVA: $\left.\mathrm{F}_{(2,4)}=8.08, \mathrm{p}=0.04\right)$, with juveniles at both copper levels approximately 1.5 times smaller than controls (Coefficients contrasts; in all cases $\mathrm{p}<0.04$ ); no significant differences was observed in the Diet treatment. 
a)

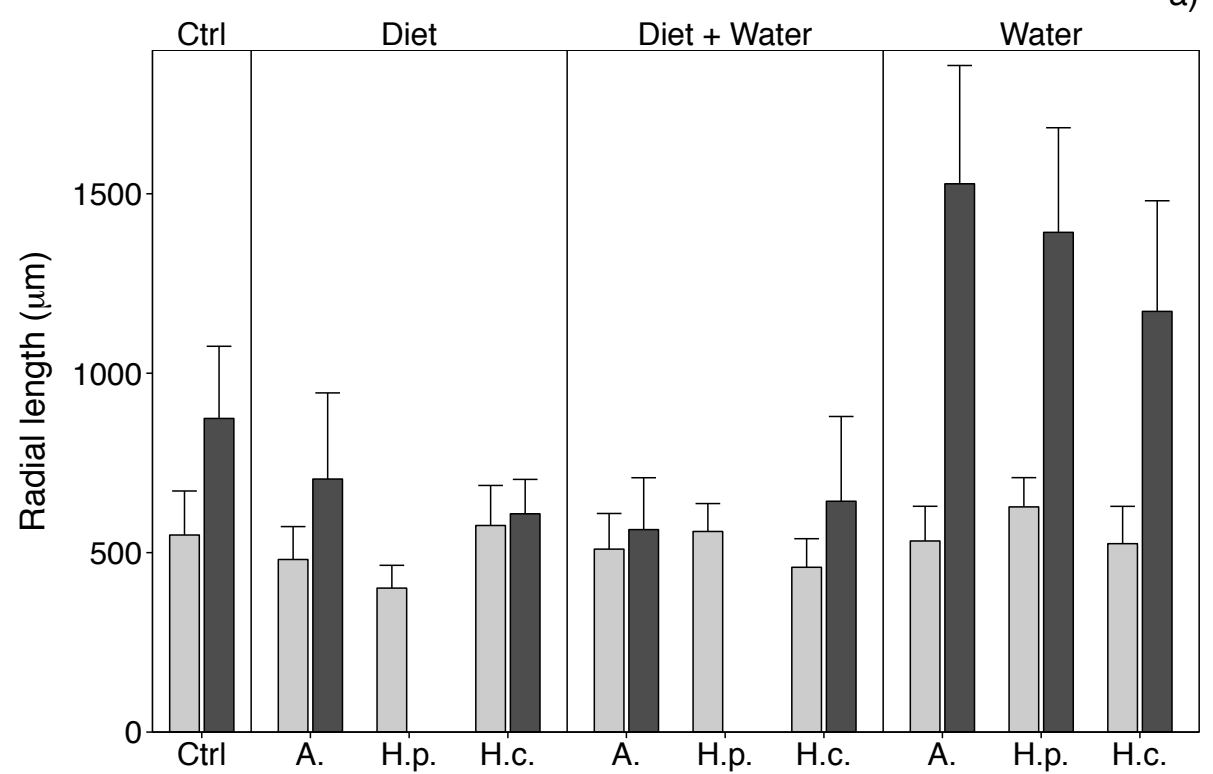

b)

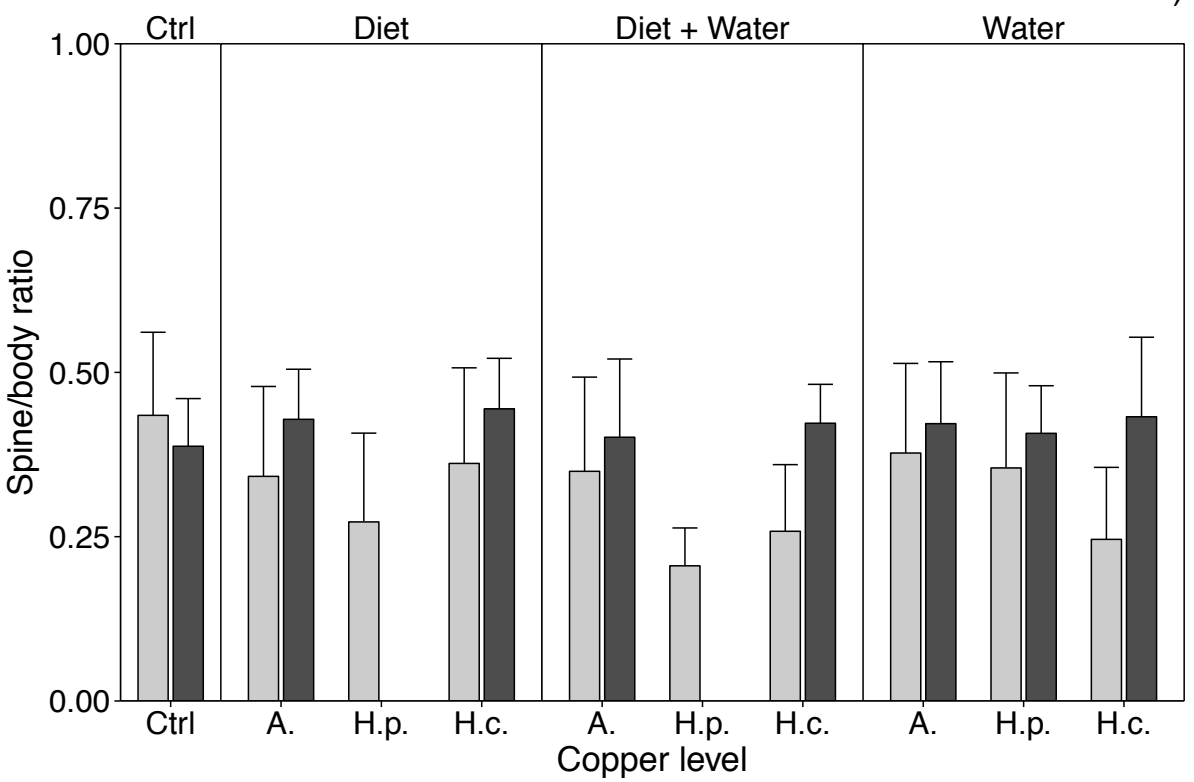

Figure 4.6: Evechinus chloroticus radial length (a) and spine/body ratio (b) at 8 and 38 days postsettlement under different copper regimes: control (Ctrl), ANZECC Chronic (A.), High Pulse (H.p.) and High Chronic (H.c.). Larvae were exposed via contaminated food (Diet), dissolved metal (Water) or both (Diet + Water). Error bars represent the standard deviation $(\mathrm{N}=3)$. No data are available in the H.p. treatment for Diet and Diet + Water, as less than five settlers per containers were alive at $38 \mathrm{~d}$ post-settlement.

SBR at settlement was best explained by copper level, with a conditional $\mathrm{R}^{2}$ of $25 \%$ (Table 4.7b). Settlers had significantly shorter spines than controls at the High Pulse and High Chronic levels, with averages of $32 \%$ of body size at the High Pulse level and $30 \%$ at the High Chronic level, against $44 \%$ in controls (Coefficient contrasts; in 
all cases $\mathrm{p}<0.001$, Figure $4.6 \mathrm{~b}$ ). However, final SBR at $38 \mathrm{~d}$ post-settlement was similar to controls in all treatments.

\subsubsection{Settler survival and development}

Normal development of juveniles at $38 \mathrm{~d}$ post-settlement was significantly affected by copper level during larval development, and the proportion of larvae with a rudiment and normal larvae before settlement (23 - $24 \mathrm{~d}$ post-fertilisation, (Table 4.8). Model fit was good, with $70 \%$ of the variation explained. However, the proportion of larvae with a rudiment and the proportion of normal larvae contributed to most of the explained variation ( $23 \%$ and $43 \%$, respectively), while copper level contributed to $34 \%$. Normal development was positively affected by both covariates (proportion of larvae with a rudiment and proportion of normal larvae). The percentage of normal juveniles at $38 \mathrm{~d}$ post-settlement was lower at the ANZECC level $(54 \% \pm 27$; mean \pm SD) and at the High Chronic level $(60 \% \pm 23)$, compared with $81 \% \pm 11$ in controls (Coefficient contrasts; in all cases $\mathrm{p}<0.03$ ).

Table 4.8: Effect of larval experience of Evechinus chloroticus on settlers' normal development at 38 days post-settlement, analysed using ANCOVA on linear models. The proportion of normal settlers was square-root arcsin transformed to meet ANCOVA assumptions. Significant effects $(\mathrm{p}<0.05)$ are highlighted in bold. $F$-ratios are calculated from Type II SS.

\begin{tabular}{lllll}
\hline Source of variation & Df & SS & $\boldsymbol{F}$ & p \\
\hline Copper level & 3 & 0.41 & 4.43 & $\mathbf{0 . 0 1}$ \\
Proportion of rudiment & 1 & 0.44 & 14.15 & $<\mathbf{0 . 0 0 1}$ \\
Larval development & 1 & 0.73 & 23.51 & $<\mathbf{0 . 0 0 1}$ \\
\hline
\end{tabular}

Juvenile survival after $38 \mathrm{~d}$ varied between 10 and 100\% across containers, and was unaffected by larval copper exposure but was positively affected by the proportion of larvae with a rudiment in the late larval stage (ANCOVA: $F_{(1,32)}=4.63, p=0.04$ ). However, model fit was poor, with only $13 \%$ of the variation explained. 


\subsection{DISCUSSION}

\subsubsection{DIETARY VS. WATERBORNE TOXICITY}

This study showed that copper accumulated in phytoplankton has a strong toxic effect on E. chloroticus post-settlement, especially given the very low amount of copper present per feed. Interestingly, dietary copper seemed to produce few direct effects on larvae, while carry-over effects were more severe when copper was administered in food rather than in water. Settlement success was on average $30 \%$ lower with dietary copper than with waterborne copper. Furthermore, surviving settlers tended to be smaller after $38 \mathrm{~d}$ post-settlement when raised in copper-laden food during larval development, while those raised in copper-spiked water had a higher growth and larger final body size than controls. These results show the importance of taking into account dietary intake when evaluating pollutant toxicity.

Other studies evaluating the toxicity of metal-laden diet on zooplankton also found a higher sensitivity to metal when obtained from food rather than from a dissolved source. The copepod Acartia tonsa had a median lethal concentration (LC50) of 43.2 $\mu \mathrm{g} / \mathrm{L}$ with waterborne silver compared to an LC50 of only $3 \mu \mathrm{g} / \mathrm{L}$ and a median effective concentration (EC50) of $0.1 \mu \mathrm{g} / \mathrm{L}$ with dietary silver (Hook \& Fisher 2001a, Bielmyer et al. 2006). Similar results were found for cadmium in copepods, however mercury was more toxic when absorbed from water showing that the relative importance of dietary vs. waterborne exposure varies between metals (Hook \& Fisher 2001b).

For carry-over effects, combined exposure to dissolved and dietary copper followed the effect of dietary copper alone; this was as expected, as dietary copper had a stronger effect than dissolved copper on settlement success, and settler size and growth. Surprisingly however, this was also the case for direct effects, where combined dietary and waterborne exposure was less toxic than waterborne exposure alone. It appears that the presence of dietary copper mitigates the toxic effect of waterborne copper, perhaps by triggering acclimation mechanisms such as metal sequestration, as suggested by Hook and Fisher (2002). Acclimation following 
dietary exposure is also supported by the fact that pulse exposure was worse than chronic exposure. In the field, organisms are likely to be exposed simultaneously to waterborne pollutants and contaminated diet. Therefore, it is crucial to evaluate the toxic effects of both acquisition pathways. However, this is the first study assessing the combined effects of waterborne and dietary metal uptake in invertebrates.

It should be noted that this study was conservative with respect to the algal copper burden. Metal burden per algal cell is higher after $24-48 \mathrm{~h}$ exposure (Bielmyer et al. 2006) and rapid cell division (as in an algal bloom induced by increase nutrients) reduces metal burden per cell (Pickhardt et al. 2002). In this study, algae were cultured for two weeks under high light-nutrient conditions leading to fast algal division. Therefore, metal burden per cell under these conditions is likely to be much lower than encountered in the field for the same water concentration following a rain event, especially in oligotrophic waters.

\subsubsection{DIRECT AND CARRY-OVER EFFECTS}

Low levels of copper exposure produced both direct and latent effects, in contrast with results from the previous chapter (section 3.3) where no direct effects were detectable. The difference is probably due to the longer exposure in the current study (chronic or four days pulse compared to two days pulse in Chapter 3). The strongest toxic effect observed in this study, however, was a carry-over effect (settlement success)

The main direct effect was a delay in rudiment development at most copper levels, but especially in the Water treatment. The higher in arm growth in presence of copper also reflects a delay in arm development. The difference was predominantly with respect to the pair of arms that develop later in the larval stage (i.e. PD and EO). For these arms, almost no growth was observed in the controls, while increased growth occurred with copper exposure. Nevertheless, final size before settlement was similar across all copper levels, indicating that these arms developed later in the presence of copper. Other direct effects included a slight increase in mortality rate at the High 
Pulse level and a decrease in normal development at the High Pulse and High Chronic levels, but in the Water treatment only.

Although the proportions of larvae with a rudiment and competent larvae were similar to controls after only three days, a delay in settlement may have major impacts for settler survival. Intrinsic metabolic costs of delayed settlement have been linked to poorer settler survival and growth (Pechenik 2006). Furthermore, a delay in competency may have a range of adverse effects in the field, such as increased predation risk and dispersal away from suitable habitat (reviewed by Pechenik 1999).

The main carry-over effect was a dramatic decrease in settlement success. Settlement success was less than $2 \%$ at the High Pulse level in the Diet and Diet + Water treatments, and less than five settlers remained alive at the end of the experiment (38 d post-settlement). Furthermore, surviving settlers had a higher rate of abnormal development in all copper treatments. The effects on settler size and growth were complex. Radial length at settlement was similar at all copper levels, but a higher growth rate in all Water copper treatments led to larger settlers at $38 \mathrm{~d}$ post-settlement. On the other hand, settlers had shorter spines at settlement in the presence of copper but the no difference in spine length remained between copper treatments and controls at $38 \mathrm{~d}$ post-settlement. This is contrary to the strong growth impairment observed in High Pulse level in Chapter 3 (Figure 3.6). The difference may be due to longer copper exposure, however the effect would be expected to be stronger and not contrary, or it could be due to time of sampling. Indeed, growth impairment in Chapter 3 was observed at $25 \mathrm{~d}$ post-settlement. Settlers in the current study might have gone through an initial phase of depressed growth before increasing to levels observed at $38 \mathrm{~d}$ post-settlement. This emphasises the need to investigate long-term effects, to have a more complete understanding of copper effects.

\subsubsection{PULSE VS. CHRONIC}

The relative effect of pulse or chronic exposure was strongly dependent on the source of copper. Indeed, when copper was present in the diet (both Diet and Diet + Water treatments), a pulse exposure was generally more toxic than a chronic exposure. On 
the other hand, when copper was administered in water alone, a chronic exposure was more toxic. This suggests that copper from the diet triggers a fast acclimation while no acclimation occurs when exposure is to waterborne copper, at least within the short time frame of the larval stage; this adds to the growing body of evidence that different routes of metal exposure induce profoundly different physiological responses (Fisher et al. 1996, Hook \& Fisher 2001b, Meyer et al. 2005). Acclimation to metals including copper has been widely reported in fish but is poorly known in invertebrates, with the exception of inherited resistance, known as micro-adaptation, reported in short-lived marine invertebrates (Dixon \& Sprague 1981, Wirgin \& Waldman 2004, McKenzie et al. 2011, Brinkman \& Woodling 2014, Sun et al. 2014).

This study shows that a short-lived bloom of contaminated phytoplankton may have a more severe impact on zooplankton than chronic pollution. This finding has important implications for pollution management, as short increases in pollution concentration are usually considered to be of little consequence as long as the average concentration throughout the year is below WQC. Furthermore, many toxicity studies investigating dietary intake of pollutants have used a chronic exposure and focused on adults, and hence may have strongly underestimated the toxic effect of a pollutant (De Schamphelaere et al. 2004, Meyer et al. 2005, Guo et al. 2013). Conversely, acclimation to copper from a dietary source seemed to counteract the negative effects of chronic waterborne pollution in the Diet + Water treatment, suggesting that $E$. chloroticus is capable of acclimating quickly to moderate levels of chronic pollution.

\subsubsection{IMPLICATIONS FOR MANAGEMENT}

This study shows that even low levels of copper pollution, close to WQC, may have a toxic effect on invertebrate larvae when the dietary route is considered. The lowest copper level in this study negatively affected settlement success by $50-70 \%$ and settler development by $45-60 \%$. Episodic spikes of pollution (e.g. in storm runoff) may seem acceptable to regulatory organizations so long as contamination does not become chronic, however this study stresses the importance of preventing sporadic discharge of pollutants as they can be more damaging to vulnerable species, or particular life stages, than chronic pollution. In addition, given the rapid algal division 
achieved under laboratory conditions, metal burden per algal cell in this study is likely to be lower than encountered in the field following a rain event, especially in oligotrophic waters. 


\title{
CHAPTER 5
}

\section{Multiple stressors: The effect of low salinity on copper toxicity in Evechinus chloroticus early life stages}

\begin{abstract}
Copper is a common pollutant in coastal waters, which are also prone to fluctuating salinity due to runoff. However, toxicity studies on marine organisms are nearly always conducted at normal seawater salinity and are thus not necessarily representative of field conditions. Here I used embryos and larvae of the sea urchin Evechinus chloroticus to characterise the effect of low salinity on copper toxicity with variable timing of exposure. In embryo/early pluteus assays, embryos were exposed to copper $(0-20 \mu \mathrm{g} / \mathrm{L})$ at $26 \mathrm{ppt}$ salinity for $72 \mathrm{~h}$ shortly after fertilisation. In larval assays, larvae were either exposed chronically to treatments or in a single pulse to better mimic realistic field conditions. In the chronic experiment, larvae were exposed to two levels of copper (none or high: $15 \mu \mathrm{g} / \mathrm{L}$ ) and two levels of salinity (normal: 36 ppt or low: $24 \mathrm{ppt}$ ), in a fully crossed design. For the pulse exposure, larvae were exposed to a single 4-day pulse of low copper concentration $(5 \mu \mathrm{g} / \mathrm{L})$ at normal salinity (36 ppt) or low salinity (24 ppt). Low salinity by itself had a dramatic impact on embryos, with a complete inhibition of hatching compared to $>90 \%$ normal development at normal salinity. There was no added effect of copper. Larvae were more resistant to hyposaline stress than were embryos, with only a minor delay in arm growth. A high level of copper administered chronically had a severe impact on larval
\end{abstract}


survival, normal development and 8 -armed pluteus development $(43 \%, 80 \%$ and $200 \%$ lower than control, respectively). However, a low level of copper administered in a single pulse was not detrimental to larvae. A strong synergistic effect of copper and salinity was observed under chronic exposure to high copper concentration and low salinity, with no larvae reaching full development compared to more than $50 \%$ in copper alone and $27 \%$ at low salinity alone. There was little evidence of increased copper toxicity at low salinity under pulse exposure to low copper concentration, except for a delay in rudiment development that was compensated for within three days. These findings demonstrate that, although low salinity and copper may have a synergistic effect under specific conditions, the combined exposure to these two stressors would not likely have major impacts on sea urchin larvae in the field.

\subsection{INTRODUCTION}

Coastal areas are impacted by terrestrial runoff following rain events, and therefore often affected by pollutants and fluctuations in water salinity simultaneously (Hayward et al. 2006). Change in rainfall patterns due to global climate change may lead to more frequent severe rainfall and flooding at high latitudes, leading to further freshwater input in coastal systems in the near future (Morrison et al. 2009, IPCC 2014). Fluctuation in salinity is an important source of environmental stress in itself, but is also known to affect metal bioavailability and toxicity to aquatic organisms. Generally, metals, including copper, are more readily bioavailable at low salinity as a result of lower complexation with free metal ions and/or lower competition between sodium ions and free metal ions for binding sites in the organism (McLusky et al. 1986, Santore et al. 2001). While salinity is well known to be an important mediator of metal toxicity in freshwater and estuarine systems (McLusky et al. 1986, Grosell et al. 2007, Lee et al. 2010), relatively few studies have looked at marine organisms and most of these have focused on adults (McLusky et al. 1986, Barbieri \& Doi 2011, Patel \& Bielmyer-Fraser 2015).

Sea urchins are ecologically important members of near-shore reef communities and are may be found near large cities, including those with harbours, where metal 
pollution is highly prevalent and often accompanied by fluctuations in salinity from urban runoff. Echinoderms are essentially stenohaline but have species-specific tolerances to variable salinity. For example, the green sea urchin Strongylocentrotus droebachiensis, one of the most tolerant species to hyposaline conditions, can tolerate prolonged exposure to salinities as low as 14 ppt as adults and 20 ppt as larvae (reviewed in Russell 2013). Such decreases in salinity are common in the field. For example, in Wellington, salinity as low as $12 \mathrm{ppt}$ was measured up to $1 \mathrm{~km}$ offshore in surface water $(30 \mathrm{~cm})$ in a river plume one day following a rain event, and $18 \mathrm{ppt}$ near-shore three days after the rain event (Tables A.1 and A.2).

Sea urchin larvae are highly sensitive to metal pollution and environmental stress in general, including hyposalinity. The effects of metals on sea urchin larvae have been widely evaluated, and are characterised by impairment of fertilisation and normal larval development (Kobayashi 1980, King \& Riddle 2001, Fernández \& Beiras 2001, Phillips et al. 2003, Bielmyer et al. 2005). The effects of low salinity on the early life stages of echinoids are less understood but include deleterious effects on fertilisation, egg and larval development, and development rate (Allen \& Pechenik 2010, Carballeira et al. 2011, Russell 2013, Delorme \& Sewell 2014). However, no study has investigated the influence of low salinity on metal toxicity in the early life stages of sea urchins. In other marine invertebrates species, low salinity generally, but not always, tends to increase metal toxicity in adults (Lee et al. 2010, Barbieri \& Doi 2011, Patel \& Bielmyer-Fraser 2015) and early life stages (MacInnes \& Calabrese 1979, Nadella et al. 2009, 2013).

Copper is a major pollutant in many industrial countries and is considered as a priority pollutant by environmental authorities due to its high toxicity to aquatic life (ANZECC 2000, US EPA 2014). Standard toxicity assays are a cost-efficient way to determine acceptable copper levels in marine waters (US EPA 2002b). While copper assays have been conducted with sea urchin embryos and larvae in many species, these tests are always conducted at normal seawater salinity and may underestimate copper toxicity under common field conditions. The time over which embryo/early pluteus formation occurs ( $1-3 \mathrm{~d}$ post-fertilisation) has been reported as the most sensitive stage to pollutants in many species, so standard toxicity assays typically end 
when larvae reach the pluteus stage (King \& Riddle 2001, ASTM 2012). Salinity effects on the other hand, are often greater earlier in development during the prehatching stage, and are detectable a few hours post-fertilisation (Kashenko 2007, Carballeira et al. 2011, Delorme \& Sewell 2014). A study using E. chloroticus embryos showed a complete inhibition of hatching under 27.5 ppt (Antonie 2003). However, longer-term assays are preferable, whenever possible, to assess the potential longer term sublethal effects of stressors throughout larval development. In my previous experiments, the effects of low levels of copper were detectable one to two weeks after exposure, during rudiment formation in late larval development (Chapter 3 and 4).

The aims of this study were to evaluate the effect of salinity on copper toxicity in early life stages of the sea urchin Evechinus chloroticus. To do this, I conducted two experiments. In the first experiment, toxicity was assessed during embryo/early pluteus development (first $72 \mathrm{~h}$ post-fertilisation) to characterise effects during the most sensitive life stage. In this experiment, embryos were exposed to four levels of copper at low salinity, plus a low salinity treatment (no copper) and a normal salinity control. In a second experiment, toxicity was evaluated later in larval development, during the pluteus stage (from $4 \mathrm{~d}$ post-fertilisation). Larvae are more likely to encounter fluctuations in salinity and metal contamination in the field post-hatching, when they are found in the surface layers for feeding (Lamare 1998). In this experiment, larvae were exposed to a chronic high copper concentration in normal salinity seawater or low salinity seawater, with an additional low salinity/no copper treatment, and normal salinity control. In addition to these chronic treatments, a treatment of pulse exposure (four days) to low concentration copper at low salinity and at normal salinity was used to mimic realistic field exposure to both stressors.

\subsection{Methods}

\subsubsection{BROODSTOCK AND SPAWNING}

Adult E. chloroticus $(8-20 \mathrm{~cm}$ test diameter) were collected from Kau Bay, Wellington $\left(41.2882^{\circ} \mathrm{S}, 174.8326^{\circ} \mathrm{E}\right)$ in October 2013 . A total of 50 urchins were 
kept at Victoria University Coastal Ecology Laboratory (VUCEL) in two 501 tanks with flow-through raw seawater. VUCEL's seawater is pumped $\sim 5 \mathrm{~m}$ from shore in the Taputeranga Marine Reserve. Raw seawater receives no treatment, while filtered seawater $(\mathrm{FSW})$ is pre-filtered $(15 \mu \mathrm{m})$ and then filtered through a $0.2 \mu \mathrm{m}$ paper cartridge. Adult E. chloroticus were fed twice a week with native kelp (Macrocystis pyrifera) and/or commercial feed (ABMAX, E.N. Hutchinson Ltd Auckland, NZ).

\subsubsection{EMBRYO/EARLY PLUTEUS EXPERIMENT}

The experiment was run in February 2014. Embryos were the product of multiple parents (three males, three females) and exposed to copper for $72 \mathrm{~h}$ from $<1 \mathrm{~h}$ postfertilisation in $300 \mathrm{ml}$ glass jars, following standard static non-renewal toxicity protocols (US EPA 2002b, ASTM 2012). The spawning, fertilisation and experimental set-up are all described in section 2.2.1 and 2.2.2. Embryos were exposed to four copper levels, all in low salinity (26 $\pm 1 \mathrm{ppt}$ ) seawater: 1, 5, 10 and 20 $\mu \mathrm{g} / \mathrm{L} \mathrm{Cu}$. In addition, there was a low salinity/no copper treatment and a normal salinity/no copper control $(35.5 \pm 0.5 \mathrm{ppt})$. There were three replicate jars for each treatment. Copper concentrations were based on a previous assay at normal salinity, and were chosen to derive median effective concentrations (EC50) and no observable effect concentrations (NOEC) (section 2.3.1). Temperature was $16.5^{\circ} \mathrm{C} \pm 0.5$ during the assay. After $72 \mathrm{~h}$, larvae were preserved in $40 \%$ ethanol and observed under a microscope at 100x magnification. The first 100 larvae encountered were assigned to one of seven developmental categories (Table 2.2).

\subsubsection{LARVAL EXPERIMENT}

This experiment was run from November to December 2013. E. chloroticus larvae were the product of multiple parents (four males, three females). Spawning and fertilisation protocols are described in section 3.2.1.

\subsubsection{Experimental design}

In this experiment, larvae were either exposed chronically to treatments, or in a single pulse to better mimic realistic field conditions. For the chronic exposure, larvae were 
exposed to four treatments: high copper $(15 \mu \mathrm{g} / \mathrm{L})$ at normal salinity $(35.5 \pm 0.5 \mathrm{ppt})$, high copper at low salinity ( $24 \pm 1 \mathrm{ppt})$, low salinity with no copper, or a normal seawater/no copper control. Larvae were subjected to these treatments from 4 to $32 \mathrm{~d}$ post-fertilisation. For the pulse exposure, larvae were exposed to a single 4-day pulse of low copper concentration $(5 \mu \mathrm{g} / \mathrm{L})$ in normal salinity $(35.5 \pm 0.5 \mathrm{ppt})$ or low salinity (24 $\pm 1 \mathrm{ppt})$ seawater. Exposure to both stressors occurred between 7 and $11 \mathrm{~d}$ post-fertilisation. All treatments had three replicate jars.

Metal stock solutions were made from reagent grade copper sulphate $\left(\mathrm{CuSO}_{4} \cdot 5 \mathrm{H}_{2} \mathrm{O}\right)$. Concentrations given are nominal, as actual dissolved copper concentrations were found to be close to nominal in the upper range measured in January 2013 using the same experimental conditions without urchin larvae (Table 3.1). The low copper level used in the pulse experiment was chosen as a realistic level occurring in moderately polluted water and was approximately twice the highest level measured in the field in the Wellington area (Figure A.2). The high copper level in the chronic treatments was chosen to induce a response during larval development and to evaluate the effect of low salinity on copper toxicity. While copper concentrations similar to the one in the high copper treatments could occur in polluted areas (Table 1.1), a chronic exposure to this level of copper and low salinity is unlikely to occur in the field. The low salinity treatment was chosen based on the salinity measured in river plumes following rain in the Wellington region (Table A.1).

\subsubsection{Larval assays}

Fertilised eggs were first placed in one $4 \mathrm{~L}$ glass jar within $1 \mathrm{~h}$ of fertilisation, at a density of 30 eggs $/ \mathrm{ml}$ for three days; the larvae were held in this jar until they reached the pluteus stage. At this time larvae were then transferred to $2 \mathrm{~L}$ glass jars at a density of 1000 larvae/L. Details of the experimental set-up are described in section 3.2.3. The temperature was $15^{\circ} \mathrm{C} \pm 1$ throughout the duration of the experiment, which was terminated at $32 \mathrm{~d}$ post-fertilisation.

Jars were sampled at 16,21, $25 \mathrm{~d}$ post-fertilisation for all treatments and again at $28 \mathrm{~d}$ post-fertilisation for the low salinity treatments. During sampling, the water level in each jar was lowered to $750 \mathrm{ml}$ to increase larval density and $3 \times 15 \mathrm{ml}$ aliquots were 
taken per jar. In addition, larval survival was measured on pooled replicates at $28 \mathrm{~d}$ post-fertilisation in the normal salinity treatment and at $32 \mathrm{~d}$ post-fertilisation in the low salinity treatments. Jars were randomly numbered and all measurements were performed blind with regard to the treatment classification. The number of live larvae was counted in each aliquot, using a dissecting microscope. Each live larva was assigned to one of nine developmental categories (see section 4.2.3). The first ten normal larvae encountered were preserved in $40 \%$ ethanol to be photographed under a compound microscope (50x magnification). Measurements of larval body and arm lengths (average of $\mathrm{R}$ and $\mathrm{L}$ arms where possible; Table 4.3), as well as size of rudiment in the late larval stage, were performed using the software ImageJ.

\subsubsection{STATISTICS}

All analyses were conducted using the software R (version 3.1), with the package 'multcomp' (Hothorn et al. 2008) for pairwise comparisons and the package 'nlme' (Pinheiro et al. 2015) for mixed effects models. Jars 2 (control) and 16 (copper/normal salinity, pulse experiment) were lost at $25 \mathrm{~d}$.

The effect of treatment on larvae was evaluated with respect to the following response variables: (1) larval survival, (2) normal larval development, (3) delayed development, (4) larval growth, and (5) final larval size.

Larval survival was the proportion of the initial number of larvae still alive at 16, 21 and $25 \mathrm{~d}$ post-fertilisation. Normal larval development was the proportion of 4, 6 and 8 -armed plutei at $16 \mathrm{~d}$ post-fertilisation, the proportion 6 and 8 -armed plutei at $21 \mathrm{~d}$ post-fertilisation, and the proportion of 8 -armed plutei at $25 \mathrm{~d}$ post-fertilisation. Both variables were square-root arcsin transformed.

Delayed development was assessed via three variables measured at $25 \mathrm{~d}$ postfertilisation: the proportion of normal larvae having reached the 8-armed pluteus stage, the proportion of 8 -armed larvae having a rudiment, and the proportion of larvae with a rudiment competent to settle (i.e. having a large, protruding rudiment; Table 4.3). All three variables were square-root arcsin transformed. 
Larval growth was measured as the proportional increase in size between 16 and $25 \mathrm{~d}$ post-fertilisation. Size was averaged per jar in each treatment and average size per jar was calculated only if more than five larvae could be measured per jar for each sampling. Variables were: body length (BL), postoral arms (PO), anterolateral arms (AL), and posterodorsal arms (PD; Table 4.3). Due to preservation issues, samples from only one jar with copper/normal salinity and copper/low salinity in the pulse experiment could be measured at 16 and $25 \mathrm{~d}$. Therefore, larval growth was analysed only for the chronic exposure. The final larval size was the individual larval size at 25 d post-fertilisation. Variables were BL, $\mathrm{PO}, \mathrm{AL}$, and $\mathrm{PD}$, as well as preoral arms (EO) and rudiment size (Table 4.3). All variables, both for larval growth and for final size, were log-transformed $(\mathrm{x}+1)$.

In the chronic experiment, the effects of copper (none, high) and salinity (low, normal), and their interaction, were evaluated using repeated measures two-way ANOVA with copper and salinity as the 'between' factors and larval age (16, 21 and $25 \mathrm{~d}$ post-fertilisation) as the 'within' factor, for survival and normal development, and two-way ANOVA for growth. At the end of the larval stage, no normal larvae remained in the high copper/low salinity treatment. Therefore, the remaining three treatments (control, low salinity and high copper/normal salinity) were analysed using one-way ANOVA for delayed development and a one-way mixed model (with jars as the random term) for final size. F-ratios were calculated for type II SS. Follow-up one-way ANOVAs and/or Tukey pairwise comparison tests were performed when appropriate.

For the pulse experiment, the effect of the three treatments (control, copper/normal salinity and copper/low salinity) were analysed using repeated measures one-way ANOVA for survival and normal development, one-way ANOVA for delayed development and growth, and a one-way mixed model (with jars as the random term) for final size. Tukey pairwise comparison tests were performed when appropriate. 


\subsection{RESULTS}

\subsubsection{EMBRYO/EARLY PLUTEUS EXPERIMENT}

Normal salinity controls had over 90\% normal development. All other treatments, including the low salinity/no copper treatment, had 0\% normal development. At $72 \mathrm{~h}$ post-fertilisation, none of the embryos at low salinity had hatched, while at normal salinity hatching usually occurs by 20 to $24 \mathrm{~h}$ post-fertilisation at $15-16^{\circ} \mathrm{C}$ (pers. obs.). In all cases, embryos seemed to be arrested before gastrulation. The egg membrane and embryo tissues did not appear damaged and no difference was observed between copper treatments.

\subsubsection{LARVAL EXPERIMENT}

\subsubsection{Larval survival}

In the chronic experiment, larval survival was affected by the presence of copper, with $30 \%$ and $55 \%$ decrease in survival in the copper/normal salinity treatment and copper/low salinity treatment, respectively, at $25 \mathrm{~d}$ post-fertilisation (Table 5.1, Figure 5.1). The effect of copper was significant from $21 \mathrm{~d}$ post-fertilisation (one-way ANOVA: $\left.F_{(1,10)}=16.39, p=0.002\right)$. Low salinity did not affect larval survival, with an average of $39 \%$ survival at low salinity (no copper) against $40 \%$ in controls at $25 \mathrm{~d}$ post-fertilisation.

Table 5.1: Repeated measures ANOVA of Evechinus chloroticus larval survival to test effects of copper exposure $(0 \mu \mathrm{g} / \mathrm{L}, 15 \mu \mathrm{g} / \mathrm{L})$ and salinity $(24 \mathrm{ppt}, 36 \mathrm{ppt})$ at 16,21 and $25 \mathrm{~d}$ post-fertilisation (Age) during the larval stage. Exposure to both stressors was chronic from 4 to 25 days postfertilisation. Significant effects $(\mathrm{p}<0.05)$ are highlighted in bold.

\begin{tabular}{lllll}
\hline Source of variation & Df & SS & $\boldsymbol{F}$ & p \\
\hline Salinity & 1 & 0.01 & 0.52 & 0.49 \\
Copper & 1 & 0.22 & 16.3 & $\mathbf{0 . 0 0 5}$ \\
Age & 2 & 0.49 & 19.3 & $<\mathbf{0 . 0 0 1}$ \\
Salinity x Copper & 1 & 0.07 & 5.46 & 0.05 \\
Salinity x Age & 2 & $<0.01$ & 0.05 & 0.95 \\
Copper x Age & 2 & 0.06 & 2.24 & 0.14 \\
\hline
\end{tabular}


In the pulse experiment, larval survival did not significantly vary with larval age or treatment (repeated measures ANOVA; Treatment: $\mathrm{F}_{(2,4)}=0.62, \mathrm{p}=0.58$; Age: $\mathrm{F}_{(2,8)}$ $=3.25, \mathrm{p}=0.09$; Treatment $\mathrm{x}$ Age: $\left.\mathrm{F}_{(4,8)}=0.32, \mathrm{p}=0.86\right)$.

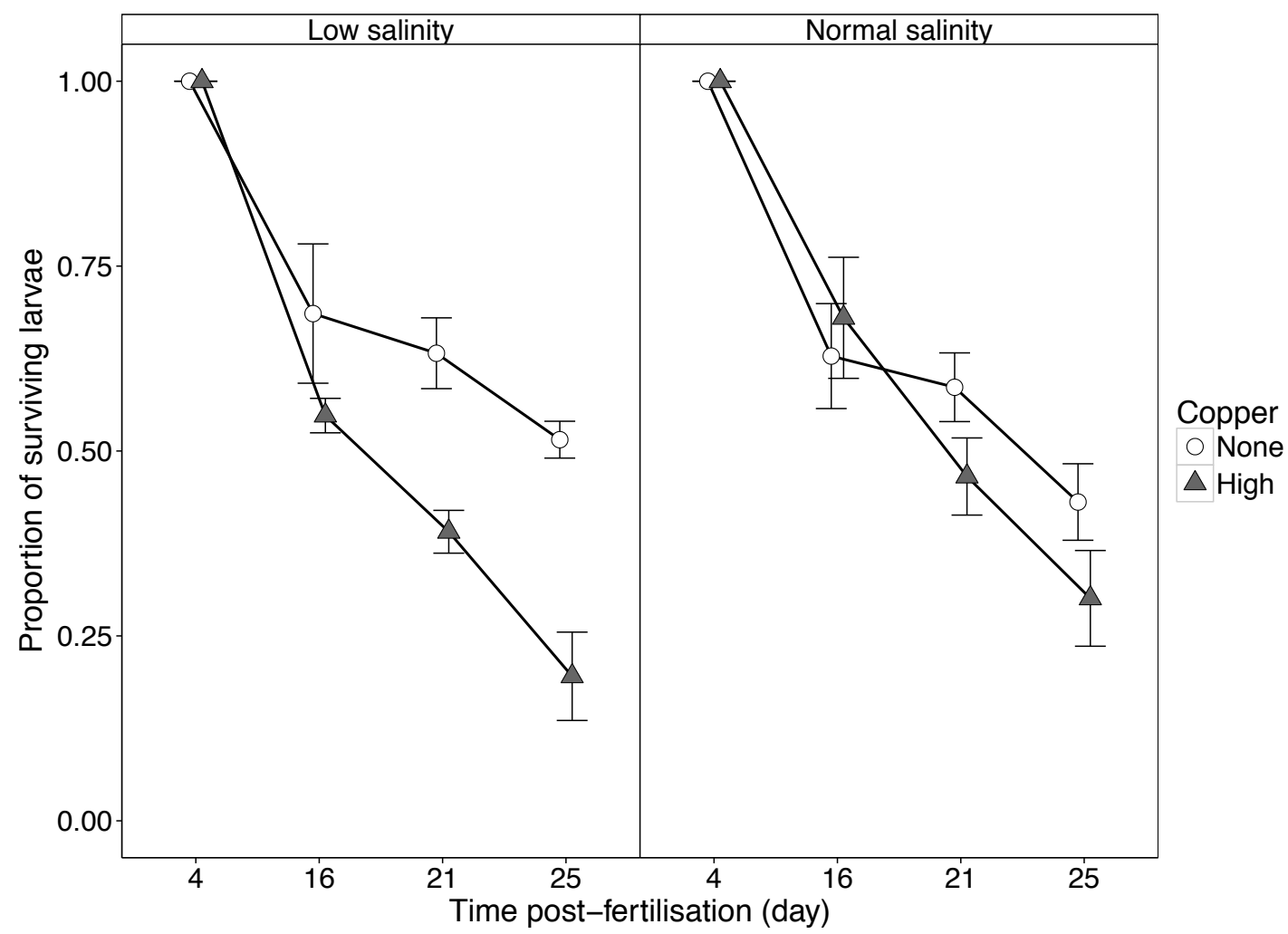

Figure 5.1: Evechinus chloroticus survival from 4 to $25 \mathrm{~d}$ post-fertilisation under different levels of copper exposure and salinity. Larvae were exposed $0 \mu \mathrm{g} / \mathrm{L}$ (None) or $15 \mu \mathrm{g} / \mathrm{L}$ (High) copper at low salinity (Low, $24 \mathrm{ppt}$ ) or normal seawater salinity (36 ppt). Exposure to both stressors was chronic from 4 to 25 days post-fertilisation. Error bars represent the standard deviation $(\mathrm{N}=3)$.

\subsubsection{Larval development}

In the chronic experiment, larval development was strongly influenced by salinity, copper and their interaction, as well as by age (Table 5.2a). The significant interaction between copper and age was driven by an increase in normal development from days 21 to 25 without copper, while a decrease occurred with copper (Figure 5.2a). Copper and salinity had a significant negative impact on the normal development of larvae from $16 \mathrm{~d}$ post-fertilisation (Table 5.3). Copper and salinity had a strong interaction from $21 \mathrm{~d}$ post-fertilisation, with no normal larvae remaining in the copper/low salinity treatment compared to $30 \%$ normal larvae in the copper/normal salinity treatment at $25 \mathrm{~d}$ post-fertilisation (Tukey HSD: in all cases $\mathrm{p}<0.01$, Figure 5.2a). 
The influence of the low salinity/no copper treatment was not significantly different from the normal salinity controls, but the proportion of normal larvae was strongly more heterogeneous in the low salinity/no copper treatments $(59 \% \pm 21$ normal larvae \pm standard deviation) than in the controls $(91 \% \pm 3)$.

Table 5.2: Repeated measures ANOVA of Evechinus chloroticus larval normal development to test effects of copper exposure and salinity at 16, 21 and $25 \mathrm{~d}$ post-fertilisation (Age) during the larval stage. Exposure to both stressors was either chronic (A), from 4 to 25 days post-fertilisation, or pulse (B), a single 4-day pulse at 7 days post-fertilisation. In the chronic experiment (A), the two main factors were salinity (24 ppt or $36 \mathrm{ppt})$ and copper $(0 \mu \mathrm{g} / \mathrm{L}$ or $15 \mu \mathrm{g} / \mathrm{L})$. In the Pulse experiment (B), treatments were normal salinity control, copper $(5 \mu \mathrm{g} / \mathrm{L})$ at normal salinity, and copper at low salinity. Significant effects $(\mathrm{p}<0.05)$ are highlighted in bold.

\begin{tabular}{lllll}
\hline Source of variation & Df & SS & $\boldsymbol{F}$ & $\mathbf{p}$ \\
\hline (A) Chronic exposure & & & & $<\mathbf{0 . 0 0 1}$ \\
Salinity & 1 & 0.91 & 80.7 & $<\mathbf{0 . 0 0 1}$ \\
Copper & 1 & 2.10 & 186 & $<\mathbf{0 . 0 0 1}$ \\
Age & 2 & 0.47 & 14.8 & $\mathbf{0 . 0 0 6}$ \\
Salinity x Copper & 1 & 0.20 & 17.7 & 0.08 \\
Salinity x Age & 2 & 0.10 & 3.12 & $\mathbf{0 . 0 1}$ \\
Copper x Age & 2 & 0.22 & 6.80 & \\
\hline (B) Pulse exposure & & & & $\mathbf{0 . 0 0 8}$ \\
Treatment & 2 & 0.25 & 19.7 & $\mathbf{0 . 0 4}$ \\
Age & 2 & 0.13 & 5.02 & 0.17 \\
Treatment x Age & 4 & 0.11 & 2.10 & \\
\hline
\end{tabular}

Table 5.3: Follow-up two-way ANOVA of the proportion of normal Evechinus chloroticus larvae, to test effects of copper exposure (none, $15 \mu \mathrm{g} / \mathrm{L}$ ), salinity $(24 \mathrm{ppt}, 36 \mathrm{ppt}$ ) and their interaction on separate age classes $(16,21$ and $25 \mathrm{~d}$ post-fertilisation). Exposure to both stressors was chronic from 4 to 25 days post-fertilisation. Significant effects $(\mathrm{p}<0.05)$ are highlighted in bold.

\begin{tabular}{llll}
\hline Larval age (days post- & Salinity & Copper & Salinity x Copper \\
fertilisation) & $\boldsymbol{F}(\mathbf{p})$ & $\boldsymbol{F}(\mathbf{p})$ & $\boldsymbol{F}(\mathbf{p})$ \\
\hline $16 \mathrm{~d}$ & $\mathbf{1 0 . 5 0}(0.01)$ & $\mathbf{3 7 . 4 5}(<\mathbf{0 . 0 0 1})$ & $0.08(0.05)$ \\
$21 \mathrm{~d}$ & $\mathbf{4 0 . 1 0}(<\mathbf{0 . 0 0 1})$ & $\mathbf{4 9 . 6 0}(<\mathbf{0 . 0 0 1})$ & $\mathbf{2 0 . 1 0 ( 0 . 0 0 2 )}$ \\
$25 \mathrm{~d}$ & $\mathbf{2 8 . 7 3 ( 0 . 0 0 2 )}$ & $\mathbf{7 6 . 8 4}(<\mathbf{0 . 0 0 1})$ & $\mathbf{8 5 . 3 0}(<\mathbf{0 . 0 0 1})$ \\
\hline
\end{tabular}

In the pulse experiment, normal larval development was significantly influenced by treatment and larval age (Table 5.2b). No difference among treatments occurred until $25 \mathrm{~d}$ post-fertilisation, when the response to the copper/low salinity treatment was significantly different from the controls (69\% lower), but not from the copper/normal salinity treatments (one-way ANOVA: $\mathrm{F}_{(2,4)}=14.6, \mathrm{p}=0.01$; Figure 5.2b). 


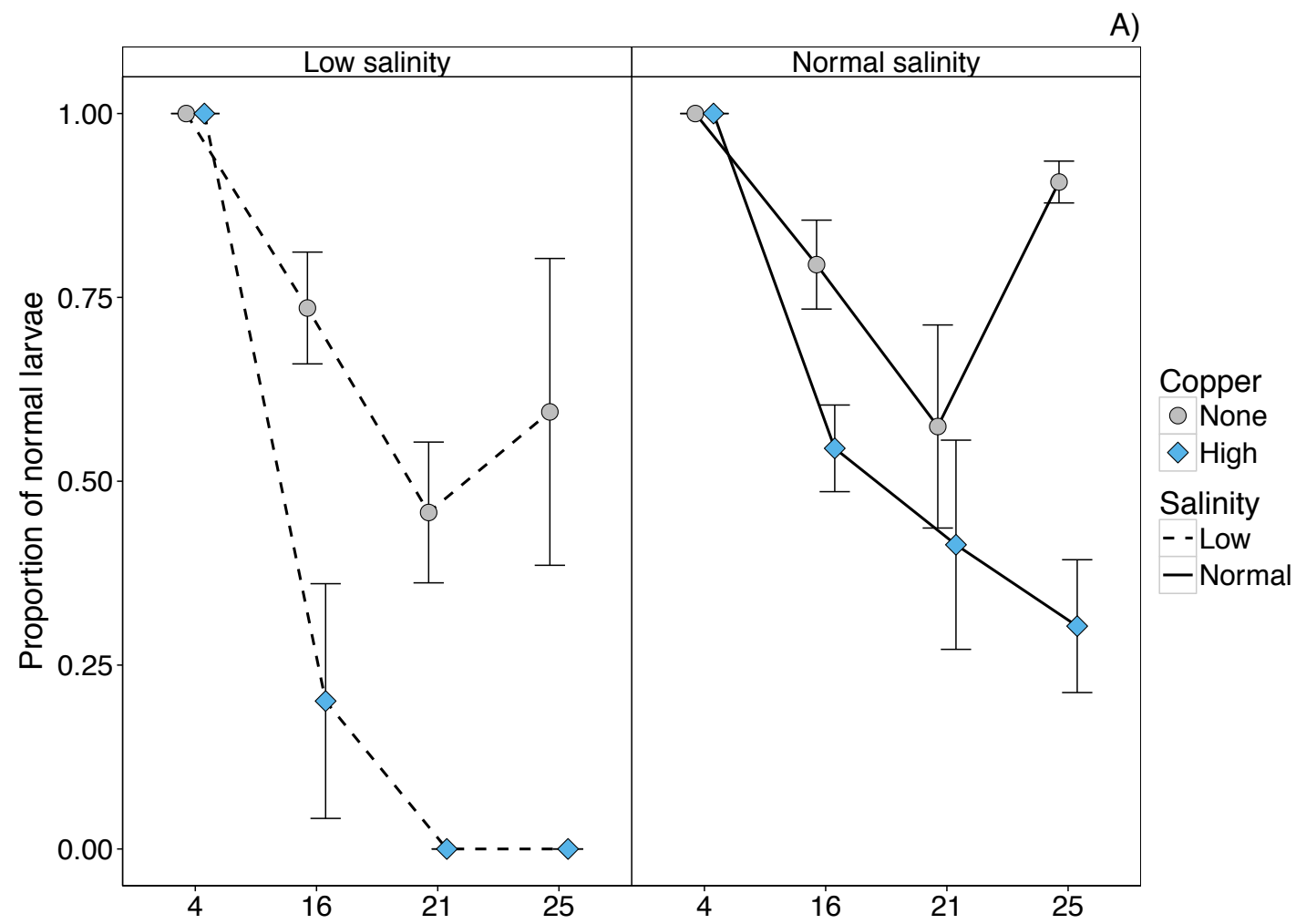

B)

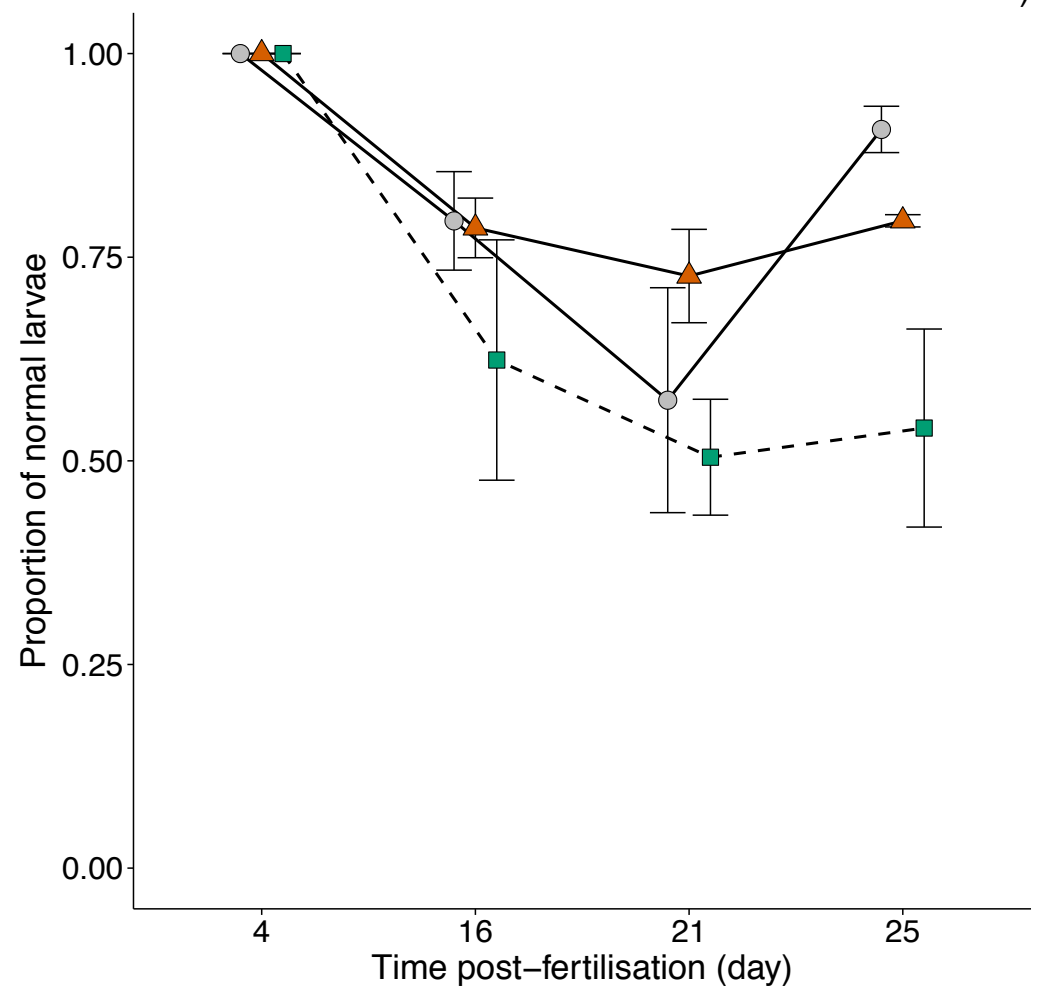

Figure 5.2: Proportion of normal Evechinus chloroticus larvae from $4 \mathrm{~d}$ to $25 \mathrm{~d}$ post-fertilisation under different levels of copper exposure and salinity. Larvae were exposed to low salinity (Low, $24 \mathrm{ppt}$ ) or natural seawater salinity (Normal, $36 \mathrm{ppt}$ ). Exposure to both stressors was either chronic (A) or a single 4-day pulse exposure (B). Copper levels are $0 \mu \mathrm{g} / \mathrm{L}$ (None and Control), $15 \mu \mathrm{g} / \mathrm{L}$ (High) in chronic exposure (A) and $5 \mu \mathrm{g} / \mathrm{L}$ (Low $\mathrm{Cu} /$ Normal salinity and Low $\mathrm{Cu} /$ Low salinity) in pulse exposure (B). Error bars represent the standard deviation $(\mathrm{N}=3)$. 


\subsubsection{Delayed development}

There was evidence of delayed development, with a reduced proportion of 8-armed plutei in both the chronic and the pulse experiments (one-way ANOVA; Chronic: $F_{(2,5)}=10.1, p=0.02$, Pulse: $\left.F_{(2,4)}=9.12, p=0.03\right)$. In the chronic experiment, only the copper/normal salinity treatment induced a significantly different response from controls (30\% vs. $88 \%$ of 8 -armed plutei, respectively; Figure 5.3a). Low salinity by itself did not significantly affect the proportion of 8 -armed plutei $(60 \%$ vs. $88 \%$ in controls). In the pulse experiment, the proportion of 8-armed plutei in the copper/low salinity treatment $(54 \%)$ was significantly different from controls but not from the copper/normal salinity treatment (77\%; Figure $5.3 \mathrm{~b})$.

The proportion of plutei with a rudiment was not significantly affected by low salinity/no copper or copper/normal salinity in the chronic experiment (one-way ANOVA: $\mathrm{F}_{(2,5)}=3.33, \mathrm{p}=0.12$; Figure 5.3a). In the pulse experiment, the difference between treatments (one-way ANOVA: $\mathrm{F}_{(2,4)}=9.35, \mathrm{p}=0.03$ ) was driven by copper/low salinity (Figure $5.3 \mathrm{~b}$ ). Only $19 \%$ of 8 -armed plutei had a rudiment in the copper/low salinity treatment, compared to $52 \%$ in controls and $55 \%$ in the copper/normal salinity treatment (Tukey HSD: in all cases $\mathrm{p}<0.05$ ).

Larvae in the copper/low salinity treatment had mostly recovered from their developmental delay after three days in the pulse experiment. At 28 d postfertilisation, the proportion of 8 -armed plutei was $79 \% \pm 32$ in copper/low salinity $v s$. $87 \% \pm 7$ in normal salinity controls, at $25 \mathrm{~d}$ post-fertilisation. Similarly, the proportion of larvae with a rudiment was $68 \% \pm 17$ in the copper/low salinity treatment vs. $60 \% \pm 1$ in the normal salinity controls. 

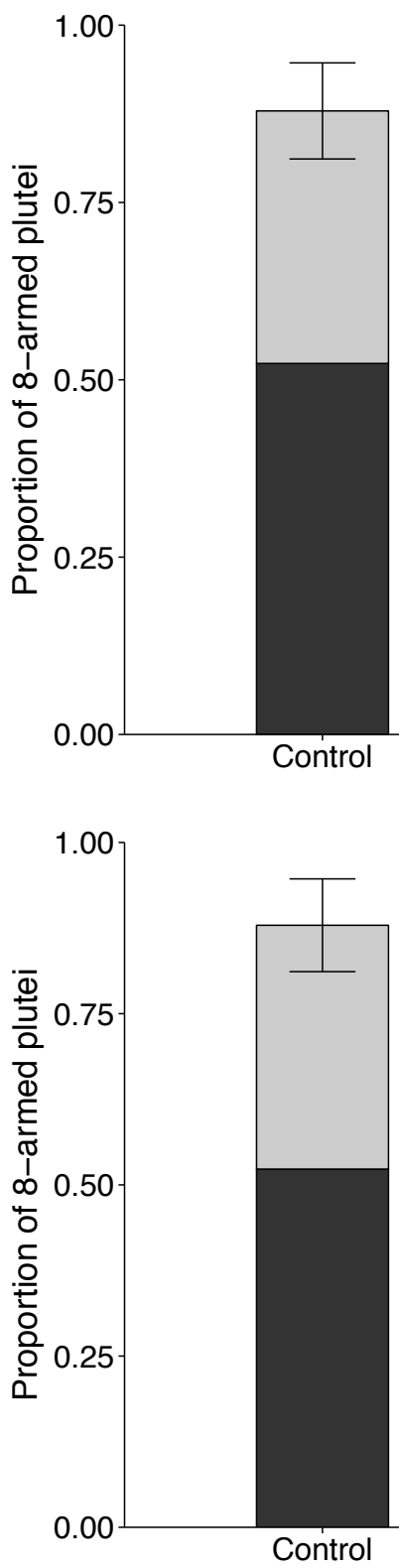

A)

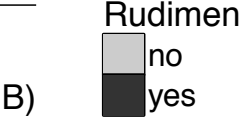

Figure 5.3: Proportion of 8-armed Evechinus chloroticus larvae with or without rudiment at 25 days post-fertilisation when exposed to stressors chronically (A), from day 4 to 25 , and a single 4-day pulse (B). Treatments in the chronic experiment (A) were: seawater control (36 ppt), high copper at normal salinity $(15 \mu \mathrm{g} / \mathrm{L})$ and low salinity/no copper $(24 \mathrm{ppt})$. Treatments in the pulse experiment (B) were: seawater control, low copper at normal salinity $(5 \mu \mathrm{g} / \mathrm{L})$ and low copper at low salinity $(5 \mu \mathrm{g} / \mathrm{L}, 24 \mathrm{ppt})$. Error bars represent the standard deviation of the total proportion of 8-armed larvae $(\mathrm{N}=3)$. 


\subsubsection{Larval size}

A delay in development was also evident in the growth of $\mathrm{AL}$ and $\mathrm{PD}$, which are arms that develop later in larval development. In controls, these arms had completed most of their growth before day 16 (Figure 5.4). In experimental treatments, AL and PD were little developed by day 16, and growth rate was higher than for controls (Table 5.4). For AL, growth was significantly higher in the copper treatment $(95 \%$ higher than controls), while for PD growth was significantly higher in the low salinity treatment ( $92 \%$ higher than control).
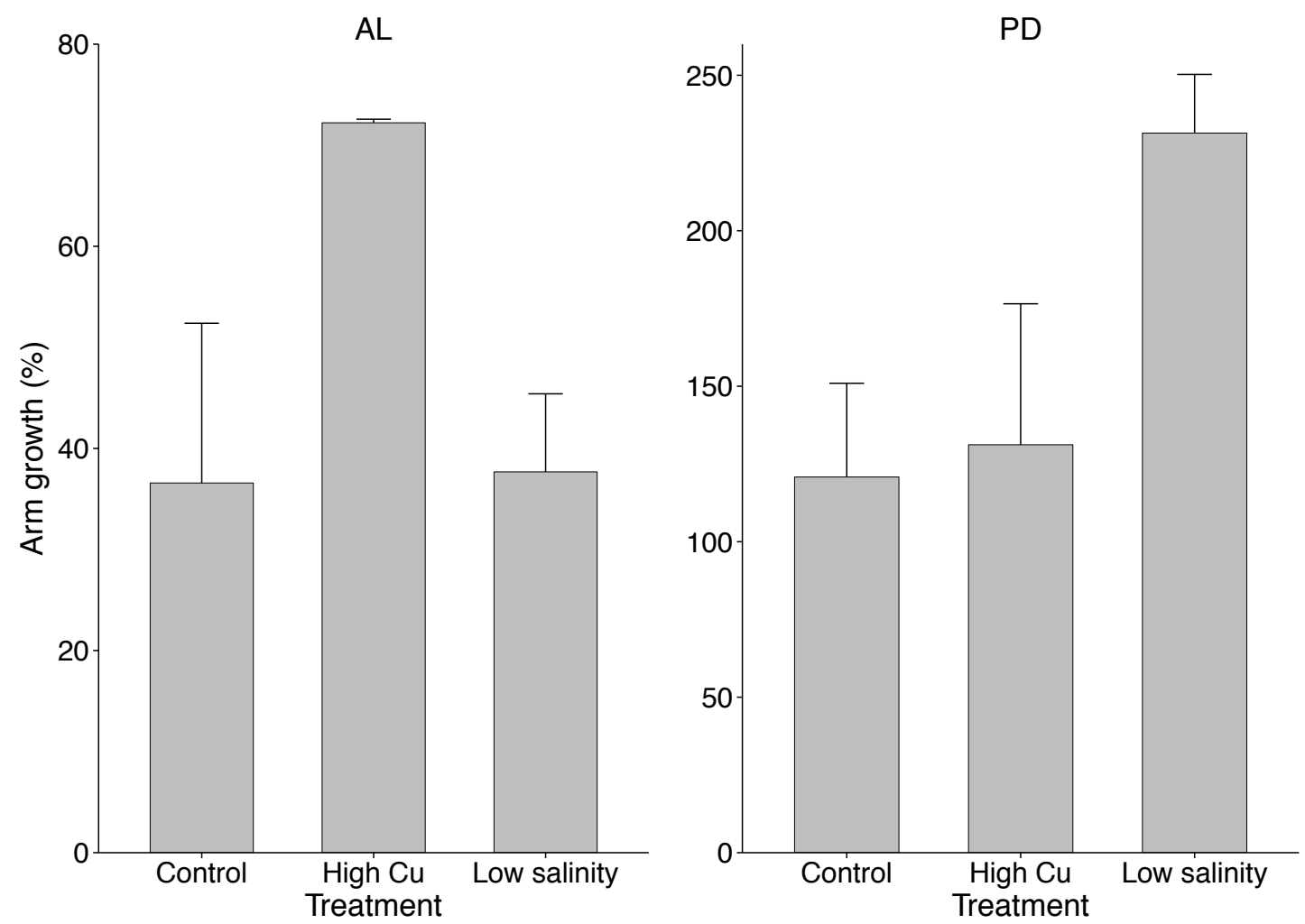

Figure 5.4: Anterolateral arm (AL) and posterodorsal arm (PD) growth in Evechinus chloroticus larvae between 16 and 25 days post-fertilisation under different regimes of copper exposure and salinity. Treatments are: seawater control (36 ppt), high copper at normal salinity $(15 \mu \mathrm{g} / \mathrm{L})$ and low salinity/no copper ( $24 \mathrm{ppt}$ ). Exposure to both stressors was chronic from 4 to 25 days post-fertilisation. Error bars represent the standard deviation $(\mathrm{N}=3)$. 
Table 5.4: One-way ANOVA of Evechinus chloroticus growth, to test effects of chronic copper at normal salinity $(15 \mu \mathrm{g} / \mathrm{L} \mathrm{Cu}, 36 \mathrm{ppt})$ and chronic low salinity with no added copper (24 ppt) between 16 and $25 \mathrm{~d}$ post-fertilisation. Growth variables were body length (BL), postoral arms (PO), anterolateral arms (AL) and posterodorsal arms (PD). Exposure to both stressors was chronic from 4 to 25 days post-fertilisation. Significant effects $(\mathrm{p}<0.05)$ are highlighted in bold.

\begin{tabular}{lllll}
\hline Variable & df & SS & $\boldsymbol{F}$ & p \\
\hline BL & 2,4 & 0.01 & 2.19 & 0.23 \\
PO & 2,4 & $<0.01$ & 0.23 & 0.80 \\
AL & 2,4 & 0.08 & 7.53 & $\mathbf{0 . 0 4}$ \\
PD & 2,4 & 0.26 & 8.17 & $\mathbf{0 . 0 4}$ \\
\hline
\end{tabular}

The final sizes late in development were not significantly different between treatments, except with respect to EO, the last pair of arms to develop. At $25 \mathrm{~d}$ postfertilisation, EO were significantly shorter in the chronic low salinity treatment (150 $\mu \mathrm{m} \pm 58$ vs. $237 \mu \mathrm{m} \pm 67$ in controls; mixed effect ANOVA: $\left.\mathrm{F}_{(2,4)}=7, \mathrm{p}=0.04\right)$, and in the pulse copper/low salinity treatment $\left(135 \mu \mathrm{m} \pm 60\right.$; mixed effects ANOVA: $F_{(2}$, 4) $=10, \mathrm{p}=0.03)$.

No difference in the size of the rudiment was observed between treatments in both the chronic and the pulse exposures at $25 \mathrm{~d}$ post-fertilisation.

\subsection{DISCUSSION}

Chronic copper exposure was severely detrimental to larval survival, normal development and late pluteus formation. Low salinity by itself had a strong effect on embryos when exposure occurred shortly after fertilisation, with a complete inhibition of development. By contrast, only a minor delay in arm growth was observed when exposure to low salinity occurred later in larval development. A strong synergistic effect between low salinity and copper was observed on normal development with chronic exposure (and high copper concentration), but not with pulse exposure to low copper levels.

\subsubsection{SINGLE STRESSOR: LOW SALINITY}

Low salinity had a far greater effect on early embryo development than for later larval development, with no hatching observed when embryos were exposed to $26 \mathrm{ppt}$ salinity shortly after fertilisation. This is consistent with the findings of a previous 
study showing no hatching of E. chloroticus embryos under 27.5 ppt (Antonie 2003). Salinity tolerance varies between echinoid species but severe effects on embryonic or larval development have been reported from 15 ppt to 32 ppt (Cowart et al. 2008, Allen \& Pechenik 2010, Russell 2013, Delorme \& Sewell 2014). Sea urchin embryos might resume development when returned to normal salinity, as observed by Allen \& Pechenik (2010). However, in their study, approximately 20\% of embryos recovered after less than $1 \mathrm{~h}$ exposure to low salinity. It is unclear whether embryos with their development arrested for three days could recover, but mortality would likely be very high. Such decreases in salinity are common in the field. In Wellington, salinity as low as $12 \mathrm{ppt}$ was measured up to $1 \mathrm{~km}$ offshore in surface water $(30 \mathrm{~cm})$ in a river plume one day following a rain event, and $18 \mathrm{ppt}$ near-shore three days after the rain event (Tables A.1 and A.2). The extent and depth of low salinity associated with a river plume varies greatly between river systems and seasonally. For example, a river plume of 16 to $26 \mathrm{ppt}$ over a depth of $10 \mathrm{~m}$ and spreading more than $20 \mathrm{~km}$ offshore has been recorded for the Columbia River (U.S West Coast) following typical annual rain events (McCabe et al. 2008). In a New Zealand fjord, Doubtful Sound, the low salinity surface layer (typically 5 - $30 \mathrm{ppt}$ ) is permanent, varying from 2 to $8 \mathrm{~m}$ deep (Stanton 1984, Lamare 1998, Antonie 2003).

The effects of low salinity when encountered later during larval development are far less severe. In this study, only a delay in growth of the last two pairs of arms to develop (i.e. the posterodorsal and preoral arms) was observed. By the end of the experiment, the posterodorsal arms had increased in length and were not significantly shorter than controls. The preoral arms were still less than $40 \%$ shorter than controls at $25 \mathrm{~d}$ post-fertilisation, but would likely reach the size of controls within several days. It is likely that all pairs of arms were affected by a delay in growth, but arms developing earlier in the larval stage had already reached control sizes by the mid larval stage, when the first size measurements were made. Shorter arm length may impact feeding ability, as feeding rate increases with arm length (Strathmann 1971). However, because the size difference was not very large and delayed arms seem to grow rapidly, the effect on feeding is probably small. 


\subsubsection{SINGLE STRESSOR: COPPER}

Chronic exposure to $15 \mu \mathrm{g} / \mathrm{L}$ of copper had a negative impact on survival, normal development, pluteus formation and, to a lesser extent, arm growth in larvae, but a four day pulse exposure to $5 \mu \mathrm{g} / \mathrm{L} \mathrm{Cu}$ had no direct impact on larval performance. This is consistent with my previous experiments on E. chloroticus (Chapter 3 and 4). No direct effect was observed on larvae exposed to $6 \mu \mathrm{g} / \mathrm{L} \mathrm{Cu}$ during a 2-day pulse exposure, but a developmental delay was observed in larvae exposed to $10 \mu \mathrm{g} / \mathrm{L} \mathrm{Cu}$ for two days (Figure B.1). Similarly, effects on development was observed in larvae exposed to $10 \mu \mathrm{g} / \mathrm{L}$ both chronically and for a 4-day pulse (Figure 4.2). This confirms that pulse exposure to copper concentrations below $10 \mu \mathrm{g} / \mathrm{L}$ produces no immediate impact on larval development, although latent effects may occur on later life stages.

\subsubsection{MULTIPLE STRESSORS}

Low salinity increased copper toxicity dramatically in E. chloroticus larvae under a chronic exposure scenario. There was no success in larval development when both stressors were present, compared with more than 50\% larvae reaching normal development (including a rudiment) by $25 \mathrm{~d}$ post-fertilisation with copper at normal salinity and $27 \%$ with no added copper at low salinity. The influence of low salinity on copper bioavailability is well known. The high concentration of cations, such as sodium, in seawater competes with the toxic free copper ion $\left(\mathrm{Cu}^{2+}\right)$ for binding sites in marine organisms, thus reducing copper accumulation and toxicity (Santore et al. 2001). Most studies on copper and salinity have shown an increase in copper toxicity under hyposaline conditions (McLusky et al. 1986, Patel \& Bielmyer-Fraser 2015). On the other hand, in some marine species, copper toxicity was independent of salinity (Nadella et al. 2009, Lee et al. 2010). However, all these studies used chronic exposure to both stressors. The present study shows little evidence of an interaction between copper and salinity under realistic field conditions (i.e. low copper concentration and 4-d pulse exposure). The proportion of normal larvae and fully developed larvae was slightly lower in the presence of copper at low salinity, resulting in a significant difference compared to controls. However, the difference between exposure to copper at low salinity and copper at normal salinity was never large enough to be significant, except with respect to rudiment formation. The 
proportion of larvae having a rudiment was $80 \%$ lower when they were exposed to copper at low salinity compared to normal salinity, but this delay was offset in less than three days. This highlights the importance of using realistic levels and durations of stressors in laboratory assays to evaluate the possible consequences of these stressors in field populations.

\subsubsection{CONSEQUENCES FOR FIELD POPULATIONS}

Although low salinity had strong deleterious effects on E. chloroticus embryos, effects on larvae were relatively small, and it is larvae that are more likely to encounter freshwater discharge as they spend more time in the surface layer for feeding. Low salinity increased copper toxicity under chronic exposure but not under pulse exposure, which is more likely in the field. Therefore, it appears that combined exposure to these two stressors would not likely have major impacts on sea urchin larvae in the field. It should be noted, however, that exposure to low salinity and copper may have latent effects not detectable in this study. Indeed, my previous experiments have shown that stressors encountered during E. chloroticus larval development may have further and more dramatic impacts on settlement success and settler performance than on larval development itself (Chapter 3 and 4). It is crucial to evaluate the potential for latent impacts of combined copper and salinity stressors in order to more fully understand the effect of copper in contaminated runoff on sea urchin populations.

If a synergistic relationship between copper and low salinity occurs under field conditions, it may be mitigated by the ability of sea urchin larvae to avoid freshwater exposure by adjusting their position in the water column (Metaxas \& Young 1998, Sameoto \& Metaxas 2008). The absence of E. chloroticus larvae in the low salinity layer in Fjordland, New Zealand, suggests that this avoidance behaviour may also be effective in the field, at least when the low salinity layer is maintained over long periods due to lack of mixing (Lamare 1998, Antonie 2003). Such behaviour would be highly beneficial to larvae, as it would also reduce the risk of exposure to copper and other contaminants associated with freshwater discharges, especially in lowdynamism systems, where residence-time of contaminants is likely to be higher. 
Furthermore, freshwater runoff is also generally characterised by elevated levels of dissolved organic carbon (DOC). DOC has been shown to reduce copper toxicity by binding with copper free ions, thus reducing their bioavailability (Nadella et al. 2009, Monteiro et al. 2013). These findings highlight the complexity of urban runoff and how the various components may affect marine populations in the field. 


\title{
CHAPTER 6
}

\section{Copper burden in gonads and fertilisation success in the sea urchin Evechinus chloroticus}

\begin{abstract}
The environmental conditions in which parents live may affect their gamete quality and offspring success. Copper is a highly prevalent pollutant in coastal systems and is well known to affect sperm quality in marine organisms. However, the effect of copper in gonadal tissue on fertilisation success in sea urchins is poorly known. Here I measured the accumulation of copper in gonads of the sea urchin Evechinus chloroticus after two weeks of exposure to $50 \mu \mathrm{g} / \mathrm{L} \mathrm{Cu}$ in the laboratory and then evaluate the fertilisation success of exposed males. Fertilisation occurred in clean seawater or in copper-polluted seawater $(15 \mu \mathrm{g} / \mathrm{L})$, to investigate whether copper contamination in the gonads affects gamete tolerance to copper in the water during fertilisation. I also compared the copper burden of experimentally contaminated animals to natural populations from a moderately polluted and a control site. Copperexposed adults had a copper burden in gonads 25-times higher than in control animals. Strong sublethal effects were observed in adults, with a near total impairment of feeding, low adherence to substrate and low spawning success. Despite an extremely elevated copper burden, the fertilisation success of exposed males was not affected. There was also no evidence of copper toxicity on gametes that were directly exposed to $15 \mu \mathrm{g} / \mathrm{L}$, whether they were from contaminated males or not. Fertilisation experiments were performed at high sperm density, which may have masked a
\end{abstract}


potential toxic effect of copper. Copper burden in animals from the urban site was $35 \%$ higher than in the control site but was well below laboratory-exposed animals. These results show that E. chloroticus is sensitive to copper as an adult, readily accumulates copper in its gonads, and is a suitable indicator of copper pollution. Elevated copper burden may have a strong impact on spawning success, especially for females, but may not impair fertilisation success, at least for males living in dense populations.

\subsection{INTRODUCTION}

Environmental stressors, such as pollutants, may impair reproductive success of adults by decreasing the quality and/or quantity of their gametes, leading to a decrease in fertilisation success and/or offspring viability. In recent years, several studies have highlighted the importance of parental effects on gamete quality and offspring success (Marshall \& Keough 2004, Marshall 2008, Burgess \& Marshall 2011, Lister et al. 2015). Parental effects are not necessarily negative; in fact, parental exposure to a stressor may increase the resistance of their offspring to the same stressor (Marshall \& Uller 2007, Suckling et al. 2014). Furthermore, in broadcast spawning species, the environment in which gametes are released can impair fertilisation success and have a carry-over effect on larval performance (Allen \& Pechenik 2010, Ritchie \& Marshall 2013).

Metals are known to impair gamete quality and fertilisation success in many marine organisms, including sea urchins. Sperm bioassays that have been used for decades demonstrate that sperm is highly sensitive to a variety of toxicants, with results on fertilisation success usually visible in minutes (Dinnel et al. 1987, 1989, Ringwood 1992). Copper is a major pollutant in many industrial countries and is considered as a priority pollutant by environmental authorities due to its high toxicity to aquatic life (ANZECC 2000, US EPA 2014). The exposure of gametes to copper affects reproduction success in sea urchins by impairing sperm motility (Hollows et al. 2007, Fitzpatrick et al. 2008). However, these studies assessed reproductive impairment via direct exposure of gametes rather than parental exposure. A decrease in gamete 
quality or fertilisation success following adult exposure to metals has been documented in sea urchins for cadmium (Au et al. 2001) and lead (Nacci et al. 2000), but has not been examined for copper. Durkina \& Evtushenko (1991) reported that adult exposure to copper increased the developmental rate of larvae, but they did not evaluate the effects on fertilisation success.

The gonads of sea urchins readily accumulate copper. Indeed sea urchins are often used as an indicator species, with metal burden in gonads reflecting the short-term fluctuation in pollution, while metal burden in hard tissues reflects long-term pollution (Flammang et al. 1997, Soualili et al. 2008, Salvo et al. 2014). The relationship between copper accumulation in gonads and fertilisation impairment is, however, still unknown (Au et al. 2001).

In this study, I evaluated whether acute exposure to high copper concentration leads to an increase in copper burden in gonads within a short time frame (two weeks), and I quantified the fertilisation success of exposed animals. Gametes were also subjected to direct exposure to a moderately elevated level of copper in the water during fertilisation, to investigate whether parental exposure affects gametes' tolerance to copper. Finally, I compared copper burden in gonads between natural populations and animals exposed in the laboratory, to evaluate whether populations from a moderately polluted urban site might be at risk of reproductive impairment.

\subsection{Methods}

\subsubsection{COPPER BURDEN IN GONADS}

\subsubsection{Laboratory experiment}

Adult E. chloroticus were collected at the beginning of the spawning season (October 2013) from Kau Bay $\left(41.2882^{\circ} \mathrm{S}, 174.8326^{\circ} \mathrm{E}\right)$, Wellington. Half of this group (KB1, $\mathrm{N}=16$ ) was kept for three weeks in the laboratory in a recirculating system in clean filtered seawater $(0.2 \mu \mathrm{m}, \mathrm{FSW})$. The other half $(\mathrm{LAB}, \mathrm{N}=16)$ was kept in similar conditions, but in clean seawater for a period of acclimation of one week and then in 
copper-contaminated FSW $(50 \mu \mathrm{g} / \mathrm{L})$ for two weeks. The recirculating system consisted of two 200 L high-density polyethylene containers from which seawater was pumped into $20 \mathrm{~L}$ tanks (eight adults per tanks). Flow rate was $6 \mathrm{~L} / \mathrm{min}$. Tanks were cleaned and the water was fully renewed every two days. Adult E. chloroticus were fed twice a week with native kelp (Macrocystis pyrifera). During the second week of exposure, kelp wet weight was recorded at each feeding, to evaluate the quantity of food consumed per tank. Temperature, $\mathrm{pH}$ and dissolved oxygen were recorded twice a week to ensure homogeneity of these parameters across tanks.

\subsubsection{Field populations}

Adult E. chloroticus were collected at the end of the spawning season (late March 2014) from Kau Bay (KB2, $\mathrm{N}=11)$, a site far from major effluents and contamination sources, and from Frank Kitts Park (FK, $N=9)$, an inner harbour site receiving urban runoff. Sites were chosen based on a pilot study that compared copper burden in gonads from seven populations across Wellington Harbour (Appendix D). Animals were kept in the same recirculating system described above, with clean FSW to acclimate for three weeks before gonads were sampled.

\subsubsection{Metal analysis}

After spawning, all animals were measured (test diameter), and the gonads were dissected out and weighed (wet weight). To reduce the risk of metal contamination during the drying process, wet samples were used in all spectrometry work. A subsample of gonad tissues was taken for analysis of copper content, while the remaining tissues were dried at $60^{\circ} \mathrm{C}$ to determine the moisture content. In this study, copper burden in tissues is reported as $\mu \mathrm{g} / \mathrm{g}$ of wet weight, but the average moisture content is provided for conversion to dry weight if necessary, for comparison with other species. Wet subsamples were digested in nitric acid and analysed by graphitefurnace atomic absorption spectrometry following the U.S. EPA standard protocol (Creed \& Martin 1997). Accuracy was checked by analysing two duplicate samples that had been fortified using a certified copper stock solution (Merck Millipore). Recovery was within $13 \%$ for each sample run. 


\subsubsection{FERTILISATION SUCCESS}

Animals from KB1 (control) and LAB (copper exposed) were induced to spawn in the laboratory, to obtain gametes from three males and three females in each group. The spawning protocol is described in Chapter 2.2.1. However, in the copper-exposed group, only one female of seven and three males of eight successfully spawned. Therefore, only exposed males were used in fertilisation assays. The three control females were paired either with the three control males (pair CC1, CC2 and CC3) or with the three exposed males (pair EC1, EC2 and EC3). Therefore, the pairs with the same number shared the same female (e.g. CC1 and EC1). Gametes from each pair were placed in six $10 \mathrm{ml}$ glass vials: three replicate controls vials containing FSW and three replicate copper vials containing $15 \mu \mathrm{g} / \mathrm{L}$ of copper (reagent grade copper sulphate $\mathrm{CuSO}_{4} \cdot 5 \mathrm{H}_{2} \mathrm{O}$ ). Eggs and sperm were left in contact for $1 \mathrm{~h}$ before being preserved in $40 \%$ ethanol. Egg density was 100 eggs $/ \mathrm{ml}$ and sperm density (measured with a heamocytometer) was $10^{5}$ per $\mathrm{ml}$. Sperm density was chosen based on a pilot study evaluating the effects of copper exposure on fertilisation success at different sperm densities. Fertilisation success was evaluated by observing 100 eggs per vial for signs of a fertilisation membrane under 200x magnification. Strongly nonspherical or otherwise damaged eggs were recorded as abnormal.

\subsubsection{STATISTICS}

All data analyses were conducted using the software R (version 3.1) with package multcomp (Hothorn et al. 2008) for pairwise comparisons and package nlme (Pinheiro et al. 2015) for mixed effects models.

\subsubsection{Copper burden in gonads}

Copper burden in gonads was analysed separately for animals used in the laboratory experiment (LAB and $\mathrm{KB} 1)$ and for animals from field populations (KB2 and FK) and control animals used in the laboratory experiment (KB1). The effect of sex, body size (test diameter), total gonad wet weight, and whether animals had released gametes before dissection were evaluated by selecting the best model using a stepwise regression based on AIC criterion. Best models were then analysed using 
ANOVAs or ANCOVAs when covariates were included. Interactions are presented only when selected in the best model. F-ratios were calculated from Type II SS. Post hoc comparisons were performed using a Tukey test $(\mathrm{p}<0.05)$ when the field population factor was significant.

\subsubsection{Fertilisation success}

The effects on fertilisation success of both adult contamination and gamete exposure to copper in the water were analysed using a nested mixed effects model, with adult exposure and gamete exposure as fixed factors, and gamete exposure being nested in adult pair (random factor).

\subsection{RESULTS}

\subsubsection{LABORATORY EXPERIMENT}

\subsubsection{Copper burden in gonads}

The copper burden was significantly affected by copper exposure, sex and total gonad weight; multiple $\mathrm{R}^{2}$ was 69\% (Table 6.1a). Exposed adults (LAB) had a copper burden in their gonads that was 25-fold higher than in control animals (KB1; Figure 6.1a). The interaction between treatment and sex, and between treatment and gonad weight were due to the fact that sex and gonad weight were a significant source of variation only in the LAB group (two-way ANOVA; Sex: $F_{(1,11)}=7.31, p=0.02$; Gonad: $\left.F_{(1,11)}=18.95, p=0.001\right)$. In the LAB group, the copper burden was $51 \%$ higher in males than in females (Figure 6.1a). Sea urchins with larger gonads had, on average, a lower copper burden than individuals with smaller gonads in the LAB group (Figure 6.2). 
Table 6.1: Effect of Evechinus chloroticus copper treatment (A) or source populations (B) and individual characteristics on copper burden in gonads, analysed using ANCOVA (A) or ANOVA (B). Individual characteristics are sex, total gonad weight and whether the animal had spawned before dissection. Animals were from natural populations (B) or were exposed to $50 \mu \mathrm{g} / \mathrm{L}$ of copper for two weeks in the laboratory (A). Copper burden was log-transformed to meet ANCOVA assumptions. Significant effects $(\mathrm{p}<0.05)$ are highlighted in bold. $F$-ratios are calculated from Type II SS.

\begin{tabular}{|c|c|c|c|c|}
\hline Source of variation & Df & SS & $\boldsymbol{F}$ & $\mathbf{P}$ \\
\hline \multicolumn{5}{|c|}{ (A) Laboratory experiment } \\
\hline Treatment & 1,24 & 24.2 & 383 & $<0.001$ \\
\hline Sex & 1,24 & 0.61 & 9.69 & 0.005 \\
\hline Gonad wt & 1,24 & 0.36 & 5.65 & 0.03 \\
\hline Treatment x Sex & 1,24 & 0.31 & 4.81 & 0.04 \\
\hline Treatment x Gonad wt & 1,24 & 1.96 & 31.0 & $<0.001$ \\
\hline \multicolumn{5}{|l|}{ (B) Field populations } \\
\hline Population & 2,30 & 0.55 & 21.2 & $<0.001$ \\
\hline Sex & 1,30 & 0.03 & 1.92 & 0.18 \\
\hline Spawned & 1,30 & 0.02 & 1.80 & 0.19 \\
\hline
\end{tabular}



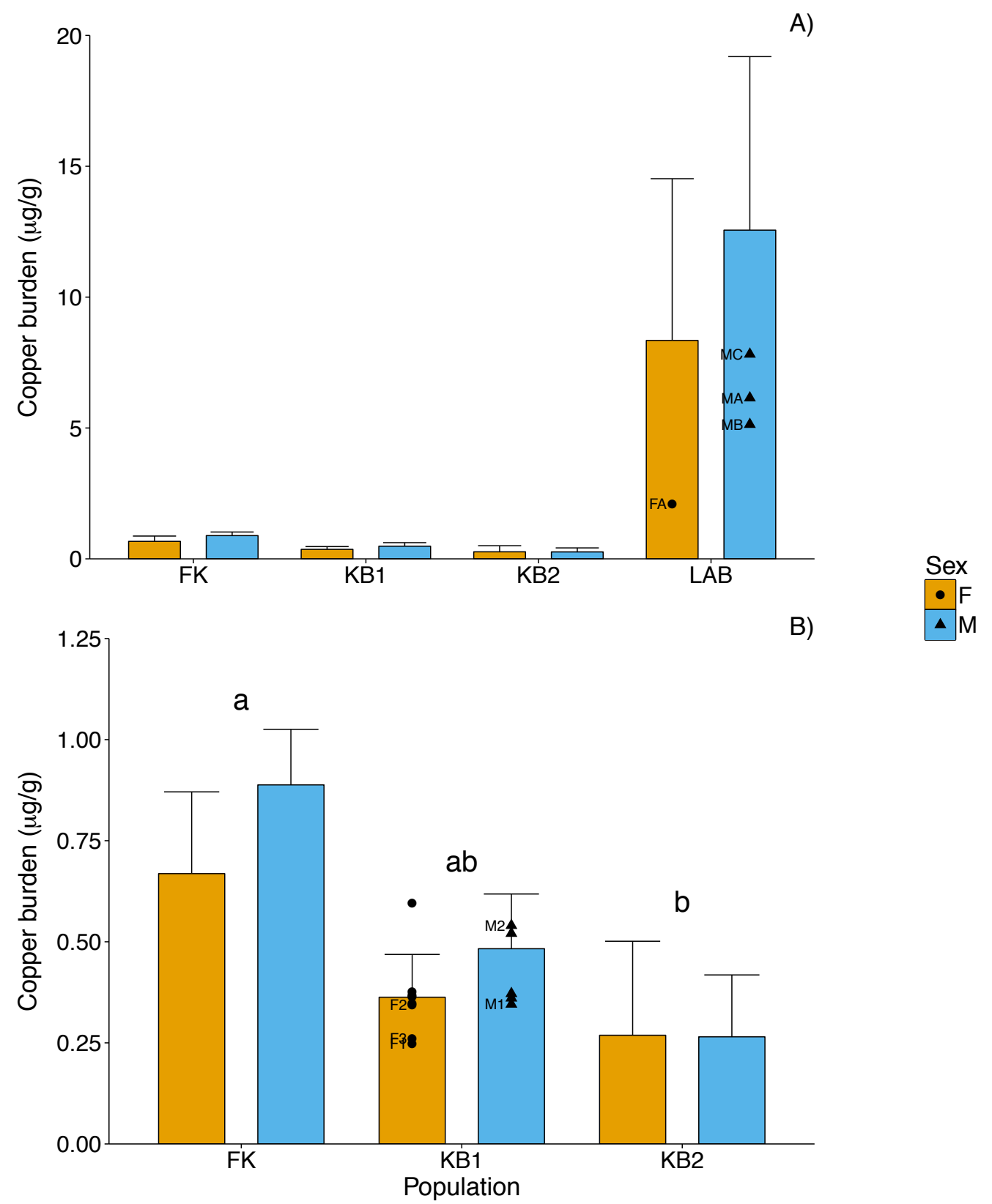

Figure 6.1: Copper accumulation in gonads ( $\mu \mathrm{g} / \mathrm{g}$ wet weight) of the sea urchin Evechinus chloroticus. Animals were from: Frank Kitts Lagoon (FK), a polluted inner city lagoon; a control site far from effluents and major contamination sources (Kau Bay, KB1 and KB2); and animals from Kau Bay held in $50 \mu \mathrm{g} / \mathrm{L}$ of copper for two weeks in the laboratory (LAB). Sea urchins were collected at the beginning of the spawning season (KB1 and LAB) and at the end of the spawning season (KB2 and FK). Error bars represent the standard deviation $(\mathrm{N}=4$ to 8). Black circles (females) and triangles (males) represent individuals that successfully spawned and text labels mark the parents used in the fertilisation experiment (e.g. F1 and M1 = pair CC1, F2 and MB = pair EC2; Figure 6.3). Lower case letters (B) show groupings based on pairwise comparisons (Tukey test, $\mathrm{p}<0.05$ ). 


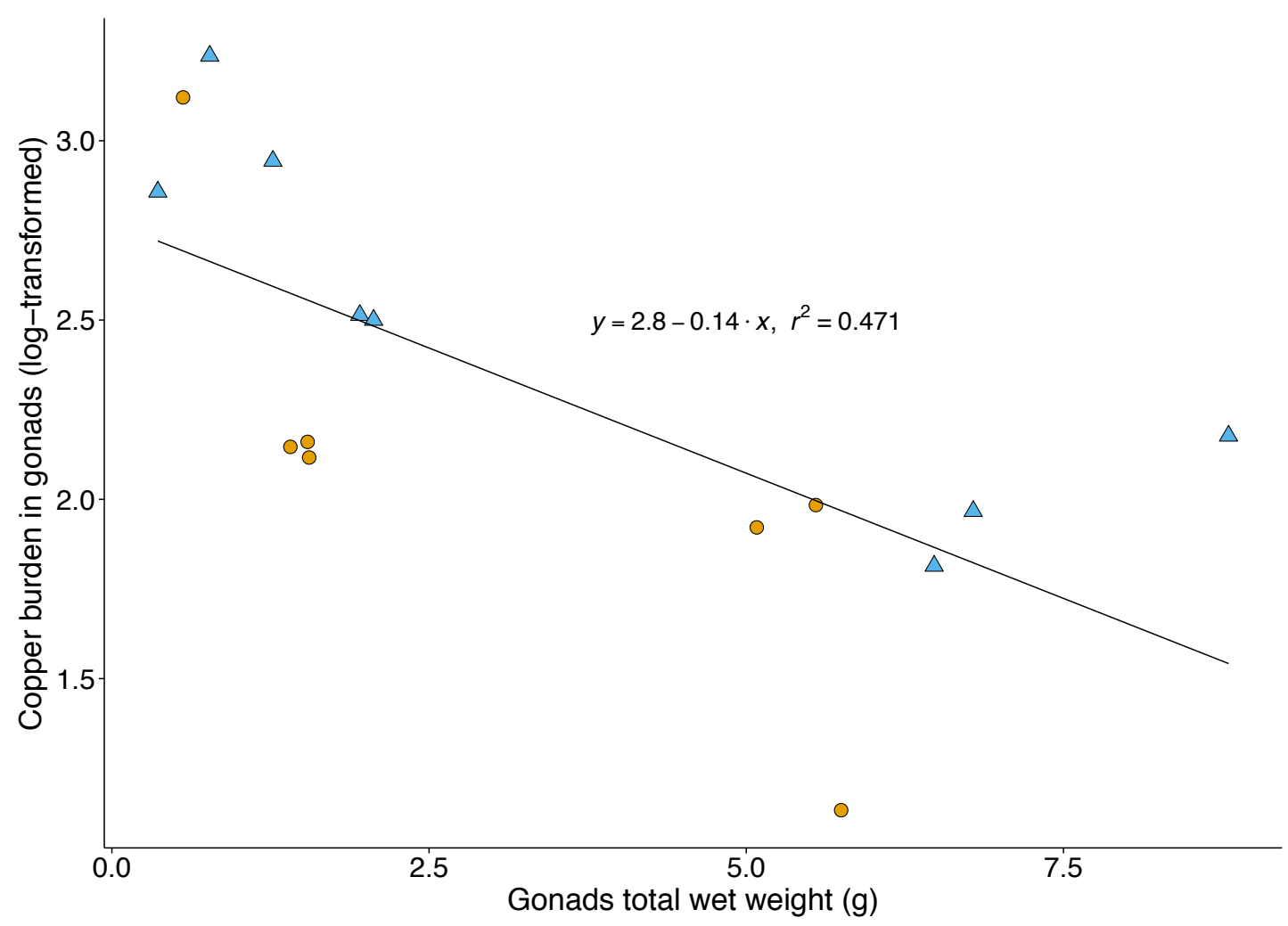

Figure 6.2: Copper burden in Evechinus chloroticus gonads vs. total gonad weight (wet weight), after two weeks of exposure to $50 \mu \mathrm{g} / \mathrm{L}$ (LAB group). Blue triangles represent males; orange circles represent females. Scale and regression equation is on log-transformed data.

\subsubsection{Sublethal effects on adults}

Sublethal effects of copper exposure on adults were not quantified from the beginning of the experiment, as they were not the focus of this study. However, a sharp decline in feeding was noted after five days, and dramatic effects on behaviour were observed after one week, including spine closure and very weak attachment to the substrate. During the last ten days of exposure, food consumption was monitored and was almost nil in tanks with copper (Table 6.2). After two weeks in copper-contaminated water, spine loss started to occur with an almost total lack of movement; the remaining spines acquired a red tinge. No death occurred in any of the tanks. 
Table 6.2: Feeding of Evechinus chloroticus during the last nine days of exposure (total exposure time was 15 days) to $50 \mu \mathrm{g} / \mathrm{L}$ of copper. The food offered was the blades, with stipes removed, of the kelp Macrocystis pyrifera.

\begin{tabular}{lccc}
\hline & Time interval (day) & Treatment & $\begin{array}{c}\text { Food consumed (g } \\
\text { wet weight) }\end{array}$ \\
\hline Feeding 1 & 5 & Control & 67 \\
& & Copper & 9.5 \\
\hline Feeding 2 & 2 & Control & 76 \\
& & Copper & 1 \\
\hline Feeding 3 & 2 & Control & 89 \\
& & Copper & 5.5 \\
\hline
\end{tabular}

Spawning success was also significantly impaired in the copper exposed group compared with the control group (Pearson Chi-square test: $\mathrm{Chi}^{2}=13.61$, df $=1, \mathrm{p}<$ 0.001). Only 4 of 15 copper-exposed animals ( 1 of 7 females and 3 of 8 males) successfully released gametes following injection with potassium chloride $(\mathrm{KCl})$. In contrast, 14 of 16 animals ( 8 of 9 females and 5 of 7 males) induced to spawn successfully released gametes in the control group. Only animals with a relatively low copper burden in their gonads successfully spawned. Spawning males in the LAB group had 2.5 times less copper in their gonads than the average exposed males, while the only female that spawned contained 4.5 times less copper than the average exposed female (Figure 6.1a and b). $\mathrm{KCl}$ induces muscular spasms in healthy animals leading to spawning and rapid spine movement. Little or no spine movement was observed in copper-exposed animals after injection with $3 \mathrm{ml}$ of $0.5 \mathrm{M} \mathrm{KCl}$.

\subsubsection{Fertilisation success}

Fertilisation success was not affected by male copper contamination or gamete exposure to copper in the water (mixed model ANOVA; Male treatment: $\mathrm{F}(1,4)<0.01$, $\mathrm{p}=0.95 ;$ Gamete treatment: $\mathrm{F}_{(1,27)}=0.43, \mathrm{p}=0.52$; Interaction term: $\mathrm{F}_{(1,27)}=0.21, \mathrm{p}$ $=0.65)$. The average fertilisation success of exposed males in clean seawater was $74 \%$ compared with $75 \%$ in control males (Figure 6.3 ). There was no evidence of copper toxicity in gametes, with an average of $72 \%$ fertilisation success when gametes where exposed to copper. Only five eggs from a total of 6575 eggs observed were recorded as abnormal, so no statistics were performed on this variable. 


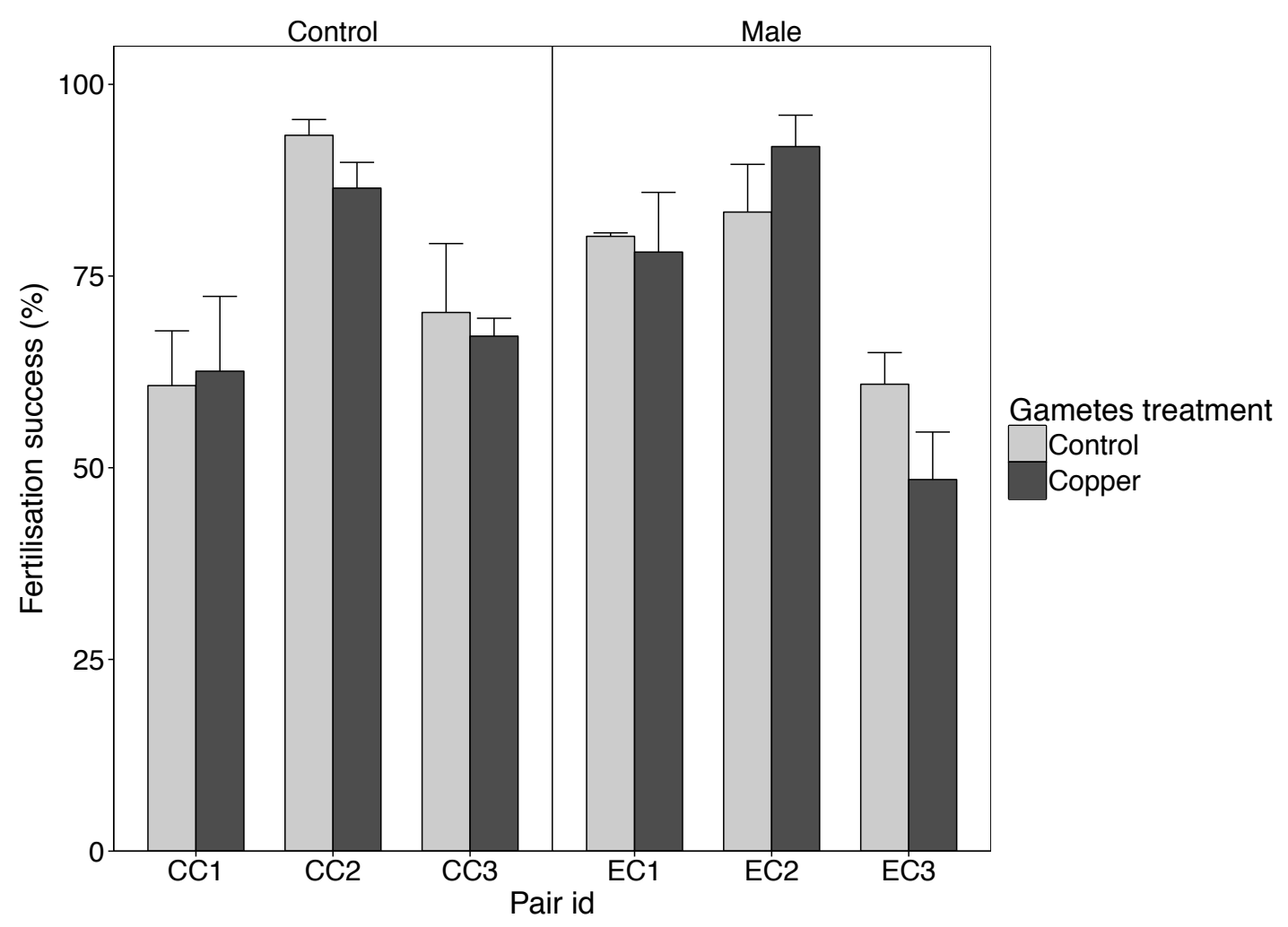

Figure 6.3: Fertilisation success of Evechinus chloroticus pairs after $1 \mathrm{~h}$. In CC pairs, both parents are controls; in EC pairs, females are controls and males have been exposed to $50 \mu \mathrm{g} / \mathrm{L}$ copper (LAB group) for two weeks prior to spawning. Pairs with the same number share the same female (e.g. F1 was used in pairs $\mathrm{CC} 1$ and EC1). Gametes from each pair have been fertilised either in clean seawater (control) or in seawater contaminated with $15 \mu \mathrm{g} / \mathrm{L}$ copper (copper). Error bars represent the standard deviation $(\mathrm{N}=3)$.

\subsubsection{FIELD POPULATIONS}

In field populations, copper burden varied significantly among populations (Table 6.1b). The best model also included sex and whether animals had spawned before dissection, but those factors were not significant. Model fit was good, with $62 \%$ of the variation explained. Urchins from the urban site (FK) had a significantly higher copper burden than urchins from the control site sampled at the same time of year (KB2), but not from those sampled earlier in the season (KB1; Figure 6.1b). However, the seasonal variation at the control site $(\mathrm{KB} 1, \mathrm{~KB} 2)$ was not significant. The average content in gonads was $85.7 \%$ (standard deviation $\pm 3.3 \%$ ) in all groups. 


\subsection{DISCUSSION}

\subsubsection{COPPER BURDEN IN GONADS}

Copper exposure in the laboratory produced a 25 -fold increase in copper burden in gonads after two weeks. This confirms that gonads can accumulate copper in a short period of time. As such E. chloroticus gonads may be a suitable indicator of shortterm pollution. Multiple studies have demonstrated that metal burden in sea urchin tissues is strongly related with metal pollution. Soft tissues, such as the gonads, are indicators of short-term contamination while calcareous tissues reflect longer term contamination (Flammang et al. 1997, Soualili et al. 2008, Catarino et al. 2008, Salvo et al. 2014).

In this study, copper burden was consistently higher in males. No previous study has reported copper accumulation by sex in sea urchins. In the starfish Asterias rubens, males had a higher copper burden in gonads than females (Catarino et al. 2008). Interestingly, this was not the case for the other metals tested in that study; cadmium, lead and zinc burdens were all higher in females. This demonstrates the need to take sex into account when monitoring echinoderms, as a sampling bias toward males or females would skew the results.

In laboratory-exposed animals, copper burden was higher in individuals with small gonads than in those with large gonads. Because of the short duration of the laboratory exposure, the equilibrium between copper intake and excretion was probably not reached, so copper in larger gonads was more 'diluted' than in small gonads. Because gonad and body size are positively correlated, sampling smaller individuals would be more appropriate to detect short-term variation in metal pollution.

\subsubsection{SUBLETHAL EFFECT ON ADULTS}

Adult individuals of $E$. chloroticus were severely affected by exposure to $50 \mu \mathrm{g} / \mathrm{L} \mathrm{Cu}$. This level of copper corresponds to a highly polluted harbour (Table 1.1). A dramatic decrease in feeding and a lower adherence to the substrate were observed from five 
days of exposure in all individuals. Furthermore, only those individuals with less accumulation of copper in their gonads were able to successfully spawn. A total reproductive failure occurred in $60 \%$ of the males and $85 \%$ of the females after two weeks of exposure. While a formal EC50 could not be derived from this experiment, sublethal effects would likely be observable from $96 \mathrm{~h}$ exposure to $50 \mu \mathrm{g} / \mathrm{L} \mathrm{Cu}$, especially if more sensitive behavioural end points, such as their position in the tank, were used. Copper contaminated animals tend to position themselves at the bottom of the tank while healthy animals are often positioned on the sides of the tank (Bielmyer et al. 2005). By comparison, an early study showed no effect of copper at concentrations of less than $300 \mu \mathrm{g} / \mathrm{L}$ on adult Echinometra mathaei (Heslinga 1976). A more recent study, however, reported sublethal effects at $10 \mu \mathrm{g} / \mathrm{L}$, on Diadema antillarum (Bielmyer et al. 2005). Very few studies report copper toxicity on adult sea urchins, as they are generally considered to be more tolerant than the early life stages. My results suggest that adult E. chloroticus have the same level of sensitivity to copper as the larval stage of some of the more tolerant species, such as Parocentrotus lividus (Table 2.6).

\subsubsection{FERTILISATION SUCCESS}

Despite the high accumulation of copper in the gonads and poor condition of animals exposed in the laboratory, the fertilisation success of the exposed males was not affected. This is consistent with a study conducted in a highly polluted fjord in Norway, where no deleterious effect on gamete quality and fertilisation success in the sea urchin Echinus acutus and the sea star Asterias rubens was observed, despite a moderately elevated metal burden (Catarino et al. 2008). On the other hand, a relationship between paternal exposure to copper and sperm quality has been well established in various invertebrates, including polychaetes and mussels (Earnshaw et al. 1986, Watson et al. 2013). In these studies, egg quality was also negatively affected by maternal exposure to copper, although to a lesser extent. In the present study, adults were exposed for only two weeks, which might have been too short to affect sperm, as gametogenesis in the sea urchin spans several months (Walker et al. 2006). Alternatively, sperm may have been affected in ways not detectable by the current study, such as DNA damage. In this case, fertilisation may occur normally but 
embryos may fail to develop. Longer-term experiments would be needed to evaluate these hypotheses.

There was no evidence of toxicity of low seawater copper concentration on spawned gametes. Therefore I could not assess whether sperm from exposed males differ in their resistance to copper relative to unexposed males. Toxic effects of copper on sperm in the water have been well established in other echinoid species, with fertilisation impairment occurring at concentrations ranging from 2 to $50 \mu \mathrm{g} / \mathrm{L}$ (Dinnel et al. 1989, Ringwood 1992, Novelli et al. 2003). It should be noted that sperm might have had motility impairment not detectable in this experiment. Indeed, a pilot study showed a trend of decreasing fertilisation success with copper exposure at a lower sperm density $\left(10^{4}\right.$ per $\left.\mathrm{ml}\right)$. However, this concentration also yielded a very low fertilisation success in controls $(<25 \%)$, and consequently a sperm concentration of $10^{5}$ per $\mathrm{ml}$ was used in the present experiment. Previous studies have demonstrated the importance of using a range of sperm concentrations to detect metal toxicity in gametes, as the toxic effect of copper in particular may be masked at high sperm densities (Marshall 2006, Hollows et al. 2007). This experiment should be repeated at a slightly lower sperm concentration, to evaluate the potential effects on low-density populations.

\subsubsection{FIELD POPULATIONS}

Individuals of E. chloroticus from the urban site of Frank Kitts Park had a higher accumulation of copper in their gonads than did animals from the control site collected at the same time of year. Frank Kitts Park receives urban runoff from two stormwater outlets. Sediments at this site were found to be moderately contaminated with copper in 1998 - 1999 (Bolton-Ritchie 2003). More recently, the blue mussel Mytilus galloprovincialis from this site had an elevated copper burden compared with those from the outer harbour (Milne 2006). The average copper burden in blue mussels was $1.7 \mu \mathrm{g} / \mathrm{g}$ (wet weight) in Frank Kitts Park, which is similar to the copper burden in E. chloroticus found in the present study. Despite being elevated, the copper burden in sea urchins from Frank Kitts Park remains 14-fold lower than in 
animals experimentally exposed to high copper concentrations. The present study suggests that copper pollution is present at the urban site, but is moderate.

\subsubsection{CONCLUSION}

E. chloroticus readily accumulates copper in gonads and is suitable as an indicator of copper pollution. Severe chronic copper pollution would likely affect adults and reduce reproductive success by impairing spawning. However, there was no evidence of fertilisation impairment in the presence of highly elevated copper burden in males or in the presence of moderate concentrations of copper in the water during fertilisation. Further work needs to be done regarding the fertilisation success of copper-exposed females to confirm whether copper is detrimental to fertilisation success. In addition, the present study did not investigate latent toxic effects; fertilised eggs may fail to develop into normal embryos and larvae. In echinoderms, only one study has examined the long-term effects of copper exposure in adults on larval performance, in the sea urchin Strongylocentrotus nudus (Durkina \& Evtushenko 1991). While the authors reported no adverse effects, though a slight increase in developmental rate, further work would be needed to confirm this pattern in other species. 



\section{CHAPTER 7 \\ General Discussion}

Pollution is one of the most important anthropogenic disturbances in coastal waters and is globally increasing worldwide. While extensive ecotoxicity studies have been carried out on copper and other metals (Fernández \& Beiras 2001, Doyle et al. 2003, Bielmyer et al. 2005), the ecologically relevant effects of metal pollution are still poorly understood (Mayer-Pinto et al. 2010). Indeed, most toxicity studies use unrealistic exposure times or concentrations, single life stages and/or single pollutants. In this thesis, the effects of copper were investigated for the sea urchin Evechinus chloroticus across multiple life stages using laboratory experiments with realistic exposure scenarios. A special emphasis was given to early life stages, carry-over and/or latent effects across the larval and juvenile development. In addition, the effect of multiple pollutants, multiple stressors (metal and low salinity) and trophic interactions were evaluated.

\subsection{MultiPle LifE-STAGES}

\subsubsection{VULNERABILITY OF E. CHLOROTICUS THROUGHOUT ITS LIFE CYCLE}

E. chloroticus is highly sensitive to copper throughout most of it's life cycle. When only direct effects (i.e. effects visible during the same life stage as exposure) and waterborne exposure are taken into account, the lowest observable effect concentrations (LOEC) showed a decreasing order of vulnerability as follows: embryo $>$ young juveniles $>$ larvae $>$ adults $<$ ? $>$ gametes (Table 7.1). Therefore, 
punctuated pollution events such as runoff are likely to affect, to some extent, all cohorts that occur in locations where these events are common, such as near river mouths or in harbours. Toxicity assays on short-lived arthropods have demonstrated the importance of using the full-life cycle to characterise pollutant effects. For example, the grass shrimp Palaemonetes pugio exposed to copper suffered no observable effects throughout their life cycle but failed to produce viable offspring (Manyin \& Rowe 2010). While full life cycle assays are not practical with long-lived organism such as most large benthic invertebrates, effort should be made to investigate the toxicity of a compound on each parts of the life cycle. While early life stages are commonly more sensitive than later stage, it does not follow that pollution may not significantly affect later stages. Testing of each life stages has been proposed for mollusks but has rarely been implemented (but see Matthiessen 2008, Kimberly \& Salice 2013). In echinoderms, gametes, embryos and larvae are commonly used in toxicity assays but juveniles and adults rarely are (Kobayashi 1980, Bay et al. 1993, King \& Riddle 2001, Bielmyer et al. 2005). The present study offers a measure of copper toxicity for all E. chloroticus' life stages.

Table 7.1: Comparative toxicity of copper in Evechinus chloroticus life stages. Copper toxicity values are based on the lowest dissolved copper concentration (LOEC) producing direct effects, i.e. effects observable during the same life stage as copper exposure. $\mathrm{nd}=$ non determined

\begin{tabular}{llll}
\hline Life stage & LOEC $(\boldsymbol{\mu g} / \mathbf{L})$ & $\begin{array}{l}\text { Duration of } \\
\text { exposure }\end{array}$ & Chapter \\
\hline $\begin{array}{l}\text { Embryo/early } \\
\text { pluteus }\end{array}$ & $2.1^{\text {a }}$ & $72 \mathrm{~h}$ & 2 \\
Juvenile & 10.4 & 2 days & 3 \\
Larva b $^{\text {Adult }}$ & 10.4 & 4 days & 4 \\
Gamete & 50 & 2 weeks & 6 \\
\hline
\end{tabular}

\footnotetext{
${ }^{\mathrm{a}}$ based on EC10 values

${ }^{\mathrm{b}}$ larvae older than $72 \mathrm{~h}$ (4- to 8 -armed pluteus stage)
}

\subsubsection{Embryo/early pluteus}

The embryo/early pluteus stage (i.e. the first $72 \mathrm{~h}$ post-fertilisation) was the most vulnerable part of the life cycle, with a LOEC of $2.1 \mu \mathrm{g} / \mathrm{L}$ (Table 7.1). The early pluteus formation has been shown to be more sensitive than fertilisation or gastrula 
development in many species, thus the early pluteus stage is a common endpoint in toxicity assays (Kobayashi 1980, King \& Riddle 2001, ASTM 2012).

\subsubsection{Juvenile}

Surprisingly, juveniles E. chloroticus were more sensitive to copper than larvae (Table 7.1). A short pulse of $10 \mu \mathrm{g} / \mathrm{L} \mathrm{Cu}$ to naive juveniles impaired radial growth, while no direct effect of copper on larval size or survival was observed (Chapter 3). To the best of my knowledge, copper toxicity on juvenile sea urchins has never been assessed before. The early days immediately following settlement are arguably the lesser known, due to difficulties in finding highly cryptic, small individuals in the field and the time necessary to raise them from larvae in the laboratory. Juvenile urchins are usually assumed to be less sensitive than larvae, as younger organisms tend to be (but not always) more vulnerable than older ones (King \& Riddle 2001, Jezierska et al. 2009, Aronzon et al. 2011, Kimberly \& Salice 2013). The present study demonstrates that juvenile sea urchins may be highly sensitive to environmental disturbances and further work on this cryptic life-stage is warranted.

\subsubsection{Larvae}

Copper toxicity on larvae was assessed during three different experiments and therefore data on this life stage is more robust than on all other life stages investigated during this research. In all experiments, a pulse exposure under $10 \mu \mathrm{g} / \mathrm{L} \mathrm{Cu}$ did not produce any direct effects (Chapters 3, 4 and 5). Exposure to $10 \mu \mathrm{g} / \mathrm{L}$ for 4 days produced moderate toxic effects (Chapter 4) and exposure to $15 \mu \mathrm{g} / \mathrm{L}$ during all the larval stage produce severe toxic effects (Chapter 5). Very few studies used echinoderms larval stage passed the early pluteus formation. In the sea urchin Heliocidaris erythrogramma, competent larvae exposed to $20 \mu \mathrm{g} / \mathrm{L} \mathrm{Cu}$ produced a low rate of normal juveniles (40\%) and 4-armed plutei of the sand dollar Peronella japonica exposed to $50 \mu \mathrm{g} / \mathrm{L} \mathrm{Cu}$ produced abnormal juveniles (Kobayashi 1980). The duration of exposure in each case was not specified. 


\subsubsection{Adult}

Adult individuals of E. chloroticus were severely affected by a 2-week exposure to 50 $\mu \mathrm{g} / \mathrm{L} \mathrm{Cu}$. However, only one copper concentration was tested and most sublethal effects were not quantified. Therefore the actual LOEC is likely to be much lower than the one reported in Table 7.1. Only two other studies reported copper toxicity on adult sea urchins: Cu LOEC with Echinometra mathaei and Diadema antillarum was 300 and $10 \mu \mathrm{g} / \mathrm{L}$, respectively, showing considerable variation between species (Heslinga 1976, Bielmyer et al. 2005). Bielmyer's results and mine demonstrate that adult sensitivity to copper may be in the same order as embryo or larval sensitivity, at least in some species (Table 2.6).

\subsubsection{Gametes}

It is not possible to determine whether gametes are more or less sensitive to copper than adults as the only concentration tested on gametes $(15 \mu \mathrm{g} / \mathrm{L})$ produced no effect but was lower than the concentration used on adults $(50 \mu \mathrm{g} / \mathrm{L}$; Table 7.1$)$. Toxic effects of copper in the water on sperm have been well established in other echinoid species, with fertilisation impairment occurring at concentrations ranging from 2 to $50 \mu \mathrm{g} / \mathrm{L}$ (Dinnel et al. 1989, Ringwood 1992, Novelli et al. 2003). Contrary to the literature, gamete assays in the present study were less sensitive than larval assays (Kobayashi 1980, Dinnel et al. 1989, Novelli et al. 2003). The observed difference might be due to species-specific response but it should also be noted that sperm might have had motility impairment and or DNA damage not detectable in Chapter 6. In addition, toxic effects might have been masked by the sperm concentration used $\left(10^{5}\right.$ per ml; Marshall 2006, Hollows et al. 2007).

\subsubsection{CARRY-OVER AND LATENT EFFECTS}

Carry-over and latent effects have strong ecological relevance especially for species with a high reproductive output. Lethal effects on larvae may have little implications for populations, due to the large number of larvae produced. Investigating the fate of the survivors, however, would give a better understanding of the implication of pollution for marine populations. 
Exposure to a stressor during larval development may produce weaker juveniles displaying negative latent effects such as growth impairment. Alternatively, latent effects may be beneficial due to selective mortality in favour of larger, faster growing or generally fitter individuals. For example in Chapter 3, copper exposure during larval development led to larger settlers immediately after settlement. However, few positive carry-over or latent effects have been reported for metal stressors in aquatic invertebrates (Table 7.2). In the present study, latent effects mostly negative. Indeed, in Chapter 3, the slight positive effect in size at settlement is unlikely to compensate for the negative effect on growth one month after settlement. And in Chapter 4, a positive effect on size post-settlement follows a strong impairment in settlement success. Few studies evaluated the latent effects of pollutants. However, the majority of these studies reported negative latent effects such as lower growth, lower survival and/or lower reproduction success (Table 7.2). This research adds to the growing body of evidence that exposure to metal pollution during larval development produce a weakened surviving cohort in aquatic invertebrates. 
Table 7.2: Latent effects of pollutants in aquatic invertebrates. ns: no significant difference from controls, +: increase from controls, -: decrease from controls, ?: not measured, PS: post-settlement.

\begin{tabular}{|c|c|c|c|c|}
\hline Species & $\begin{array}{l}\text { Metal } \\
\text { (concentration, } \\
\text { duration of } \\
\text { exposure) }\end{array}$ & End point & $\begin{array}{l}\text { Effect } \\
\text { observed (\% } \\
\text { lower/higher } \\
\text { than control } \\
\text { if provided) }\end{array}$ & Reference \\
\hline \multirow{4}{*}{$\begin{array}{l}\text { Sea urchin } \\
\text { (Evechinus } \\
\text { chloroticus) }\end{array}$} & \multirow{4}{*}{$\begin{array}{l}\text { Copper } \\
(10 \mu \mathrm{g} / \mathrm{L}, 2 \\
\text { days })\end{array}$} & Settlement success & ns & \multirow{4}{*}{$\begin{array}{l}\text { Present } \\
\text { study } \\
\text { Chapter } 3\end{array}$} \\
\hline & & Size at settlement & $+(14 \%)$ & \\
\hline & & $\begin{array}{l}\text { Survival }<1 \text { month } \\
\text { PS }\end{array}$ & ns & \\
\hline & & Size $<1$ month PS & $-(30 \%)$ & \\
\hline \multirow{4}{*}{$\begin{array}{l}\text { Sea urchin } \\
\text { (Evechinus } \\
\text { chloroticus) }\end{array}$} & \multirow{4}{*}{$\begin{array}{l}\text { Copper } \\
(10 \mu \mathrm{g} / \mathrm{L}, \\
\text { chronic during } \\
\text { larval stage) }\end{array}$} & Settlement success & $-(600 \%)$ & \multirow{4}{*}{$\begin{array}{l}\text { Present } \\
\text { study } \\
\text { Chapter } 4\end{array}$} \\
\hline & & Size at settlement & ns & \\
\hline & & $\begin{array}{l}\text { Survival > } 1 \text { month } \\
\text { PS }\end{array}$ & ns & \\
\hline & & Size $>1$ month PS & $+(130 \%)$ & \\
\hline \multirow{5}{*}{$\begin{array}{l}\text { Bryozoan } \\
\text { (Watersipora } \\
\text { subtorquata) }\end{array}$} & \multirow{5}{*}{$\begin{array}{l}\text { Copper } \\
(100 \mu \mathrm{g} / \mathrm{L}, 6 \mathrm{~h})\end{array}$} & Settlement success & ns & \multirow{5}{*}{$\begin{array}{l}(\mathrm{Ng} \mathrm{\&} \\
\text { Keough } \\
2003)\end{array}$} \\
\hline & & $\begin{array}{l}\text { Survival }<1 \text { month } \\
\text { PS }\end{array}$ & ns & \\
\hline & & Size $<1$ month PS & - & \\
\hline & & $\begin{array}{l}\text { Survival > } 1 \text { month } \\
\text { PS }\end{array}$ & $-(600 \%)$ & \\
\hline & & Size $<1$ month PS & $-(100 \%)$ & \\
\hline \multirow{3}{*}{$\begin{array}{l}\text { Freshwater snail } \\
\text { (Physa pomilia) }\end{array}$} & \multirow{3}{*}{$\begin{array}{l}\text { Cadmium } \\
(10 \mu \mathrm{g} / \mathrm{L} \text {, } \\
\text { chronic during } \\
\text { egg } \\
\text { development) }\end{array}$} & Hatching success & ns & \multirow{3}{*}{$\begin{array}{l}\text { (Kimberly \& } \\
\text { Salice } \\
2014 \text { ) }\end{array}$} \\
\hline & & $\begin{array}{l}\text { Size }<1 \text { month post- } \\
\text { hatching }\end{array}$ & $+(25 \%)$ & \\
\hline & & $\begin{array}{l}\text { Size }>1 \text { month post- } \\
\text { hatching }\end{array}$ & - $(10 \%)$ & \\
\hline $\begin{array}{l}\text { Mussel } \\
\text { (Mytilus edulis) }\end{array}$ & $\begin{array}{l}\text { Copper (8 } \mu \mathrm{g} / \mathrm{L} \text {, } \\
\text { chronic during } \\
\text { larval } \\
\text { development) }\end{array}$ & $\begin{array}{l}\text { Survival > } 1 \text { month } \\
\text { PS }\end{array}$ & $-(900 \%)$ & $\begin{array}{l}\text { (Hoare et al. } \\
\text { 1995) }\end{array}$ \\
\hline $\begin{array}{l}\text { Polychaete } \\
\text { (Capitella sp.I) and } \\
\text { gastropod } \\
\text { (Crepidula } \\
\text { fornicate) }\end{array}$ & $\begin{array}{l}\text { Cadmium }(2000 \\
\mu \mathrm{g} / \mathrm{L} \text { and } \\
20000 \mu \mathrm{g} / \mathrm{L}, \\
\text { respectively, } \\
48 \mathrm{~h})\end{array}$ & $\begin{array}{l}\text { Survival }<1 \text { month } \\
\text { PS }\end{array}$ & ns & $\begin{array}{l}\text { (Pechenik } \\
\text { et al. 2001) }\end{array}$ \\
\hline $\begin{array}{l}\text { Sponge } \\
\text { (Scopalina } \\
\text { lophyropoda) }\end{array}$ & $\begin{array}{l}\text { Copper (30 } \\
\mu \mathrm{g} / \mathrm{L} \text {, chronic } \\
\text { during larval } \\
\text { development) }\end{array}$ & $\begin{array}{l}\text { Survival > } 1 \text { month } \\
\text { PS }\end{array}$ & $+(250 \%)$ & $\begin{array}{l}\text { (Cebrian \& } \\
\text { Uriz 2007) }\end{array}$ \\
\hline $\begin{array}{l}\text { Shrimp } \\
\text { (Palaemonetes } \\
\text { pugio) }\end{array}$ & $\begin{array}{l}\text { Copper }(9 \mu \mathrm{g} / \mathrm{L} \text {, } \\
\text { chronic full life } \\
\text { cycle) }\end{array}$ & $\begin{array}{l}\text { Survival > } 1 \text { month } \\
\text { post-metamorphosis }\end{array}$ & $\begin{array}{l}\text { - (0 larvae per } \\
\text { replicates vs. } \\
1870 \text { in } \\
\text { controls) }\end{array}$ & $\begin{array}{l}\text { (Manyin \& } \\
\text { Rowe 2010) }\end{array}$ \\
\hline
\end{tabular}


It should be noted that the magnitude and even the presence of latent effects observed depends strongly on the endpoints measured and the time at which they are measured. In Chapter 3, individuals exposed as larvae to $10.4 \mu \mathrm{g} / \mathrm{L} \mathrm{Cu}$ for two days developed normally during the larval stage but had strongly impaired subsequent growth, with average body size decreasing by $24 \%$ in the 25 days following settlement (Table 7.2). However, in a subsequent experiment, exposure to the same concentration during a longer period (4 days) produced no difference in size when measured at 38 days postsettlement (Chapter 4). This suggests that growth impairment occurs shortly following metamorphosis but may be compensated for later during juvenile development. While early growth impairment would likely affect young settlers' survival in the field, this effect is less severe than if the size discrepancy would continue or increase during juvenile development. These results emphasise the need to both evaluate long-term effect and monitor intermediate endpoints to better characterise the effect of a stressor on the development of marine organisms.

\subsubsection{ADULT-GAMETES TRANSITION}

Environmental stressors, such as pollutants, may impair the reproductive success of adults by decreasing the quality and/or quantity of their gametes, leading to a decrease in fertilisation success and/or offspring viability. In recent years, several studies have highlighted the importance of parental effects on gamete quality and offspring success (Marshall \& Keough 2004, Marshall 2008, Burgess \& Marshall 2011, Lister et al. 2015). In Chapter 6, the quantity of gametes produced by adults exposed to $50 \mu \mathrm{g} / \mathrm{L} \mathrm{Cu}$ for two weeks was severely affected given the very low spawning success ( $40 \%$ in males, $15 \%$ in females). However, the quality of the gametes that were spawned did not seem to be affected with no difference in fertilisation success in exposed males (the fertilisation success could not be evaluated in females given the small number of spawning females). This result is somewhat contradictory to the literature as a relationship between paternal exposure to copper and sperm quality has been well established in various invertebrates, including polychaetes and mussels (Earnshaw et al. 1986, Watson et al. 2013). Furthermore a decrease in gamete quality or fertilisation success following adult exposure to metals 
has been documented in sea urchins for cadmium (Au et al. 2001) and lead (Nacci et al. 2000). The discrepancy may be due to the duration of copper exposure, which might have been too short to affect sperm quality. Indeed, in the present study, adults were exposed for only two weeks as opposed to one month in the two previously cited studies on sea urchins (Nacci et al. 2000, Au et al. 2001). Alternatively, sperm may have been affected in ways not detectable by the current study, such as DNA damage. In this case, fertilisation may occur normally but embryos may fail to develop. Longer-term experiments would be needed to evaluate these hypotheses.

\subsection{REALISTIC EXPOSURE SCENARIOS}

\subsubsection{PULSE VS. CHRONIC EXPOSURE}

The concentration of pollutants in coastal water is usually not constant but surges after storm events or pollutant discharge (Govindasamy et al. 1998, Milne \& Watts 2008, TenBrook et al. 2008). In this study, the relative effect of pulse or chronic exposure was strongly dependent on the source of copper. Indeed, when copper was present in the diet (both Diet and Diet + Water treatments) of larvae, a pulse exposure was generally more toxic than a chronic exposure. On the other hand, when copper was administered in water alone, a chronic exposure was more toxic (Chapter 4). Looking at pulse exposure rather than chronic exposure is not particularly new; many studies, mostly in fish and freshwater organisms, have shown that pulse exposures to a stressor may have significant deleterious effects (Handy 1994, Brown et al. 2002, Forbes \& Cold 2005). For some chemicals, including metals, pesticides, acids, and ammonia, pulse exposure led to stronger effects than chronic exposure in freshwater animals (Ingersoll \& Winner 1982, Handy 1994, Schulz \& Liess 2000). However, most long-term studies in marine organisms continue to use exclusively chronic exposure (De Schamphelaere et al. 2004, Meyer et al. 2005, Guo et al. 2013).

Furthermore, regulatory authorities in many countries, including New Zealand, only include an exposure magnitude in their WQC that is designed to protect from chronic exposure (ANZECC 2000, TenBrook et al. 2008). This approach provides no sciencebased guidelines as to the acceptable duration and frequency of exceedance of the 
WQC. My study shows that chronic exposure is not necessarily a worst-case scenario and that effort should be made to prevent episodic discharge of copper in coastal waters.

\subsubsection{MULTIPLE EXPOSURES}

In this study, juveniles previously exposed to copper as larvae were less resistant to a subsequent exposure, with up to four times higher mortality (Chapter 3 ). This is one of the first studies to demonstrate the effect of further exposure to a pollutant in later life stages in aquatic organisms. A recent study showed an increase in sensitivity to cadmium in juvenile freshwater snails, Physa pomilia, previously exposed to the same stressor during embryonic development (Kimberly \& Salice 2014). A change in stressor tolerance has been reported with multiple exposures during the same life stage in freshwater fish (Dixon \& Sprague 1981, Brinkman \& Woodling 2014). Decreased tolerance to pollutant following exposure during larval development has important ecological relevance, as larvae exposed to pollution are likely to settle in a polluted area; this is especially the case for species with low dispersal. This result further demonstrates that the surviving cohort following copper exposure during larval development is weakened.

\subsection{MultiPle STRESSORS}

Marine organisms are constantly exposed to a mixture of abiotic stressors, which will interact in a synergistic, strictly-additive or antagonistic fashion. Many studies have investigated the effects of metal mixtures and have found that these vary strongly depending on the metal pairs and on the test organisms (reviewed in Norwood et al. 2003). In addition, very few studies have evaluated the interaction of metal stress and other abiotic stress such as salinity or dissolved organic carbon (but see MacInnes \& Calabrese 1979, Nadella et al. 2009, 2013). 


\subsubsection{MetAl MiXTURE}

In Chapter 2, the simple mixture of copper, lead and zinc were found to be strictlyadditive in both E. chloroticus and H. iris. In a review of more than 60 studies on aquatic organisms, more than half of the studies reported a less-than-additive effect of metal mixtures while the other half reported a more-than-additive effect (Norwood et al. 2003). However, the vast majority of papers reviewed in Norwood (2003) are on freshwater organisms. Of the few studies that have addressed metal mixtures on larval development of echinoderms, the reported effects were either strictly-additive or could not be distinguished from simple additivity when experimental variability was taken into account (Fernandez and Beiras 2001, Phillips et al. 2003, Kobayashi and Okamura 2005, Xu et al. 2011). It should also be noted that most studies on metal mixtures, including the present one, investigate only immediate toxic effects and may therefore underestimate the toxicity of metal mixtures over the full life cycle of an organism.

\subsubsection{METAL AND OTHER ABIOTIC STRESSORS}

The toxicity of multiple stressors in an area of growing interest (reviewed by Przeslawski et al. 2015). However, the stressors most commonly studied are climate change stressors (salinity, temperature and $\mathrm{pH}$ ). The interaction between pollutants and other abiotic stressors has received comparatively little attention in marine organisms. While salinity is well known to be an important mediator of metal toxicity in freshwater and estuarine systems (McLusky et al. 1986, Grosell et al. 2007, Lee et al. 2010), relatively few studies have looked at marine organisms and most of these have focused on adults (McLusky et al. 1986, Barbieri \& Doi 2011, Patel \& Bielmyer-Fraser 2015). In Chapter 5, low salinity increased copper toxicity dramatically in E. chloroticus larvae under a chronic exposure scenario. There was no success in larval development when both stressors were present, compared with more than $50 \%$ larvae reaching normal development (including a rudiment) by $25 \mathrm{~d}$ postfertilisation with copper at normal salinity and $27 \%$ with no added copper at low salinity. Most studies on copper and salinity have shown an increase in copper toxicity under hyposaline conditions (McLusky et al. 1986, Patel \& Bielmyer-Fraser 2015). On the other hand, in some marine species, copper toxicity was independent of 
salinity (Nadella et al. 2009, Lee et al. 2010). However, all these studies used chronic exposure to both stressors. The present study shows little evidence of an interaction between copper and salinity under realistic field conditions (i.e. low copper concentration and 4-d pulse exposure). However, exposure to low salinity and copper may have latent effects not detectable in this study. Indeed, my previous experiments have shown that stressors encountered during E. chloroticus larval development may have further and more dramatic impacts on settlement success and settler performance than on the larval development itself (Chapter 3 and 4). It is crucial to evaluate the potential for latent impacts of combined copper and salinity stressors in order to more fully understand the effect of copper in contaminated runoff on sea urchin populations.

\subsection{TROPHIC INTERACTIONS}

Most marine toxicity studies focus on waterborne pollutants, while organisms living in a polluted area are likely to be exposed to contaminated food as well. In Chapter 4, I investigated the toxic effect of environmentally realistic levels of copper from the diet vs. waterborne exposure. Overall, the settlement success was 30\% lower in dietary treatments than in waterborne treatments. Surviving settlers exposed to dietary copper, as larvae were on average $30 \%$ smaller than controls, while those exposed to dissolved copper were $60 \%$ larger. Furthermore, surviving settlers had a higher rate of abnormal development in all copper treatments. Interestingly, dietary copper seemed to produce few direct effects on larvae, while carry-over effects were more severe when copper was administered in food rather than in water. The importance of the dietary pathway is well recognised in humans and top predators especially for pollutants with strong biomagnification, such as mercury, or hydrophobic pollutants such as PCBs (polychlorinated biphenyls) for which the waterborne pathway is negligible (Meyer et al. 2005, TenBrook et al. 2008, Mathews \& Fisher 2009, Jakimska et al. 2011). In recent years, however, the dietary pathway has been shown to be an important route of intake in lower trophic levels as well (Griscom et al. 2002, Huang et al. 2010, Bielmyer et al. 2012). Most studies have focused on bioaccumulation patterns in filter feeders or grazers and little work has been done on 
planktonic species or early life stages (but see Table 7.3). The relative importance of the dietary route $v s$. Waterborne exposure in zooplankton is dependent on the pollutant. For example, in copepods, mercury was more toxic when present in dissolved form than in the diet (Hook \& Fisher 2001b). However, most studies have reported a higher toxicity of dietary metals.

Table 7.3: The relative toxicity of waterborne and dietary metals on planktotrophic organisms.

\begin{tabular}{|c|c|c|c|c|c|}
\hline Species & Metal & $\begin{array}{l}\text { Measure } \\
\text { of toxicity }\end{array}$ & $\begin{array}{l}\text { Water- } \\
\text { borne }\end{array}$ & Dietary & Reference \\
\hline $\begin{array}{l}\text { Copepod } \\
\text { Acartia tonsa }\end{array}$ & Silver & $\begin{array}{l}\mathrm{LC} 50 \\
(\mu \mathrm{g} / \mathrm{L})\end{array}$ & 43.2 & 3 & $\begin{array}{l}\text { (Hook \& Fisher } \\
\text { 2001a, Bielmyer et al. } \\
\text { 2006) }\end{array}$ \\
\hline $\begin{array}{l}\text { Copepod } \\
\text { Acartia tonsa } \\
\text { and } A \text {. hudsonica }\end{array}$ & Mercury & $\begin{array}{l}\text { LOEC } \\
(\mathrm{nM})\end{array}$ & 0.25 & 1 & $\begin{array}{l}\text { (Hook \& } \quad \text { Fisher } \\
2001 \mathrm{~b})\end{array}$ \\
\hline $\begin{array}{l}\text { Copepod } \\
\text { Acartia tonsa } \\
\text { and } A \text {. hudsonica }\end{array}$ & Cadmium & $\begin{array}{l}\text { LOEC } \\
(\mathrm{nM})\end{array}$ & 2 & 1 & $\begin{array}{l}\text { (Hook \& Fisher } \\
2001 \mathrm{~b})\end{array}$ \\
\hline $\begin{array}{l}\text { Freshwater } \\
\text { cladoceran } \\
\text { Daphnia magna }\end{array}$ & Zinc & $\begin{array}{l}\text { LOEC } \\
(\mu \mathrm{g} / \mathrm{L})\end{array}$ & $>155$ & 28 & $\begin{array}{l}\text { (De Schamphelaere et } \\
\text { al. 2004) }\end{array}$ \\
\hline $\begin{array}{l}\text { Sea urchin } \\
\text { (larvae) } \\
\text { Evechinus } \\
\text { chloroticus }\end{array}$ & Copper & $\begin{array}{l}\text { LOEC } \\
(\mu \mathrm{g} / \mathrm{L}) \\
\text { based on } \\
\text { settlement } \\
\text { success }\end{array}$ & 10.4 & 2.3 & $\begin{array}{l}\text { Present study } \\
\text { (Chapter 4) }\end{array}$ \\
\hline $\begin{array}{l}\text { Sea urchin } \\
\text { (larvae) }\end{array}$ & $\begin{array}{l}\text { Copper } \\
\text { (nano- } \\
\text { particules } \\
\text { ) }\end{array}$ & $\begin{array}{l}\text { Mortality } \\
\text { (\% of } \\
\text { controls) }\end{array}$ & $\mathrm{n} / \mathrm{a}^{\mathrm{a}}$ & $70 \%$ & $\begin{array}{l}\text { (Gambardella et al. } \\
\text { 2014) }\end{array}$ \\
\hline
\end{tabular}

\footnotetext{
${ }^{a}$ toxicant not available via waterborne exposure
}

For other marine invertebrates, many studies have reported a higher increase in metal burden following dietary exposure compared with waterborne exposure (Wang \& Fisher 1999, Griscom et al. 2002, Meyer et al. 2005, Huang et al. 2010). It remains unclear, however, if an increase in metal burden necessarily translates into an increase in toxicity (Hook \& Fisher 2001a, De Schamphelaere \& Janssen 2004, De Schamphelaere et al. 2004). De Schamphelaere et al. (2004) reported that despite similar zinc body burden between the two modes of exposure in freshwater cladocerans, the toxic effects were different. Dietary exposure was detrimental to reproductive output but no toxic effect was observed with waterborne exposure. In Chapter 4, dietary exposure produced toxic effects that were not only more severe 
than dissolved exposure but were also acting on different components of $E$. chloroticus development. For example, dietary exposure produced no direct effect on larval development but impaired post-settlement growth, while larvae exposed to dissolved copper displayed delayed larval development but better post-settlement growth. Furthermore, E. chloroticus seemed to develop a resistance to copper when exposure was at least partially from the diet but not when exposure was strictly waterborne. The different mechanisms of toxicity between dietary and dissolved metal exposure may be explained by a difference in metal repartition in tissues. Indeed dietary metal tends to accumulate in soft tissues while dissolved metal tends to be more sequestered in hard tissues (Fisher et al. 1996, Hook \& Fisher 2001a, Campbell et al. 2005). This shows metal burden in tissues may not be appropriate to determine toxic effects, especially in small organisms for which metal partitioning cannot be taken into account. Further research is needed on a range of organisms to better understand the toxic effects of dietary metals.

\subsection{RECOMMENDATION FOR MANAGEMENT}

This thesis provides valuable information on the sensitivity to metals of two important local species: the sea urchin E. chloroticus and the abalone H. iris. In New Zealand, copper, lead and zinc are commonly found in concentrations exceeding WQC in urban effluents (Milne \& Watts 2008, Neale 2009), but very few studies have investigated their effects on local coastal organisms (but see Fukunaga et al. 2010, 2011). H. iris and to a lesser extent, E. chloroticus, are comparatively more sensitive to metal than related species, highlighting the importance of using local species to determine WQC (Tables 2.6 and 2.7). H. iris already suffers from a low recruitment rate, which is thought to be a main limiting factor in population growth (McShane et al. 1994, McShane 1995). Furthermore, this species may be especially vulnerable to metal contamination, as the larval stage is very short and larvae stay close to shore where they are more likely to encounter metal pollution. They also have a limited dispersal due to the short larval stage, so populations in contaminated areas are less likely to receive recruits from an unpolluted area. In addition, H. iris tends to spawn during storms (citation), increasing the risk of exposure to large river 
plumes with maximal metal contamination. The current copper contamination near a stream outfall comprised of agricultural effluent could potentially result in severe effect on $H$. iris population (Figure A.2).

\subsubsection{WATER QUALITY CRITERIA (WGC)}

This study demonstrated that current WQC for zinc fails to protect the early life stages of $H$. iris and, to a lesser extent, E. chloroticus. Zinc WQC (15 $\mu \mathrm{g} / \mathrm{L})$ was above the EC50 for H. iris $(13.1 \mu \mathrm{g} / \mathrm{L})$ and above the EC10 for E. chloroticus $(9.7$ $\mu \mathrm{g} / \mathrm{L}$; Table 2.4). In addition, these values are based on short-term standard toxicity assays (72 h) and do not take latent effects into consideration. The results of my research would suggest that WGC for zinc be lowered to $3 \mu \mathrm{g} / \mathrm{L}$ to be below $H$. iris EC10. However, it would be preferable to conduct long-term toxicity assays to evaluated potential latent effect and inform a better WQC. H. iris would be a good candidate to evaluate long-term zinc toxicity, given its very high sensitivity and high ecological and commercial importance.

Copper and lead WQC seem to be adequate for both species but should be strictly enforced in the case of copper as concentrations only slightly higher than WQC could have important effect on the early life stages of vulnerable invertebrate species (Table 2.4).

Additive model for simple metal mixture seems appropriate of copper, lead and zinc simple mixtures. This research supports the use of the current additivity model described in the WQC for invertebrate larvae, given the very similar results obtained with two test organisms belonging to distant phyla (H. iris and E. chloroticus). It should be noted, however, that synergistic or antagonistic effects might occur with other classes of pollutants such as organic pollutants or with complex mixtures (more than two compounds). 


\subsubsection{PREVENTING EPISODIC DISCHARGE OF POLLUTANTS}

This study shows that a short-lived bloom of contaminated phytoplankton may have a more severe impact on zooplankton than chronic pollution. This finding has important implications for pollution management, as short increases in pollution concentration are usually considered to be of little consequence as long as the average concentration throughout the year is below WQC. Furthermore, many toxicity studies investigating dietary intake of pollutants have used a chronic exposure and focused on adults, and hence may have strongly underestimated the toxic effect of a pollutant (De Schamphelaere et al. 2004, Meyer et al. 2005, Guo et al. 2013). Actions to reduce pollution, such as increasing the buffer zone around agricultural streams, should be taken even when the contaminant(s) exceed WQC only episodically. For copper, I suggest that a concentration above $3 \mu \mathrm{g} / \mathrm{L}$ occurring on a monthly basis or more frequently be considered as a pollution level that should be addressed. Monitoring in coastal water suggests that agricultural effluent may be at high risk of episodic exceedances of copper (Appendix A). In addition, agricultural effluents are also typically rich in nutrients, which may produce contaminated algal blooms and have significant impact on the zooplankton and other trophic levels. As such, agricultural effluents as well as industrial effluents should be targeted in monitoring programs.

\subsubsection{DIETARY ASSAYS}

This study adds to the growing body of evidence that the dietary route is very important in metal toxicity even for low trophic levels. There is still a large knowledge gap in dietary toxicity with no reliable models or standard protocol to evaluate dietary toxicity (Schlekat et al. 2001, Meyer et al. 2005). However, risk assessments should include dietary assays using contaminated diet when relevant.

\subsubsection{MONITORING PROGRAMME AND RECOMMENDED ACTIONS}

I recommend a routine monitoring (yearly or every $2-3$ years) of streams and rivers in New Zealand for metal pollution. Some regional councils already have such a routine monitoring programme in place but tend to target rivers and streams impacted by industries or dense urban areas. Streams and rivers impacted by agricultural 
activities should also be included, especially with regard to copper. In addition, routine monitoring (yearly or every $2-3$ years) of metal pollution in coastal water using bioindicators such as kina or blue mussels should be conducted to evaluate pollution non-related to effluent discharges. In areas identified as areas of concern by the routine monitoring, intensive monitoring should be conducted to evaluate the frequency and intensity of pulses of pollution. I suggest measuring pollutants after every rain event over several months. Finally, areas where WQC are monthly, or more frequently, exceeded should be considered as a polluted area in need of mitigation.

\subsection{FUTURE DIRECTIONS}

This thesis evaluated the effect of copper on E. chloroticus across multiple life stages and using realistic exposure regimes including low concentrations, episodic exposure, repeated exposure, dietary intake and multiple stressors (metal mixture and low salinity). These experiments highlighted areas requiring further investigations:

My experiments demonstrated that juvenile E. chloroticus do not develop a resistance to waterborne copper exposure but are instead more vulnerable to further copper stress. However, the stronger toxicity of pulse exposure vs. chronic exposure in dietary assays suggested a potential acclimation to dietary copper. The resistance of sea urchin to dietary and/or waterborne copper following dietary exposure during larval development should be investigated. Furthermore, young juveniles prove to be highly sensitive to copper stress. Further research on this cryptic and under-studied life stage and its tolerance to metal and to other stressors is needed.

In this thesis, I have addressed the toxicity of copper under hyposaline conditions. However, metal discharge in freshwater runoff is also usually associated with high sediments. Dissolved organic carbon (DOC) is known to impact metal toxicity by complexing with free metal ions and thus reducing its bioavailability (Nadella et al. 2009, Monteiro et al. 2013). Therefore the combined effect of elevated sediment, elevated copper and low salinity should be investigated to better understand the likely 
impact of copper under field conditions. This research has highlighted the importance of investigating latent effects. Therefore, the evaluation of multiple stressors (low salinity, high DOC, multiple metals) should include latent effects.

I investigated one major of trophic interaction by looking at the toxicity of coppercontaminated phytoplankton. Another important trophic interaction would be the vulnerability of contaminated E. chloroticus to predation. Indeed metal toxicity may result in sublethal effect affecting behaviour such as predator avoidance. Such effects have been shown in vertebrates (Lefcort et al. 1998, Zhou \& Weis 1998, Scott \& Sloman 2004) but have been more rarely evaluated in invertebrates and then mostly on adults (reviewed in Fleeger et al. 2003). This potential sublethal effect should be studied in E. chloroticus in both adult and early life stages. Juveniles would be particularly well suited for such investigation, as predation at this stage is high and is a major factor for population persistence (Hunt \& Scheibling 1997, Clemente et al. 2013).

Finally, the effects of long-term metal exposure on gamete quality and resistance to pollution in offspring should be evaluated. In this thesis, I examined the fertilisation success of copper-exposed male E. chloroticus. The effect of copper exposure on females' fertilisation success and, most importantly, on embryos viability should be explored. Several studies have demonstrated the importance of parental history on gametes quality and offspring success (Marshall \& Keough 2004, Marshall 2008, Burgess \& Marshall 2011). Parental exposure to a stressor may confer an increased resistance of their offspring to the same stressor (Marshall \& Uller 2007, Suckling et al. 2014, Lister et al. 2015). For example, embryos of the sea urchin Sterechinus neumayeri from PAH-contaminated females had an increased resistance to oxidative stress than embryos from naive females (Lister et al. 2015). However, this resistance did not translate into an increase in offspring survival. 


\subsection{CONCLUSION}

This research demonstrated the importance of considering latent effect when evaluating a pollutant's toxic effect. Juvenile E. chloroticus were more sensitive to copper exposure when they had previously been exposed to copper during larval development suggesting that single life stage experiments may greatly underestimate metal toxicity. The dietary route proved to be very important even in a low trophic level organism and the toxic effects of dietary intake could not be predicted based on waterborne assays. The importance of using environmentally realistic exposure regimes was highlighted, as pulse exposure was more toxic than chronic exposure in dietary assays. Finally E. chloroticus was a suitable indicator species given its high sensitivity to copper and ease of maintenance in the laboratory. This study provides a first measure of metal toxicity on this endemic species of cultural and commercial importance in New Zealand. 


\title{
APPENDIX A \\ Dissolved metal concentrations in Wellington coastal area
}

\begin{abstract}
A.1 AIMS
Dissolved concentrations of copper, lead and zinc were measured in coastal water adjacent to a river or stream in four sites in the Wellington region to evaluate the prevalence of local metal pollution and provide realistic metal concentrations to use in laboratory experiments. The spatial and temporal scale of metal discharge following a rain event was also observed in the Hutt river plume.
\end{abstract}

\section{A.2 MethodS}

Coastal water was collected near the mouth of river or stream in four sites in the Wellington region: Orongorongo (ORO), Makara (MAK), Hutt (HUT) and Owhiro (OWH) (Figure A.1). The Orongorongo River passes mostly through a protected forest, the Rimutaka forest and through some rural land, mainly pastures, toward its lower reach. This site was considered as a low human impact site. Makara stream is affected by agricultural runoff throughout all its length. The Hutt River receives both residential and industrial runoff as its catchment includes the populated Hutt valley. Owhiro stream is a small stream passing through Wellington's active Southern Landfill. At each site, two water samples were collected $3 \mathrm{~m}$ from shore at approximately $30 \mathrm{~cm}$ deep in acid washed high-density polyethylene plastic bottles. 

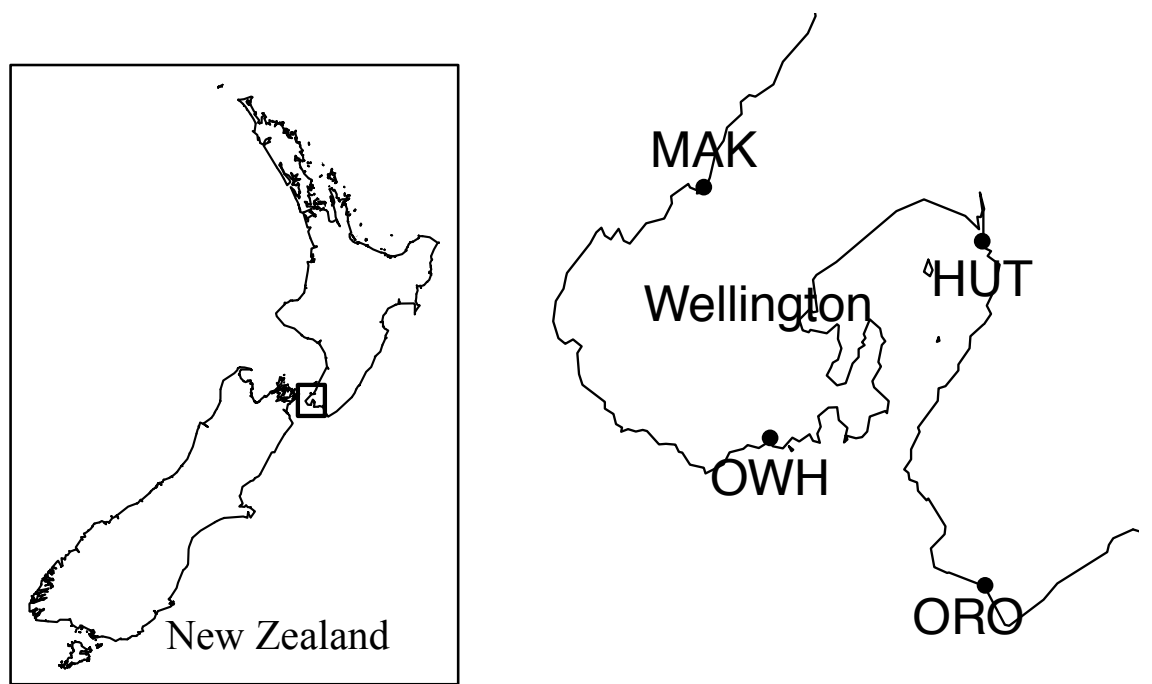

Figure A.1: Location of the water sampling sites in the region of Wellington. MAK: Makara stream, HUT: Hutt River, OWH: Owhiro stream, ORO: Orongorongo River.

Water was collected once during a period of low rain $(<5 \mathrm{~mm}$ daily rainfall for five days prior to sampling) to provide a baseline concentration of trace metals and on the day following three major rain events (rain 1 to 3), defined by over $15 \mathrm{~mm}$ rainfall in the previous $24 \mathrm{~h}$ (Table A.1). Rain events were ranked in three categories: 1 (15- 20 $\mathrm{mm}$ in $24 \mathrm{~h}), 2(20-30 \mathrm{~mm})$ and $3(>30 \mathrm{~mm})$. Category 1 rain event occur every month on average; catergory 2 rain events occur every two months; category 3 rain event every three to four month with at strong variability between year. For example in 2013, a category 3 rain event occurred almost every month from February to October. On the other hand, only two category 3 rain events occurred in 2012 (in January and March; CliFlo). All the rain events sampled in this study occurred between October and January during the spawning season of Evechinus chloroticus in 2011 to 2013. 
Table A.1: Details of the freshwater input during sampling. Rainfall for the $24 \mathrm{~h}$ previous water collection is from Wellington airport weather station (CliFlo). Rain events were ranked as 1 (15 - 20 $\mathrm{mm}$ in $24 \mathrm{~h}), 2(20-30 \mathrm{~mm})$ or $3(>30 \mathrm{~mm})$. River flow at the time of sampling followed by maximum flow in the $24 \mathrm{~h}$ prior sampling and time of maximum flow in hour before sampling, in brackets, is from Orongorongo river at Truss Bridge (ORO) and Hutt river at Taita Gorge (HUT) (GWRC database). Salinity was measured by refractometer in coastal water at $3 \mathrm{~m}$ from shore. Water samples were collected at approximately $30 \mathrm{~cm}$ depth.

\begin{tabular}{|c|c|c|c|c|c|c|c|c|}
\hline \multirow[t]{2}{*}{ Sampling } & \multirow{2}{*}{$\begin{array}{l}\mathbf{R} \\
\mathbf{a} \\
\mathbf{n} \\
\mathbf{k}\end{array}$} & \multirow[t]{2}{*}{$\begin{array}{l}\text { Rain- } \\
\text { fall } \\
(\mathrm{mm})\end{array}$} & \multicolumn{2}{|c|}{$\begin{array}{c}\text { River flow (cubic m / sec) } \\
\text { (max flow, hours before } \\
\text { sampling) }\end{array}$} & \multicolumn{4}{|c|}{$\begin{array}{c}\text { Salinity in water samples } \\
(\mathrm{ppt})\end{array}$} \\
\hline & & & HUT & ORO & HUT & MAK & OWH & ORO \\
\hline Baseline & - & 2.2 & $18(31,23 \mathrm{~h})$ & $0.7(1.8,17 \mathrm{~h})$ & 12 & 19 & - & 1 \\
\hline Rain 1 & 3 & 32.8 & $19(21,15 \mathrm{~h})$ & $3.4(14,24 \mathrm{~h})$ & 28 & 11 & - & 12 \\
\hline Rain 2 & 2 & 21.4 & $12(16,17 \mathrm{~h})$ & $1.0(2.1,24 \mathrm{~h})$ & 30 & 12 & 21 & 1 \\
\hline Rain 3 & 3 & 39.6 & $50(200,18 \mathrm{~h})$ & $2.8(20,17 \mathrm{~h})$ & 6 & 6 & 26 & 9 \\
\hline Rain 4 & 1 & 19.4 & $53(190,16 \mathrm{~h})$ & - & 6 & - & - & - \\
\hline
\end{tabular}

All samples were collected in an outgoing tide, $1-3 \mathrm{~h}$ after high tide. Sampling in Owhiro was done only for rain event 2 and 3. During a fourth rain event (rain event 4), the spatial and temporal scale of the metal contamination brought by the Hutt River was evaluated. On the day following the rain event, surface water $(30 \mathrm{~cm}$ deep) samples were collected at $3 \mathrm{~m}, 50 \mathrm{~m}, 100 \mathrm{~m}$ and $1 \mathrm{~km}$ from shore. In addition, samples were taken at $3 \mathrm{~m}$ from shore every day for the three days following the rain event (rain event $=$ day 0 ).

Salinity was measured in the laboratory and samples were filtered through a $0.45 \mu \mathrm{m}$ trace metal-free mesh (digiFilter, SCP Science). The filtrate was acidified with reagent grade nitric acid (Merck Millipore) and kept in a trace metal-free plastic tube (digiTubes, SCP Science). Trace metal content (copper, lead and zinc) was analysed by ICP-MS at Environmental Laboratory Services, Lower Hutt. Detection limits were $0.5 \mu \mathrm{g} / \mathrm{L} \mathrm{Cu}, 0.5 \mu \mathrm{g} / \mathrm{L} \mathrm{Pb}, 2 \mu \mathrm{g} / \mathrm{L} \mathrm{Zn}$. Each water sample was analysed in duplicate and the average is used in all graphs and tables below. 


\section{A.3 RESUlTS AND DisCUSSION}

No metals were detectable in baseline samples while copper and zinc were elevated after a rain event at most sites (Figure A.2). Copper was the only metal found above the water quality criteria (WQC; (ANZECC 2000). Zinc was found in Hutt and Owhiro during all the rain events sampled but was always well below WQC. Lead was only present in relatively high concentration $(2.4$ to $2.9 \mu \mathrm{g} / \mathrm{L})$ from one rain event. Given the high concentration observed and the discrepancy with other rain events, a contamination of the water samples occurring in the laboratory might be responsible for the elevated lead levels in the rain event 1. 

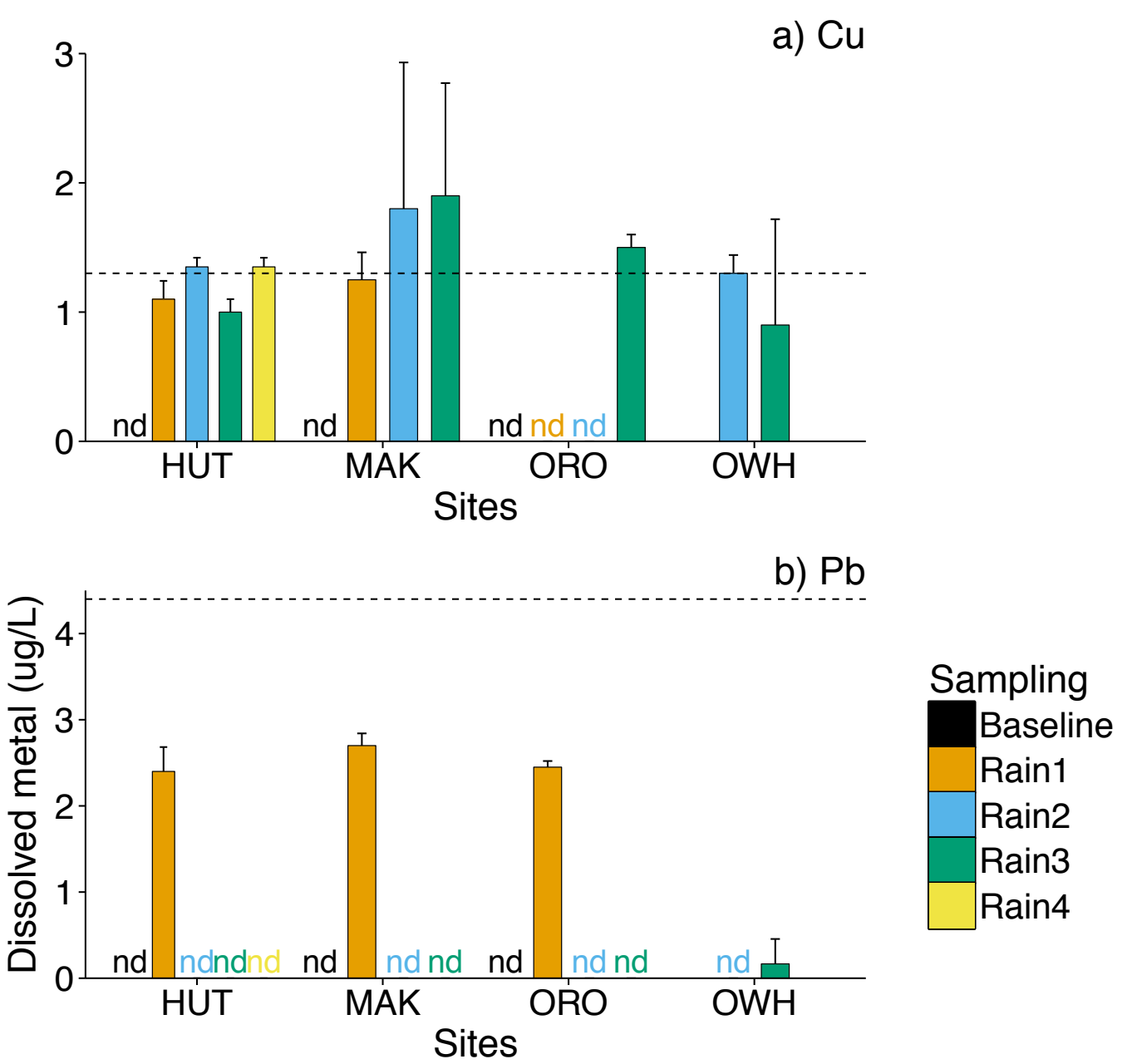

c) $\mathrm{Zn}$

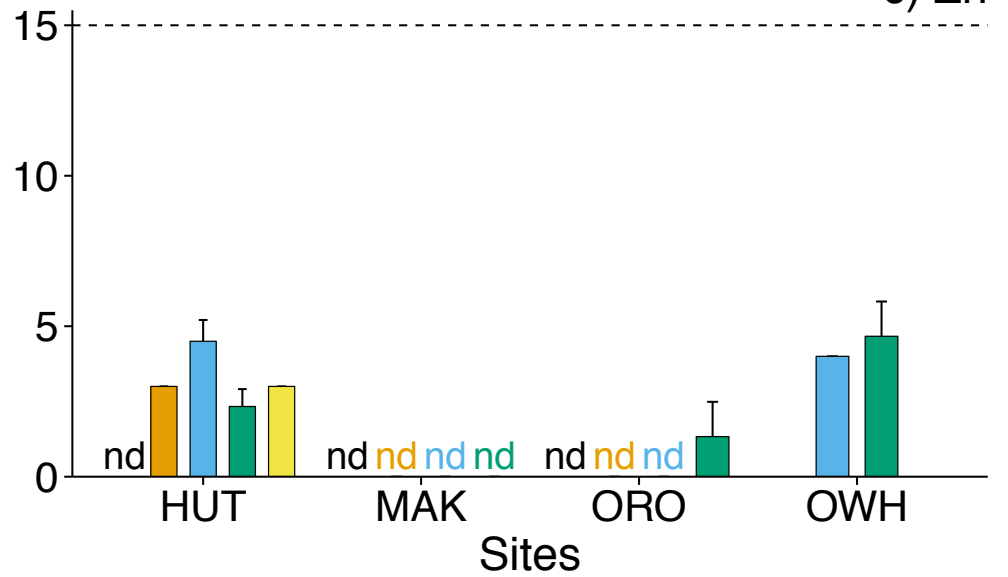

Figure A.2: Dissolved copper (A), lead (B) and zinc (C) in costal water near a stream or river discharge. HUT $=$ Hutt river, MAK = Makara stream, ORO = Orongorongo river, OWH $=$ Owhiro stream. Water samples were collected during a dry period (baseline) or on the day following a major rain event (rain 1 to 4). All water samples were collected $3 \mathrm{~m}$ from shore between 2011 and 2013. Error bars represent the standard deviation $(\mathrm{N}=2)$. The dashed line represents the current water quality criteria for $95 \%$ species protection (ANZECC 2000). nd = non detectable. Detection limits were $0.5 \mu \mathrm{g} / \mathrm{L} \mathrm{Cu}, 0.5 \mu \mathrm{g} / \mathrm{L} \mathrm{Pb}, 2 \mu \mathrm{g} / \mathrm{L} \mathrm{Zn}$. 
Orongorongo was the least contaminated site with a detectable level of dissolved copper present only during rain event 3 (Figure A.2), which was the largest rain event sampled for Orongorongo - i.e. highest maximum flow rate (Table A.1). Makara was the site of most concern with copper concentration above WQC found in at least one sample during two of the three rain events sampled. Copper concentration at this site reached 2.6 and $2.9 \mu \mathrm{g} / \mathrm{L}$ and could be due to copper-based agricultural products such as pesticides and fungicides. Owhiro stream itself is heavily polluted as shown by the monitoring of a broad range of contaminants in freshwater conducted in 2008 (Milne \& Watts 2008). However, as Owhiro stream is a very small stream, dilution occurs quickly in coastal water and relatively high salinity (21 and $26 \mathrm{ppt}$ ) were observed at $3 \mathrm{~m}$ from shore. Consequently, copper was near WQC and zinc was below WQC in coastal seawater at this site (Figure A.2).

It should be noted that the rain events sampled here were not exceptional and occur on a monthly basis throughout the year in the Wellington region (CliFlo). Furthermore, metal concentration was likely higher during the maximum river flow, which occurred 15 to $24 \mathrm{~h}$ prior to water sampling (Table A.1). A monitoring study of river and streams in the Wellington area showed that metal concentration was usually at its highest during the first flush and decreased rapidly afterwards (Milne \& Watts 2008). However, maximum flow in the Hutt and Orongorongo rivers occurred on the day of the rainstorm when coastal water could not be sampled due to severe weather conditions.

Metal contamination from a polluted river can affect a large coastal area. In this study, surface levels of copper and zinc up to $1 \mathrm{~km}$ from shore were similar to shore levels (Table A.2). Copper and zinc seemed to have a different residence time in the water column. Copper was detectable only on the day following the rain event while zinc concentration peaked at day 2 (rain event $=$ day 0$)$ and remained detectable up to day 3 (Table A.2). All water samples were surface samples collected at approximately $30 \mathrm{~cm}$ deep. Therefore the vertical profile of metal concentrations during in the river plume has not been evaluated. 
Table A.2: Dissolved metal ( $\mu \mathrm{g} / \mathrm{L})$ and salinity from $3 \mathrm{~m}$ to $1 \mathrm{~km}$ offshore $(\mathrm{A})$ in the Hutt river plume for three days following a rain event (B). For the spatial gradient (A), water samples were taken on the day following the rain event (day 1) between $3 \mathrm{~m}$ and $1 \mathrm{~km}$ from shore. For the temporal gradient (B), water samples were taken at $3 \mathrm{~m}$ from shore, everyday for three days following the rain event (rain event day = day 0$)$.

\begin{tabular}{|c|c|c|c|c|}
\hline & $\mathbf{C u}$ & $\mathbf{P b}$ & $\mathbf{Z n}$ & Salinity (ppt) \\
\hline \multicolumn{5}{|c|}{ (A) Spatial gradient } \\
\hline $3 \mathrm{~m}$ & 1.4 & $<0.5$ & 3 & 6 \\
\hline $50 \mathrm{~m}$ & 1.3 & $<0.5$ & 3 & 6 \\
\hline $100 \mathrm{~m}$ & 0.9 & $<0.5$ & 2 & 2 \\
\hline $500 \mathrm{~m}$ & 1.2 & $<0.5$ & $<2$ & 2 \\
\hline $1000 \mathrm{~m}$ & 1.3 & $<0.5$ & 2 & 12 \\
\hline \multicolumn{5}{|c|}{ (B) Temporal gradient } \\
\hline Day 1 & 1.4 & $<0.5$ & 3 & 6 \\
\hline Day 2 & $<0.5$ & $<0.5$ & 5 & 34 \\
\hline Day 3 & $<0.5$ & $<0.5$ & 2 & 18 \\
\hline
\end{tabular}





\section{APPENDIX B}

\section{Direct effects of copper exposure on Evechinus chloroticus larval stage (Additional data from Chapter 3)}

\section{B.1 MethoDS}

\section{B.1.1 EXPERIMENTAL METHODS}

All experimental methods are described in section 3.2.3.

\section{B.1.2 STATISTICS}

Jars 10 (Late ANZECC treatment), 19 (Late High treatment) and 30 (Early Field treatment) were lost at $11 \mathrm{~d}, 6 \mathrm{~d}$ and $25 \mathrm{~d}$ respectively. Direct effects of copper treatments on larval stages were evaluated by (1) survival, (2) normal development, (3) delayed development, (4) growth and (5) morphometrics.

\section{B.1.2.1 Larval survival and development}

Survival rate was expressed as larval density at age $\mathrm{d} /$ larval density at age 4 to remove natural variation in early survival across jars. Normal development was expressed as the proportion of live larvae rated as normal (Table 3.2). In both survival and normal development analysis, $13 \mathrm{~d}$ was removed as only partial sampling was done (Late exposure group only) and $25 \mathrm{~d}$ and $27 \mathrm{~d}$ were considered as the same level 
of treatment to allow comparison between the two timing groups. Delayed development was measured as the proportion of normal larvae at the final stage of 8armed plutei during last sampling ( $25 \mathrm{~d}$ post-fertilisation for Early group and $27 \mathrm{~d}$ for Late group). Jar 15 (Early ANZECC treatment) was not sampled at $25 \mathrm{~d}$ and removed from the survival and normal development analyses to have a balanced design.

Larval survival and normal development was analysed using a three-ways split-plot factorial Repeated Measures ANOVA with copper level and timing of exposure as 'between' factors and larval age (in days post-fertilisation) as 'within' factor. The effect of copper level on delayed development was analysed using a one-way ANOVA separately for Early and Late groups as sampling was done two days later in Late group, which may affect the proportion of 8-armed plutei. All three variables were square-root arcsin transformed to meet ANOVA assumptions. F-ratios values were calculated from Type II SS. When copper level factor was significant $(\mathrm{p}<0.05)$ a post-hoc Dunnett's comparison test was used to compare all treatments against their control.

\section{B.1.2.2 Larval growth and morphometrics}

For traits present from mid-larval stages: body length (BL), postoral arms (PO) and anterolateral arms (AL), average growth rate per jar was measured between $11 \mathrm{~d}$ and $25 \mathrm{~d}$ post-fertilisation in Early exposure group and between $13 \mathrm{~d}$ and $27 \mathrm{~d}$ postfertilisation. Time interval was 14 days in both timing groups. All response variables were analysed using two-ways ANOVAs with copper level, exposure timing and their interaction as main factors and met ANOVA assumptions without transformation. Fratios were calculated from Type II SS.

For traits present only in late larval stages: posterodorsal arms (PD), preoral arms (EO) and rudiment size (R), or for which growth is of no interest (i.e. stomach size), measures during last sampling (25 d in Early exposure group and $27 \mathrm{~d}$ in Late exposure group) were analysed separately for both exposure-timing groups. One-way ANOVAs on mixed effect linear models to account for non-independence of individual larvae within a jar were used with copper level as fixed effect, jars as random effect and individual larvae as residuals. Assumptions were graphically 
checked and were met without transformation. F-ratios were calculated from Type I SS.

Rudiment presence was expressed as the proportion of 8 -armed pluteus having a rudiment visible under compound microscope per jar. Rudiment presence was squareroot arcsin transformed and analysed using a separate one-way ANOVA for both exposure timing groups. F-ratios were calculated from Type I SS.

\section{B.2 RESULTS}

\section{B.2.1 LARVAL SURVIVAL AND DEVELOPMENT}

Larval survival and normal development were not affected by copper exposure or timing of exposure (Table B.1). Only larval age had a significant effect, with survival and proportion of normal larvae declining with time.

Table B.1: Repeated measures ANOVA of Evechinus chloroticus larval survival rate (A) and larval normal development rate (B) to test effects of copper exposure (copper level) and timing of exposure (timing) during 3 sampling (Age) throughout larval stage. Significant effects $(p<0.05)$ are highlighted in bold.

\begin{tabular}{lllll}
\hline Source of variation & df & SS & $\boldsymbol{F}$ & p \\
\hline (A) Larval survival & & & & \\
Timing & 1,16 & 0.0392 & 0.708 & 0.413 \\
Copper level & 4,16 & 0.628 & 2.838 & 0.059 \\
Age & 2,32 & 12.49 & 178.5 & $<\mathbf{0 . 0 0 1}$ \\
Timing x Copper level & 4,16 & 0.209 & 0.942 & 0.465 \\
Timing x Age & 2,32 & 0.032 & 0.464 & 0.633 \\
Copper level x Age & 8,32 & 0.470 & 1.678 & 0.142 \\
\hline (B) Larval normal development & & & \\
Timing & 1,16 & 0.097 & 2.532 & 0.131 \\
Copper level & 4,16 & 0.153 & 0.999 & 0.437 \\
Age & 2,32 & 3.922 & 80.18 & $<\mathbf{0 . 0 0 1}$ \\
Timing x Copper level & 4,16 & 0.151 & 0.985 & 0.443 \\
Timing x Age & 2,32 & 0.134 & 2.739 & 0.080 \\
Copper level x Age & 8,32 & 0.265 & 1.356 & 0.253 \\
\hline
\end{tabular}

However, there was a trend of delayed development (Figure B.1) with a lower proportion of 8-arms larvae in the High copper level in both Early and Late exposure groups (Early exposure: $0.53 \pm 0.46$ in High level $v s 0.79 \pm 0.17$ in control; Late exposure: $0.52 \pm 0.22$ in High level vs $0.95 \pm 0.03$ controls; mean \pm standard 
deviation). However, this difference was significant only in the Late exposure group (Dunnett's contrasts, Early: $\mathrm{t}=-1.26, \mathrm{p}=0.57$; Late: $\mathrm{t}=-5.06, \mathrm{p}=0.002$ ).

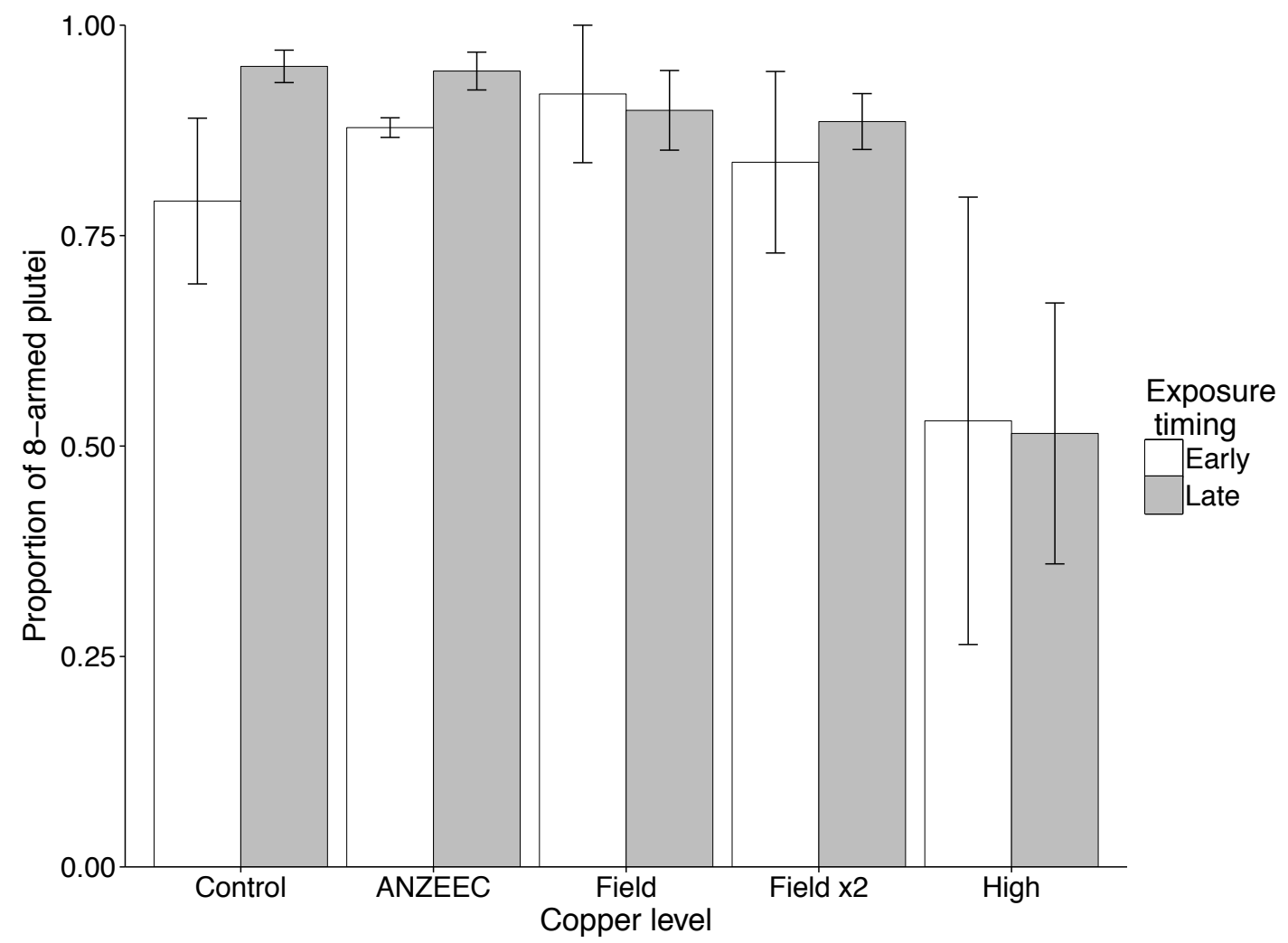

Figure B.1: Delayed development of Evechinus chloroticus larvae exposed to copper expressed as proportion of normal larvae having reached the 8-armed pluteus stage at day 25 post-fertilisation for Early exposure group (white bars) and day 27 for Late exposure group (grey bars). Error bars represent the standard error of the mean $(\mathrm{N}=3)$.

\section{B.2.2 LARVAL GROWTH AND MORPHOMETRICS}

Larval growth for all three variables: body length (BL), postoral arms (PO) and anterolateral arms (AL), was significantly lower in the Early exposure group with and average of $23 \%$ growth in $\mathrm{BL}, 18 \%$ in $\mathrm{PO}$ and $51 \%$ in $\mathrm{AL}$ against a growth rate of respectively $31 \%, 27 \%$ and $95 \%$ in Late exposure group (Table B.2). However, copper level was not significant and controls for each variable were also slightly lower in Early treatment than in Late treatment, although the difference was significant only for $\mathrm{AL}$ ( $\mathrm{t}$-test; $\mathrm{t}=-3.45, \mathrm{df}=4, \mathrm{p}=0.03$; Figure B.2). This suggests that the difference between Early and Late treatment is due to stage-dependent growth rather than timing of copper exposure. Indeed growth rate in Late groups was 
measured slightly later (13 - $17 \mathrm{~d}$ post-fertilisation) than in Early groups $(11-25 \mathrm{~d}$ post-fertilisation). Interestingly, growth rate was higher in Late groups for all variables and copper levels except for arm growth (both PO and AL) in High copper level. There might be a trend of decreasing arm growth in High copper level but it is masked by the difference in sampling timing.

Table B.2: Effect of copper exposure (Level) and timing of exposure (Timing) on Evechinus chloroticus growth rate during the last 14 days of larval stage analysed using a two-ways ANOVA model. Significant effects $(\mathrm{p}<0.05)$ are highlighted in bold.

\begin{tabular}{lccc}
\hline Variable & Timing $\boldsymbol{F}(\mathbf{p})$ & Level $\boldsymbol{F}(\mathbf{p})$ & Timing x Level $\boldsymbol{F}(\mathbf{p})$ \\
\hline Body length (BL) & $\mathbf{6 . 5 9 ( 0 . 0 2 )}$ & $0.23(0.92)$ & $0.92(0.48)$ \\
Postoral arm length (PO) & $\mathbf{1 1 . 0 5 ( 0 . 0 0 5 )}$ & $2.99(0.05)$ & $1.43(0.27)$ \\
Antelateral arm length (AL) & $\mathbf{7 . 6 4 ( 0 . 0 1 )}$ & $1.71(0.20)$ & $1.05(0.41)$ \\
\hline
\end{tabular}



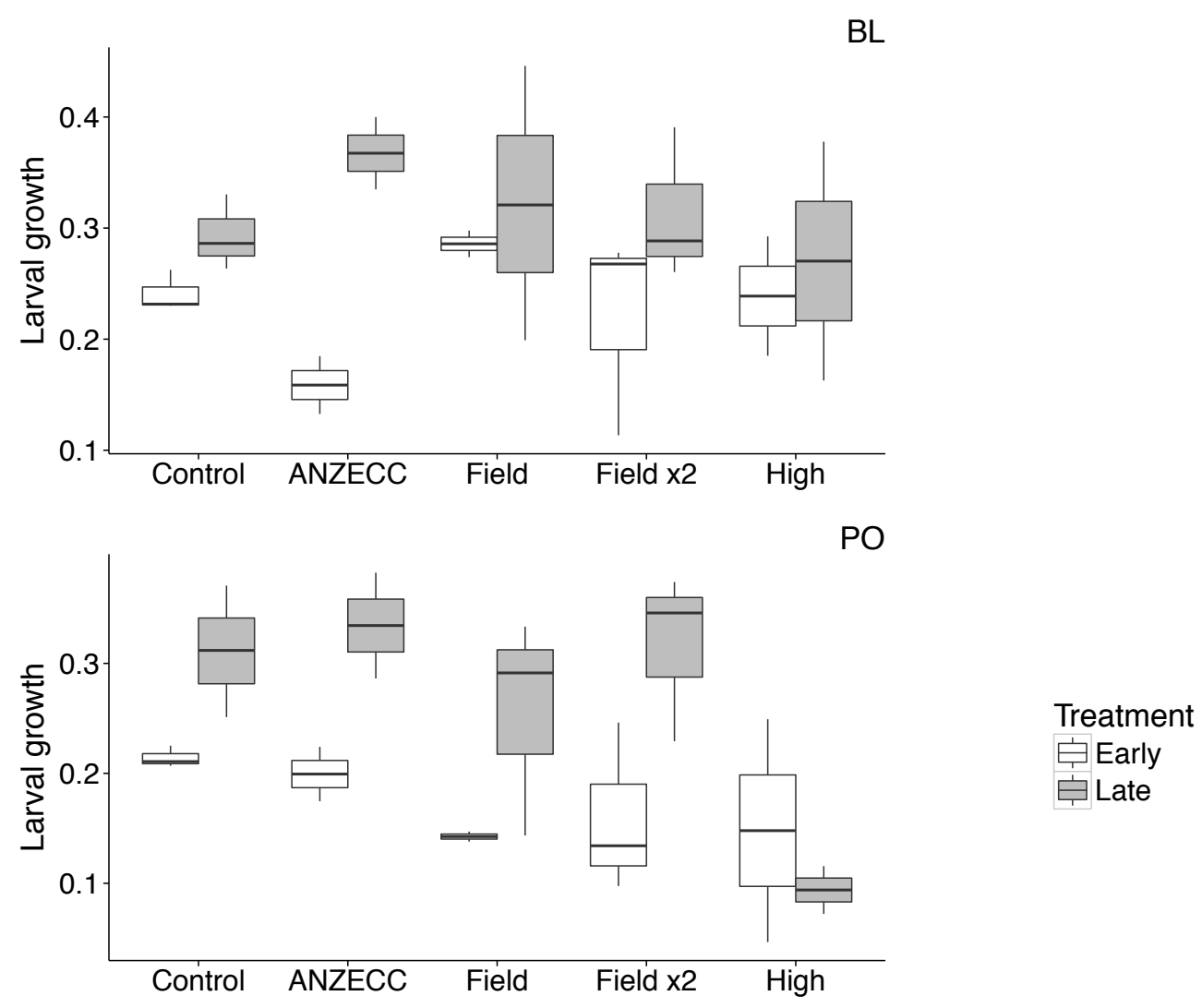

$\mathrm{AL}$

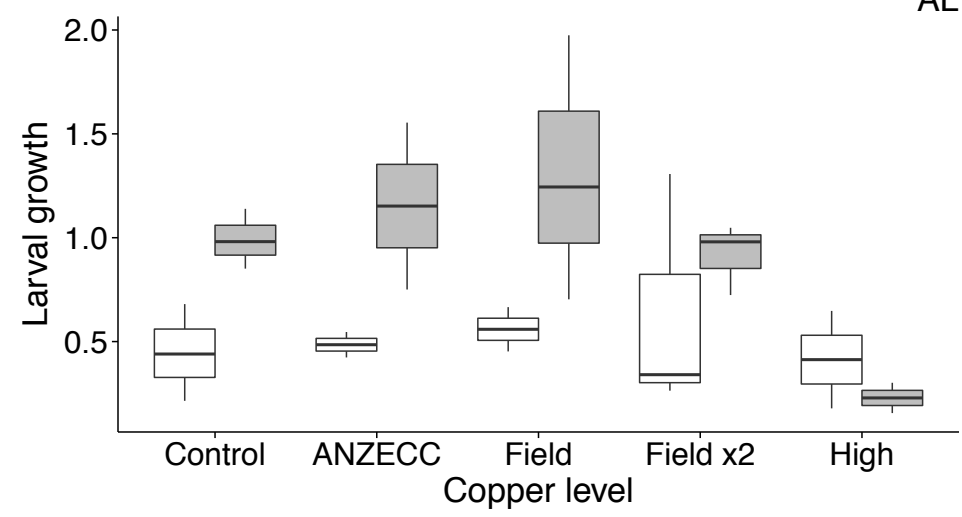

Figure B.2: Proportion of growth of Evechinus chloroticus larvae body length (BL), postoral arms (PO) and anterolateral arms (AL) during the last 2 weeks of larval stage. Larvae where exposed to different levels of copper either Early (4 - 6 days post-fertilisation) or Late (11 - 13 days postfertilisation) in larval stage. Boxes represent the median and quartiles.

Copper exposure had no significant effect on larval morphometric measures at the end of the larval stage (PD, EO and R) except for EO in Early exposure group (Table B.3). However, the significance in EO was driven by a difference between Field and High copper level (Tukey comparisons: $p=0.02$ ). Rudiment presence was not affected by copper exposure in both timing groups (one-way ANOVA, Early group: F $=4.28, \mathrm{p}=0.06$; Late group: $\mathrm{F}=0.25, \mathrm{p}=0.90)$. The difference between Early and 
Late groups could not be evaluated, as measurements were not taken on the same day for both groups.

Table B.3: Effect of copper exposure (copper level) on Evechinus chloroticus morphometric measurements in late larval stage ( $25 \mathrm{~d}$ post-fertilisation for Early exposure group and $27 \mathrm{~d}$ for Late exposure group) analysed using a one-way ANOVA on mixed effect model. Significant effects ( $\mathrm{p}<$ $0.05)$ are highlighted in bold.

\begin{tabular}{lcc}
\hline Variable & Copper level in Early group & Copper level in Late group \\
& $\boldsymbol{F}(\mathbf{p})$ & $\boldsymbol{F}(\mathbf{p})$ \\
\hline Posterodorsal arm length (PD) & $1.05(0.45)$ & $0.39(0.31)$ \\
Preoral arm length (EO) & $\mathbf{5 . 8 1}(\mathbf{0 . 0 2})$ & $1.96(0.19)$ \\
Stomach size & $1.11(0.42)$ & $0.62(0.66)$ \\
Rudiment size & $0.37(0.77)$ & \\
\hline
\end{tabular}





\section{APPENDIX C}

\section{Bioaccumulation of copper, lead and zinc by the planktonic alga Dunaliella tertiolecta}

\section{C.1 Methods}

\section{C.1.1 EXPERIMENTAL METHODS}

Dunaliella tertiolecta was cultured in $100 \mathrm{ml}$ trace metal-free HDPE plastic tubes (digitubes, SCP Science, Canada). Basic culture medium was prepared by adding standard F/2 medium to natural filtered seawater (FSW), pre-filtered to $15 \mu \mathrm{m}$ and then filtered through a $0.2 \mu \mathrm{m}$ paper cartridge. Tubes and culture medium were sterilised by autoclave $\left(121^{\circ} \mathrm{C}, 15 \mathrm{~min}\right.$ cycle $)$.

Metal enriched culture media were prepared by adding reagent grade metals after autoclaving: copper sulphate $\left(\mathrm{CuSO}_{4} .5 \mathrm{H}_{2} \mathrm{O}\right)$, lead nitrate $\left(\mathrm{Pb}\left(\mathrm{NO}_{3}\right)_{2}\right)$ and zinc sulphate $\left(\mathrm{ZnSO}_{4} \cdot 7 \mathrm{H}_{2} \mathrm{O}\right)$, to standard $\mathrm{F} / 2$ medium. Nominal concentrations for each metal level used are shown in Table C.1. The ANZECC level was based on the current recommended water quality trigger value for $95 \%$ species protection (ANZECC 2000). The Field $\mathrm{x} 2$ concentration was twice the maximum dissolved copper concentration measured from 29 seawater samples collected across four sites in the Wellington region between September 2011 and January 2012 (Figure A.2). The High level was chosen as a realistic level occurring in moderately polluted water 
such as near large cities (Table 1.1). Three replicate tubes were used for each metal and level of contamination plus control.

Table C.1: Concentrations of copper (A), lead (B) and zinc (C) used in algal culture (nominal concentration) and corresponding cellular concentration in Dunaliella tertiolecta \pm standard deviation (sd). Cellular concentration is measured in total recoverable metal per cell. Metal concentration per algal dry weight is based on a dry weight of $1.25 \times 10^{10}$ cells $/ g$ (Fábregas et al. 1995).

\begin{tabular}{|c|c|c|c|c|c|}
\hline Metal level & $\begin{array}{l}\text { Nominal } \\
\text { concentration }\end{array}$ & $\mathbf{N}$ & $\begin{array}{l}\text { Mean cellular } \\
\text { concentration } \\
(\text { fg/cell) }\end{array}$ & $\pm s d$ & $\begin{array}{l}\text { Metal } \\
\text { concentration } \\
\text { per dry weight } \\
(\mu \mathrm{g} / \mathrm{g})\end{array}$ \\
\hline \multicolumn{6}{|l|}{ (A) Copper } \\
\hline Control & 0 & 3 & 1.4 & 1.2 & 17.5 \\
\hline ANZECC & 1.3 & 3 & 5.3 & 0.8 & 66.3 \\
\hline Field x2 & 5.8 & 3 & 13.7 & 2.3 & 171.7 \\
\hline High & 10 & 2 & 28.1 & 0.7 & 351.3 \\
\hline \multicolumn{6}{|l|}{ (B) Lead } \\
\hline Control & 0 & 3 & 0.5 & 0.6 & 6.7 \\
\hline ANZECC & 4.4 & 3 & 2.5 & 0.3 & 31.5 \\
\hline Field x2 & 5.4 & 1 & 2.1 & - & 27.0 \\
\hline High & 10.4 & 3 & 16.41 & 6.2 & 205.2 \\
\hline \multicolumn{6}{|l|}{ (C) Zinc } \\
\hline Control & 0 & 3 & 10.0 & 4.4 & 125.1 \\
\hline Field x2 & 9.4 & 2 & 22.8 & 6.3 & 284.4 \\
\hline ANZECC & 15 & 2 & 30.8 & 1.6 & 384.4 \\
\hline High & 50 & 2 & 75.5 & 6.3 & 943.1 \\
\hline
\end{tabular}

Culture tubes were inoculated with rinsed D. tertiolecta at a density of $2 \times 10^{5}$ cells / $\mathrm{ml}$. Algae were cultured for 14 days at $13^{\circ} \mathrm{C} \pm 1$ under a $12 \mathrm{~h}$ light-cycle. Oxygenation was provided by daily manual stirring. After two weeks of culture, an aliquot of 60 $\mathrm{ml}$ was taken per tubes. D. tertiolecta cells were rinsed thoroughly to remove unabsorbed metals by three successive centrifugations and resuspensions in clean FSW (1201 g for $5 \mathrm{~min}$ ). Precipitated cells were then resuspended in $20 \mathrm{ml}$ deionized (ddi.) water and cell density was measured with a heamocytometer. Algal suspension was acidified with reagent grade nitric acid (final concentration: 1\%) to preserve metal content and were sent to Environmental Laboratory Services, Lower Hutt, for total recoverable metal analysis. Metal concentrations were expressed in femtogram of metal per algal cell (cellular concentration). 


\section{C.1.2 STATISTICS}

The effect of metal spikes in culture medium on final concentration of metal in algal cells were analysed using separate linear regression on each metal tested. In lead, cellular concentration was log-transformed to meet the linear relationship assumption. Comparison between the different copper levels and controls was examined using $a$ priori coefficients contrasts from one-way ANOVAs. A dry weight of $1.25 \times 10^{10}$ cells/g of dry weight was used to convert cellular metal in metal accumulation per weight (Fábregas et al. 1995).

\section{C.2 RESUlTS}

Bioaccumulation occurred in all three metals tested with a significant increase of cellular metal concentration with metal exposure (Table C.2). The relationship between metal in culture and cellular metal was linear for copper and zinc, and exponential for lead across the metal range tested (Figure C.1).

Table C.2: Effect of metal exposure on cellular metal concentration of Dunaliella tertiolecta analysed by linear regression. Data was log-transformed in lead. Significant effects $(p<0.05)$ are highlighted in bold.

\begin{tabular}{lllll}
\hline Metal & df & Estimate & $\boldsymbol{t}$ & p \\
\hline Copper & 9 & 2.60 & 12.8 & $<\mathbf{0 . 0 0 1}$ \\
Lead & 8 & 0.23 & 9.0 & $<\mathbf{0 . 0 0 1}$ \\
Zinc & 7 & 1.31 & 17.6 & $<\mathbf{0 . 0 0 1}$ \\
\hline
\end{tabular}



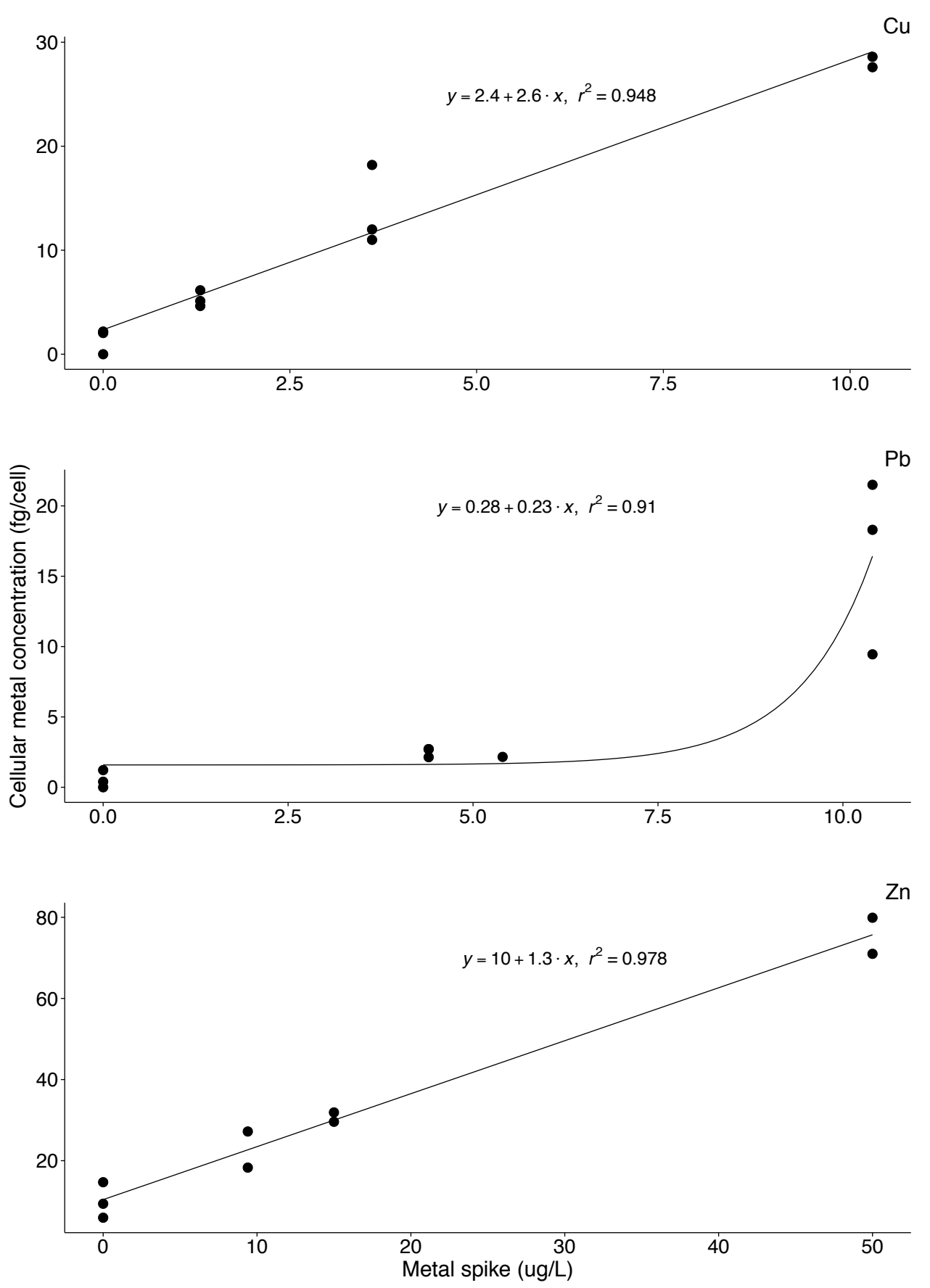

Figure C.1: Bioaccumulation of copper $(\mathrm{Cu})$, lead $(\mathrm{Pb})$ and zinc $(\mathrm{Zn})$ by Dunaliella tertiolecta after 1 week of culture in metal-spiked medium. Cellular metal concentration is the total recoverable metal per cell. Regression equation and $\mathrm{R}^{2}$ shown in $\mathrm{Pb}$ is based on $\log$-transformed data, $\log (\mathrm{y}+1)$.

Cellular copper concentration was more than 3-fold higher in the lowest copper level (ANZECC), 10-fold higher in Field x2 and more than 20-fold higher in High level (Table C.1a). However, due to the very small sample size and thereby lack of power, only Field x 2 and High levels were significantly different from controls (Coefficient contrasts; Field $x 2: \mathrm{t}=6.7, \mathrm{p}<0.001$; High: $\mathrm{t}=13.1, \mathrm{p}<0.001$ ). 
Cellular lead concentration was 4 to 5-fold higher in ANZECC and Field x2 level and more than 30-fold higher in High level (Table C.1b). Only the High level was significantly different from control (Coefficient contrasts: $t=5.36, p=0.002$ ).

Cellular zinc concentration was 2-fold higher in Field x2, 3-fold higher in ANZECC and more than 7-fold higher in High level (Table C.1c). All copper levels were significantly different from control (Coefficient contrasts; Field x2: $\mathrm{t}=2.84, \mathrm{p}=0.04$; ANZECC: $\mathrm{t}=4.62, \mathrm{p}=0.006$; High: $\mathrm{t}=14.6, \mathrm{p}<0.001$ ). 



\section{APPENDIX D}

\section{Fertilisation success and copper burden in Evechinus chloroticus: pilot studies}

\section{D.1 AIMS}

\section{Copper burden pilot}

Copper burdens in the gonads of adult E. chloroticus from seven sites across Wellington Harbour were compared to select a population with elevated copper burden for further analysis.

\section{Fertilisation success pilot}

The effect of copper on E. chloroticus gametes was evaluated at different sperm concentrations to determine the sperm concentration yielding the maximum observable effect of copper toxicity on fertilisation success.

\section{D.2 METHODS}

\section{D.2.1 COPPER BURDEN PILOT}

Five adults (test size $>7 \mathrm{~cm}$ ) were collected from seven sites across Wellington Harbour in September - November 2012 (Figure D.1). Animals were measured (test diameter), and the gonads were dissected and weighed (wet weight). A subsample of gonad tissues was taken for analysis for copper content while, the remaining tissues 
were dried at $60^{\circ} \mathrm{C}$ to determine the moisture content. Wet subsamples were digested in nitric acid and analysed by graphite-furnace atomic absorption spectrometry following the U.S. EPA standard protocol (Creed \& Martin 1997). All copper burden values presented here should be used only to compare samples analysed in the same run (i.e. all samples presented here but excluding samples in Chapter 6) due to difference in the calibration procedure.

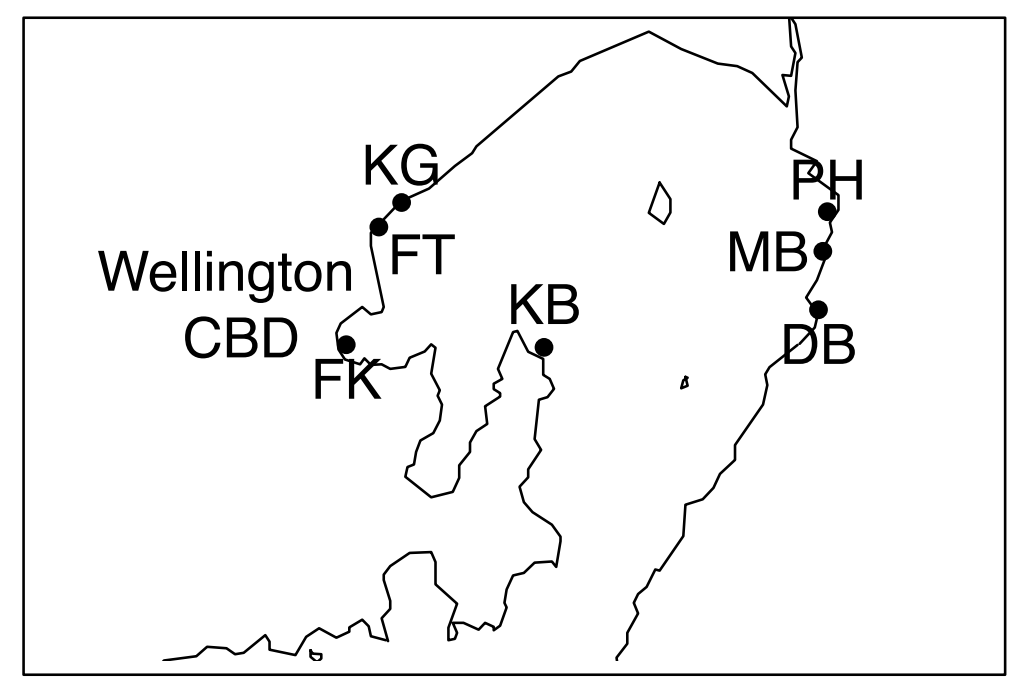

Figure D.1: Map of Wellington Harbour showing sampling sites. FK: Frank Kitts park, FT: Ferry terminal, KG: Kaiwharawhara gorge, KB: Kau Bay, PH: Point Howard, MB: Mahina Bay, DB: Days Bay.

\section{D.2.2 FERTILISATION SUCCESS PILOT}

Broodstock was collected at the beginning of the spawning season (October 2013) in Kau Bay (KB, Figure D.1). Adults were kept in the laboratory for two months prior to spawning and were fed twice a week with native kelp (Macrocystis pyrifera) and/or commercial feed (ABMAX, E.N. Hutchinson Ltd Auckland NZ). E. chloroticus gametes from three males and three females were obtained by inducing spawning with potassium chloride (as described in section 3.2.1). Gametes from different parents were pooled in equivalent concentration, to obtain a composite sperm and egg stock. Fertilisation occurred in $10 \mathrm{ml}$ glass vials containing seawater spiked with 0,5 , 15 or $50 \mathrm{ug} / \mathrm{L}$ of copper (reagent grade copper sulfate CuSO4.5H2O). Egg density was $100 \mathrm{eggs} / \mathrm{ml}$ and sperm density (measured with a haemocytometer) was $10,10^{2}$, $10^{3}$ or $10^{4}$ per $\mathrm{ml}$. Eggs and sperm were left in contact for $1 \mathrm{~h}$ before being preserved in $40 \%$ ethanol. All treatments had three replicate vials. Fertilisation success was 
evaluated by observing 100 eggs per vials for sign of a fertilisation membrane, under x200 magnification

\section{D.3 RESULTS}

\section{D.3.1 COPPER BURDEN PILOT}

Copper burden in E. chloroticus appeared to be elevated at the urban sites of FK and FT, and to a lesser extent at KG (Table D.1). The two individuals sampled from the industrial site showed no detectable copper. Most individuals from residential sites had a copper burden below detectable levels. Due to ease of access, FK was selected as the polluted site for Chapter 6 .

Table D.1: Copper burden in Evechinus chloroticus from seven sites across Wellington Harbour. FK, FT and $\mathrm{KG}$ receive urban runoff. $\mathrm{PH}$ is receives industrial and urban runoff. $\mathrm{KB}, \mathrm{MB}$ and $\mathrm{DB}$ receive residential runoff.

\begin{tabular}{llll}
\hline Site & Size $(\mathrm{mm})$ & Gonad total weight $(\mathrm{g})$ & Copper burden $(\mu \mathrm{g} / \mathrm{g})$ \\
\hline FK & 62 & 2.42 & 1.19 \\
FK & 70 & 7.44 & 0.46 \\
FK & 63 & 0.92 & nd \\
FK & 61 & 4.22 & 0.76 \\
\hline FT & 61 & 5.11 & 1.76 \\
FT & 76 & 17.10 & 0.13 \\
FT & 77 & 7.24 & 0.19 \\
\hline KG & 71 & 8.47 & 0.01 \\
KG & 68 & 5.64 & 0.04 \\
KG & 66 & 4.71 & nd \\
\hline PH & 80 & - & nd \\
PH & 81 & - & nd \\
\hline KB & 67 & 7.67 & nd \\
\hline MB & 60 & 2.03 & nd \\
MB & 64 & 5.46 & 0.35 \\
\hline DB & 70 & - & nd \\
\hline
\end{tabular}

\section{D.3.2 FERTILISATION SUCCESS PILOT}

The fertilisation success was below $1 \%$ in seawater with no added copper, at all but the highest sperm concentration $\left(10^{4}\right.$ per $\left.\mathrm{ml}\right)$. At the highest sperm concentration, the fertilisation success had a dose-response relationship with copper concentration 
(Figure D.2). However, the fertilisation success was very low, even in controls, with 9, 16 and $52 \%$ success in the three control replicates. Therefore, a $10^{5}$ per $\mathrm{ml}$ sperm density was chosen for the research described in Chapter 6.

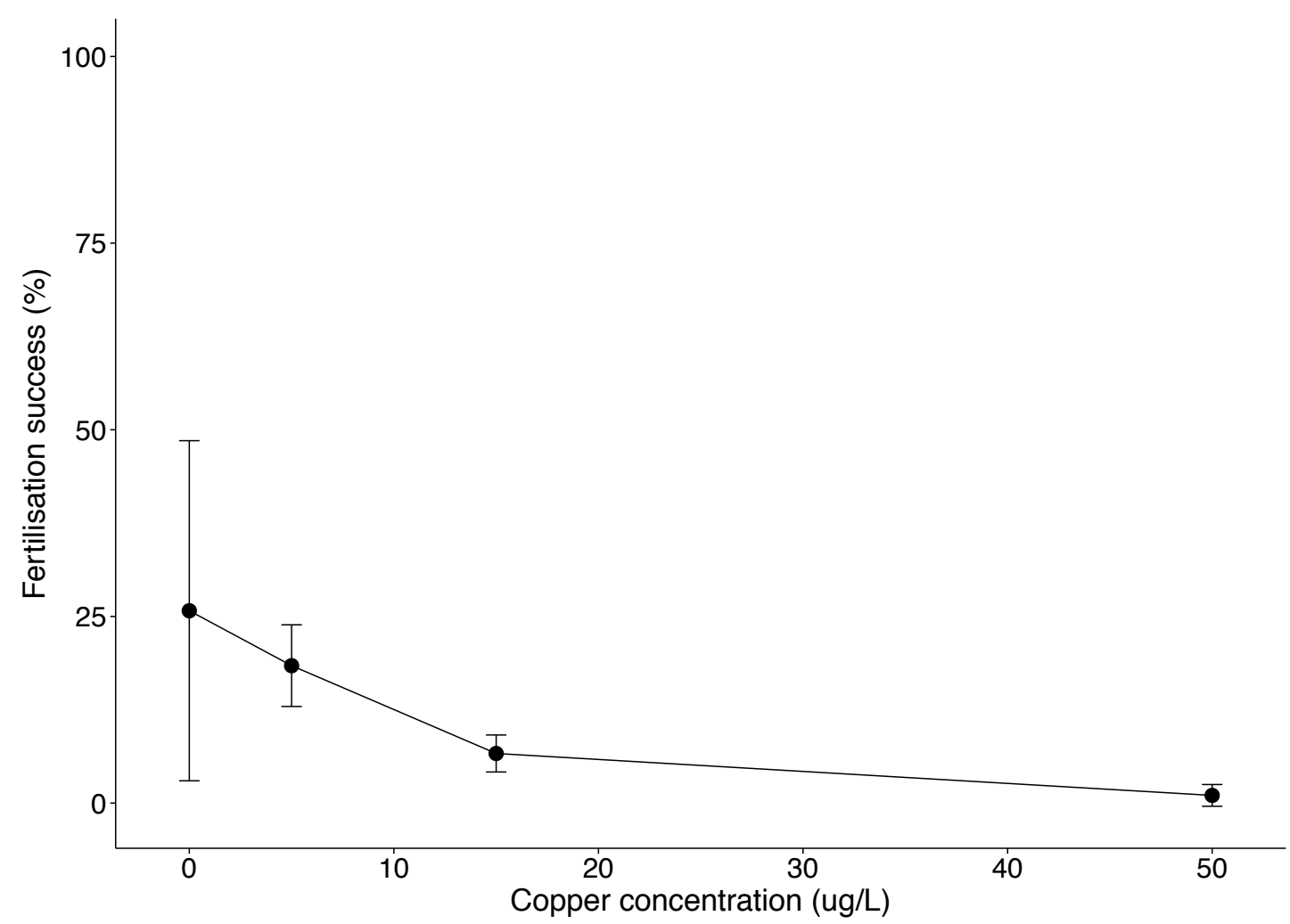

Figure D.2: Fertilisation success of Evechinus chloroticus with gamete exposure to increasing copper concentrations. The error bars represent the standard deviation $(\mathrm{N}=3)$. 



\section{REFERENCES}

Ahn I-Y, Ji J, Park H (2009) Metal accumulation in sea urchins and their kelp diet in an Arctic fjord (Kongsfjorden, Svalbard). Mar Pollut Bull 58:1571-1577

Allen RM, Marshall DJ (2010) The larval legacy: cascading effects of recruit phenotype on post-recruitment interactions. Oikos 119:1977-1983

Allen JD, Pechenik JA (2010) Understanding the effects of low salinity on fertilization success and early development in the sand dollar Echinarachnius parma. Biol Bull 218:189-199

Anderson BS, Hunt JW, McNulty HR, Stephenson MD, Palmer FH, Denton DL, Reeve M (1994) Refinement of effluent toxicity testing protocols for four marine species. State Water Resources Control Board, California Environmnental Protection Agency

Anderson BS, Hunt JW, Turpen SL, Coulon AR, Martin M, Palmer FH (1990) Protocol development and interlaboratory testing with complex effluents. Water Resources Control Board, State of California

Andrew NL (1988) Ecological aspects of the common sea urchin, Evechinus chloroticus, in northern New Zealand: A review. N Z J Mar Freshw Res $22: 415-426$

Antonie CR (2003) Effects of low salinity on Evechinus chloroticus Valenciennes. MSc Thesis, University of Otago, Dunedin, New Zealand

ANZECC (2000) Australian and New Zealand guidelines for fresh and marine water quality. Volume 1, The guidelines. Australian and New Zealand Environment and Conservation Council

Aronzon CM, Sandoval MT, Herkovits J, PérezColl CS (2011) Stage-dependent susceptibility to copper in Rhinella arenarum embryos and larvae. Environ Toxicol Chem 30:2771-2777

ASTM (2012) Guide for conducting static acute toxicity tests with Echinoid embryos. ASTM International

Au DWT, Lee C., Chan K., Wu RSS (2001) Reproductive impairment of sea urchins upon chronic exposure to cadmium. Part I: Effects on gamete quality. Environ Pollut 111:1-9

Barbieri E, Doi SA (2011) The effects of different temperature and salinity levels on the acute toxicity of zinc in the Pink Shrimp (Farfantepenaeus paulensis). Mar Freshw Behav Physiol 44:251-263

Bay S, Burgess R, Nacci D (1993) Status and applications of echinoid (Phylum Echinodermata) toxicity test methods. ASTM Spec Tech Publ 1179:281-281 
Bielmyer GK, Brix KV, Capo TR, Grosell M (2005) The effects of metals on embryo-larval and adult life stages of the sea urchin, Diadema antillarum. Aquat Toxicol 74:254-263

Bielmyer GK, Grosell M, Brix KV (2006) Toxicity of silver, zinc, copper, and nickel to the copepod Acartia tonsa exposed via a phytoplankton Diet. Environ Sci Technol 40:2063-2068

Bielmyer GK, Jarvis TA, Harper BT, Butler B, Rice L, Ryan S, McLoughlin P (2012) Metal accumulation from dietary exposure in the sea urchin, Strongylocentrotus droebachiensis. Arch Environ Contam Toxicol 63:86-94

Bolton-Ritchie LA (2003) The effect of stormwater discharge on the nearshore benthic environment of inner Wellington Harbour. PhD Thesis, Victoria University of Wellington, New Zealand

Bremer PJ, Barker MF, Loutit MW (1990) A comparison of the roles of direct absorption and phytoplankton ingestion in accumulation of chromium by sea urchin larvae. Mar Environ Res 30:233-241

Brinkman SF, Woodling JD (2014) Acclimation and deacclimation of brown trout (Salmo trutta) to zinc and copper singly and in combination with cadmium or copper. Arch Environ Contam Toxicol 67:214-223

Brown MD, Carter J, Thomas D, Purdie DM, Kay BH (2002) Pulse-exposure effects of selected insecticides to juvenile Australian crimson-spotted rainbowfish (Melanotaenia duboulayi). J Econ Entomol 95:294-298

Bryan GW (1971) The effects of heavy metals (other than mercury) on marine and estuarine organisms. Proc R Soc Lond B Biol Sci 177:389-410

Burgess SC, Marshall DJ (2011) Temperature-induced maternal effects and environmental predictability. J Exp Biol 214:2329-2336

Caley MJ, Carr MH, Hixon MA, Hughes TP, Jones GP, Menge BA (1996) Recruitment and the local dynamics of open marine populations. Annu Rev Ecol Syst 27:477-500

Calow P, Sibly RM, Forbes V (1997) Risk assessment on the basis of simplified lifehistory scenarios. Environ Toxicol Chem 16:1983-1989

Campbell PG, Clearwater SJ, Brown PB, Fisher NS, Hogstrand C, Lopez GR, Mayer LM, Meyer JS (2005) Digestive physiology, chemistry, and nutrition. In: Meyer JS, Adams WJ, Brix KV, Luoma SN, Mount DR, Stubblefield WA, Wood CM (eds) Toxicity of dietborne metals to aquatic organisms. SETAC Press, Florida, USA, p 13-57

Carballeira C, Martín-Díaz L, DelValls TA (2011) Influence of salinity on fertilization and larval development toxicity tests with two species of sea urchin. Mar Environ Res 72:196-203 
Catarino AI, Cabral HN, Peeters K, Pernet P, Punjabi U, Dubois P (2008) Metal concentrations, sperm motility, and Rna/Dna ratio in two Echinoderm species from a highly contaminated fjord (the Sørfjord, Norway). Environ Toxicol Chem 27:1553-60

Cebrian E, Uriz MJ (2007) Contrasting effects of heavy metals and hydrocarbons on larval settlement and juvenile survival in sponges. Aquat Toxicol 81:137-143

Chapman GA (1990) Culture and toxicity testing of West Coast marine organisms : proceedings of a workshop held in Sacramento, California, February 27-28, 1990.

Chevan A, Sutherland M (1991) Hierarchical Partitioning. Am Stat 45:90-96

Chong K, Wang W-X (2001) Comparative studies on the biokinetics of Cd, Cr, and $\mathrm{Zn}$ in the green mussel Perna viridis and the Manila clam Ruditapes philippinarum. Environ Pollut 115:107-121

Clemente S, Hernández JC, Montaño-Moctezuma G, Russell MP, Ebert TA (2013) Predators of juvenile sea urchins and the effect of habitat refuges. Mar Biol 160:579-590

Clements WH, Kiffney PM (1994) Assessing contaminant effects at higher levels of biological organization. Environ Toxicol Chem 13:357-359

CliFlo: NIWA's National Climate Database on the Web. Url: cliflo.niwa.co.nz

Conroy PT, Hunt JW, Anderson BS (1996) Validation of a short-term toxicity test endpoint by comparison with longer-term effects on larval red abalone Haliotis rufescens. Environ Toxicol Chem 15:1245

Constable AJ (1993) The role of sutures in shrinking of the test in Heliocidaris erythrogramma (Echinoidea: Echinometridae). Mar Biol 117:423-430

Cowart DA, Ulrich PN, Miller DC, Marsh AG (2008) Salinity sensitivity of early embryos of the Antarctic sea urchin, Sterechinus neumayeri. Polar Biol $32: 435-441$

Crean AJ, Monro K, Marshall DJ (2011) Fitness consequences of larval traits persist across the metamorphic boundary. Evolution 65:3079-3089

Creed JT, Martin TD (1997) Method 200.12 Determination of trace elements in marine waters by stabilized temperature graphite furnace atomic absorption. National Exposure Research Laboratory. Office of Research and Development. U.S. Enviromental Protection Agency, Cincinnati, OH

Damiens G, Mouneyrac C, Quiniou F, His E, Gnassia-Barelli M, Romeo M (2006) Metal bioaccumulation and metallothionein concentrations in larvae of Crassostrea gigas. Environ Pollut 140:492-499 
Degnan SM, Imron, Geiger DL, Degnan BM (2006) Evolution in temperate and tropical seas: Disparate patterns in southern hemisphere abalone (Mollusca: Vetigastropoda: Haliotidae). Mol Phylogenet Evol 41:249-256

Delorme NJ, Sewell MA (2014) Temperature and salinity: two climate change stressors affecting early development of the New Zealand sea urchin Evechinus chloroticus. Mar Biol 161:1999-2009

Devi VU (1995) Bio-accumulation and metabolic effects of zinc on marine fouling dreissinid bivalve,Mytilopsis sallei (Recluz). Water Air Soil Pollut 81:295304

Diederich CM, Jarrett JN, Chaparro OR, Segura CJ, Arellano SM, Pechenik JA (2011) Low salinity stress experienced by larvae does not affect postmetamorphic growth or survival in three calyptraeid gastropods. J Exp Mar Biol Ecol 397:94-105

Dinnel PA, Link JM, Stober QJ (1987) Improved methodology for a sea urchin sperm cell bioassay for marine waters. Arch Environ Contam Toxicol 16:23-32

Dinnel PA, Link JM, Stober QJ, Letourneau MW, Roberts WE (1989) Comparative sensitivity of sea urchin sperm bioassays to metals and pesticides. Arch Environ Contam Toxicol 18:748-755

Dix TG (1969) Larval life span of the echinoid evechinus chloroticus (val.). N Z J Mar Freshw Res 3:13-16

Dix TG (1970a) Biology of evechinus chloroticus (Echinoidea: Echinometridae) from different localities. Part I: General. N Z J Mar Freshw Res 4:91-116

Dix TG (1970b) Biology of Evechinus chloroticus (echinoidea: Echinometridae) from different localities. Part III: Reproduction. N Z J Mar Freshw Res 4:385-405

Dix TG (1972) Biology of evechinus chloroticus (Echinoidia: Echinometridae) from different localities. Part IV: Age, growth, and size. N Z J Mar Freshw Res 6:48-68

Dixon DG, Sprague JB (1981) Acclimation to Copper by Rainbow Trout (Salmo gairdneri) - A Modifying Factor in Toxicity. Can J Fish Aquat Sci 38:880888

Doyle CJ, Pablo F, Lim RP, Hyne RV (2003) Assessment of metal toxicity in sediment pore water from lake Macquarie, Australia. Arch Environ Contam Toxicol 44:0343-0350

Dupont S, Dorey N, Stumpp M, Melzner F, Thorndyke M (2013) Long-term and trans-life-cycle effects of exposure to ocean acidification in the green sea urchin Strongylocentrotus droebachiensis. Mar Biol 160:1835-1843 
Durkina V, Evtushenko Z (1991) Changes in activity of certain enzymes in sea-urchin embryos and larvae after exposure of adult organisms to heavy-metals. Mar Ecol-Prog Ser 72:111-115

Earnshaw MJ, Wilson S, Akberali HB, Butler RD, Marriott KRM (1986) The action of heavy metals on the gametes of the marine mussel, Mytilus edulis (L.) - III. The effect of applied copper and zinc on sperm motilityin relation to ultrastructural damage and intracellular metal localisation. Mar Environ Res 20:261-278

Ebert TA (1983) Recruitment in echinoderms. Echinoderm Stud 1:169-203

Eisler R (2007) Eisler's Encyclopedia of Environmentally Hazardous Priority Chemicals. Elsevier, Amsterdam

Engle V (2012) National Coastal Condition Reports IV. Office of Research and Development/Office of Water, Environmental Protection Agency, Washington DC, USA

Fábregas J, Patiño M, Arredondo-Vega BO, Tobar JL, Otero A (1995) Renewal rate and nutrient concentration as tools to modify productivity and biochemical composition of cyclostat cultures of the marine microalga Dunaliella tertiolecta. Appl Microbiol Biotechnol 44:287-292

Fatoki OS, Mathabatha S (2001) An assessment of heavy metal pollution in the East London and Port Elizabeth harbours. Water Sa 27:233-240

Fenaux L, Strathmann MF, Strathmann RR (1994) Five tests of food-limited growth of larvae in coastal waters by comparisons of rates of development and form of echinoplutei. Limnol Oceanogr 39:84-98

Fernández N, Beiras R (2001) Combined toxicity of dissolved mercury with copper, lead and cadmium on embryogenesis and early larval growth of the Paracentrotus lividus sea-urchin. Ecotoxicology 10:263-271

Fischer J, Phillips NE (2014) Carry-over effects of multiple stressors on benthic embryos are mediated by larval exposure to elevated UVB and temperature. Glob Change Biol 20:2108-2116

Fisher NS, Teyssié J-L, Fowler SW, Wang W-X (1996) Accumulation and retention of metals in mussels from food and water: A comparison under field and aboratory conditions. Environ Sci Technol 30:3232-3242

Fitzpatrick JL, Nadella S, Bucking C, Balshine S, Wood CM (2008) The relative sensitivity of sperm, eggs and embryos to copper in the blue mussel (Mytilus trossulus). Comp Biochem Physiol Part C Toxicol Pharmacol 147:441-449

Flammang P, Warnau M, Temara A, Lane DJW, Jangoux M (1997) Heavy metals in Diadema setosum (Echinodermata, Echinoidea) from Singapore coral reefs. J Sea Res 38:35-45 
Fleeger JW, Carman KR, Nisbet RM (2003) Indirect effects of contaminants in aquatic ecosystems. Sci Total Environ 317:207-233

Flemming CA, Trevors JT (1989) Copper toxicity and chemistry in the environment: a review. Water Air Soil Pollut 44:143-158

Forbes VE, Cold A (2005) Effects of the pyrethroid esfenvalerate on life-cycle traits and population dynamics of Chironomus riparius - Importance of exposure scenario. Environ Toxicol Chem 24:78-86

Formigari A, Irato P, Santon A (2007) Zinc, antioxidant systems and metallothionein in metal mediated-apoptosis: Biochemical and cytochemical aspects. Comp Biochem Physiol Part C Toxicol Pharmacol 146:443-459

Franco JL, Trivella DBB, Trevisan R, Dinslaken DF, Marques MRF, Bainy ACD, Dafre AL (2006) Antioxidant status and stress proteins in the gills of the brown mussel Perna perna exposed to zinc. Chem Biol Interact 160:232-240

Freeman DJ, Marshall BA, Ahyong ST, Wing SR, Hitchmough RA (2010) Conservation status of New Zealand marine invertebrates, 2009. N Z J Mar Freshw Res 44:129-148

Fukunaga A, Anderson MJ, Webster-Brown JG (2011) Assessing the nature of the combined effects of copper and zinc on estuarine infaunal communities. Environ Pollut 159:116-124

Fukunaga A, Anderson MJ, Webster-Brown JG, Ford RB (2010) Individual and combined effects of heavy metals on estuarine infaunal communities. Mar Ecol-Prog Ser 402:123-136

Gadd J, Cameron M (2012) Antifouling biocides in marinas: Measurement of copper concentrations and comparison to model predictions for eight Auckland sites. Auckland Council technical report TR2012/033, New Zealand

Gaines S, Brown S, Roughgarden J (1985) Spatial variation in larval concentrations as a cause of spatial variation in settlement for the barnacle, Balanus glandula. Oecologia 67:267-272

Gambardella C, Gallus L, Gatti AM, Faimali M, Carbone S, Antisari LV, Falugi C, Ferrando S (2014) Toxicity and transfer of metal oxide nanoparticles from microalgae to sea urchin larvae. Chem Ecol 30:308-316

Geffard A, Geffard O, Amiard JC, His E, Amiard-Triquet C (2007) Bioaccumulation of metals in sediment elutriates and their effects on growth, condition index, and metallothionein contents in oyster larvae. Arch Environ Contam Toxicol $53: 57-65$

Ghorani V, Shahri NM, Ghassemzadeh F, Mortazavi MS (2013) The effect of lead toxicity on embryonic development and early larval growth of the Echinometra mathaei sea urchin (Persian Gulf), morphologic and morphometric studies. Indian J Geo-Mar Sci 42:29-34 
Gillard GB, Garama DJ, Brown CM (2014) The transcriptome of the NZ endemic sea urchin Kina (Evechinus chloroticus). BMC Genomics 15:1-27

Gimenez L, Anger K, Torres G (2004) Linking life history traits in successive phases of a complex life cycle: effects of larval biomass on early juvenile development in an estuarine crab, Chasmagnathus granulata. Oikos 104:570580

Gleason TR, Munns WR, Nacci DE (2000) Projecting population-level response of purple sea urchins to lead contamination for an estuarine ecological risk assessment. J Aquat Ecosyst Stress Recovery Former J Aquat Ecosyst Health $7: 177-185$

Gobler CJ, Talmage SC (2013) Short- and long-term consequences of larval stage exposure to constantly and ephemerally elevated carbon dioxide for marine bivalve populations. Biogeosciences 10:2241-2253

Gorski J, Nugegoda D (2006) Sublethal toxicity of trace metals to larvae of the blacklip abalone, Haliotis rubra. Environ Toxicol Chem 25:1360-1367

Govindasamy C, Viji Roy AG, Jayapaul A (1998) Seasonal variation of heavy metals in water and zooplankton of Pondicherry coast, Bay of Bengal. Int J Ecol Environ Sci 24:141-146

Green A, Chapman P, Allen H, Campbell P, Cardwell R, Schamphelaere K De, Delbeke K, Mount D, Stubblefield W (2007) Aquatic Toxicity for Hazard Identification of Metals and Inorganic Metal Substances. In: Adams WJ, Chapman PM (eds) Assessing the Hazard of Metals and Inorganic Metal Substances in Aquatic and Terrestrial Systems. SETAC Press, Florida, USA, p 89-112

Griscom SB, Fisher NS, Luoma SN (2002) Kinetic modeling of Ag, Cd and Co bioaccumulation in the clam Macoma balthica: quantifying dietary and dissolved sources. Mar Ecol Prog Ser 240:127-141

Grosell M, Blanchard J, Brix KV, Gerdes R (2007) Physiology is pivotal for interactions between salinity and acute copper toxicity to fish and invertebrates. Aquat Toxicol 84:162-172

Grosell M, Nielsen C, Bianchini A (2002) Sodium turnover rate determines sensitivity to acute copper and silver exposure in freshwater animals. Comp Biochem Physiol Part C Toxicol Pharmacol 133:287-303

Guo F, Tu R, Wang W-X (2013) Different responses of abalone Haliotis discus hannai to waterborne and dietary-borne copper and zinc exposure. Ecotoxicol Environ Saf 91:10-17

GWRC database Rivers levels and flows online database. Greater Wellington Regional Council. Url: graphs.gw.govt.nz/rivers-and-streams-2 
Haldsrud R, Krokje A (2009) Induction of DNA double-strand breaks in the H4IIE cell line exposed to environmentally relevant concentrations of copper, sadmium, and Zinc, singly and in combinations. J Toxicol Environ Health A $72: 155-163$

Handy RD (1994) Intermittent exposure to aquatic pollutants: assessment, toxicity and sublethal responses in fish and invertebrates. Comp Biochem Physiol C Pharmacol Toxicol Endocrinol 107:171-184

Hayward BW, Grenfell HR, Sabaa AT, Morley MS, Horrocks M (2006) Effect and timing of increased freshwater runoff into sheltered harbor environments around Auckland City, New Zealand. Estuaries Coasts 29:165-182

Heslinga GA (1976) Effects of copper on the coral-reef echinoid Echinometra mathaei. Mar Biol 35:155-160

Hinton DE, Kullman SW, Hardman RC, Volz DC, Chen P-J, Carney M, Bencic DC (2005) Resolving mechanisms of toxicity while pursuing ecotoxicological relevance? Mar Pollut Bull 51:635-648

Hoare, K, Davenport, J, Beaumont, R A (1995) Effects of exposure and previous exposure to copper on growth of veliger larvae and survivorship of Mytilus edulis juveniles. Mar Ecol Prog Ser 120:163-168

Hollows CF, Johnston EL, Marshall DJ (2007) Copper reduces fertilisation success and exacerbates Allee effects in the field. Mar Ecol Prog Ser 333:51-60

Honda K, Yamamoto Y, Tatsukawa R (1987) Distribution of heavy metals in Antarctic marine ecosystem. Proc NIPR Symp Polar Biol:184-197

Hook SE, Fisher NS (2001a) Sublethal effects of silver in zooplankton: Importance of exposure pathways and implications for toxicity testing. Environ Toxicol Chem 20:568-574

Hook SE, Fisher NS (2001b) Reproductive toxicity of metals in calanoid copepods. Mar Biol 138:1131-1140

Hook SE, Fisher NS (2002) Relating the reproductive toxicity of five ingested metals in calanoid copepods with sulfur affinity. Mar Environ Res 53:161-174

Hothorn T, Bretz F, Westfall P (2008) Simultaneous inference in general parametric models. Biom J 50:346-363

Huang X, Guo F, Ke CH, Wang WX (2010) Responses of abalone Haliotis diversicolor to sublethal exposure of waterborne and dietary silver and cadmium. Ecotoxicol Environ Saf 73:1130-1137

Hunt JW, Anderson BS (1989) Sublethal effects of zinc and municipal effluents on larvae of the red abalone Haliotis rufescens. Mar Biol 101:545-552 
Hunt J, Anderson B (1993) From Research to Routine - a Review of Toxicity Testing with Marine Mollusks. In: Landis WG, Hughes JS, Lewis MA (eds) Environmental Toxicology and Risk Assessment. American Society for Testing and Materials, Philadelphia, USA, p 320-339

Hunt H, Scheibling R (1997) Role of early post-settlement mortality in recruitment of benthic marine invertebrates. Mar Ecol Prog Ser 155:269-301

Hwang J, Suh S-S, chang M, Yun Park S, Kwon Ryu T, Lee S, Lee T-K (2014) Effects of triclosan on reproductive prarmeters and embryonic development of sea urchin, Strongylocentrotus nudus. Ecotoxicol Environ Saf 100:148-152

Ingersoll CG, Winner RW (1982) Effect on Daphnia pulex of daily pulse exposures to copper or cadmium. Environ Toxicol Chem 1:321-328

IPCC (2014) Climate change 2014: Impacts, adaptation, and vulnerability. Part A: Global and sectoral aspects. Cambridge University Press, Cambridge, UK and New York, USA

Jakimska A, Konieczka P, Skóra K, Namieśnik J (2011) Bioaccumulation of Metals in Tissues of Marine Animals, Part I: the Role and Impact of Heavy Metals on Organisms. Pol J Environ Stud 20:1117-1125

Jezierska B, Sarnowski P, Witeska M, Lugowska K (2009) Disturbances of early development of fish caused by heavy metals (a review). Electron J Ichthyol 5:76-96

Johnson DW (2008) Combined effects of condition and density on post-settlement survival and growth of a marine fish. Oecologia 155:43-52

Johnson PCD (2014) Extension of Nakagawa \& Schielzeth's R-GLMM(2) to random slopes models. Methods Ecol Evol 5:944-946

Johnston EL, Keough MJ (2002) Direct and indirect effects of repeated pollution events on marine hard-substrate assemblages. Ecol Appl 12:1212-1228

Johnston EL, Webb JA, Keough MJ (2003) Pulse disturbances to the colonization of hard-substrates and in situ determination of copper using diffusive gradients in thin-films (DGT): quantifying dose and response in the field. Biofouling 19:335-345

Kashenko SD (2007) Adaptive responses of embryos and larvae of the heart-shaped sea urchin Echinocardium cordatum to temperature and salinity changes. Russ J Mar Biol 33:381-390

Kimberly DA, Salice CJ (2013) Interactive effects of contaminants and climaterelated stressors: High temperature increases sensitivity to cadmium. Environ Toxicol Chem 32:1337-1343 
Kimberly DA, Salice CJ (2014) If you could turn back time: Understanding transgenerational latent effects of developmental exposure to contaminants. Environ Pollut 184:419-425

King CK, Gale SA, Hyne RV, Stauber JL, Simpson SL, Hickey CW (2006) Sensitivities of Australian and New Zealand amphipods to copper and zinc in waters and metal-spiked sediments. Chemosphere 63:1466-1476

King CK, Riddle MJ (2001) Effects of metal contaminants on the development of the common Antarctic sea urchin Sterechinus neumayeri and comparisons of sensitivity with tropical and temperate echinoids. Mar Ecol Prog Ser 215:143154

Kobayashi N (1980) Comparative sensitivity of various developmental stages of sea urchins to some chemicals. Mar Biol 58:163-171

Kobayashi N, Okamura H (2004) Effects of heavy metals on sea urchin embryo development. 1. Tracing the cause by the effects. Chemosphere 55:1403-1412

Kobayashi N, Okamura H (2005) Effects of heavy metals on sea urchin embryo development. Part 2. Interactive toxic effects of heavy metals in synthetic mine effluents. Chemosphere 61:1198-1203

Laing G Du, Rinklebe J, Vandecasteele B, Meers E, Tack FMG (2009) Trace metal behaviour in estuarine and riverine floodplain soils and sediments: A review. Sci Total Environ 407:3972-3985

Lamare MD (1998) Origin and transport of larvae of the sea urchin Evechinus chloroticus (Echinodermata: Echinoidea) in a New Zealand fiord. Mar Ecol Prog Ser 174:107-121

Lamare MD, Barker MF (1999) In situ estimates of larval development and mortality in the New Zealand sea urchin Evechinus chloroticus (Echinodermata: Echinoidea). Mar Ecol Prog Ser 180:197-211

Lamare MD, Barker MF (2001) Settlement and recruitment of the New Zealand sea urchin Evechinus chloroticus. Mar Ecol Prog Ser 218:153-166

Lamare MD, Brewin PE, Barker MF, Wing SR (2002) Reproduction of the sea urchin Evechinus chloroticus (Echinodermata: Echinoidea) in a New Zealand fiord. N Z J Mar Freshw Res 36:719-732

Lane AC, Mukherjee J, Chan VBS, Thiyagarajan V (2013) Decreased pH does not alter metamorphosis but compromises juvenile calcification of the tube worm Hydroides elegans. Mar Biol 160:1983-1993

Lee JA, Marsden ID, Glover CN (2010) The influence of salinity on copper accumulation and its toxic effects in estuarine animals with differing osmoregulatory strategies. Aquat Toxicol 99:65-72 
Lefcheck J, Casallas JS (2014) rsquared.glmer: A R-squared for generalized linear mixed-effects models function in $\mathrm{R}$.

Lefcort H, Meguire RA, Wilson LH, Ettinger WF (1998) Heavy metals alter the survival, growth, metamorphosis, and antipredatory behavior of Columbia spotted frog (Rana luteiventris) tadpoles. Arch Environ Contam Toxicol $35: 447-456$

Levitan DR (1988) Density-dependent size regulation and negative growth in the sea urchin Diadema antillarum Philippi. Oecologia 76:627-629

Lindegarth M, Underwood AJ (2002) A manipulative experiment to evaluate predicted changes in intertidal, macro-faunal assemblages after contamination by heavy metals. J Exp Mar Biol Ecol 274:41-64

Lister KN, Lamare MD, Burritt DJ (2015) Pollutant resilience in embryos of the Antarctic sea urchin Sterechinus neumayeri reflects maternal antioxidant status. Aquat Toxicol 161:61-72

Lorenzo JI, Nieto O, Beiras R (2002) Effect of humic acids on speciation and toxicity of copper to Paracentrotus lividus larvae in seawater. Aquat Toxicol 58:27-41

MacDiarmid A (Ed) (2007) Treasures of the sea: Ngā taonga a tangaroa. A summary of biodiversity in the New Zealand Marine Ecoregion. WWF-New Zealand, Wellington, New Zealand

MacInnes JR, Calabrese A (1979) Combined effects of salinity, temperature, and copper on embryos and early larvae of the American oyster, Crassostrea virginica. Arch Environ Contam Toxicol 8:553-562

Mac Nally R (1996) Hierarchical partitioning as an interpretative tool in multivariate inference. Aust J Ecol 21:224-228

Mager EM (2012) Lead. In: Wood CM, Farrell AP, Brauner CJ (eds) Homeostasis and Toxicology of Non-Essential Metals. Mager, Edward M.; Univ Miami, Miami, FL 33152 USA, p 185-236

Mann KH (2000) Ecology of coastal waters: with implications for management, 2nd ed. Blackwell Science, Malden, Massachusetts, USA

Mann R, Campos B, Luckenbach M (1991) Swimming rate and responses of larvae of 3 mactrid bivalves to salinity discontinuities. Mar Ecol Prog Ser 68:257-269

Mann RM, Hyne RV, Spadaro DA, Simpson SL (2009) Development and application of a rapid amphipod reproduction test for sediment quality assessment. Environ Toxicol Chem 28:1244-1254

Manyin T, Rowe CL (2010) Reproductive and life stage-specific effects of aqueous copper on the grass shrimp, Palaemonetes pugio. Mar Environ Res 69:152157 
Manzo S (2004) Sea urchin embryotoxicity test: proposal for a simplified bioassay. Ecotoxicol Environ Saf 57:123-128

Manzo S, Buono S, Cremisini C (2008) Predictability of copper, irgarol, and diuron combined effects on sea urchin Paracentrotus lividus. Arch Environ Contam Toxicol 54:57-68

Manzo S, Buono S, Cremisini C (2010) Cadmium, lead and their mixtures with copper: Paracentrotus lividus embryotoxicity assessment, prediction, and offspring quality evaluation. Ecotoxicology 19:1209-1223

Marshall DJ (2006) Reliably estimating the effect of toxicants on fertilization success in marine broadcast spawners. Mar Pollut Bull 52:734-738

Marshall DJ (2008) Transgenerational plasticity in the sea: context-dependent maternal effects across the life history. Ecology 89:418-427

Marshall DJ, Keough MJ (2004) When the going gets rough: effect of maternal size manipulation on larval quality. Mar Ecol Prog Ser 272:301-305

Marshall DJ, Keough MJ (2008) The evolutionary ecology of offspring size in marine invertebrates. In: Sims DW (ed) Advances in Marine Biology. Elsevier Academic Press Inc, San Diego, p 1-60

Marshall DJ, Morgan SG (2011) Ecological and evolutionary consequences of linked life-history stages in the sea. Curr Biol 21:R718-R725

Marshall DJ, Pechenik JA, Keough MJ (2003) Larval activity levels and delayed metamorphosis affect post-larval performance in the colonial, ascidian Diplosoma listerianum. Mar Ecol-Prog Ser 246:153-162

Marshall DJ, Uller T (2007) When is a maternal effect adaptive? Oikos 116:19571963

Martin M, Osborn KE, Billig P, Glickstein N (1981) Toxicities of ten metals to Crassostrea gigas and Mytilus edulis embryos and Cancer magister larvae. Mar Pollut Bull 12:305-308

Martin M, Stephenson MD, Martin JH (1977) Copper toxicity experiments in relation to abalone deaths observed in a power plant's cooling waters. Calif Fish Game 63:95-100

Mathews T, Fisher NS (2009) Dominance of dietary intake of metals in marine elasmobranch and teleost fish. Sci Total Environ 407:5156-5161

Matthiessen P (2008) An assessment of endocrine disruption in mollusks and the potential for developing internationally standardized mollusk life cycle test guidelines. Integr Environ Assess Manag 4:274-284

Mayer-Pinto M, Underwood AJ, Tolhurst T, Coleman RA (2010) Effects of metals on aquatic assemblages: What do we really know? J Exp Mar Biol Ecol 391:1-9 
McCabe RM, Hickey BM, MacCready P (2008) Observational estimates of entrainment and vertical salt flux in the interior of a spreading river plume. $\mathrm{J}$ Geophys Res Oceans 113:C08027

McCready S, Birch GF, Long ER, Spyrakis G, Greely CR (2006) Relationships Between Toxicity and Concentrations of Chemical Contaminants in Sediments from Sydney Harbour, Australia, and Vicinity. Environ Monit Assess 120:187-220

McGeer JC, Szebedinszky C, McDonald DG, Wood CM (2002) The role of dissolved organic carbon in moderating the bioavailability and toxicity of $\mathrm{Cu}$ to rainbow trout during chronic waterborne exposure. Comp Biochem Physiol Part C Toxicol Pharmacol 133:147-160

McKenzie LA, Brooks R, Johnston EL (2011) Heritable pollution tolerance in a marine invader. Environ Res 111:926-932

McLusky D, Bryant V, Campbell R (1986) The effects of temperature and salinity on the toxicity of heavy-metals. Oceanogr Mar Biol 24:481-520

McRae A (1959) Evechinus chloroticus (Val.), an endemic New Zealand echinoid. Trans Proc R Soc N Z 86:205-267

McShane PE (1995) Recruitment variation in abalone: its importance to fisheries management. Mar Freshw Res 46:555-570

McShane PE, Schiel DR, Mercer SF, Murray T (1994) Morphometric variation in Haliotis iris (Mollusca:Gastropoda): analysis of 61 populations. N Z J Mar Freshw Res 28:357-364

Menge BA, Sutherland JP (1976) Species diversity gradients: synthesis of the roles of predation, competition, and temporal heterogeneity. Am Nat 110:351-369

Metaxas A, Young CM (1998) Behaviour of echinoid larvae around sharp haloclines: effects of the salinity gradient and dietary conditioning. Mar Biol 131:443459

Meyer JS, Adams WJ, Brix KV, Luoma SN, Mount DR, Stubblefield WA, Wood CM (Eds) (2005) Toxicity of dietborne metals to aquatic organisms.

Miller SL, Abraham ER (2011) Characterisation of New Zealand kina fisheries. Ministry of Fisheries, Wellington, New Zealand

Miller BA, Emlet RB (1999) Development of newly metamorphosed juvenile sea urchins (Strongylocentrotus franciscanus and S. purpuratus): morphology, the effects of temperature and larval food ration, and a method for determining age. J Exp Mar Biol Ecol 235:67-90

Milne JR (2006) Contaminants in shellfish flesh. An investigation into microbiological and trace metal contaminants in shellfish from selected locations in the Wellington region. Environmental Monitoring and 
Investigations Department, Greater Wellington Regional Council, Wellington, New Zealand

Milne JR, Watts L (2008) Stormwater contaminants in urban streams in the Wellington region. Environmental Monitoring and Investigations Department, Greater Wellington Regional Council, Wellington, New Zealand

Monteiro SCR, Pinho GLL, Hoffmann K, Barcarolli IF, Bianchini A (2013) Acute waterborne copper toxicity to the euryhaline copepod Acartia tonsa at different salinities: Influence of natural freshwater and marine dissolved organic matter. Environ Toxicol Chem 32:1412-1419

Moore DRJ, Caux PY (1997) Estimating low toxic effects. Environ Toxicol Chem 16:794-801

Morgan SG (1995) Life and death in the plankton: larval mortality and adaptation. CRC Press, New York, USA

Morrison MA, Lowe ML, Parsons DM, Usmar NR, McLeod IM (2009) A review of land-based effects on coastal fisheries and supporting biodiversity in New Zealand. Ministry of Fisheries, Wellington, New Zealand

Moss GA, Tong LJ (1992) Effect of stage of larval development on the settlement of the abalone, Haliotis iris. N Z J Mar Freshw Res 26:69-73

Munns WR, Black DE, Gleason TR, Salomon K, Bengtson D, Gutjahr-Gobell R (1997) Evaluation of the effects of dioxin and PCBs on Fundulus heteroclitus populations using a modeling approach. Environ Toxicol Chem 16:1074-1081

Nacci D, Serbst J, Gleason TR, Cayula S, Thursby G, Jr WRM, Johnston RK (2000) Biological responses of the sea urchin, Arbacia punctulata, to lead contamination for an estuarine ecological risk assessment. J Aquat Ecosyst Stress Recovery 7:187-199

Nadella SR, Fitzpatrick JL, Franklin N, Bucking C, Smith S, Wood CM (2009) Toxicity of dissolved $\mathrm{Cu}, \mathrm{Zn}, \mathrm{Ni}$ and $\mathrm{Cd}$ to developing embryos of the blue mussel (Mytilus trossolus) and the protective effect of dissolved organic carbon. Comp Biochem Physiol Part C Toxicol Pharmacol 149:340-348

Nadella SR, Tellis M, Diamond R, Smith S, Bianchini A, Wood CM (2013) Toxicity of lead and zinc to developing mussel and sea urchin embryos: Critical tissue residues and effects of dissolved organic matter and salinity. Comp Biochem Physiol Part C Toxicol Pharmacol 158:72-83

Nakagawa S, Schielzeth H (2013) A general and simple method for obtaining R2 from generalized linear mixed-effects models. Methods Ecol Evol 4:133-142

Nasrolahi A, Pansch C, Lenz M, Wahl M (2012) Being young in a changing world: how temperature and salinity changes interactively modify the performance of larval stages of the barnacle Amphibalanus improvisus. Mar Biol 159:331340 
Naylor JR, Andrew NL, Kim SW (2006) Demographic variation in the New Zealand abalone Haliotis iris. Mar Freshw Res 57:215-224

Neale MW (2009) State of the Environment Monitoring: River Water Quality Annual Report 2007. Auckland Regional Council, Auckland, New Zealand

Ng TYT, Keough MJ (2003) Delayed effects of larval exposure to $\mathrm{Cu}$ in the bryozoan Watersipora subtorquata. Mar Ecol Prog Ser 257:77-85

Norwood WP, Borgmann U, Dixon DG, Wallace A (2003) Effects of metal mixtures on aquatic biota: A review of observations and methods. Hum Ecol Risk Assess 9:795-811

Novelli AA, Losso C, Ghetti PF, Ghirardini AV (2003) Toxicity of heavy metals using sperm cell and embryo toxicity bioassays with Paracentrotus lividus (Echinodermata: Echinoidea): Comparisons with exposure concentrations in the Lagoon of Venice, Italy. Environ Toxicol Chem 22:1295-1301

O’Callaghan FV, O'Callaghan M, Najman JM, Williams GM, Bor W (2007) Prenatal alcohol exposure and attention, learning and intellectual ability at 14 years: A prospective longitudinal study. Early Hum Dev 83:115-123

Osman AGM (2010) Water Quality and Heavy Metal Monitoring in Water, Sediments, and Tissues of the African Catfish Clarias gariepinus (Burchell, 1822) from the River Nile, Egypt. J Environ Prot 01:389-400

Oteiza PI, Mackenzie GG (2005) Zinc, oxidant-triggered cell signaling, and human health. Mol Aspects Med 26:245-255

Ozoh PTE (1992) The effect of temperature and salinity on copper body-burden and copper toxicity to Hediste (Nereis) diversicolor. Environ Monit Assess 21:1117

Paquin PR, Gorsuch JW, Apte S, Batley GE, Bowles KC, Campbell PGC, Delos CG, Toro DM Di, Dwyer RL, Galvez F, Gensemer RW, Goss GG, Hogstrand C, Janssen CR, McGeer JC, Naddy RB, Playle RC, Santore RC, Schneider U, Stubblefield WA, Wood CM, Wu KB (2002) The biotic ligand model: a historical overview. Comp Biochem Physiol Part C Toxicol Pharmacol 133:335

Patel P, Bielmyer-Fraser GK (2015) The influence of salinity and copper exposure on copper accumulation and physiological impairment in the sea anemone, Exaiptasia pallida. Comp Biochem Physiol Part C Comp Pharmacol:39-47

Pechenik JA (1987) Environmental influences on larval survival and development. In: Giese AC, Pearse JS (eds) Reproduction of marine invertebrates. Blackwell Scientific, Palo Alto, CA, p 551-608

Pechenik J (1990) Delayed metamorphosis by larvae of benthic marine invertebrates Does it occur? Is there a price to pay? Ophelia 32:63-94 
Pechenik JA (1999) On the advantages and disadvantages of larval stages in benthic marine invertebrate life cycles. Mar Ecol Prog Ser 177:269-297

Pechenik JA (2006) Larval experience and latent effects - metamorphosis is not a new beginning. Integr Comp Biol 46:323-333

Pechenik JA, Gleason T, Daniels D, Champlin D (2001) Influence of larval exposure to salinity and cadmium stress on juvenile performance of two marine invertebrates (Capitella sp I and Crepidula fornicata). J Exp Mar Biol Ecol 264:101-114

Pechenik JA, Wendt DE, Jarrett JN (1998) Metamorphosis is not a new beginning. Bioscience 48:901-910

Phillips NE (2002) Effects of nutrition-mediated larval condition on juvenile performance in a marine mussel. Ecology 83:2562-2574

Phillips NE (2004) Variable timing of larval food has consequences for early juvenile performance in a marine mussel. Ecology 85:2341-2346

Phillips BM, Anderson BS, Hunt JW (1998) Spatial and temporal variation in results of purple urchin (Strongylocentrotus purpuratus) toxicity tests with zinc. Environ Toxicol Chem 17:453-459

Phillips BM, Nicely PA, Hunt JW, Anderson BS, Tjeerdema RS, Palmer SE, Palmer FH, Puckett HM (2003) Toxicity of cadmium-copper-nickel-zinc mixtures to larval purple sea urchins (Strongylocentrotus purpuratus). Bull Environ Contam Toxicol 70:0592-0599

Phillips NE, Shima JS (2006) Differential effects of suspended sediments on larval survival and settlement of New Zealand urchins Evechinus chloroticus and abalone Haliotis iris. Mar Ecol-Prog Ser 314:149-158

Pickhardt PC, Folt CL, Chen CY, Klaue B, Blum JD (2002) Algal blooms reduce the uptake of toxic methylmercury in freshwater food webs. Proc Natl Acad Sci 99:4419-4423

Pinheiro J, Bates D, DebRoy S, Sarkar D, R Core Team (2015) nlme: Linear and nonlinear mixed effects models.

Przeslawski R, Byrne M, Mellin C (2015) A review and meta-analysis of the effects of multiple abiotic stressors on marine embryos and larvae. Glob Change Biol $21: 2122-2140$

Raimondo S, McKenney CL (2005) Projected population-level effects of thiobencarb exposure on the mysid, Americamysis bahia, and extinction probability in a concentration-decay exposure system. Environ Toxicol Chem 24:564-572

Ramachandran S, Patel TR, Colbo MH (1997) Effect of copper and cadmium on three malaysian tropical estuarine invertebrate larvae. Ecotoxicol Environ Saf $36: 183-188$ 
Reinfelder JR, Fisher NS (1991) The assimilation of elements ingested by marine copepods. Science 251:794-796

Ringwood AH (1992) Comparative sensitivity of gametes and early developmental stages of a sea urchin species (Echinometra mathaei) and a bivalve species (Isognomon californicum) during metal exposures. Arch Environ Contam Toxicol 22:288-295

Ritchie H, Marshall DJ (2013) Fertilisation is not a new beginning: sperm environment affects offspring developmental success. J Exp Biol 216:31043109

Roberts DA, Johnston EL, Müller S, Poore AGB (2008) Field and laboratory simulations of storm water pulses: Behavioural avoidance by marine epifauna. Environ Pollut 152:153-162

Roose P, Albaiges J, Bebianno MJ, Camphuysen C, Cronin M, Leeuw J de, Gabrielsen G, Hutchinson T, Hylland K, Jansson B, Jenssen BM, Schulz-Bull D, Szefer P, Webster L, Bakke T, Janssen C (2011) Chemical Pollution in Europe's Seas: Programmes, Practices and Priorities for Research, Marine Board Position Paper 16. Marine Board-ESF, Ostend, Belgium

Rosen G, Rivera-Duarte I, Colvin MA, Dolecal RE, Raymundo LJ, Earley PJ (2015) Nickel and Copper Toxicity to Embryos of the Long-Spined Sea Urchin, Diadema savignyi. Bull Environ Contam Toxicol 95:6-11

Rowley R (1990) Newly Settled Sea-Urchins in a Kelp Bed and Urchin Barren Ground - a Comparison of Growth and Mortality. Mar Ecol Prog Ser 62:229240

Rozman KK, Doull J, Hayes WJ (2010) Dose and time determining, and other factors, influencing toxicity. In: Hayes' Handbook of Pesticide Toxicology. Academic Press, p 3-103

Rumbold DG, Snedaker SC (1997) Evaluation of bioassays to monitor surface microlayer toxicity in tropical marine waters. Arch Environ Contam Toxicol 32:135-140

Russell MP (2013) Echinoderm Responses to Variation in Salinity. In: Lesser M (ed) Advances in Marine Biology, Vol 66. Elsevier Academic Press Inc, San Diego, p 171-212

Salvo A, Potorti AG, Cicero N, Bruno M, Turco V Lo, Bella G Di, Dugo G (2014) Statistical characterisation of heavy metal contents in Paracentrotus lividus from Mediterranean Sea. Nat Prod Res 28:718-726

Sameoto JA, Metaxas A (2008) Can salinity-induced mortality explain larval vertical distribution with respect to a halocline? Biol Bull 214:329-338 
Santore RC, Toro DM Di, Paquin PR, Allen HE, Meyer JS (2001) Biotic ligand model of the acute toxicity of metals. 2. Application to acute copper toxicity in freshwater fish and Daphnia. Environ Toxicol Chem 20:2397-2402

Schamphelaere KAC De, Canli M, Lierde V Van, Forrez I, Vanhaecke F, Janssen CR (2004) Reproductive toxicity of dietary zinc to Daphnia magna. Aquat Toxicol 70:233-244

Schamphelaere KAC De, Janssen CR (2004) Effects of chronic dietary copper exposure on growth and reproduction of Daphnia magna. Environ Toxicol Chem 23:2038-2047

Schiff K, Brown J, Diehl D, Greenstein D (2007) Extent and magnitude of copper contamination in marinas of the San Diego region, California, USA. Mar Pollut Bull 54:322-328

Schlekat CE, Lee B-G, Luoma SN (2001) Dietary metals exposure and toxicity to aquatic organisms: Implications for Ecological Risk Assessement. In: Newman MC, Roberts MHJ, Hale RC (eds) Coastal and Estuarine Risk Assessment. Lewis Publishers, CRC Press, New York, USA

Schulz R, Liess M (2000) Toxicity of fenvalerate to caddisfly larvae: chronic effects of 1-vs 10-h pulse-exposure with constant doses. Chemosphere 41:1511-1517

Scott GR, Sloman KA (2004) The effects of environmental pollutants on complex fish behaviour: integrating behavioural and physiological indicators of toxicity. Aquat Toxicol 68:369-392

Sewell MA, Cameron MJ, McArdle BH (2004) Developmental plasticity in larval development in the echinometrid sea urchin Evechinus chloroticus with varying food ration. J Exp Mar Biol Ecol 309:219-237

SFEI (2015) Contaminant data display and download. San Francisco Estuary Institute, Regional Monitoring Program. Url: sfei.org/programs/rmp-data

Shahidul Islam M, Tanaka M (2004) Impacts of pollution on coastal and marine ecosystems including coastal and marine fisheries and approach for management: a review and synthesis. Mar Pollut Bull 48:624-649

Al-Shami SA, Rawi CSM, Ahmad AH, Nor SAM (2011) Genotoxicity of heavy metals to the larvae of Chironomus kiiensis Tokunaga after short-term exposure. Toxicol Ind Health 28:734-739

Shima JS, Noonburg EG, Phillips NE (2010) Life history and matrix heterogeneity interact to shape metapopulation connectivity in spatially structured environments. Ecology 91:1215-1224

Shima JS, Swearer SE (2009) Larval Quality Is Shaped by Matrix Effects: Implications for Connectivity in a Marine Metapopulation. Ecology 90:12551267 
Soualili D, Dubois P, Gosselin P, Pernet P, Guillou M (2008) Assessment of seawater pollution by heavy metals in the neighbourhood of Algiers: use of the sea urchin, Paracentrotus lividus, as a bioindicator. Ices J Mar Sci 65:132-139

Sprague JB (1970) Measurement of pollutant toxicity to fish. II. Utilizing and applying bioassay results. Water Res 4:3-32

Stanton BR (1984) Some oceanographic observations in the New Zealand fjords. Estuar Coast Shelf Sci 19:89-104

Stauber JL, Andrade S, Ramirez M, Adams M, Correa JA (2005) Copper bioavailability in a coastal environment of Northern Chile: Comparison of bioassay and analytical speciation approaches. Mar Pollut Bull 50:1363-1372

Stauber JL, Florence TM (1990) Mechanism of toxicity of zinc to the marine diatom Nitzschia closterium. Mar Biol 105:519-524

Stofberg RL, Simon CA, Snyman RG (2011) Effects of heavy metals on the development and survival of abalone Haliotis midae larvae. Afr J Mar Sci 33:339-345

Strathmann RR (1971) The feeding behavior of planktotrophic echinoderm larvae: Mechanisms, regulation, and rates of suspension feeding. J Exp Mar Biol Ecol 6:109-160

Strathmann MF (1987) Reproduction and development of marine invertebrates of the northern Pacific Coast. University of Washington Press, Seattle.

Strathmann RR, Fenaux L, Strathmann MF (1992) Heterochronic developmental plasticity in larval sea urchins and its implications for evolution of nonfeeding larvae. Evolution 46:972-986

Suckling CC, Clark MS, Peck LS, Cook EJ (2014) Experimental influence of pH on the early life-stages of sea urchins I: different rates of introduction give rise to different responses. Invertebr Reprod Dev 58:148-159

Sun PY, Foley HB, Handschumacher L, Suzuki A, Karamanukyan T, Edmands S (2014) Acclimation and adaptation to common marine pollutants in the copepod Tigriopus californicus. Chemosphere 112:465-471

Tellis MS, Lauer MM, Nadella S, Bianchini A, Wood CM (2014) Sublethal mechanisms of $\mathrm{Pb}$ and $\mathrm{Zn}$ toxicity to the purple sea urchin (Strongylocentrotus purpuratus) during early development. Aquat Toxicol 146:220-229

TenBrook PL, Tjeerdema RS, Hann P, Karkoski J (2008) Methods for Deriving Pesticide Aquatic Life Criteria. In: Whitacre DM (ed) Reviews of Environmental Contamination and Toxicology Volume 199. Springer USA, p $1-92$ 
Thrush SF, Hewitt JE, Cummings V, Ellis JI, Hatton C, Lohrer A, Norkko A (2004) Muddy waters: elevating sediment input to coastal and estuarine habitats. Front Ecol Environ 2:299-306

Tong L J, Moss G A, Redfearn P, Illingworth J (1992) A manual of techniques for culturing paua, Haliotis iris, through to the early juvenile stage. New Zealand Fisheries

Toro DM Di, Allen HE, Bergman HL, Meyer JS, Paquin PR, Santore RC (2001) Biotic ligand model of the acute toxicity of metals. 1. Technical Basis. Environ Toxicol Chem 20:2383-2396

Trevisan R, Flesch S, Mattos JJ, Milani MR, Bainy ACD, Dafre AL (2014) Zinc causes acute impairment of glutathione metabolism followed by coordinated antioxidant defenses amplification in gills of brown mussels Perna perna. Comp Biochem Physiol Part C Toxicol Pharmacol 159:22-30

Udayakumar P, Chandran A, Jose JJ, Rajesh BR, Babu KN, Ouseph PP (2011) Seasonal dynamics of dissolved metals in surface coastal waters of Southwest India. Bull Environ Contam Toxicol 87:662-668

Underwood AJ, Fairweather PG (1989) Supply-side ecology and benthic marine assemblages. Trends Ecol Evol 4:16-20

US EPA (2002a) Short-term methods for estimating the chronic toxicity of effluents and receiving waters to marine and estuarine organisms. U.S. Environmental Protection Agency, Office of Water, Washington DC, USA

US EPA (2002b) Methods for Measuring the Acute Toxicity of Effluents and Receiving Waters to Freshwater and Marine Organisms. U.S. Environmental Protection Agency, Office of Water, Washington DC, USA

US EPA (2007) Updated Aquatic Life Copper Criteria. U.S. Environmental Protection Agency, Office of Water, Washington DC, USA

US EPA (2014) National Recommended Water Quality Criteria.

Valdés J, Román D, Rivera L, Ávila J, Cortés P (2011) Metal contents in coastal waters of San Jorge Bay, Antofagasta, northern Chile: a base line for establishing seawater quality guidelines. Environ Monit Assess 183:231-242

Vazquez E, Young CM (1996) Responses of compound ascidian larvae to haloclines. Mar Ecol Prog Ser 133:179-190

Walker CW, Unuma T, Lesser MP (2006) Gametogenesis and reproduction of sea urchins. Edible Sea Urchins Biol Ecol Elsevier Amst Neth:11-33

Walsh C, Mac Nally R (2013) hier.part: Hierarchical partitioning.

Wang W-X, Fisher NS (1998) Accumulation of trace elements in a marine copepod. Limnol Oceanogr 43:273-283 
Wang W-X, Fisher NS (1999) Delineating metal accumulation pathways for marine invertebrates. Sci Total Environ 237-238:459-472

Warnau M, Pagano G (1994) Developmental Toxicity of $\mathrm{PbCl} 2$ in the Echinoid Paracentrotus lividus (Echinodermata). Bull Environ Contam Toxicol 53:434441

Watson GJ, Leach A, Fones G (2008) Effects of copper and other metals on fertilization, embryo development, larval survival and settlement of the polychaete Nereis (Neanthes) virens. Invertebr Reprod Dev 52:101-112

Watson GJ, Pini J, Leach A, Fones G (2013) Long-term incubation of adult Nereis virens (Annelida: Polychaeta) in copper-spiked sediment: The effects on adult mortality, gametogenesis, spawning and embryo development. Aquat Toxicol 128-129:1-12

Wirgin I, Waldman JR (2004) Resistance to contaminants in North American fish populations. Mutat Res 552:73-100

Xing R-L, Wang C-H, Cao X-B, Chang Y (2007) The potential value of different species of benthic diatoms as food for newly metamorphosed sea urchin Strongylocentrotus intermedius. Aquaculture 263:142-149

Xu X, Li Y, Wang Y, Wang Y (2011) Assessment of toxic interactions of heavy metals in multi-component mixtures using sea urchin embryo-larval bioassay. Toxicol In Vitro 25:294-300

Zhou T, Weis JS (1998) Swimming behavior and predator avoidance in three populations of Fundulus heteroclitus larvae after embryonic and/or larval exposure to methylmercury. Aquat Toxicol 43:131-148

Zizza M, Giusi G, Crudo M, Canonaco M, Facciolo RM (2013) Lead-induced neurodegenerative events and abnormal behaviors occur via ORXRergic/GABAARergic mechanisms in a marine teleost. Aquat Toxicol $126: 231-241$ 